\title{
Nitroxide-Mediated Controlled Degradation of Polypropylene
}

Alexandros Psarreas

\author{
A thesis \\ presented to the University of Waterloo \\ in fulfilment of the \\ thesis requirement for the degree of
}

Master of Applied Science

in

Chemical Engineering

Waterloo, Ontario, Canada, 2006

(C) Alexandros Psarreas 2006 
I hereby declare that I am the sole author of this thesis. This is a true copy of the thesis, including any required final revisions, as accepted by my examiners.

I understand that my thesis may be electronically available to the public.

Alexandros Psarreas 


\section{Abstract \\ Nitroxide-Mediated Controlled Degradation of Polypropylene}

Controlled-rheology polypropylene resins (CRPP) have been produced industrially for years using reactive extrusion processes employing peroxides as free radical initiators. The molecular weight characteristics of CRPP materials can be tailor-made depending on the final application in a very efficient and economic manner.

A PP-based nitroxide (NOR) with the trade name Irgatec CR76 has been recently developed by CIBA Chemicals, as a source of radicals and it is currently being evaluated for the production of CRPP. NORs are well-known as powerful stabilizers to protect plastics from the negative influence of light and heat, and easy in handling during processing. Preliminary experimental results exhibit a qualitative difference between Irgatec CR76 and other commonly used peroxides.

The purpose of this research work is to evaluate this new material as a potential replacement of commonly used peroxides in the production of CRPP. CRPP will be produced by reactive processing using varying amounts of Irgatec CR76 and the rheological properties of the materials produced will be investigated. By comparing results with Irgatec CR76 to those from other typical initiators, the effectiveness of Irgatec CR76 as an initiator will also be assessed.

The results of this research will have an impact not only on the potential extension of uses of the specific PP-based NOR (Irgatec CR76), but also, more generally, on the wider application of additives during degradation of PP. Potentially new materials can be produced with enhanced heat and light protection along with the other benefits inherent to standard CRPP. 


\section{Acknowledgements}

The following thesis would not have come true, if a group of people wouldn't offer a continuous support on my research, in a collective way that integrates me as scientist and as person.

These people are: my main supervisor, and the person who contributed significantly in my decision to come in Canada, Professor Alex Penlidis. My cosupervisors, and always willing to share with me some of their knowledge, Professors Neil McManus and Costas Tzoganakis. The members of the Polymer Processing Lab of the Chemical Engineering Department of the University of Waterloo who sensibly helped and supported me during my research: Mercy Bulsari, Ramin Khesareh, Bob Lee and especially Dr Shuihan Zhu and Dr Matthew J. Scorah who contributed in the experimental part regarding the production and characterization of Controlled Rheology Polypropylene (CRPP) with tetrafunctional peroxide initiator.

Finally and most importantly, I want to thank my family for the encouragement and support through this long journey. Especially I would like to thank my mother Vasiliki, for all these things she offered and continues to offer, so many that are impossible to be numbered in the acknowledgments of a thesis.

For the completion of this research, financial support from the Natural Sciences and Engineering Research Council (NSERC) of Canada and the Canada Research Chair (CRC) program is greatly appreciated. In addition, the author has to the thank CIBA Chemicals for the supply of the new radical generator. Moreover, assistance with samples characterization by Equistar Chemicals is gratefully acknowledged. 


\section{TABLE OF CONTENTS}

$\begin{array}{lr}\text { Abstract } & \text { iii } \\ \text { Acknowledgements } & \text { iv } \\ \text { Table of Contents } & \mathrm{V} \\ \text { List of Tables } & \text { viii } \\ \text { List of Figures } & \mathrm{x} \\ \text { Abbreviations } & \mathrm{xv} \\ \text { Symbols } & \mathrm{xvi}\end{array}$

I. Introduction - Thesis Objectives and Overview

II. Literature Review 3

2.1 Degradation of PP 3

2.2 Peroxides as Radical Initiators 5

2.2.1 Kinetics of Peroxide-initiated Degradation of PP 6

2.2.2 Rheology \& MWD of CRPP 9

2.3 Nitroxides as Radical Initiators 11

2.3.1 Introduction 11

$\begin{array}{ll}\text { 2.3.2 Nitroxides in CRPP } & 14\end{array}$

$\begin{array}{lr}\text { III. Experimental } & 18\end{array}$

3.1 CRPP Production 19

3.1.1 Haake Mixer 19

3.1.1.1 General description 19

3.1.1.2 Specifications $\quad 22$

3.1.1.3 Experimental procedure 22

3.2 CRPP Characterization 26

3.2.1 Grinder 26

3.2.2 Melt Flow Rate (MFR) Apparatus 28

3.2.2.1 General description- specifications 28 
3.2.2.2 Experimental procedure

3.2.3 Hot Press 30

3.2.4 Parallel Plate Rheometer 32

3.2.4.1 General description $\quad 34$

3.2.4.2 Main specifications $\quad 39$

3.2.4.3 Experimental procedure $\quad 40$

3.2.5 Fourier Transform Infrared (FT-IR) Spectroscopy 41

3.2.6 Gel Permeation Chromatography (GPC) 44

3.2.6.1 General 44

3.2.6.2 Specifications and experimental procedure $\quad 46$

3.2.7 Capillary Rheometer $\quad 47$

3.2.7.1 General 47

3.2.7.2 Specifications and experimental procedure $\quad 50$

IV. Results and Discussion $\quad 52$

4.1 CRPP Production Measurements 53

4.1.1 Haake Mixer Measurements 53

4.1.2 Modeling of the Polymer Melt in Haake Mixer 55

4.2 CRPP Characterization 58

4.2.1 Melt Flow Rate Measurements $\quad 58$

4.2.1.1 General results $\quad 58$

4.2.1.2 Statistical analysis $\quad 60$

4.2.1.3 Specifications and experimental procedure $\quad 64$

4.2.2 Parallel Plate Rheometer Measurements 66

4.2.2.1 Zero shear viscosity directly from experimental data 74

4.2.2.2 Zero shear viscosity predicted from CarreauYasuda model $\quad 87$

4.2.3 Fourier Transform Infrared Spectroscopy Analysis $\quad 99$

4.2.4 Gel Permeation Chromatography Analysis 101

4.3 CRPP Produced with Tetrafunctional Peroxide Initiator 108

$\begin{array}{ll}\text { V. Conclusions and Recommendations for Future Work } & 125\end{array}$ 
$\begin{array}{ll}\text { Appendices } & 134\end{array}$

Appendix I: Charts of Torque vs. Time in Haake Mixer 135

Appendix II: Modeling of Polymer Melt in Haake Mixer 138

Appendix III: Parallel Plate Rheometer Frequency Sweeps of CRPP 142

Appendix IV: Fourier Transform Infrared (FT-IR) Spectra 151 


\section{LIST OF TABLES}

Table 2.1: End-use applications of Polypropylene (Tzoganakis et al., 1988) 4

Table 2.2a: Commonly-used Organic Peroxides 5

Table 2.2b: Commonly-used Organic Peroxides 6

Table 3.1: Materials used for production of CRPP in the Haake mixer 23

Table 3.2: Parameters of experiments in the Haake mixer (CRPP manufacturing) 24

Table 3.3: Antioxidant used for the preparation of the CRPP before the hot press 31

Table 3.4: IR Absorption table (http://scienceofspectroscopy.info)

Functional group and respective absorption band position $\left(\mathrm{cm}^{-1}\right) \quad 43$

Table 3.5: Techniques used with the most important parameters 51

Table 4.1: Zero shear viscosity (in Pa·sec) determined from G"/ $\omega$ vs. $\omega$ graphs at $170{ }^{\circ} \mathrm{C}$

Table 4.2: Zero shear viscosity (in Pa.sec) determined from G"/ $\omega$ vs. $\omega$ graphs at $190{ }^{\circ} \mathrm{C}$

Table 4.3: Zero shear viscosity (in Pa.sec) determined from G"/ $\omega$ vs. $\omega$ graphs at $210^{\circ} \mathrm{C} \quad 84$

Table 4.4: Carreau-Yasuda model parameters from the numerical simulation of complex viscosity vs. frequency at $170{ }^{\circ} \mathrm{C}$ for CRPP produced at $230{ }^{\circ} \mathrm{C} \quad 94$

Table 4.5: Carreau-Yasuda model parameters from the numerical simulation of complex viscosity vs. frequency at $170{ }^{\circ} \mathrm{C}$ for CRPP produced at $250{ }^{\circ} \mathrm{C} \quad 94$

Table 4.6: Carreau-Yasuda model parameters from the numerical simulation of complex viscosity vs. frequency at $170{ }^{\circ} \mathrm{C}$ for CRPP produced at $270{ }^{\circ} \mathrm{C} \quad 94$

Table 4.7: Carreau-Yasuda model parameters from the numerical simulation of complex viscosity vs. frequency at $170{ }^{\circ} \mathrm{C}$ for CRPP produced at $290{ }^{\circ} \mathrm{C}$

Table 4.8: Carreau-Yasuda model parameters from the numerical simulation of complex viscosity vs. frequency at $190{ }^{\circ} \mathrm{C}$ for CRPP produced at $230{ }^{\circ} \mathrm{C}$

Table 4.9: Carreau-Yasuda model parameters from the numerical simulation of complex viscosity vs. frequency at $190{ }^{\circ} \mathrm{C}$ for CRPP produced at $250{ }^{\circ} \mathrm{C}$

Table 4.10: Carreau-Yasuda model parameters from the numerical simulation of complex viscosity vs. frequency at $190{ }^{\circ} \mathrm{C}$ for CRPP produced at $270{ }^{\circ} \mathrm{C}$

Table 4.11: Carreau-Yasuda model parameters from the numerical simulation of complex viscosity vs. frequency at $190{ }^{\circ} \mathrm{C}$ for CRPP produced at $290{ }^{\circ} \mathrm{C}$

Table 4.12: Carreau-Yasuda model parameters from the numerical simulation of complex viscosity vs. frequency at $210{ }^{\circ} \mathrm{C}$ for CRPP produced at $230{ }^{\circ} \mathrm{C}$

Table 4.13: Carreau-Yasuda model parameters from the numerical simulation of complex viscosity vs. frequency at $210{ }^{\circ} \mathrm{C}$ for CRPP produced at $250{ }^{\circ} \mathrm{C}$

Table 4.14: Carreau-Yasuda model parameters from the numerical simulation of complex viscosity vs. frequency at $210{ }^{\circ} \mathrm{C}$ for CRPP produced at $270{ }^{\circ} \mathrm{C}$

Table 4.15: Carreau-Yasuda model parameters from the numerical simulation of complex viscosity vs. frequency at $210{ }^{\circ} \mathrm{C}$ for CRPP produced at $290{ }^{\circ} \mathrm{C}$ 
Table 4.16: Molecular Weights determined from GPC analysis for selected CRPP resins

Table 4.17: Polydispersity indices ER and PDR, complex viscosity $\eta^{*}$ at $\mathrm{G}^{*}=2 \cdot 10^{4} \mathrm{~Pa}$ and its approximate increase for the selected CRPP resins

Table 4.18: Materials used for production of CRPP with monofunctional and tetrafunctional peroxide initiator

Table 4.19: GPC analysis for CRPP samples 


\section{LIST OF FIGURES}

Figure 2.1: Chemical Structure of PP 3

Figure 2.2: Chemical structure of tetra functional radical initiator Luperox JWEB50 6

Figure 2.3: Peroxide initiated degradation mechanism 1

$\begin{array}{ll}\text { Figure 2.4: CRPP reaction scheme } & 8\end{array}$

Figure 2.5: Simulation and experimental results of weight average MW and MWD of CRPP for varying peroxide concentration (Tzoganakis, 1988) 9

Figure 2.6: Viscosity vs. shear rate and MWD of CRPP for varying peroxide concentration (Tzoganakis, 1988)

Figure 2.7: TEMPO (2, 2, 6,6 - Tetramethylpiperidine 1 - oxyl) 11

$\begin{array}{ll}\text { Figure 2.8: Formation of TEMPO from hydroxylamine } & 12\end{array}$

$\begin{array}{ll}\text { Figure 2.9: 2, 2, 6, 6- Tetramethylpiperidine } & 13\end{array}$

Figure 2.10: Formation of nitroxyl radicals from amines 13

Figure 2.11: Performance of the PP-based nitroxide Irgatec CR76 in CRPP manufacturing $\begin{array}{ll}\text { (Pfaendner, 2003) } & 14\end{array}$

Figure 2.12: Suggested NOR initiated degradation mechanism 16

Figure 3.1: Haake mixer: lateral and front view (Bousmina et al., 1999) 20

Figure 3.2: Haake mixer: typical variation of the measured torque as a function of time $\begin{array}{ll}\text { (Bousmina et al., 1999) } & 21\end{array}$

Figure 3.3: Wiley mill with six revolving and four stationary blades 27

$\begin{array}{ll}\text { Figure 3.4: MFR apparatus } & 28\end{array}$

Figure 3.5: Typical flow chart of a material and application areas of Rheometers 33

Figure 3.6: Cone and Plate Viscometer (or Weissenberg Rheogoniometer) 33

Figure 3.7: Parallel plate rheometer (or disk-plate rheometer) 33

Figure 3.8: Dynamic measurements in the parallel plate rheometer 35

Figure 3.9: Typical strain sweep with the linear viscoelastic region of the material 37

Figure 3.10: Typical frequency sweep of the material 37

Figure 3.11: Rheometer AR 2000 39

Figure 3.12: Head of Rheometer AR 2000 40

Figure 3.13: Principles of GPC $\quad 45$

Figure 3.14: Flow inside the capillary rheometer 48

Figure 3.15: Flow chart in logarithmic scale of typical capillary rheometer results 49

Figure 4.1: Final torque of CRPP polymer melt in the Haake mixer, as function of the nominal temperature in the mixing chamber $\quad 54$

Figure 4.2: Logarithm of shear stress vs. logarithm of shear rate for the two dies in the $\begin{array}{ll}\text { capillary rheometer } & 55\end{array}$

Figure 4.3: Analytical solution for shear viscosity of the CRPP melt in Haake mixer 57 
Figure 4.4: Performance of MFR index of the produced CRPP samples

Figure 4.5: Performance of MFR index of the produced CRPP samples with error bars at $95 \%$ confidence level

Figure 4.6: MFR experimental points for PP with 0, 0.75 and 3\% Irgatec CR76 62

Figure 4.7: MFR experimental points for PP with 0.75 and 3\% Irgatec CR76

Figure 4.8: MFR experimental points for PP with 0 and 0.75\% Irgatec CR76

Figure 4.9: MFR experimental points for PP with $0.75 \%$ Irgatec CR76 and 250 ppm Luperox 101

Figure 4.10: MFR experimental points for PP with 0 and 250 ppm Luperox 101 64

Figure 4.11: Bar chart with experimental results with and without $\mathrm{N}_{2}$ at $250{ }^{\circ} \mathrm{C}$ 65

Figure 4.12: Bar chart with experimental results with and without $\mathrm{N}_{2}$ at $290{ }^{\circ} \mathrm{C}$ 65

Figure 4.13: G" vs. G' at $170{ }^{\circ} \mathrm{C}$ of CRPP produced in Haake Mixer at $230{ }^{\circ} \mathrm{C}$ 67

Figure 4.14: G" vs. G' at $170{ }^{\circ} \mathrm{C}$ of CRPP produced in Haake Mixer at $250{ }^{\circ} \mathrm{C}$

Figure 4.15: G" vs. G' at $170{ }^{\circ} \mathrm{C}$ of CRPP produced in Haake Mixer at $270{ }^{\circ} \mathrm{C}$

Figure 4.16: G" vs. G' at $170{ }^{\circ} \mathrm{C}$ of CRPP produced in Haake Mixer at $290{ }^{\circ} \mathrm{C}$ 68

Figure 4.17: G" vs. G' at $190{ }^{\circ} \mathrm{C}$ of CRPP produced in Haake Mixer at $230{ }^{\circ} \mathrm{C}$ 68

Figure 4.18: G" vs. $\mathrm{G}^{\prime}$ at $190{ }^{\circ} \mathrm{C}$ of CRPP produced in Haake Mixer at $250{ }^{\circ} \mathrm{C}$

Figure 4.19: G" vs. G' at $190{ }^{\circ} \mathrm{C}$ of CRPP produced in Haake Mixer at $270{ }^{\circ} \mathrm{C}$ 69 Figure 4.20: G" vs. G' at $190{ }^{\circ} \mathrm{C}$ of CRPP produced in Haake Mixer at $290{ }^{\circ} \mathrm{C}$ 70

Figure 4.21: G" vs. G' at $210{ }^{\circ} \mathrm{C}$ of CRPP produced in Haake Mixer at $230{ }^{\circ} \mathrm{C}$ 70

Figure 4.22: G" vs. G' at $210{ }^{\circ} \mathrm{C}$ of CRPP produced in Haake Mixer at $250{ }^{\circ} \mathrm{C}$

Figure 4.23: G" vs. G' at $210{ }^{\circ} \mathrm{C}$ of CRPP produced in Haake Mixer at $270{ }^{\circ} \mathrm{C}$

Figure 4.24: G" vs. G' at $210{ }^{\circ} \mathrm{C}$ of CRPP produced in Haake Mixer at $290{ }^{\circ} \mathrm{C}$

Figure 4.25: G"/ $\omega$ vs. $\omega$ at $170{ }^{\circ} \mathrm{C}$ of CRPP produced in Haake Mixer at $230^{\circ} \mathrm{C}$

Figure 4.26: G"/ $\omega$ vs. $\omega$ at $170{ }^{\circ} \mathrm{C}$ of CRPP produced in Haake Mixer at $250^{\circ} \mathrm{C}$

Figure 4.27: G"/ $\omega$ vs. $\omega$ at $170{ }^{\circ} \mathrm{C}$ of CRPP produced in Haake Mixer at $270{ }^{\circ} \mathrm{C}$

Figure 4.28: G"/ $\omega$ vs. $\omega$ at $170{ }^{\circ} \mathrm{C}$ of CRPP produced in Haake Mixer at $290^{\circ} \mathrm{C}$

Figure 4.29: G"/ $\omega$ vs. $\omega$ at $190{ }^{\circ} \mathrm{C}$ of CRPP produced in Haake Mixer at $230^{\circ} \mathrm{C}$

Figure 4.30: G"/ $\omega$ vs. $\omega$ at $190{ }^{\circ} \mathrm{C}$ of CRPP produced in Haake Mixer at $250^{\circ} \mathrm{C}$

Figure 4.31: G"/ $\omega$ vs. $\omega$ at $190{ }^{\circ} \mathrm{C}$ of CRPP produced in Haake Mixer at $270{ }^{\circ} \mathrm{C}$

Figure 4.32: G"/ $\omega$ vs. $\omega$ at $190{ }^{\circ} \mathrm{C}$ of CRPP produced in Haake Mixer at $290{ }^{\circ} \mathrm{C}$

Figure 4.33: G"/ $\omega$ vs. $\omega$ at $210{ }^{\circ} \mathrm{C}$ of CRPP produced in Haake Mixer at $230{ }^{\circ} \mathrm{C}$

Figure 4.34: G"/ $\omega$ vs. $\omega$ at $210{ }^{\circ} \mathrm{C}$ of CRPP produced in Haake Mixer at $250{ }^{\circ} \mathrm{C}$

Figure 4.35: G"/ $\omega$ vs. $\omega$ at $210{ }^{\circ} \mathrm{C}$ of CRPP produced in Haake Mixer at $270{ }^{\circ} \mathrm{C}$

Figure 4.36: G"/ $\omega$ vs. $\omega$ at $210{ }^{\circ} \mathrm{C}$ of CRPP produced in Haake Mixer at $290{ }^{\circ} \mathrm{C}$

Figure 4.37: Superimposition of the results at 170,190 and $210{ }^{\circ} \mathrm{C}$ (with $190{ }^{\circ} \mathrm{C}$ reference temperature) for CRPP produced in Haake Mixer at $230{ }^{\circ} \mathrm{C}$

Figure 4.38: Superimposition of the results at 170,190 and $210{ }^{\circ} \mathrm{C}$ (with $190{ }^{\circ} \mathrm{C}$ reference temperature) for CRPP produced in Haake Mixer at $250{ }^{\circ} \mathrm{C}$ 
Figure 4.39: Superimposition of the results at 170,190 and $210{ }^{\circ} \mathrm{C}$ (with $190{ }^{0} \mathrm{C}$ reference temperature) for CRPP produced in Haake Mixer at $270{ }^{\circ} \mathrm{C}$

Figure 4.40: Superimposition of the results at 170,190 and $210{ }^{\circ} \mathrm{C}$ (with $190{ }^{\circ} \mathrm{C}$ reference temperature) for CRPP produced in Haake Mixer at $290{ }^{\circ} \mathrm{C}$

Figure 4.41: Zero shear viscosity $\eta_{0}$ of the CRPP determined at $170{ }^{0} \mathrm{C}$ from the $\mathrm{G} / \omega$ graphs, vs. the production temperature of the CRPP

Figure 4.42: Zero shear viscosity $\eta_{0}$ of the CRPP determined at $190{ }^{0} \mathrm{C}$ from the $\mathrm{G} / \omega$ graphs, vs. the production temperature of the CRPP

Figure 4.43: Zero shear viscosity $\eta_{0}$ of the CRPP determined at $210{ }^{0} \mathrm{C}$ from the $\mathrm{G}^{\prime \prime} / \omega$ graphs, vs. the production temperature of the CRPP

Figure 4.44: Complex viscosity vs. frequency of the CRPP determined at $170{ }^{\circ} \mathrm{C}$ for CRPP produced at $230{ }^{\circ} \mathrm{C}$

Figure 4.45: Complex viscosity vs. frequency of the CRPP determined at $170{ }^{\circ} \mathrm{C}$ for CRPP produced at $250{ }^{\circ} \mathrm{C}$

Figure 4.46: Complex viscosity vs. frequency of the CRPP determined at $170{ }^{\circ} \mathrm{C}$ for CRPP produced at $270{ }^{\circ} \mathrm{C}$

Figure 4.47: Complex viscosity vs. frequency of the CRPP determined at $170{ }^{\circ} \mathrm{C}$ for CRPP produced at $290{ }^{\circ} \mathrm{C}$

Figure 4.48: Complex viscosity vs. frequency of the CRPP determined at $190{ }^{\circ} \mathrm{C}$ for CRPP produced at $230{ }^{\circ} \mathrm{C}$

Figure 4.49: Complex viscosity vs. frequency of the CRPP determined at $190{ }^{\circ} \mathrm{C}$ for CRPP produced at $250{ }^{\circ} \mathrm{C}$

Figure 4.50: Complex viscosity vs. frequency of the CRPP determined at $190{ }^{\circ} \mathrm{C}$ for CRPP produced at $270{ }^{\circ} \mathrm{C}$

Figure 4.51: Complex viscosity vs. frequency of the CRPP determined at $190{ }^{\circ} \mathrm{C}$ for CRPP produced at $290{ }^{\circ} \mathrm{C}$

Figure 4.52: Complex viscosity vs. frequency of the CRPP determined at $210{ }^{\circ} \mathrm{C}$ for CRPP produced at $230{ }^{\circ} \mathrm{C}$

Figure 4.53: Complex viscosity vs. frequency of the CRPP determined at $210{ }^{\circ} \mathrm{C}$ for CRPP produced at $250{ }^{\circ} \mathrm{C}$

Figure 4.54: Complex viscosity vs. frequency of the CRPP determined at $210{ }^{\circ} \mathrm{C}$ for CRPP produced at $270{ }^{\circ} \mathrm{C}$

Figure 4.55: Complex viscosity vs. frequency of the CRPP determined at $210{ }^{\circ} \mathrm{C}$ for CRPP produced at $290{ }^{\circ} \mathrm{C}$

Figure 4.56: Relative absorbance $\left(888 \mathrm{~cm}^{-1} / 459 \mathrm{~cm}^{-1}\right)$ of each CRPP vs. temperature of production

Figure 4.57: Relative absorbance $\left(888 \mathrm{~cm}^{-1} / 841 \mathrm{~cm}^{-1}\right)$ of each CRPP vs. temperature of production

Figure 4.58: MWD for CRPP resins produced from pure PP at $230{ }^{\circ} \mathrm{C}$, pure PP at $250{ }^{0} \mathrm{C}$, pure PP at $290{ }^{\circ} \mathrm{C}$ and PP with 250 ppm Luperox 101 at $290{ }^{\circ} \mathrm{C}$ 
Figure 4.59: MWD for CRPP resins produced from PP with $0.75 \%$ Irgatec CR76 at $290{ }^{\circ} \mathrm{C}$, PP with $1.5 \%$ Irgatec CR76 at $250{ }^{\circ} \mathrm{C}$, PP with $1.5 \%$ Irgatec CR76 at $290{ }^{\circ} \mathrm{C}$ and PP with $3 \%$ Irgatec CR76 at $290{ }^{\circ} \mathrm{C}$

Figure 4.60: Zero shear viscosity, as determined for 170,190 and $210{ }^{0} \mathrm{C}$ using the $\mathrm{G} / / \omega$ experimental data vs. the determined $\mathrm{M}_{\mathrm{w}}$ for the 8 tested CRPP resins including linear regression models for each data set

Figure 4.61: Zero shear viscosity, as determined for 170,190 and $210{ }^{\circ} \mathrm{C}$ using numerical simulation vs. the determined $\mathrm{M}_{\mathrm{w}}$ for the 8 tested CRPP resins including linear regression models for each data set

Figure 4.62: Storage modulus G' vs. $\omega$ for CRPP produced at $200{ }^{\circ} \mathrm{C}$ and tested at $190{ }^{\circ} \mathrm{C}$ in the cone and plate viscometer

Figure 4.63: Storage modulus $\mathrm{G}^{\prime}$ vs. $\omega$ for CRPP produced at $230{ }^{\circ} \mathrm{C}$ and tested at $190{ }^{0} \mathrm{C}$ in the cone and plate viscometer

Figure 4.64: Loss modulus G" vs. $\omega$ for CRPP produced at $200{ }^{\circ} \mathrm{C}$ and tested at $190{ }^{\circ} \mathrm{C}$ in the cone and plate viscometer

Figure 4.65: Loss modulus G" vs. $\omega$ for CRPP produced at $230{ }^{\circ} \mathrm{C}$ and tested at $190{ }^{\circ} \mathrm{C}$ in the cone and plate viscometer

Figure 4.66: Complex viscosity $\eta^{*}$ vs. $\omega$ for CRPP produced at $200{ }^{\circ} \mathrm{C}$ and tested at $190{ }^{0} \mathrm{C}$ in the cone and plate viscometer

Figure 4.67: Complex viscosity $\eta^{*}$ vs. $\omega$ for CRPP produced at $230{ }^{\circ} \mathrm{C}$ and tested at $190{ }^{0} \mathrm{C}$ in the cone and plate viscometer

Figure 4.68: Storage modulus G' vs. $\omega$ for CRPP produced at $200{ }^{\circ} \mathrm{C}$ and tested at $210{ }^{\circ} \mathrm{C}$ in the cone and plate viscometer

Figure 4.69: Storage modulus G' vs. $\omega$ for CRPP produced at $230{ }^{\circ} \mathrm{C}$ and tested at $210{ }^{\circ} \mathrm{C}$ in the cone and plate viscometer

Figure 4.70: Loss modulus G" vs. $\omega$ for CRPP produced at $200{ }^{\circ} \mathrm{C}$ and tested at $210{ }^{\circ} \mathrm{C}$ in the cone and plate viscometer

Figure 4.71: Loss modulus G" vs. $\omega$ for CRPP produced at $230{ }^{\circ} \mathrm{C}$ and tested at $210{ }^{\circ} \mathrm{C}$ in the cone and plate viscometer

Figure 4.72: Complex viscosity $\eta^{*}$ vs. $\omega$ for CRPP produced at $200{ }^{\circ} \mathrm{C}$ and tested at $210{ }^{0} \mathrm{C}$ in the cone and plate viscometer

Figure 4.73: Complex viscosity $\eta^{*}$ vs. $\omega$ for CRPP produced at $230{ }^{\circ} \mathrm{C}$ and tested at $210{ }^{0} \mathrm{C}$ in the cone and plate viscometer

Figure 4.74: The temperature effect: MWD for virgin PP (pellets), CRPP produced from virgin PP at $200{ }^{\circ} \mathrm{C}$ and CRPP produced from virgin $\mathrm{PP}$ at $230{ }^{\circ} \mathrm{C}$

Figure 4.75: MWD for CRPP produced at $200{ }^{0} \mathrm{C}$ from PP with $0.01 \%$ A1 and from PP with $0.0166 \%$ A2

Figure 4.76: MWD for CRPP produced at $230{ }^{\circ} \mathrm{C}$ from PP with $0.01 \%$ A1 and from PP with $0.0166 \%$ A2 
Figure 4.77: MWD for CRPP produced at $200{ }^{\circ} \mathrm{C}$ from PP with $0.03 \%$ A1 and from PP with $0.055 \%$ A2

Figure 4.78: MWD for CRPP produced at $230{ }^{\circ} \mathrm{C}$ from PP with $0.03 \%$ A1 and from PP with $0.055 \% \mathrm{~A} 2$

Figure 4.79: MWD for CRPP produced at $200{ }^{\circ} \mathrm{C}$ from PP with $0.1 \% \mathrm{~A} 1$ and from PP with $0.166 \%$ A2

Figure 4.80: MWD for CRPP produced at $230{ }^{\circ} \mathrm{C}$ from PP with $0.1 \% \mathrm{~A} 1$ and from PP with $0.166 \%$ A2

Figure 4.81: Intrinsic viscosity vs. $\log \mathrm{M}$ for CRPP produced at $200{ }^{\circ} \mathrm{C}$ from PP with $0.01 \%$ A1 and from PP with $0.0166 \%$ A2

Figure 4.82: Intrinsic viscosity vs. $\log \mathrm{M}$ for CRPP produced at $230{ }^{\circ} \mathrm{C}$ from PP with $0.01 \%$ A1 and from PP with $0.0166 \%$ A2

Figure 4.83: Intrinsic viscosity vs. $\log \mathrm{M}$ for CRPP produced at $200{ }^{0} \mathrm{C}$ from PP with $0.03 \%$ A1 and from PP with $0.055 \%$ A2

Figure 4.84: Intrinsic viscosity vs. $\log \mathrm{M}$ for CRPP produced at $230{ }^{\circ} \mathrm{C}$ from PP with $0.03 \%$ A1 and from PP with $0.055 \%$ A2

Figure 4.85: Intrinsic viscosity vs. $\log \mathrm{M}$ for CRPP produced at $200{ }^{0} \mathrm{C}$ from PP with $0.1 \%$ A1 and from PP with $0.166 \%$ A2

Figure 4.86: Intrinsic viscosity vs. $\log \mathrm{M}$ for CRPP produced at $230{ }^{\circ} \mathrm{C}$ from PP with $0.1 \%$ A1 and from PP with $0.166 \%$ A2

Figure AI.1: Torque vs. time for $230{ }^{\circ} \mathrm{C}$ in Haake mixer 135 Figure AI.2: Torque vs. time for $250{ }^{\circ} \mathrm{C}$ in Haake mixer 136 Figure AI.3: Torque vs. time for $270{ }^{\circ} \mathrm{C}$ in Haake mixer 136

Figure AI.4: Torque vs. time for $290{ }^{\circ} \mathrm{C}$ in Haake mixer

Figures AIII.1 to A.III20: G' and G" vs. angular frequency, measured at $170{ }^{\circ} \mathrm{C}$ $142-145$

Figures AIII.21 to AIII.40: G' and G" vs. angular frequency, measured at $190{ }^{\circ} \mathrm{C}$ $145-147$ Figures AIII.41 to AIII.60: $\mathrm{G}^{\prime}$ and G" vs. angular frequency, measured at $210^{\circ} \mathrm{C}$ $148-150$ Figures AIV.1 to AIV.80: FT-IR spectra for the CRPP resins 


\section{ABBREVIATIONS}

ASTM American Society for Testing Materials

ATRP Atom Transfer Radical Polymerization

CFRP Controlled Free Radical Polymerization

CRPP Controlled Rheology Polypropylene

DF Degrees of freedom

ER Polydispersity at the High MW End

FT-IR Fourier Transform Infrared (spectroscopy)

GFC Gel Filtration Chromatography

GPC Gel Permeation Chromatography

${ }^{1} \mathrm{H}-\mathrm{NMR} \quad$ Proton Nuclear Magnetic Resonance (spectroscopy)

HM Haake mixer

IV Intrinsic Viscosity

IR Infrared

LCB Long Chain Branching

LVR Linear Viscoelastic Region

MFI Melt Flow Index

MFR Melt Flow Rate

MMA Methyl Methacrylate

MW Molecular Weight

MWD Molecular Weight Distribution

NMP Nitroxide-mediated Process

NOR Nitroxide

PDI Polydispersity Index

PDR Overall Polydispersity Measure

PP Polypropylene

PPR Parallel Plate Rheometer

RAFT Reversible Addition-Fragmentation chain Transfer

RPM Rotors per minute

SEC Size exclusion chromatography

TTS Time - Temperature Superimposition 


\section{SYMBOLS}

Greek

$\alpha \quad$ Mark-Houwink exponent

$\gamma \quad$ Strain

$\gamma_{0} \quad$ Strain Amplitude

$\dot{\gamma} \quad$ Shear Rate

$\dot{\gamma}_{\text {app }} \quad$ Apparent Shear Rate

$\dot{\gamma}_{\mathrm{w}} \quad$ Wall Shear Rate

$\Gamma \quad$ Torque

$\delta \quad$ Phase Angle

$\Delta \mathrm{P}$

$\eta$

$\eta_{0}$

$\eta_{\infty}$

$\eta^{*}$

$[\eta]$

$\lambda$

$\rho$

Density

$\sigma_{0}$

$\tau$

$\tau_{\mathrm{W}}$

$\sigma$

$\omega$

$\Omega$

\section{Latin}

a

$\mathrm{a}_{\mathrm{T}}$

D

$\mathrm{g}^{\prime}$

$\mathrm{G}^{\prime}$

G"

$\mathrm{G}^{*}$

K

$\mathrm{L}$

$\mathrm{M}$

$M_{n} \quad$ Number Average MW

$\mathrm{M}_{\mathrm{v}} \quad$ Viscosity Average MW

$\mathrm{M}_{\mathrm{w}} \quad$ Weight Average MW

$\mathrm{M}_{\mathrm{z}} \quad \mathrm{z}$ Average MW

$\mathrm{M}_{\mathrm{z}+1} \quad \mathrm{z}+1$ Average MW

$\mathrm{n} \quad$ Power-law index

N Rotation Speed

Q Volumetric Flow rate

$\mathrm{r} \quad$ Distance from Axis

R Radius

S Standard Deviation

$\mathrm{t} \quad$ Factor $\mathrm{t}$ of $\mathrm{t}$-Distribution

$\mathrm{V} \quad$ Frequency

V Volume

$\overline{\mathrm{x}} \quad$ Sample numerical Average

$\mathrm{x}_{1} \quad$ Mass Fraction 


\section{Introduction - Thesis Objectives and Overview}

The degradation of polypropylene (PP) is a well-known procedure in polymer processing engineering and the plastics industry. Its importance is based on the fact that by thermally decomposing, and -as a result- reducing, the length of the carbon chain of PP, we can obtain different products with varying rheological properties. Because of that, these products are referred to as controlled-rheology polypropylenes (CRPP).

CRPP have been produced industrially for years using reactive extrusion processes which employ peroxides as free radical initiators. Although peroxides have dominated as free radical initiators for CRPP, a PP-based nitroxide (NOR) with the trade name Irgatec CR76 has been recently developed by CIBA Chemicals and might be a potential substitute for peroxides. The fact that this new initiator is a NOR is perhaps surprising, since NORs are well-known as powerful stabilizers that protect plastics from the negative influence of light and heat. A potential benefit of NORs is that they should be easier (safer) in handling during processing (than peroxides).

Preliminary experimental results (Pfaendner, 2003) exhibited a qualitative difference between Irgatec CR76 and commonly used peroxides. These results suggest the possibility that PP-based NOR might be a substitute for peroxides, and considering the above-mentioned advantages of NORs, this might lead to a fundamental change in the industrial production of CRPP.

The scope of this thesis is to examine this option. Firstly, to investigate if NOR is actually more efficient and effective than a commonly-used peroxide, and if it causes more degradation than the peroxide at the same low concentrations. In addition, if that occurs at different experimental conditions than the conditions of the preliminary experimental results, so we can generalize this method.

Chapter 2 deals with the theoretical background, by providing a literature review of degradation of PP, and about the use of peroxides and nitroxides as radical initiators 
for the production of CRPP. This background is supported by information about kinetics and rheology of the produced CRPP resin.

Chapter 3 is the chapter that presents the experimental methods of this research. This includes methods and instruments that were used for the different experimental procedures. In addition, information about the used substances and mixtures is provided. By reading this chapter, the reader has potentially the ability to replicate all the experimental results which are presented in the next chapter. Chapter 3 is divided in two main parts: the CRPP description and the CRPP characterization. The first part presents the experimental procedure for the production of the CRPP, and the second the experimental procedure for the characterization of the produced CRPP.

Chapter 4 is the part of the thesis where the experimental results are presented. It is separated in three parts.

The first deals with the CRPP production, which took place in a Haake mixer. The second part deals with the CRPP characterization, which was done using four different experimental instruments (Melt Flow Rate apparatus, parallel plate rheometer, Fourier Transform Infrared Spectroscopy apparatus and Gel Permeation Chromatography apparatus). In addition to the experimental results, the rheological properties of the polymer melt inside the Haake mixer were modeled according to existing literature.

Finally, the third part deals with peroxide-mediated degradation of PP by using a tetra-functional peroxide initiator. The results were compared to the PP degradation results with the mono-functional peroxide, the one that was used for comparison with the NOR, thus making the study of NOR-mediated CRPP and peroxide-mediated CRPP more comprehensive.

Chapter 5 summarizes and offers concluding remarks. It also provides recommendations for future work on this novel topic of employing hindered amines for CRPP production. 


\section{Literature Review}

This chapter gives a report of the previous and present situation on theories of CRPP technology using peroxides and NORs as radical initiators. The purpose is to cover in a brief but comprehensive way the background of this research. Section 2.1 covers the degradation of PP, while sections 2.2 and 2.3 cover the degradation of PP using peroxide and NOR initiators, respectively.

\subsection{Degradation of Polypropylene (PP)}

Polypropylene (Figure 2.1) is one of the most common materials in the plastics industry. Its useful properties rank it as one of the dominant thermoplastic materials among modern plastics. PP's chemical structure is generally influenced by the polymerization system used during its production. Polypropylenes are produced, using heterogeneous Ziegler-Natta catalysts and metallocenes, and have weight-average molecular weights (MW) in the range of $3 \cdot 10^{5} \mathrm{~g} / \mathrm{mol}$ to $5 \cdot 10^{5} \mathrm{~g} / \mathrm{mol}$ and polydispersities between 5 and 20 (Tzoganakis et al., 1988).

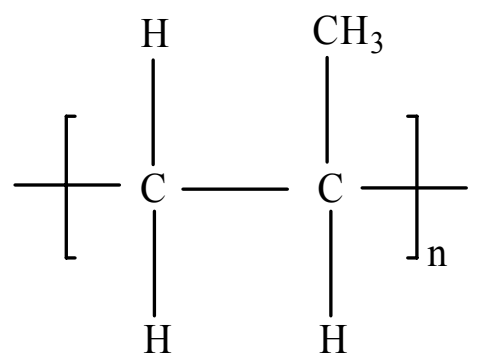

Figure 2.1: Chemical Structure of PP 
Generally, commercial PP resins have broad Molecular Weight Distribution (MWD) as a result of the broad distribution of active sites on the catalyst. MWD is a difficult characteristic to control, especially when Ziegler-Natta catalysts are being used. Because the MWD significantly determines the properties and the performance in processing, this characteristic must be controlled. Control of MWD of the PP in conventional reactors is difficult because it requires the addition of chain terminators and chain transfer agents. These operations decrease output of the reactor and are often uneconomical. Therefore, as an alternative, this control is accomplished via a post-reactor operation that is commonly known as degradation of polypropylene (PP).

The degradation of $\mathrm{PP}$ is a well-known procedure in polymer processing engineering and the plastics industry. Its importance is based on the fact that by thermally decomposing and as a result, reducing the length of the carbon chain of the PP, we can obtain different products with controlled rheological properties. Because of that, these products are referred to as Controlled-Rheology Polypropylenes (CRPP). The importance of this can be shown by referring to Table 2.1, where CRPP resins of different Melt Flow Index (MFI), give a variety of plastic products.

Table 2.1: End-use applications of Polypropylene (Tzoganakis et al., 1988)

\begin{tabular}{|c|c|}
\hline $\begin{array}{l}\text { MFI } \\
\left(230^{\circ} \mathrm{C} / 5 \mathrm{~kg}\right)\end{array}$ & End Use \\
\hline 2 & $\begin{array}{l}\text { Compression } \\
\text { molding, pipes }\end{array}$ \\
\hline $1-5$ & $\begin{array}{l}\text { Extrusion blow } \\
\text { moldings }\end{array}$ \\
\hline $5-15$ & $\begin{array}{l}\text { Biaxially oriented } \\
\text { moldings }\end{array}$ \\
\hline $5-15$ & Film tapes \\
\hline $5-15$ & Monofilaments \\
\hline $5-20$ & $\begin{array}{l}\text { General injection } \\
\text { moldings }\end{array}$ \\
\hline 30 & $\begin{array}{l}\text { High-speed injection } \\
\text { moldings }\end{array}$ \\
\hline $30-40$ & Flat films \\
\hline $40-80$ & Staple films \\
\hline 60 & Spun-bonded fabrics \\
\hline
\end{tabular}


Several researchers have studied MWD of CRPP (Tzoganakis (1988), Tzoganakis et al. (1988), Malz (1995), Bonilla - Rios et al. (1995), Carrot et al. (1996), Bonilla Rios et al. (1998), Asteasuain et al. (2003)). In general, it has been concluded that CRPP resins have lower molecular weight, narrower MWD and reduced viscosity. In addition, it has become clear that one of the most significant challenges for the polymer processing engineer is the problem of inter-conversion between rheological data and the MWD (Shroff and Mavridis (1995)).

The process of degradation needs what is called a "radical initiator". This is a chemical substance which - under particular circumstances- will promote the formation of radicals that will lead to chain degradation. Especially for the PP resins, peroxides have dominated as free radical initiators; CRPP have been produced industrially for years using reactive extrusion processes which employ peroxides as free radical initiators.

\subsection{Peroxides as Radical Initiators}

Peroxide is a chemical substance that contains a "peroxy" unit, one that has a chemical formula of $\mathrm{O}_{2}{ }^{2-}$. Industrial peroxides are organic substances, which are very reactive. Peroxides have become a synonym for the radical initiators for CRPP. Table 2.2 shows some typical commercial organic peroxides, while Figure 2.2 shows the general formula of a typical peroxide initiator (tetra functional).

Table 2.2a: Commonly-used Organic Peroxides

\begin{tabular}{|c|c|c|}
\hline Commercial Name & IUPAC name & Provider \\
\hline Luperox P & Tert-Butyl Peroxybenzoate & Atofina \\
\hline Luperox 101 & Benzoyl Peroxide & Aldrich \\
\hline Luperox A98 & n-Butyl-4,4-di-(t-butylperoxy) valerate & Atofina \\
\hline Lupersol 230 & AtoChem \\
\hline
\end{tabular}


Table 2.2b: Commonly-used Organic Peroxides

\begin{tabular}{|c|c|}
\hline Abbreviation & IUPAC name \\
\hline DYBP & 2,5-Dimethyl-3-hexin-2,5-di-t-butylperoxide \\
\hline DTBP & Di-t-butyl Peroxide \\
\hline DCUP & Dicumylperoxide \\
\hline DTBPH (or DHBP) & $2,5-$ Dimethyl $-2,5-$ di - tert -butylperoxyhexane \\
\hline
\end{tabular}

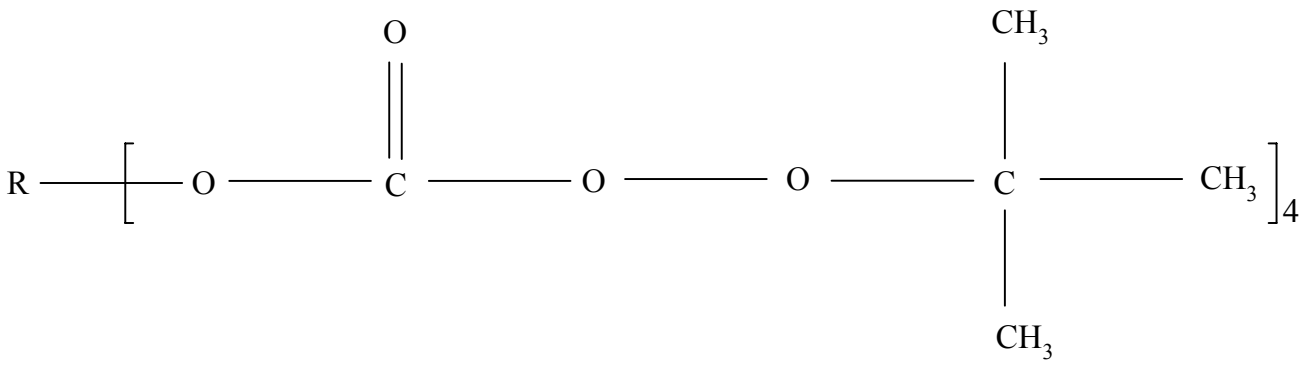

Figure 2.2: Chemical structure of tetra functional radical initiator Luperox JWEB50

\subsubsection{Kinetics of peroxide-initiated degradation of PP}

For peroxide-initiated degradation of PP, several models have been developed (Balke et al. (1987), Suwanda et al. (1988a, 1988b), Tzoganakis (1988), Tzoganakis et al. (1988)) and the peroxide decomposition efficiency at low peroxide concentration has been determined.

Regarding model development, Tzoganakis (1988) proposed a rheokinetic model, a kinetic model based on rheological data. The peroxide initiated degradation mechanism is shown in Figure 2.3 and the CRPP reaction scheme is shown in Figure 2.4. What is proposed is that, under ideal conditions, primary radicals are generated from the thermal decomposition of the peroxide. The primary radicals abstract hydrogen from the PP backbone, with the formation of a tertiary radical along the alkyl chain as a result. These polymer radicals are unstable due to the steric hindrance of the methyl group. This causes 
a $\beta$ scission reaction, which leads to the production of a shorter polymeric chain and a polymer radical with the radical center located on the chain end as shown in Figure 2.3. Because each tertiary carbon on the polymer molecule has an equal chance of being attacked, larger molecules are more likely to undergo scission.

Peroxide thermal decomposition and organic peroxide radical formation:

$$
\mathrm{ROOR} \longrightarrow 2 \mathrm{RO}^{\bullet}
$$

Radical attack, hydrogen abstraction and polymer radical formation:

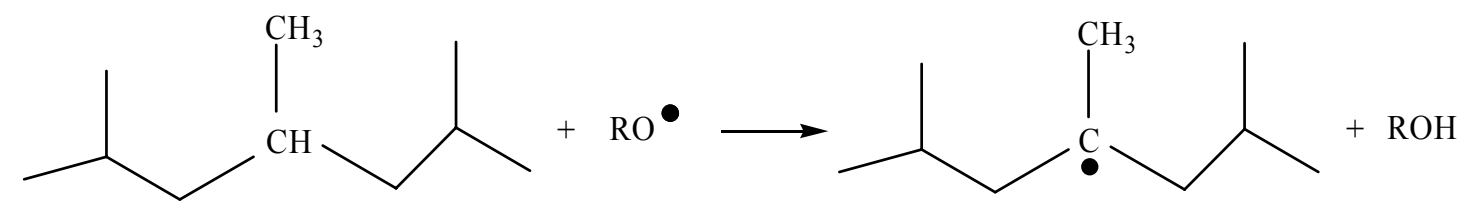

$\beta$-scission and new polyolefin formation:

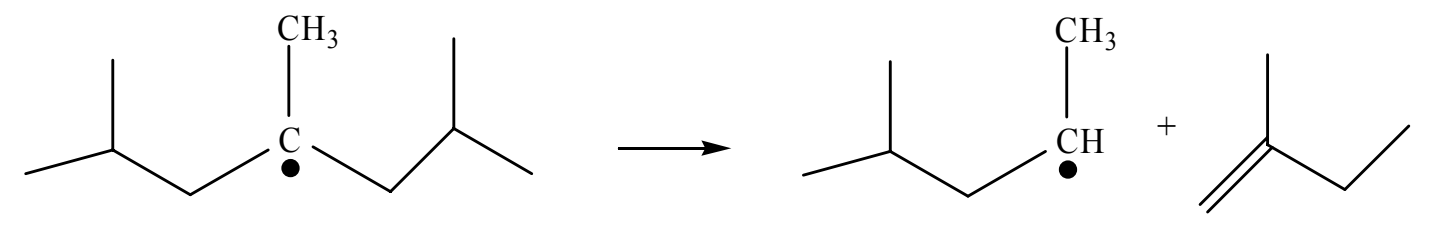

Figure 2.3: Peroxide initiated degradation mechanism

Figure 2.4 shows the CRPP reaction scheme. It describes the total degradation reaction in five steps: initiation, chain scission, transfer, thermal degradation and, finally, termination. The first two steps are the steps that are described in Figure 2.3.

Simulations based on this kinetic model have been developed. The results have been compared with experimental data obtained from the production of CRPP. 
Representative results from this comparison are shown in Figure 2.5. For low concentrations of peroxide, the simulation gives satisfactory results and reliable conclusions can be made for these concentrations (Tzoganakis, 1988).

Estimates have also been made regarding the determination of the peroxide decomposition efficiency at low peroxide concentration. At low peroxide concentration $(\leq 0.04 \%)$, the predicted weight average MW $\left(\overline{\mathrm{M}}_{\mathrm{W}}\right)$ values appear to correlate quite well with the extruder degradation data, as calculated by the method from Suwanada et al. (1988b). In these low peroxide concentration ranges, changes of $\bar{M}_{W}$ are in the order of 2.5\%. Such changes in $\overline{\mathrm{M}}_{\mathrm{w}}$ are not easily detected either by rheological or other characterization methods. At higher peroxide concentrations, common in industrial CRPP resins, the changes in $\overline{\mathrm{M}}_{\mathrm{w}}$ are more distinct and measurable.

Initiation:

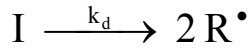

Chain scission:

$$
\mathrm{P}_{\mathrm{n}}+\mathrm{R}^{\cdot} \stackrel{\mathrm{k}_{1}}{\longrightarrow} \mathrm{P}_{\mathrm{r}}+\mathrm{P}_{\mathrm{n}-\mathrm{r}}^{\cdot}+\mathrm{R}
$$

Transfer:

$$
\mathrm{P}_{\mathrm{n}}+\mathrm{P}_{\mathrm{r}}^{\bullet} \stackrel{\mathrm{k}_{2}}{\longrightarrow} \mathrm{P}_{\mathrm{r}}+\mathrm{P}_{s}^{\bullet}+\mathrm{P}_{\mathrm{n}-\mathrm{s}}
$$

Thermal Degradation:

$$
\mathrm{P}_{\mathrm{n}} \stackrel{\mathrm{k}_{3}}{\longrightarrow} \mathrm{P}_{\mathrm{r}}^{\bullet}+\mathrm{P}_{\mathrm{n}-\mathrm{r}}^{\cdot}
$$

Termination:

$$
\mathrm{P}_{\mathrm{n}}^{\cdot}+\mathrm{P}_{\mathrm{r}}^{\bullet} \stackrel{\mathrm{k}_{4}}{\longrightarrow} \mathrm{P}_{\mathrm{n}}+\mathrm{P}_{\mathrm{r}}
$$

Figure 2.4: CRPP reaction scheme 


\subsubsection{Rheology \& MWD of CRPP}

Peroxide degradation of $\mathrm{PP}$ is a post reactor operation with the purpose of lowering the average MW and narrowing the MWD. The changes in the MWD of CRPP are influenced not only by the amount of peroxide but also by the MWD of the starting resin. Fritz and Stohrer (1986), Tzoganakis (1988), Tzoganakis et al. (1989a), Tzoganakis et al. (1989b), and Triacca et al. (1994) studied the rheological properties of CRPP. It was found that as the amount of peroxide is increased, the breadth of the MWD as well as the shear viscosity decreased (Figures $2.5 \mathrm{~b}$ and 2.6 ).

Many researchers have studied extensively the influence of the peroxides on PP resins. Ryu et al. (1992) have described in detail parameters affecting CRPP such as concentration of peroxide, reaction time and reaction temperature. A number of studies on the peroxide-initiated PP controlled degradation in single or twin-screw extruders were reported. Within the temperature range of 200 to $230{ }^{\circ} \mathrm{C}$, no effect of temperature on MW was reported in single or twin-screw extruders or ampoule experiments.
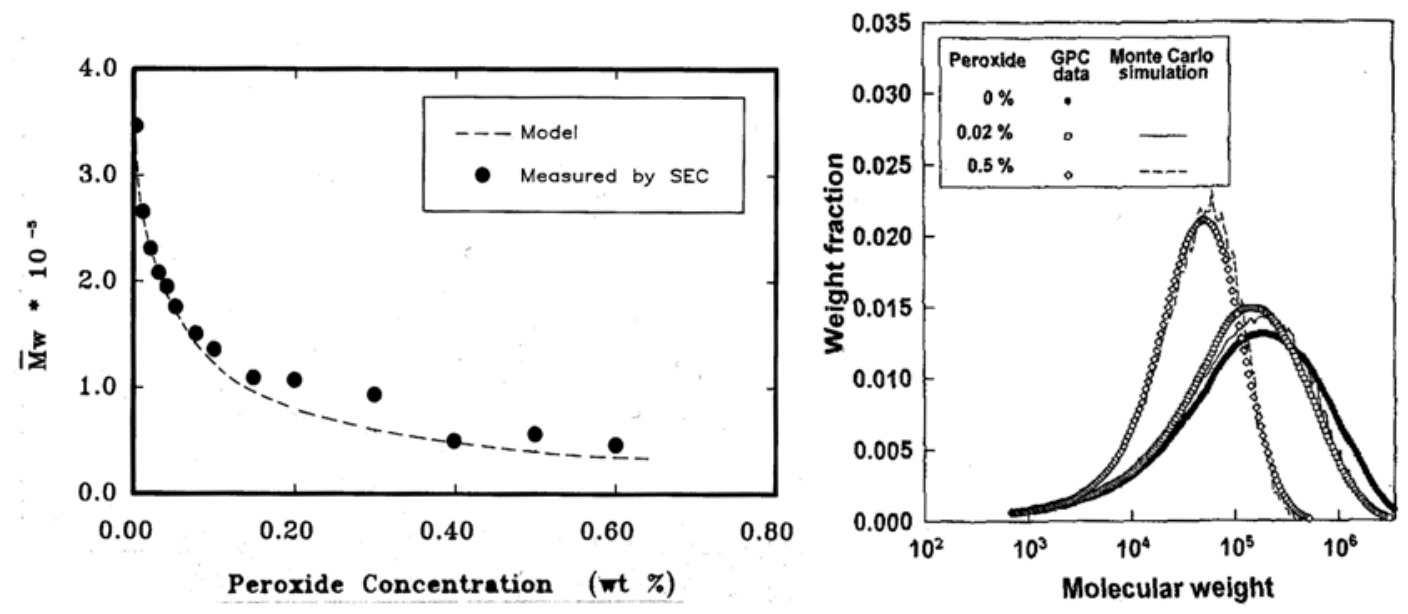

Figure 2.5: Simulation and experimental results of weight average MW and MWD of CRPP for varying peroxide concentration (Tzoganakis, 1988) 

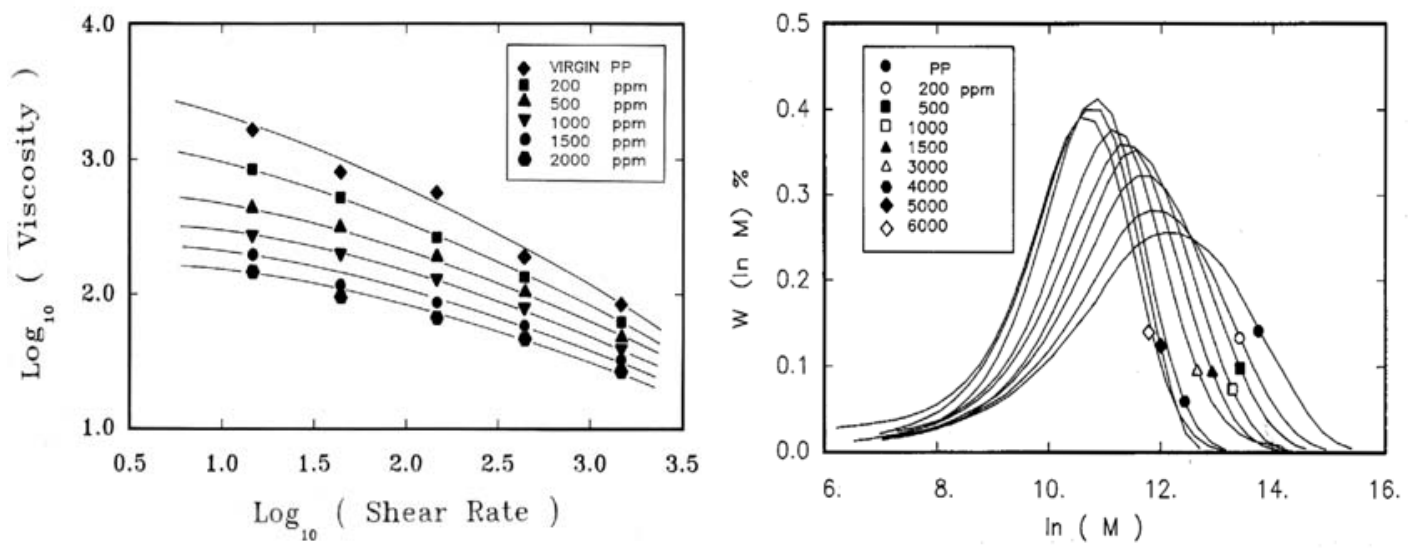

Figure 2.6: Viscosity vs. shear rate and MWD of CRPP for varying peroxide concentration (Tzoganakis, 1988)

Melt Flow Index (MFI) has also been studied (Tzoganakis, 1988). It was found that MFI increases linearly with the peroxide concentration when the latter does not exceed $0.4 \mathrm{wt} \%$ and beyond that it starts to level off. It has been reported that the CRPP process can convert a low MFI commodity resin to high MFI CRPP resins with MFI up to 100 times the original value (Tzoganakis et al, 1989a). In addition, these CRPP resins have superior processing properties because of the reduced viscosity and elasticity.

Azizi and Ghasemi (2003) studied the CRPP process in a twin screw extruder. They concluded that the peroxide concentration is the most dominant variable. According to them also, the MFI is influenced significantly by the peroxide concentration for values up to $0.6 \mathrm{wt} \%$. Slight differences in the MFI results between Tzoganakis (1988) and Azizi and Ghasemi (2003) can be explained by the fact that different virgin PP resins, different organic peroxide initiators and different process methods (single screw vs. twin screw extruder) were used in each case. 


\subsection{Nitroxides as Radical Initiators}

\subsubsection{Introduction}

An amine oxide, also known as amine- $N$-oxide, $N$-oxide or nitroxide (NOR), is a chemical compound that contains the functional group $\mathrm{R}_{3} \mathrm{~N}^{+}-\mathrm{O}^{-}$(also written as $\mathrm{R}_{3} \mathrm{~N}=\mathrm{O}$ or $\mathrm{R}_{3} \mathrm{~N} \rightarrow \mathrm{O}$ ). In a strict sense the term amine oxide applies only to oxides of tertiary amines including nitrogen-containing aromatic compounds like pyridine, but is also used for the analogous derivatives of primary and secondary amines.

One of the most famous nitroxides is the 2,2,6,6-Tetramethylpiperidine 1-oxyl $\left(\mathrm{C}_{9} \mathrm{H}_{18} \mathrm{NO}\right)$ or better known as TEMPO (Figure 2.7). TEMPO is a remarkably stable radical with many applications in organic synthesis. TEMPO was discovered by chemists Lebelev and Kazarnowskii in 1960. It is prepared by oxidation of 2,2,6,6tetramethylpiperidine. TEMPO is widely used in electron spin resonance spectroscopy as a probe for biological systems and also as a radical trap. TEMPO is called a hindered amine. 4 bulky methyl groups surround the nitroxyl amine group and drive selectivity in reactions.

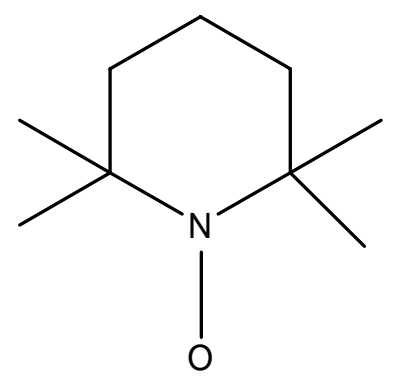

Figure 2.7: TEMPO $(2,2,6,6$ - Tetramethylpiperidine 1 - oxyl $)$

Nitroxides are $\mathrm{N}, \mathrm{N}$-disubstituted $\mathrm{N}-\mathrm{O}$ compounds with an unpaired electron delocalized in the $\mathrm{N}-\mathrm{O} \pi$ system. This $\pi$ electron system effectively forms a bond order 
of one-and-a-half as indicated by the bond energy of $100 \mathrm{kcal} / \mathrm{mol}$, which is midway between the energy of a $\mathrm{N}-\mathrm{O}$ single bond $(53 \mathrm{kcal} / \mathrm{mol})$ and a $\mathrm{N}=\mathrm{O}$ double bond (145 $\mathrm{kcal} / \mathrm{mol}$ ). The gain in energy from the delocalization of the unpaired electron has been calculated to be approximately $30 \mathrm{kcal} / \mathrm{mol}$ (Nilsen et al., 2006). The common formation of a nitroxide happens by the treatment of corresponding hydroxylamines with oxidants such as oxygen, with or without catalyst. Figure 2.8 shows such a formation for TEMPO.
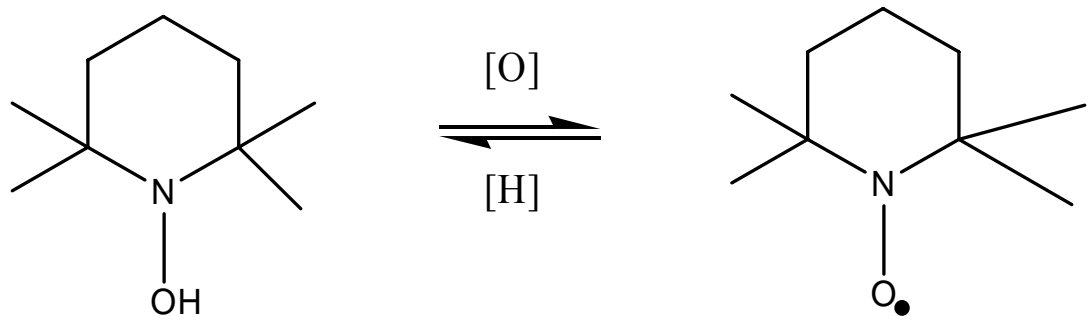

Figure 2.8: Formation of TEMPO from hydroxylamine

Nitroxides are well-known in polymer reaction engineering. Because of their importance as radical generators, they retain a significant position in Controlled Radical Polymerization (CRP). In the past decade, the field of CRP has seen tremendous development as evidenced by the large number of publications related to these techniques. In particular, there are three methods of considerable importance: stable freeradical polymerization [SFRP; e.g., nitroxide-mediated radical polymerization (NMRP)], metal-catalyzed atom transfer radical polymerization (ATRP), and degenerative chain transfer [e.g., reversible addition-fragmentation transfer (RAFT)] (Pyun and Matyjaszewski (2001), Matyjaszewski and Davis (2002)). Nitroxide mediated CRP has been studied extensively by many researchers such as Georges et al. (1996), Fukuda et al. (1996), Georges et al. (1997), Georges et al. (1998), Wannemacher et al. (2003), Braun (2005), and others.

Indeed, one of the main areas where hindered amines find massive application is as light stabilizers, protecting polyolefins and other polymeric materials against photodegradation. Most of the commercial hindered amine light stabilizers are derivatives of 2, 2, 6, 6 - tetramethylpiperidine (Denisov (1974)), see Figure 2.9. 


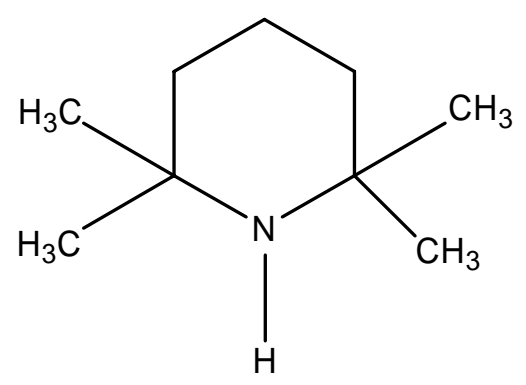

Figure 2.9: 2, 2, 6,6-Tetramethylpiperidine

These stabilizers protect polymers by functioning as light-stable antioxidants. Their antioxidant activity can be explained by the reaction sequence shown in Figure 2.10 (Denisov (1974)).

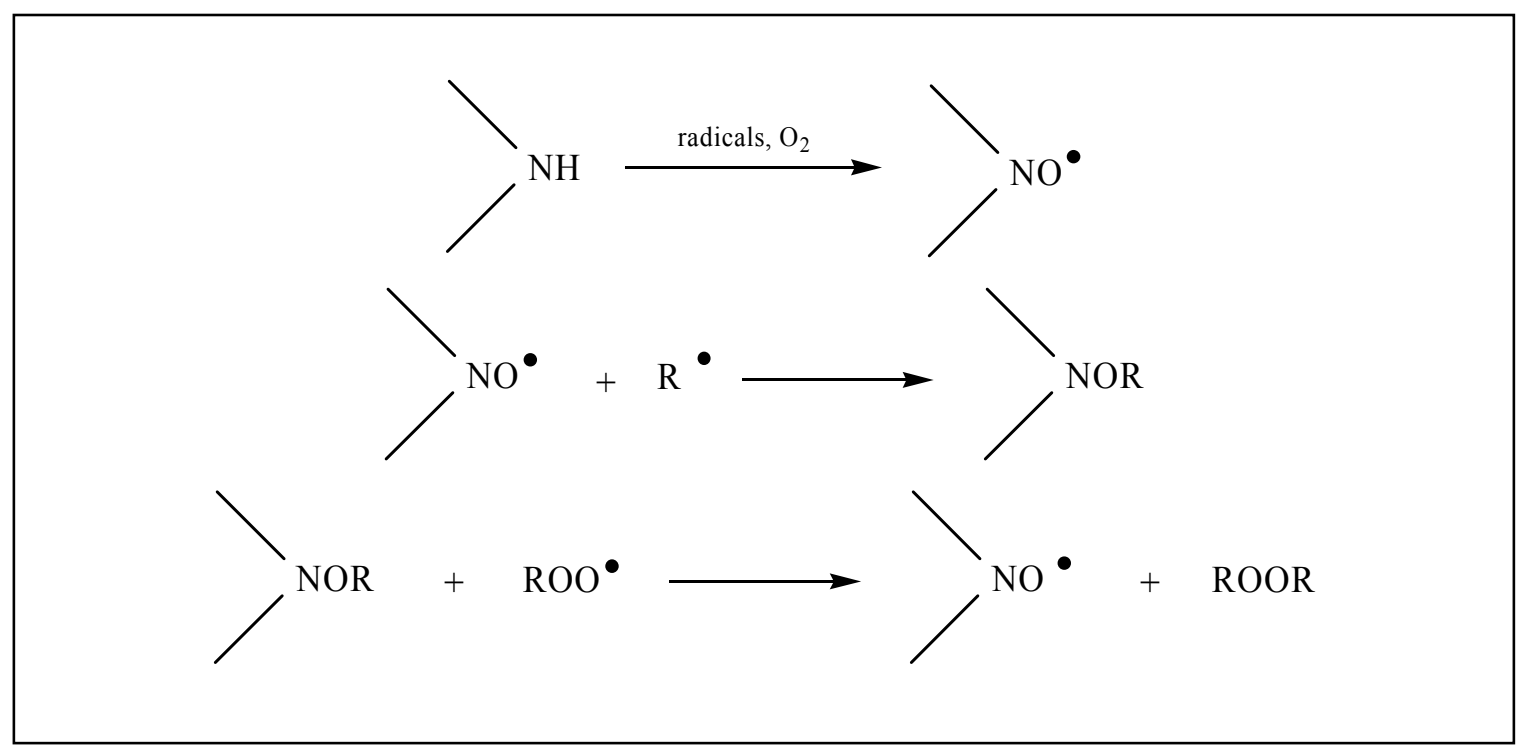

Figure 2.10: Formation of nitroxyl radicals from amines

According to this reaction sequence, hindered-amine derivatives terminate propagating reactions by trapping both alkyl and peroxy radicals. Since the nitroxyl radicals are not consumed in the overall reaction, they are effective at low concentrations.

It has been also found that oligomeric hindered-amine light stabilizers are highly effective in protecting PP multifilaments against oxidization when exposed at $120{ }^{\circ} \mathrm{C}$ in a forced-air oven (Tozzi et al. (1978)). 


\subsubsection{Nitroxides in CRPP}

Despite the fact that hindered amines have an extensive presence in CRP, there were few indications that they may be effective in initiating polymer degradation, since their traditional employment was stabilization. Carlsson et al. (1982) studied the decomposition of polypropylene hydroperoxide induced by hindered amines, while Micallef et al. (2005) used a novel fluorescent nitroxide to monitor the thermo-oxidative degradation of polypropylene.

So it was surprising when, in 2003, Pfaendner presented work that showed hindered amines can have a strategic role beyond stabilization. In contrast, they can be used as radical generators for efficient polymer modification.

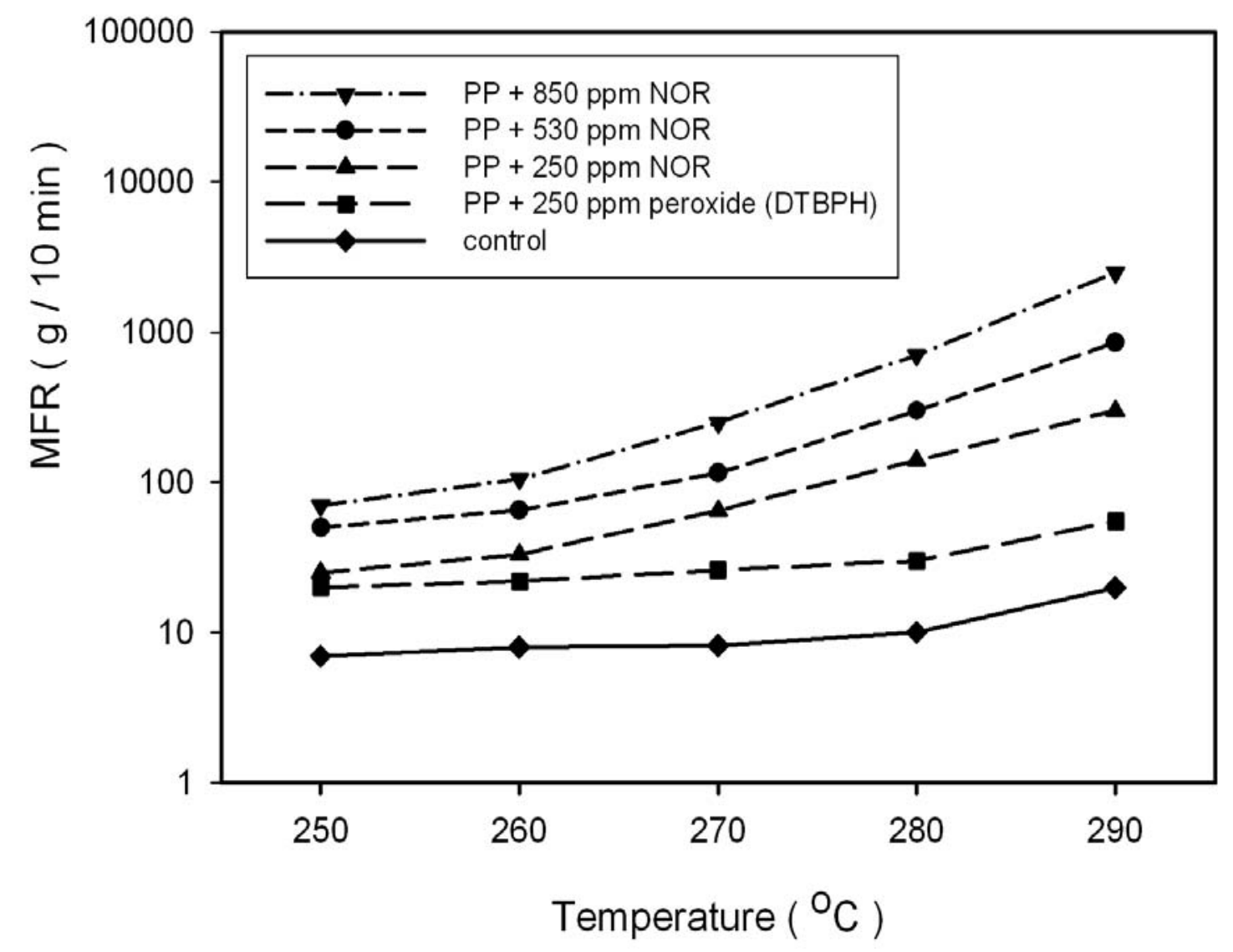

Figure 2.11: Performance of the PP-based nitroxide Irgatec CR76 in CRPP manufacturing (Pfaendner, 2003) 
Pfaendner's presentation showed a PP-based nitroxide (NOR) with the trade name Irgatec CR76 $\left(\right.$ CIBA $^{\circledR}$ Chemicals) which might be a potential substitute for peroxides. Preliminary experimental results exhibited a qualitative difference between Irgatec CR76 and commonly-used peroxide (DTBPH). This is reflected in Figure 2.11, where at low concentrations and at high process temperatures $\left(\geq 250{ }^{0} \mathrm{C}\right)$, the Melt Flow Index (Melt Flow Rate, MFR, in case of PP) is significantly higher for PP treated with the nitroxide radical generator.

The conditions for this study were:

- Virgin polymer: Profax PH 350, with $0.1 \%$ Irganox B 225 and $0.05 \%$ CaStearate

- Extrusion: Twin screw, $100 \mathrm{rpm}, 4 \mathrm{~kg} / \mathrm{h}$, under $\mathrm{N}_{2}$

- $\quad$ NOR: Irgatec CR76, PP-based nitroxide (NOR) by CIBA ${ }^{\circledR}$ Chemicals

- Peroxide: DTBPH (2,5-Dimethyl-2,5-di-tert-butylperoxyhexane)

A possible NOR-initiated degradation mechanism is shown in Figure 2.12. This mechanism pictures the typical radical formation of NOR, the nitroxide radical effect on the vinyl polymer chain, and the $\beta$ scission reaction of the polymer radical due to instability. The final result is a shorter polymeric chain and a polymer radical with the radical center located on the chain end. It is almost the same mechanism as in Figure 2.3, but now instead of peroxide there is a hindered amine. 


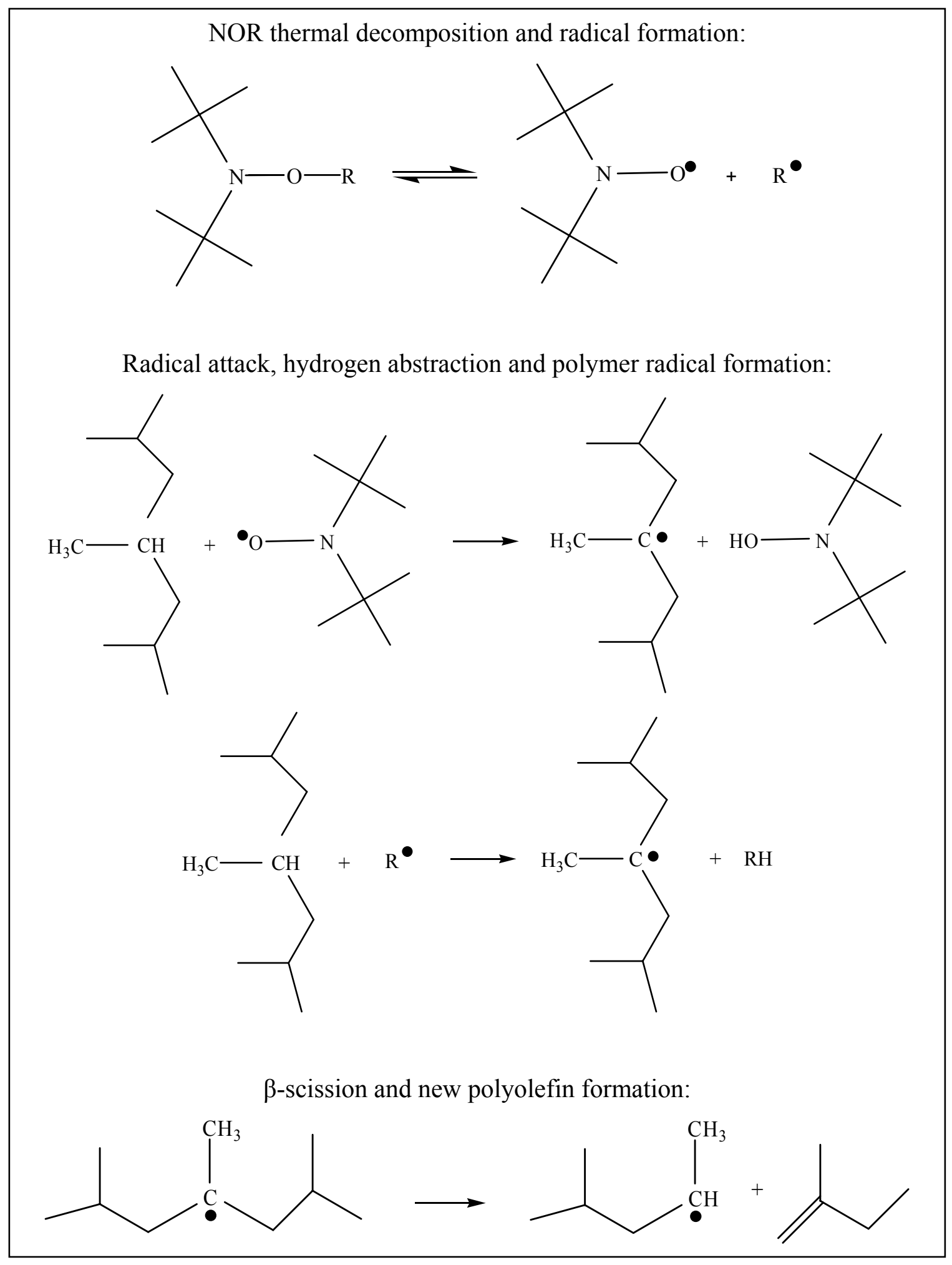

Figure 2.12: Suggested NOR initiated degradation mechanism 
In conclusion, controlled degradation of high MW polypropylene resins to products with high MFR (> 200) and narrower MWD is an important modification step in the polypropylene industry. As it can be seen in Figure 2.11, the preliminary performance at high temperatures of this brand-new nitroxide generator seems significant. This makes it possible to replace or supplement peroxides in CRPP. CRPP have been produced industrially for years using reactive extrusion processes which employ peroxides as free radical initiators. Peroxides have dominated as free radical initiators for CRPP.

NORs are well-known as powerful stabilizers to protect plastics from the negative influence of light and heat and, in addition, NORs are potentially easier in handling during processing. In addition to the above, the use of peroxides does influence the material properties not only in the sense of the desired effect, but also leading to side reactions of the involved radicals (degradation vs. cross-linking, disproportionation, combination reactions), especially under higher local concentrations of peroxide due to inhomogeneous mixing (Pfaendner, 2003).

Given the nitroxide-mediated CRPP preliminary experimental results from Pfaendner and the above-mentioned drawbacks of the peroxide-mediated CRPP, it can be said that Pfaendner's results offer the potential for innovative technological changes. If that potential comes to fruition, NORs like Irgatec CR76 could be used as replacements of peroxides as free radical initiators in polymer industry.

The purpose of this thesis is to investigate this option by studying the same nitroxide additive used by Pfaendner over a wide range of experimental conditions; and to investigate if this NOR is actually more efficient and effective than other commonly used peroxides. The experiments were carried out in a Haake mixer and not in a twin screw extruder, with a different type of peroxide initiator, at almost the same concentrations of initiator, for a range of temperatures of 230 to $290{ }^{\circ} \mathrm{C}$. Finally, the rheological properties and the MWD of the produced CPRR resins were studied. 


\section{Experimental}

In this chapter a brief but comprehensive description of the experimental procedures is given. The experimental procedures include materials, instruments, the main apparatus and any other equipment used for the experimental production and study of the CRPP. In that order, the sections that follow are divided between CRPP production and CRPP characterization. CRPP production focuses on the experimental procedure for the Haake mixer, where the production of the CRPP takes place. CRPP characterization focuses on the comprehensive description of the instruments and methods that were used for the characterization of that CRPP samples. These instruments include: MFR apparatus, Parallel Plate Rheometer, Fourier Transform Infrared Spectroscopy (FT-IR) and Gel Permeation Chromatography (GPC). In addition, ancillary devices that were used for the modification of the shape of the sample like a grinder and hot press are added to the CRPP characterization section, followed by the description of the capillary rheometer. This device was not used for experimental analysis of the produced CRPP, but for modeling the polymer melt inside the Haake mixer as a power law fluid. 


\subsection{CRPP Production}

The CRPP sample production was done in the Haake mixer. Its general description, specifications and the experimental procedure for that production with the necessary conditions, are discussed in what follows.

\subsubsection{Haake mixer}

\subsubsection{General description}

The Haake mixer is a well-known type of batch mixer widely used in most laboratories working on polymer processing. It requires only a relatively small amount of material and is usually used as a preliminary testing step before the actual processing for verifying, for instance, the quantity of mixing, the feasibility of polymer-polymer interreaction, polymer crosslinking and degradation, etc.

A typical Haake mixer is illustrated in Figure 3.1. It consists of two rotors (blades) of spiral cross section, and a heated chamber of bi-circular cross section. Each rotor applies to the center of the correspondent circular cross section. During the mixing process, many parameters can be controlled. Usually the most important of them are the temperature of the mixing area and the rotation speed of the blades; the latter is commonly referred to as rpm (rotation per minute). Other important parameters are the torque of the rotors, the total torque of the rotors, the mixing time, etc.

As mentioned above, it is a batch mixer. That means the importation of the mixing materials happens in the form of discrete loads (batches) and not continuously. The load takes place in the beginning of the process so, after some time, the mixing from transient state reaches a steady state. This can be seen on the main data readout for the Haake mixer, which is a graph of torque vs. time where the torque of the blades approaches a specific steady state value. 
A typical graph of torque $(\Gamma)$ vs. time $(\mathrm{t})$, for transient state conditions in the Haake mixer, is illustrated in Figure 3.2. The polymer in form of granules/pellets or powder is fed in the heated mixing chamber, fused and milled by one or two rotating blades at a fixed rpm speed, while the torque is recorded as a function of time. The curve illustrates the thermomechanical history experienced by the polymer under mixing.
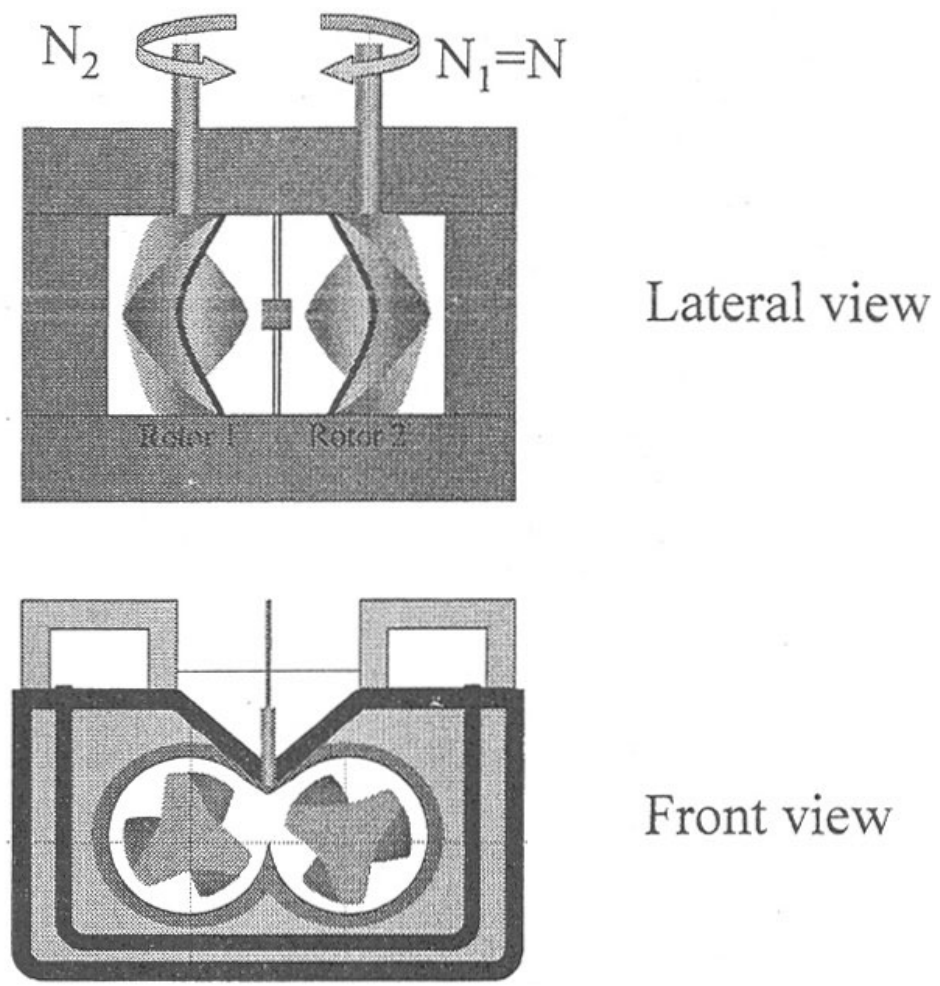

\section{Front view}

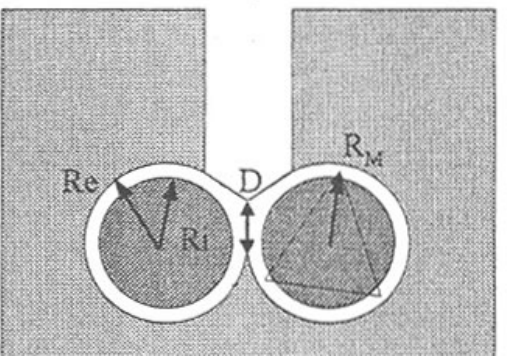

Figure 3.1: Haake mixer: lateral and front view (Bousmina et al., 1999) 


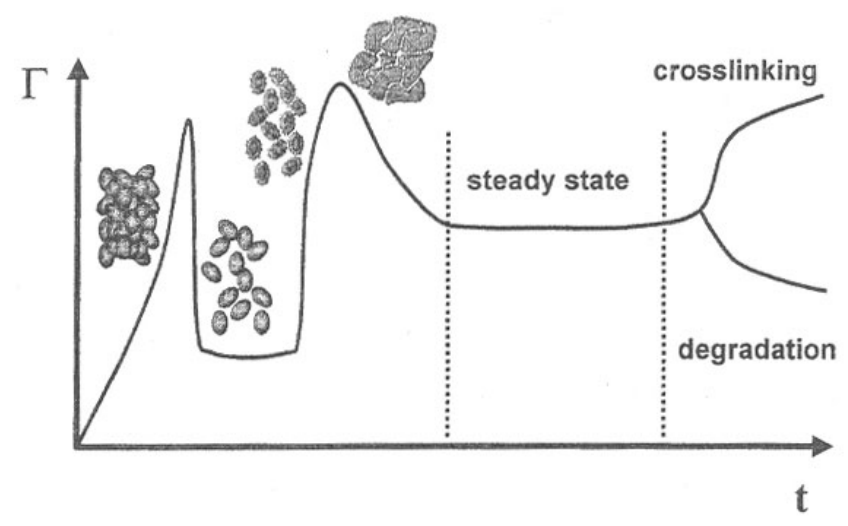

Figure 3.2: Haake mixer: typical variation of the measured torque as a function of time

(Bousmina et al., 1999)

When the polymer is introduced in the mixing chamber, the solid granules (or powder) offer a certain resistance to the free rotation of the blades and therefore the torque increases. When the resistance is overcome, the torque required to rotate the blades at the fixed speed decreases and reaches after more or less a short time a steady state. The torque increases again due to the melting of the surface of the granules that coalesce giving specks of particles. When the heat transfer is sufficient to completely melt the core of the particles, one obtains a macroscopic continuum easier to mix. Consequently, the torque decreases and reaches again a steady state regime and then increases or decreases later depending whether crosslinking or degradation phenomena take place. In practice, the time corresponding to the first maximum is very short and is seldom observed. The time required to reach steady state depends on the material and the processing conditions (temperature and rpm).

Figure 3.2 is not what is necessarily seen in a torque vs. time chart of Haake mixer. Many times the first peak is predominant, while the second remains minor. Also the steady state duration may vary according to many phenomena and experimental parameters. The crosslinking or the degradation period may also start soon after the torque obtains minimal values. 


\subsubsection{Specifications}

The type of the Haake mixer that was used is a Rheocord 90, model Rheomix 3000. Its capacity in the mixing chamber is $625 \mathrm{~cm}^{3}$ (without rotors) and is able to provide: $300 \mathrm{Nm}$ maximum torque, $4.15 \mathrm{~kW}$ total heating capacity and $450{ }^{\circ} \mathrm{C}$ maximum temperature. It also has electrical temperature control with air cooling. It is equipped with 3 control thermocouples and one melt temperature thermocouple that detects the temperature inside the mixing chamber. The mixing chamber of bi-circular cross section has depth $8.3 \mathrm{~cm}$, and each of the circular cross sections has radius $3.4 \mathrm{~cm}$. The blades (rotors) rotate at a ratio of 3:2. That means the main blade (the one which is connected directly to the machine) has 1.5 times the angular velocity that the secondary blade (the one which is connected via gear with the main blade) has when they rotate together.

The blades are connected to a torquemeter, so the instant torque, provided by the Haake mixer in order to retain a constant rpm for the blades, is recorded during an experiment. The temperature, the torque and the rpm in the mixing chamber are instantly recorded. These three parameters had been selected for the experimental process to be recorded and plotted as functions of the mixing time. Rpm was kept constant at $100 \mathrm{~min}^{-1}$, while the two other parameters could change.

\subsubsection{Experimental procedure}

The experimental procedure described for the Haake mixer serves the purpose of producing CRPP without radical initiator, with Irgatec CR76 as nitroxide initiator, and with Luperox 101 as peroxide initiator. For this reason, the production of CRPP was carried out in the Haake mixer using the following mixtures:

A. pure PP (Pro-fax PDC 1280) produced as CRPP (no initiator)

B. NOR-mediated CRPP, produced by the mixing of PP (PDC 1280) with $0.75 \%$, $1.5 \%$ and $3 \%$ of Irgatec CR76

C. peroxide-mediated CRPP, produced by the mixing of PP (PDC 1280) with $250 \mathrm{ppm}$ of peroxide (Luperox 101) 
These three different CRPP (CRPP produced by virgin PP, NOR-mediated CRPP and peroxide-mediated CRPP) are used for a comparative study, in order to systematically evaluate the results of Pfaendner (see Figure 2.11).

It has to be highlighted that $0.75 \%$ of Irgatec CR76 contains $250 \mathrm{ppm}$ of NOR relative to PP. That means that the NOR-mediated CRPP, produced by the mixing of PP with $0.75 \%$ of Irgatec CR76, can be compared to the peroxide-mediated CRPP, produced by the mixing of PP with $250 \mathrm{ppm}$ of peroxide (Luperox 101), as both of them contain equal amounts of additive. In addition, all the other CRPP additive concentrations ( $0 \%$ additive initiator, $1.5 \%, 3 \%$ Irgatec CR76) contribute to a further study of NOR as radical initiator. The materials that were used for the production of CRPP and the mixtures used are shown at Tables 3.1 and 3.2, respectively.

Table 3.1: Materials used for production of CRPP in the Haake mixer

\begin{tabular}{|c|c|c|c|c|}
\hline $\begin{array}{c}\text { Commercial } \\
\text { name }\end{array}$ & $\begin{array}{c}\text { Physical } \\
\text { status }\end{array}$ & Chemical nature & $\begin{array}{c}\text { Synopsis of } \\
\text { material }\end{array}$ & Provider \\
\hline $\begin{array}{c}\text { Pro-fax } \\
\text { PDC 1280 }\end{array}$ & pellets & PP resin from industry (MFR =1.2) & PP resin & Basell \\
\hline Irgatec CR76 & pellets & $\begin{array}{c}\text { Sterically hindered hydroxylamine ester in } \\
\text { a polymer matrix, a PP-based NOR } \\
(\sim 3.34 \% \text { NOR) }\end{array}$ & $\begin{array}{c}\text { PP-based } \\
\text { nitroxide }\end{array}$ & $\begin{array}{c}\text { Ciba } \\
\text { Chemicals }\end{array}$ \\
\hline Luperox 101 & liquid & $\begin{array}{c}2,5 \text {-bis(tert-butylperoxy)-2,5- } \\
\text { dimethylhexane, } \\
\text { a peroxide initiator (90\% peroxide) }\end{array}$ & Peroxide & Aldrich \\
\hline
\end{tabular}

CRPP resin production, using the mixtures described above, was carried out at four different nominal temperatures: $230,250,270$ and $290{ }^{\circ} \mathrm{C}$. That meant 5 different concentrations $\times 4$ different temperatures $=20$ experiments in the Haake mixer. The term "nominal" refers to the existing temperature in the Haake mixer before the entrance of the reactants. Because of the reactants' introduction, the temperature inside the mixing chamber initially decreases. But after some time, the temperature approaches the initial 
temperature conditions set by the user. In our case, every experiment had a duration of 5 minutes (300 seconds). During this time, the temperature of the chamber had recovered and approached the set value early on.

Table 3.2: Parameters of experiments in the Haake mixer (CRPP manufacturing)

\begin{tabular}{|c|c|c|c|}
\hline $230{ }^{0} \mathrm{C}$ & $250{ }^{0} \mathrm{C}$ & $270^{0} \mathrm{C}$ & $290^{0} \mathrm{C}$ \\
\hline $\mathrm{PP}+3 \%$ Irgatec CR76 & $\mathrm{PP}+3 \%$ Irgatec CR76 & $\mathrm{PP}+3 \%$ Irgatec CR76 & $\mathrm{PP}+3 \%$ Irgatec CR76 \\
\hline $\mathrm{PP}+1.5 \%$ Irgatec & $\mathrm{PP}+1.5 \%$ Irgatec & $\mathrm{PP}+1.5 \%$ Irgatec & $\mathrm{PP}+1.5 \%$ Irgatec \\
\hline CR76 & CR76 & CR76 & CR76 \\
\hline $\mathrm{PP}+0.75 \%$ Irgatec & $\mathrm{PP}+0.75 \%$ Irgatec & $\mathrm{PP}+0.75 \%$ Irgatec & $\mathrm{PP}+0.75 \%$ Irgatec \\
\hline CR76 & CR76 & CR76 & CR76 \\
\hline $\begin{array}{c}\mathrm{PP}+250 \mathrm{ppm} \\
\text { peroxide }\end{array}$ & $\mathrm{PP}+250 \mathrm{ppm}$ peroxide & $\mathrm{PP}+250$ ppm peroxide & $\begin{array}{c}\mathrm{PP}+250 \mathrm{ppm} \\
\text { peroxide }\end{array}$ \\
\hline Pure PP & Pure PP & Pure PP & Pure PP \\
\hline
\end{tabular}

One other factor that had to be considered was the method of importation of materials into the mixing chamber. Virgin PP (PDC 1280) and Irgatec CR76 were in the form of pellets. All the experiments were planned considering that the chamber had a capacity of $200 \mathrm{~g}$. That means that every compound of reactants had to weigh $200 \mathrm{~g}$. For pure PP produced as CRPP and NOR-mediated CRPP this was easy. In the first case, 200 $\mathrm{g}$ of virgin PP were added to the chamber while in the second case $200 \mathrm{~g}$ of compound of virgin PP and Irgatec CR76 were added. For the latter, the needed concentrations were:

- For NOR-mediated CRPP produced by the mixing of PP with $0.75 \%$ of Irgatec CR76, $198.5 \mathrm{~g}$ of PP and $1.5 \mathrm{~g}$ of Irgatec CR76 were required.

- For NOR-mediated CRPP produced by the mixing of PP with 1.5\% of Irgatec CR76, $197 \mathrm{~g}$ of PP and $3 \mathrm{~g}$ of Irgatec CR76 were required.

- For NOR-mediated CRPP produced by the mixing of PP with 3\% of Irgatec CR76, 194 $\mathrm{g}$ of PP and $6 \mathrm{~g}$ of Irgatec CR76 were required. 
All the compounds (in pellet form) were mixed in room temperature before they entered the mixing chamber in the Haake mixer.

In the case of peroxide initiator, the calculations were a little more complex, as Luperox 101 is in liquid form and also not pure peroxide, but was in a percentage of $90 \%$ (Tables 2.2 and 3.1). The required $250 \mathrm{ppm}$ of peroxide is a very small amount and that made accurate weighing of that amount from Luperox 101 difficult. Apart from that, there was a high risk of unequal mixing of this small amount of liquid with the PP pellets. In order to solve these issues, it was necessary to prepare a masterbatch. Specifically, $4 \mathrm{~g}$ of Luperox 101 were dissolved in $6 \mathrm{~g}$ of ethanol (which means $40 \%$ concentration w/w). At room temperature, the density of Luperox 101 is $877 \mathrm{~g} / 1$, while the density of ethanol is $789 \mathrm{~g} / 1$.

This meant that the density of the masterbatch was:

$\rho=x_{1} \rho_{1}+x_{2} \rho_{2}=0.4 \cdot 877+0.6 \cdot 789=824.2 \mathrm{~g} / \mathrm{l}$

According to the above, the needed weight of the solution in order to have $250 \mathrm{ppm}$ of peroxide was:

$\frac{90 m l}{100 m l}\left(\frac{m}{200 g}\right) \frac{40 g}{100 g}=\frac{250 g}{10^{6} g} \Rightarrow m=0.1389 \mathrm{~g}$

And the volume of that:

$V=\frac{0.1389 g}{824.2 g / l} \Rightarrow V=1.68 \cdot 10^{-4} l=168 \mu l$

For every experiment for production of peroxide-mediated CRPP in the Haake mixer, this amount of the solution was injected by using a small-volume syringe. The injection took place quickly, just after the importation of the PP was finished.

It was important in every experiment for the importation (either virgin PP alone, or with Irgatec CR76 or Luperox 101) to finish in the first 90 seconds, so all the experiments could be regarded on the same basis. The breadth and the height of the first peak in the torque-time chart are functions of the way that the materials enter the mixing chamber. 


\subsection{CRPP Characterization}

CRPP characterization includes all instruments and methods that were used for the characterization of that CRPP sample. These instruments include: MFR apparatus, parallel plate rheometer, Fourier Transform Infrared Spectroscopy (FT-IR) and Gel Permeation Chromatography (GPC). In addition, auxiliary devices that were used for the modification of the shape of the sample and its preparation for the main instruments, like grinder and hot press, are added in the CRPP characterization section.

\subsubsection{Grinder}

The grinder is used for producing fine particles by size reduction to granular size through attrition and compressive forces. After mixing in the Haake mixer and upon cooling, the pieces of the CRPP produced appear in relatively large size lumps. In order to effectively reduce that size to a grain size level, each CRPP sample was introduced into the lab grinder. The lab grinder is a Wiley mill. This mill prepares materials for analysis with minimal moisture loss. Well-dried samples are preferred. In this grinding mill, the material is loaded (cut into crude pieces or lumps) into a hopper. From the hopper, the material drops by gravity into the path of a set of rotating hard steel blades (driven by an electric motor). The revolving knives work against stationary knives and the resulting powder is forced through a steel screen. The powdered material then drops into a waiting collection vessel underneath. The amount of open area in a mill screen determines the particle size and grinding efficiency. The screen must be designed to maintain its integrity and provide the greatest amount of open area. A typical Wiley mill is illustrated in Figure 3.3.

After each CRPP was milled in the grinder, it was collected in plastic zip bags and labelled. The thinner the particles collected from the grinder, the better the samples were for further testing. Especially for the preparation of disks in the hot press, particles of small grains were required in order to avoid entrapment of air bubbles. 
One other point that has to be highlighted is that the grinder process contributes to the randomization of the experimental procedure. This happens because the small grains that pass through the grinder screen become independent samples with the only common factor being the properties of the original CRPP they come from. That means that the measurements recorded after the grinder stage, used a mix of grains which came from different areas of the original CRPP sample and not from one part of that sample, something that could lead to a systematic error. The mixed grains of the original CRPP determine the final properties of the CRPP sample. It is obvious that the smaller the particles collected from the grinder, the higher is the degree of experimental randomization.
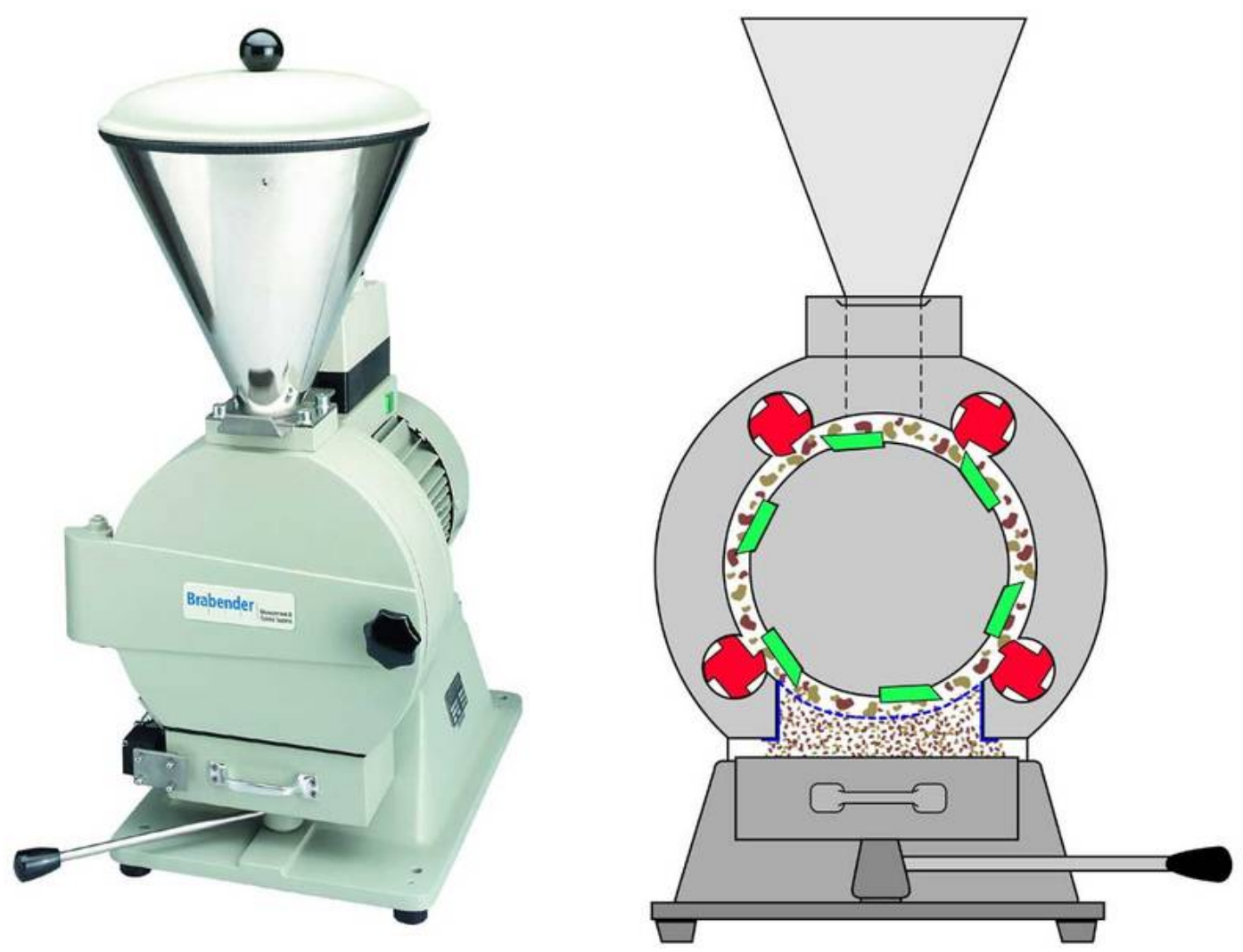

Figure 3.3: Wiley mill with six revolving and four stationary blades 


\subsubsection{Melt Flow Rate (MFR) Apparatus}

\subsubsection{General description - specifications}

Melt Flow Rate (MFR) apparatus is the device that is used for the determination of the MFR index. The whole device includes the MFR capillary surrounded by a heated barrel, a die in the exit of the capillary tube, and a piston with a weight attached to it, which presses on the inside melted test material in order to extrude it (Figure 3.4).

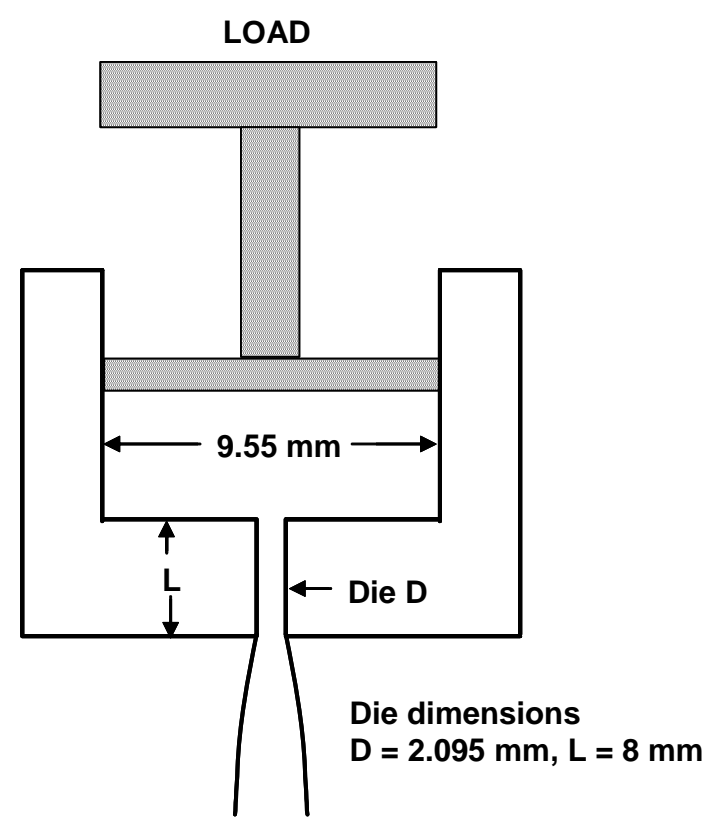

Figure 3.4: MFR apparatus

The whole device (and the capillary tube) is almost the same as that used for the determination of the viscosity with the method of the Capillary Rheometer. The main differences are: 
- In the pistons. Instead of the Capillary Rheometer piston the MFR piston is used. MFR piston's total weight is coordinated according to the MFR Protocol (ASTM, 2004). For PP the total weight has to be $2.16 \mathrm{~kg}$. In our case, the piston's net weight was $100 \mathrm{~g}$, which means the adjusted weight must be $2.06 \mathrm{~kg}$.

- The temperature of the heated barrel. That temperature according to the MFR Protocol (ASTM, 2004) has to remain constant at $230{ }^{\circ} \mathrm{C}$ (for PP).

- In the die. While the dies that are used in the Capillary Rheometer can vary, in the MFR measurements the die must always be the same with specific geometrical characteristics. According to the MFR Protocol (ASTM, 2004), the die shall have a smooth straight bore $2.0955 \pm 0.0051 \mathrm{~mm}$ in diameter and $8 \pm 0.025 \mathrm{~mm}$ in length.

All the other parts of the MFR capillary device are parts of the original Capillary Rheometer (Kayeness Inc. Galaxy V, model 8052). The Capillary Rheometer data was used later, for modeling the rheological properties of the sample inside the batch mixer, according to Bousmina et al. (1999).

\subsubsection{Experimental procedure}

Each CRPP sample, after being cut into small particles in the grinder, was tested. For each CRPP sample, 5 independent measurements of MFR were made. Considering the 20 different CRPP samples produced in different concentrations and/or temperatures in the Haake mixer, a total of 100 independent MFR experiments were carried out.

In every experiment, $7 \mathrm{~g}$ of sample was loaded inside the capillary. Because the temperature of the barrel was already $230{ }^{\circ} \mathrm{C}$ and possible degradation might occur if the sample remained too long inside the capillary, the sample had to remain an optimum time that will be enough for the material to obtain uniform temperature $\left(230{ }^{0} \mathrm{C}\right)$, but not so long that it would cause degradation. In that way, 5 minutes as residence time was chosen. The sample was loaded manually in the capillary, while a temporary piston was adjusted on the underside of the die, preventing the melted polymer from running out. When the entire sample was inside, the main piston of the $2.16 \mathrm{~kg}$ total weight was 
adjusted on the top of the capillary. After 5 minutes, the temporary piston was removed and the material was allowed to run out of the die.

The outflow of the polymer sample was timed with a chronometer. The MFR index represents the weight of the material in $g$ that runs out of the die in a period of 10 minutes. Therefore, if the outflow time $\left(t_{f}\right)$ of the polymer is not equal to 10 minutes (600 seconds), the MFR index can be found from the following equation: $\mathrm{MFR}=600 \frac{\mathrm{m}_{\mathrm{f}}}{\mathrm{t}_{\mathrm{f}}}$

where $\mathrm{m}_{\mathrm{f}}$ is the mass of the sample that runs out of the die during the period $t_{f}$ (in seconds).

For better results and minimum error, because in our case MFR is high and $t_{f}$ is small, $\mathrm{m}_{\mathrm{f}}$ and $\mathrm{t}_{\mathrm{f}}$ have to have the largest possible values, as very small $\mathrm{m}_{\mathrm{f}}$ and $\mathrm{t}_{\mathrm{f}}$ might lead to unreliable MFR results. It is important that the cut off point is the same as the point used to initiate the timing of the test.

The MFR of each sample was found as the average of the 5 independent measurements that were recorded for each one of these samples. In addition, these 5 independent experiments can provide useful statistical information for the MFR index of each CRPP sample. All these are presented and discussed in the next chapter.

\subsubsection{Hot Press}

The hot press was used for the preparation (by shape modification) of the samples for the parallel plate rheometer and the Fourier Transform Infrared Spectroscopy (FT-IR). Before the moulding in the hot press, each CRPP sample was mixed in a solution of antioxidant (Irganox 1010, Table 3.3) in acetone. The proportionality was 1 part of antioxidant with 99 parts of CRPP (w/w) in approximately $100 \mathrm{ml}$ of acetone. Then, after the acetone had evaporated, grains of dry sample were placed in the hot press. There, either they were moulded into a specific mold giving disks of $25 \mathrm{~mm}$ diameter and $1 \mathrm{~mm}$ 
width for the parallel plate rheometer, or were pressed into thin films which were used for FT-IR analysis.

Table 3.3: Antioxidant used for the preparation of the CRPP before the hot press

\begin{tabular}{|c|c|c|c|}
\hline $\begin{array}{c}\text { Commercial } \\
\text { name }\end{array}$ & $\begin{array}{c}\text { Physical } \\
\text { status }\end{array}$ & Chemical Type & Provider \\
\hline Irganox 1010 & powder & $\begin{array}{c}\text { Benzenepropanoic acid } \\
\text { (tetrakis-(methylene-(3,5-di-terbutyl-4-hydrocinnamate)methane) }\end{array}$ & Ciba \\
\hline
\end{tabular}

The hot press is a simple device of two heated parallel plates; the upper remains constant while the lower can be adjusted vertically and squeeze at high pressures the material that has been trapped between them. The motion of the lower plate is based on a hydraulic system that is operated manually by the user. The hydraulic system multiplies the mechanical power, so little manual effort can cause pressure of thousands lbs between the plates.

The hot press can provide maximum pressure of 50,000 lbs and maximum temperature of $600{ }^{0} \mathrm{~F}$. It is also supplied with a fume hood, connected to the lab ventilation. For the experimental procedure two clean and smooth metallic plates can be used as intermediates between the sample and the main heated plates of the hot press. These temporary plates can be removed and cleaned, in addition to the main plates of the hot press whose role is to provide heat and pressure. Hot press is also supported with moulds of different shape and geometry.

For every experiment, the pressure employed was 20,000 lbs and the temperature was in the order of $350{ }^{0} \mathrm{~F}\left(\sim 175{ }^{\circ} \mathrm{C}\right)$. Typical overhead vinyl transparencies were also located between the pressed material and the temporary plates in order to keep the melt resin clean and to make easier the detachment of the configured CRPP disk or film from the plates after the experiment. The duration of the residence of the sample in the hot press was approximately 5 minutes. This time was enough for the material to melt and take the needed shape. 
If the samples are prepared in the hot press for experiments in the parallel plate rheometer, then each sample must have the shape of a disk of $25 \mathrm{~mm}$ diameter and $1 \mathrm{~mm}$ width. This is achieved via a metallic mould with 4 circular gaps that can provide 4 disks of those dimensions. If the samples are prepared in the hot press for experiments in the FT-IR device, then no mould is needed. A couple of CRPP sample grains are placed between two transparencies. The latter are placed between two temporary plates, which are subsequently placed between the hot press plates. The final product was a CRPP thin film. The thinner that film, the better for obtaining reliable FT-IR results.

In both cases, the temporary plates with the transparencies and the products inside are frozen immediately in a tube of cold water. After freezing, the product was collected, the transparencies were disposed off, and the temporary plates were placed in a hot oven for further cleaning.

\subsubsection{Parallel Plate Rheometer (PPR)}

One of the most important issues in rheology, is the measurement of the shear viscosity of a polymer melt. For that measurement, researchers concluded that the cone and plate viscometer (or Weissenberg rheogoniometer) can be used for small shear rates while the capillary rheometer can be used for higher shear rates (Figure 3.5). One special form of cone and plate viscometer (Figure 3.6) is the parallel plate rheometer (or diskplate rheometer), as illustrated in Figure 3.7. It is almost the same apparatus, with the main difference that the cone is replaced by a flat disk. The parallel plate rheometer is frequently used for polymer melts, blends and composites.

Some of the advantages of the parallel plate rheometer, that make it so popular for shear viscosity measurements in small shear rates, are:

- It is very easy to clean

- It is easy to set a gap for the distance between the two plates

- The gap is variable

- High shear rates $\left(\geq 10 \mathrm{~s}^{-1}\right)$ can be achieved 


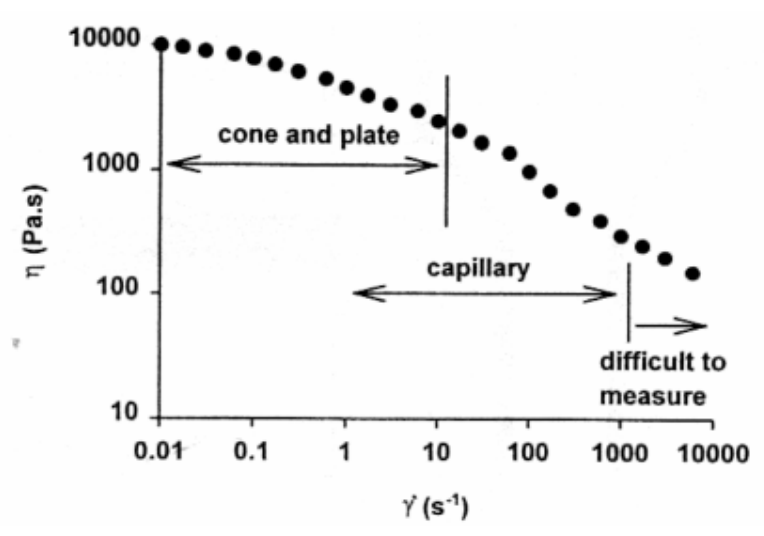

Figure 3.5: Typical flow chart of a material and application areas of rheometers

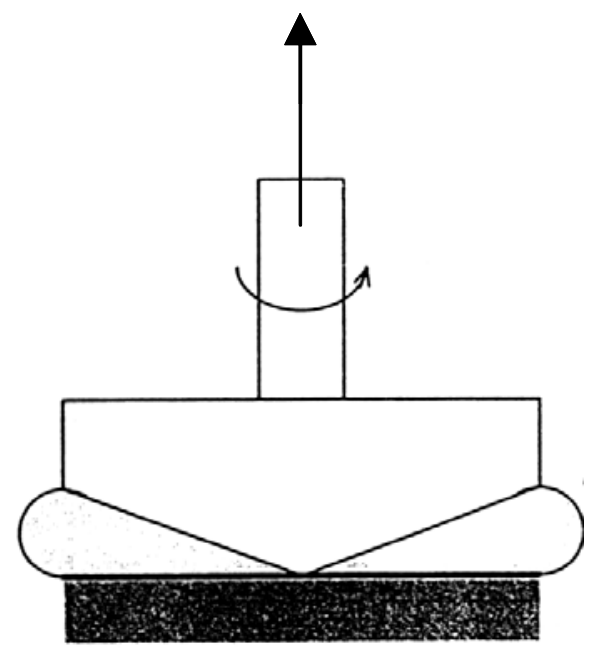

Figure 3.6: Cone and Plate Viscometer (or Weissenberg rheogoniometer)

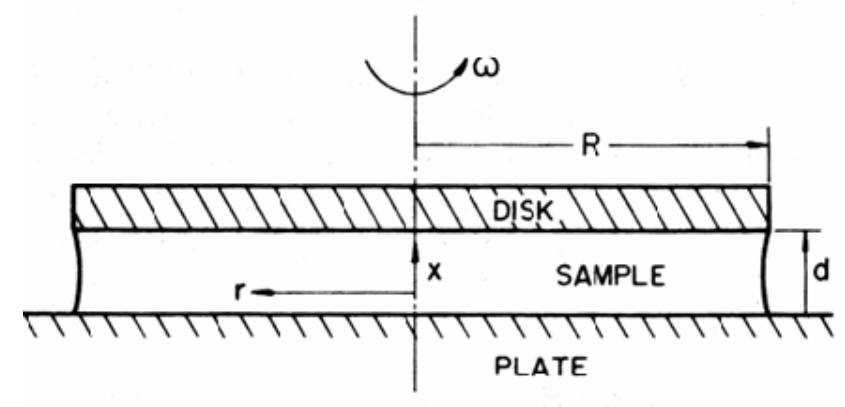

Figure 3.7: Parallel plate rheometer (or disk-plate rheometer) 


\subsubsection{General description}

A PPR was used for the measurement of the rheological characteristics of the CRPP resins which were produced in the Haake mixer. PPR mainly consists of the following parts:

- Two flat circular plates, of $25 \mathrm{~mm}$ diameter, placed parallel to each other. The lower one remains fixed while the upper is able to rotate.

- A heated chamber, where the two parallel plates are placed.

- An electromechanical rotor that applies vertically on the top of that chamber and rotates the upper plate with the help of pressed air.

- Thermocouples and detectors that instantly and accurately detect the temperature of the chamber, the gap and the normal force between the two plates, the displacement, the stress and the strain of the sample, the imposed frequency, etc.

In addition to the above, a PPR has to be accompanied with the following:

- Constant air flow (this can be a pump of pressed air).

- Software, in order to transfer the measurements in an online connected pc.

Beyond the necessary equipment, it might be provided:

- Secondary gas flow, i.e., nitrogen which can prevent oxidization in the heated chamber.

- Cleaning tools.

The use of PPR is based on the theory of viscoelasticity. The purpose of the PPR is to examine the viscoelastic and rheological properties of the sample by imposing a controlled sinusoidal dynamic oscillation (Figure 3.8).

The measured variables in the PPR's dynamic measurements are:

- The stress. Represents torsional force per area.

- The strain. Represents deformation of material.

- The phase angle. Represents lag between applied stress and the resultant strain.

- The frequency. Represents time period of the oscillation.

From these variables, a variety of viscoelastic properties can be calculated, as follows (Aklonis et al. (1972), Ferry (1980)): 
- Storage (Elastic) Modulus (G'), which can be derived as:

$\mathrm{G}^{\prime}=\frac{\text { stress }}{\text { strain }} \cdot \cos ($ phase angle $)$

- Loss (Viscous) Modulus (G"), which can be derived as:

$\mathrm{G}^{\prime \prime}=\frac{\text { stress }}{\text { strain }} \cdot \sin ($ phase angle $)$

- Complex Modulus $\left(\mathrm{G}^{*}\right)$, which can be derived as:

$\mathrm{G}^{*}=\frac{\text { stress }}{\text { strain }}$

- Complex Viscosity $\left(\eta^{*}\right)$, which can be derived as:

$$
\eta^{*}=\frac{\mathrm{G}^{*}}{\text { frequency }}
$$

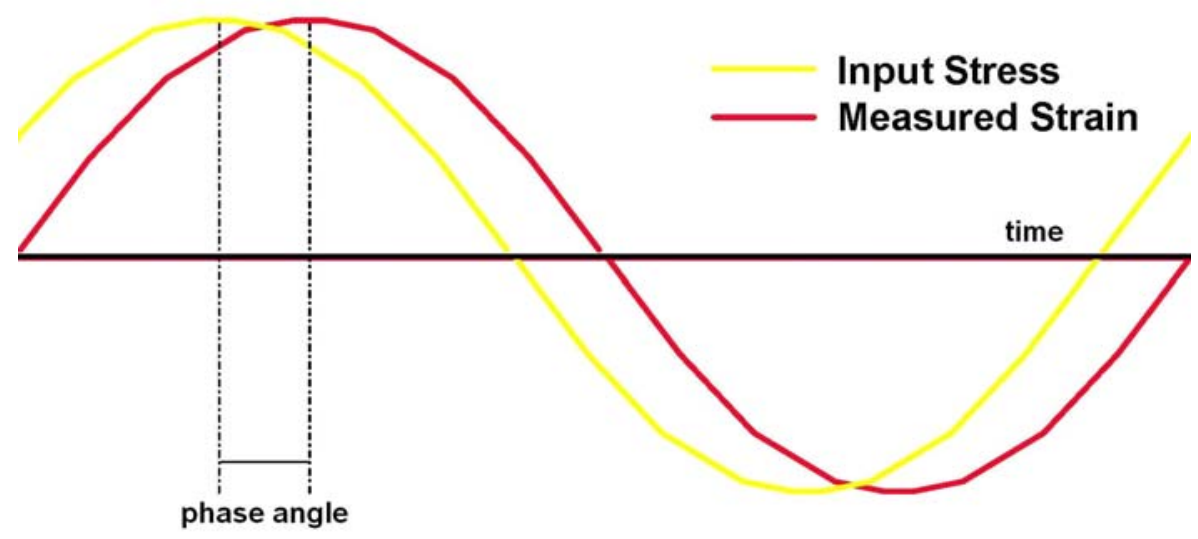

Figure 3.8: Dynamic measurements on the parallel plate rheometer

In mathematical terms, the above can be expressed as:

Measured dynamic strain:

$\gamma(\mathrm{t})=\gamma_{0} \sin (\omega \mathrm{t})$

Input dynamic stress: 
$\sigma(\mathrm{t})=\sigma_{0} \sin (\omega \mathrm{t}+\delta)$

where $\gamma_{0}$ is the strain amplitude, $\sigma_{0}$ is the stress amplitude, $\omega$ is the frequency, and $\delta$ is the phase angle (or phase shift or loss angle).

The tangent of the phase angle is given as:

$\tan \delta=\frac{\mathrm{G}^{\prime \prime}}{\mathrm{G}^{\prime}}$

The dynamic shear stress can be represented by the equation:

$\sigma(t)=\gamma_{0}\left[G^{\prime}(\omega) \sin (\omega t)+G^{\prime \prime}(\omega) \cos (\omega t)\right]$

and the magnitude of complex viscosity as:

$\left|\eta^{*}\right|=\left[\left(\eta^{\prime}\right)^{2}+\left(\eta^{\prime \prime}\right)^{2}\right]^{1 / 2}=\left[\left(\frac{G^{\prime \prime}}{\omega}\right)^{2}+\left(\frac{G^{\prime}}{\omega}\right)^{2}\right]^{1 / 2}$

For completely elastic material $G^{\prime \prime}=0$, while for completely viscous material $\mathrm{G}^{\prime}=0$.

The imposed frequency covers a relatively wide spectrum of frequencies, starting low (usually $0.01 \mathrm{~Hz})$ and ending in high values $(\sim 100 \mathrm{~Hz})$. The instant values of $\mathrm{G}^{\prime}, \mathrm{G}$, $\mathrm{G}^{*}$ and $\eta^{*}$ are recorded as functions of the imposed frequency, and can be plotted as dependent variables of it. This procedure is usually described as frequency sweep.

Usually before the frequency sweep, the strain sweep takes place (Figure 3.9). The term "strain sweep" describes the sweep that takes place by keeping the imposed frequency constant and changing the strain (or the stress) on the sample. The importance of the strain sweep is that it provides information about the Linear Viscoelastic Region (LVR) of the material. If the material does not exhibit LVR, the frequency sweep will fail as the material will not give a linear response to the imposed frequency.

The main advantages of the presence of linear viscoelasticity during the strain sweep are:

- It measures inherent structure.

- It indicates sample stability.

- It finds a suitable strain/stress for other experiments.

After a suitable strain/stress value is found via the strain sweep, the frequency sweep takes place as described before. Usually $\mathrm{G}^{\prime}, \mathrm{G}^{\prime \prime}$, and $\delta$ are plotted versus the 
imposed frequency (Figure 3.10). Frequency sweep can be performed in various temperatures giving very useful results.

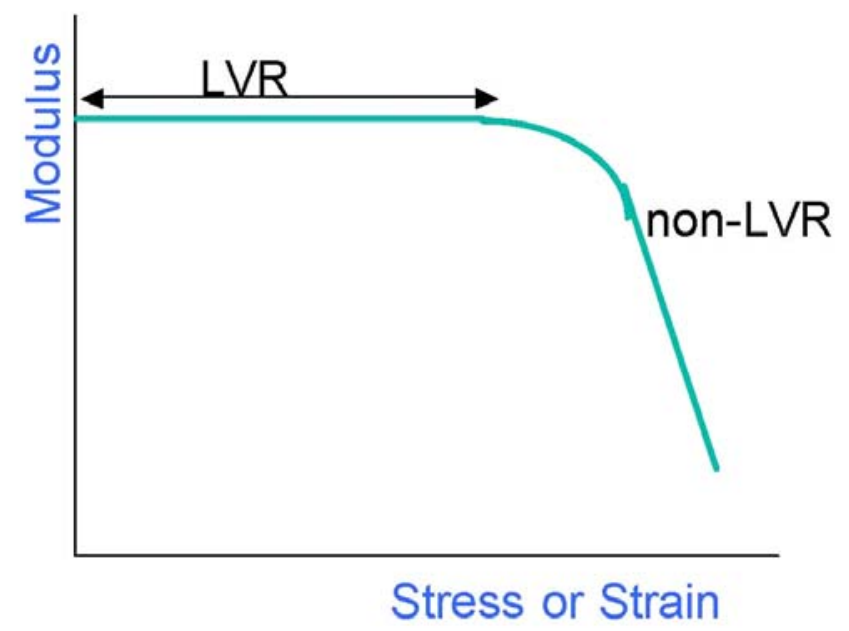

Figure 3.9: Typical strain sweep with the Linear Viscoelastic Region of the material

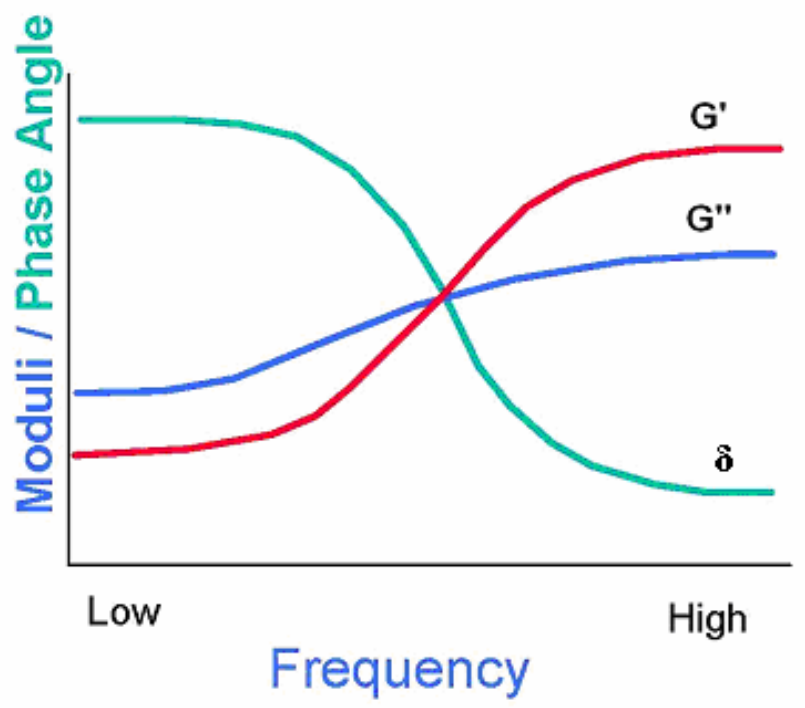

Figure 3.10: Typical frequency sweep of the material 
Temperature is another important variable aside from frequency that affects rheological properties. It has been found that frequency and temperature are related in an inversely proportional way. Past studies have found that the rheological data collected at several temperatures can be brought together to form a single "master" curve. This relationship is known as Time - Temperature Superimposition (TTS). From a practical viewpoint, this allows the construction of curves over a wider range of frequencies than is realistically possible when data are collected for a fixed temperature. By raising the temperature, information about the lower frequency regions can be gained without performing extremely long experiments.

In TTS, different modulus plots received in different temperatures and plotted in a logarithmic chart versus the imposed frequency, can be superimposed between them by using a factor $\mathrm{a}_{\mathrm{T}}$. That factor represents the horizontal shift of each modulus curve. Before the shift, one modulus curve has to be appointed as reference curve. It is obvious that the $\mathrm{a}_{\mathrm{T}}$ factor for the reference curve is zero.

The frequency sweep provides a lot of information. Some points that have to be highlighted are the following:

- The frequency that corresponds to Loss Modulus equal to Storage Modulus $\left(G^{\prime}=G^{\prime \prime}\right)$ is called critical frequency or crossover and is of major importance.

- The complex shear viscosity $\left(\eta^{*}\right)$ can be correlated with the steady shear viscosity ( $\eta$ ) via the Cox-Merz Rule. This is an empirical relationship, and while it can be very useful, it must be applied with caution. The Cox-Merz rule states that $\eta^{*}(\omega)$ is virtually identical to $\eta(\dot{\gamma})$, with the frequency $\omega$ corresponding to shear rate $\dot{\gamma}$ (Cox et al., 1958). The rule applies for unfilled, structurally simple (linear) polymers.

- The zero shear viscosity and the dynamic measurements can be correlated by the following equation (Ferry (1980), Berger and Meissner (1992)): $\eta_{0}=\lim _{\omega \rightarrow 0}\left(\frac{\mathrm{G}^{\prime \prime}}{\omega}\right)$ 


\subsubsection{Main specifications}

The laboratory parallel plate rheometer is a TA Instruments AR 2000 model. It can provide torque from 0.1 to $200 \mu \mathrm{Nm}$, frequency from 0.12 to $100 \mu \mathrm{Hz}$ and angular velocity from 8 to $300 \mathrm{rad} / \mathrm{s}$ under controlled stress, and from 2 to $300 \mathrm{rad} / \mathrm{s}$ under controlled strain. It can also detect normal force from 1 to 5,000 $\mathrm{g}$ and minimum strain of $6 \cdot 10^{-5}$. It has the ability to use liquid nitrogen for low temperatures and for fast cooling. It has many other secondary specifications that are not in the scope of this thesis. More information can be found from the manuals of the apparatus. The Rheometer AR 2000 and its main head (the part that rotates the upper plate) are illustrated in Figures 3.11 and 3.12 .
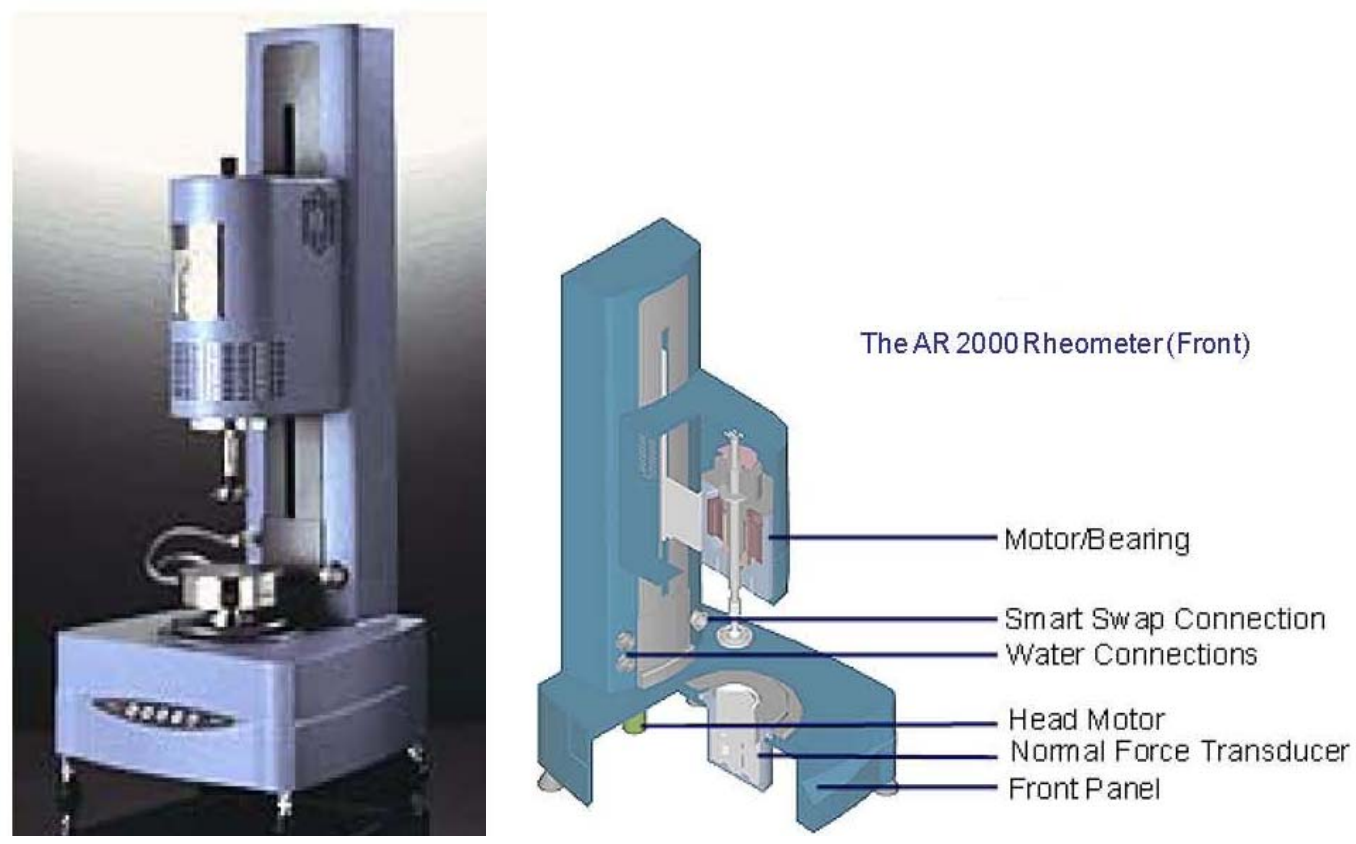

Figure 3.11: Rheometer AR 2000 


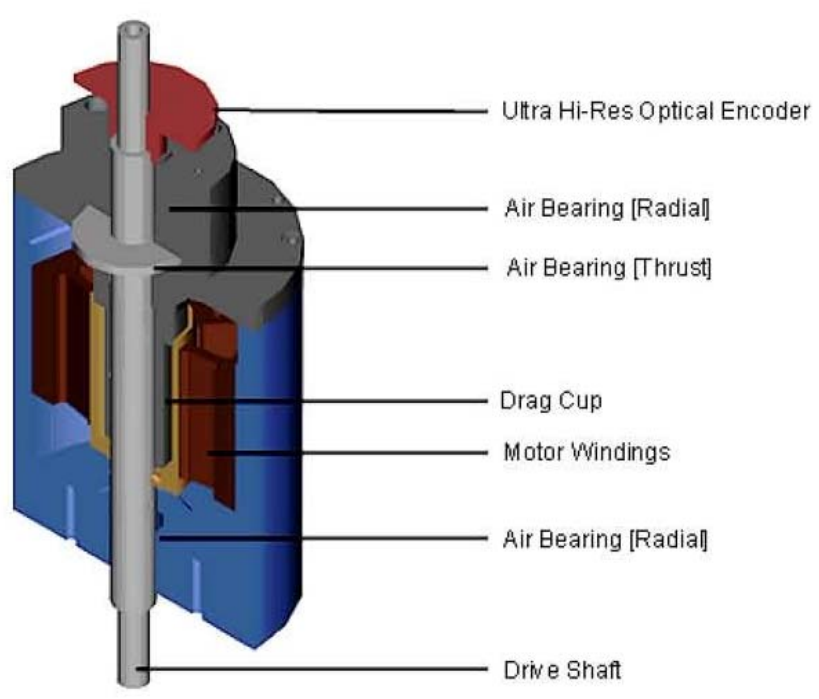

Figure 3.12: Head of Rheometer AR 2000

\subsubsection{Experimental procedure}

The experimental procedure included two levels. First, the strain sweep was recorded, which verified the linear viscoelastic region of the sample. Second, the frequency sweep followed, which determined the viscoelastic properties.

Before everything, the Rheometer was calibrated for the inertia and gap between the parallel plates. The inertia must approach the smallest possible value while the gap must be zeroed. Before the gap was zeroed and the plates touched each other, the normal force could be calibrated to small values, something that allowed afterwards safe experiments as when the gap was fixed in a value for the sample, high values of normal force for that gap will indicate sample stability between the plates.

The samples were disks prepared in the hot press as described previously, with dimensions $25 \mathrm{~mm}$ diameter and $1 \mathrm{~mm}$ width. These disks were placed between the two parallel plates. Both of them are circular of $25 \mathrm{~mm}$ diameter each. As soon as the sample was inside the plates, the gap was fixed at exactly $1 \mathrm{~mm}(1000 \mu \mathrm{m})$. If the upper plate was lowered and touched the sample, the values of the normal force were increased 
dramatically. This meant that the sample was secured into that gap. After a while, when the temperature approached the melting point of the sample, the values of the normal force started decreasing. This was an indication that the sample changed from the solid to the melt phase. The temperatures used were $170{ }^{\circ} \mathrm{C}$ for the strain sweep and 170, 190 and $210{ }^{\circ} \mathrm{C}$ for the subsequent frequency sweep. Each experiment for each sample took place in one temperature. Finally, the viscoelastic sweeps in these three temperatures were superimposed using the $190{ }^{\circ} \mathrm{C}$ as the reference curve.

The strain sweep experiments took place at $170{ }^{\circ} \mathrm{C}$, and exhibited a linear viscoelastic region for all cases. The dynamic storage shear modulus $\mathrm{G}^{\prime}$ and dynamic loss shear modulus $\mathrm{G}^{\prime \prime}$ remained constant when the percentage of the strain changed up to a limit of $\sim 20 \%$, while the strain frequency was set by the user at $10 \mathrm{~Hz}$. Because of that value of strain, it was concluded that a $10 \%$ of strain could be safely used for the frequency sweep experiments.

The frequency sweep experiments took place using that percentage of strain. G', $\mathrm{G}^{\prime \prime}$ and $\delta$ were presented as functions of the imposed frequency (dynamic measurements). That imposed frequency covered a spectrum from 0.01 to $100 \mathrm{~Hz}$. That was regarding all three different temperatures: 170,190 and $210{ }^{\circ} \mathrm{C}$. Afterwards, the results of each sample in these three different temperatures were superimposed, as a result of the viscoelastic theory. In addition to the above, constant nitrogen flow of $3.51 /$ min was provided inside the apparatus during the whole experimental procedure, necessary for the prevention of any possible oxidization of the sample. The nitrogen was supplied in industrial cylinders provided by Praxair, and was of purification grade 4.8 .

\subsubsection{Fourier Transform Infrared (FT-IR) Spectroscopy}

Generally, Fourier transform spectroscopy is a measurement technique whereby spectra are collected based on measurements of the temporal coherence of a radiative source, using time-domain measurements of the electromagnetic radiation or other type of radiation. It can be applied to a variety of types of spectroscopy including optical 
spectroscopy, infrared spectroscopy (FT-IR), nuclear magnetic resonance, and electron spin resonance spectroscopy.

Fourier Transform Infrared Spectroscopy (FT-IR) is a powerful tool for identifying types of chemical bonds in a molecule by producing an infrared absorption spectrum which is like a molecular "fingerprint". FTIR spectrum provides qualitative information about the molecular structure, and represents one of the most common techniques of chemical analysis because of its simplicity and speed. In addition to FT-IR, many other techniques can be used to obtain quantitative information, like Proton Nuclear Magnetic Resonance spectroscopy ( $\left.{ }^{1} \mathrm{H}-\mathrm{NMR}\right)$.

FT-IR's applications include drug analysis, fiber analysis, ink analysis, paper analysis, biological analysis, etc. (Catterton, 2004). More anallytically, FT-IR spectroscopy can be used for the following benefits:

- It is non-destructive for thermally stable components and materials

- Provides precise measurement with no external calibration

- Fast analysis of the sample

- It can analyze solids, liquids, and gases

- It can analyze organic and inorganic molecules and materials

- It is a confirmatory technique for other instrumental results

Typically when a molecule is exposed to infrared (IR) radiation, it absorbs specific frequencies of radiation. The frequencies which are absorbed are dependent upon the functional groups within the molecule and the symmetry of the molecule. IR radiation can only be absorbed by bonds within a molecule, if the radiation has exactly the right energy to induce a vibration of the bond. This is the reason only specific frequencies are absorbed.

Infrared spectroscopy focuses on electromagnetic radiation in the frequency range $400-4000 \mathrm{~cm}^{-1}$, where $\mathrm{cm}^{-1}$ is known as wavenumber (1/wavelength). To generate the infrared spectrum, radiation containing all frequencies in the IR region is passed through the sample. The absorbed frequencies appear as a decrease in the detected signal. This information is displayed as a spectrum of \% transmitted radiation plotted against wavenumber. 
In Organic Chemistry, infrared spectroscopy is very useful for qualitative analysis (identification) of organic compounds because a unique spectrum is produced by every organic substance with peaks corresponding to distinct structural features. Also, each functional group absorbs infrared light at a unique frequency. For example, a carbonyl group, $\mathrm{C}=\mathrm{O}$, always absorbs infrared light at $1670-1780 \mathrm{~cm}^{-1}$, which causes the carbonyl bond to stretch.

A carbonyl group always absorbs infrared radiation in this frequency range because the bond between the carbon atoms is constantly stretching and contracting within a range of bond lengths. This "vibration" occurs as if the bond was a spring connecting the two atoms and it always occurs within a certain frequency range, 1670$1780 \mathrm{~cm}^{-1}$. When a molecule is irradiated with infrared radiation, a vibrating bond will absorb energy of the same frequency as its vibration, increasing the amplitude of the oscillation.

Table 3.4 presents some typical functional group and the respective absorption band position.

Table 3.4: IR Absorption table (http://scienceofspectroscopy.info) Functional group and respective absorption band position $\left(\mathrm{cm}^{-1}\right)$

\begin{tabular}{|c|c|c|c|c|c|}
\hline $\mathrm{C}-\mathrm{H}$ & $=\mathrm{C}-\mathrm{H}$ & $\mathrm{C}=\mathrm{C}$ & $\equiv \mathrm{C}-\mathrm{H}$ & $\mathrm{C} \equiv \mathrm{C}$ & $\mathrm{C}-\mathrm{Cl}$ \\
\hline $2850-2960$ & $3020-3100$ & $1650-1670$ & 3300 & $2100-2260$ & $600-800$ \\
\hline $\mathrm{C}-\mathrm{Br}$ & $\mathrm{C}-\mathrm{I}$ & $\mathrm{C}-\mathrm{OH}$ & $-\mathrm{C}-\mathrm{H}$ & & $\mathrm{N}-\mathrm{H}$ \\
\hline $500-600$ & 500 & $1050-1150$ & 3030 & 1600,1500 & $3310-3500$ \\
\hline $\mathrm{C}-\mathrm{N}$ & $\mathrm{C}=\mathrm{O}$ & $\mathrm{COOH}$ & $\mathrm{C} \equiv \mathrm{N}$ & $\mathrm{NO}_{2}$ & $\mathrm{O}-\mathrm{H}$ \\
\hline 1030,1230 & $1670-1780$ & $2500-3100$ & $2210-2260$ & 1540 & $3400-3640$ \\
\hline
\end{tabular}

One of the main advantages of FT-IR is that it doesn't demand external calibration. This major advantage of FT-IR is known as "Connes Advantage", the utilization of a laser to calibrate IR wavelengths. Particularly, the FT-IR utilizes a laser- 
controlled interferometer or the Michelson interferometer. A Helium/Neon $(\mathrm{He} / \mathrm{Ne})$ laser is utilized because the wavenumber of the laser is always constant and its accuracy can be read by the instrument to $0.01 \mathrm{~cm}^{-1}$. This is much more accurate than is needed for identification. The distance of the laser to the interferometer is fixed, so with the known wavelength and the known distance, the instrument is able to calibrate itself with every scan.

IR spectra were obtained using a FTS 3000MX by Excalibur Bio Rad. The infrared spectrum was used for comparison between the nitroxide-mediated and the peroxide-mediated CRPP and detection of the molecular structure of each CRPP product. Each sample was introduced into the FT-IR cell as a thin film (produced in the hot press). Experience showed that with a thinner film better results were obtained. The absorption spectrum was set at 32-bit. Generally, the IR spectrum appears at the range of 400 to $4000 \mathrm{~cm}^{-1}$ of wavenumber. From that spectrum, only some particular areas were useful for this research's scope.

\subsubsection{Gel Permeation Chromatography (GPC)}

\subsubsection{General}

Gel Permeation Chromatography (GPC) represents one of the most important techniques in polymer characterization, and is the predominant technique in the science of macromolecules for the determination of their molecular weight characteristics. It belongs to the family of Size Exclusion Chromatography (SEC), in which particles are separated based on their size, or in more technical terms, their hydrodynamic volume. It is usually applied to large molecules (i.e. polymers) or macromolecular complexes such as proteins. It dominates the SEC family to such a degree, that many times GPC is refered to as SEC. GPC can also be found as Gel Filtration Chromatography (GFC).

In polymer science and engineering, GPC is the most popular and convenient method for determining the average molecular weight and the molecular weight 
distribution of a polymer. This technique has gained wide acceptance among the plastics material manufacturers and the processors because of the low cost, simplicity, and its ability to provide accurate, reliable information in a very short time. MWD is such an important characteristic for the polymer material, because not only provides basic information regarding the processability of the polymer, but also gives valuable information for predicting its mechanical properties.
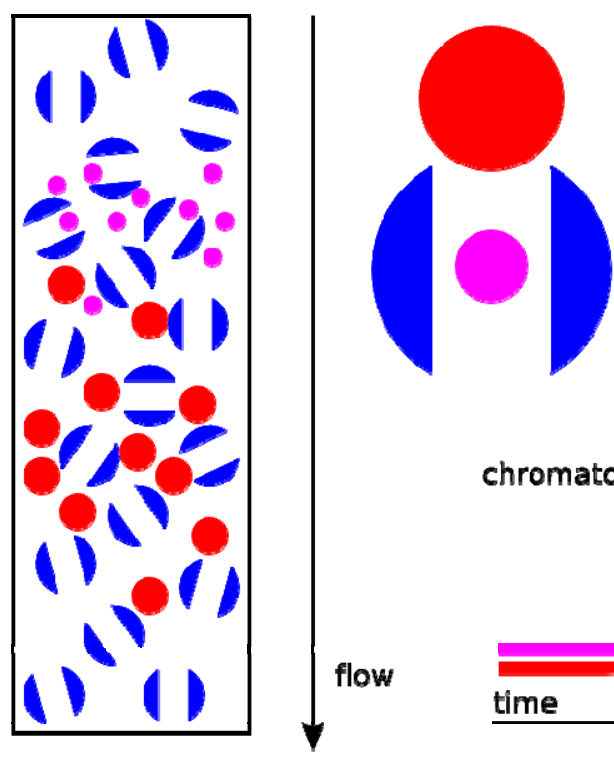

Large particles cannot enter gel and are excluded. They have less volume to traverse and elute sooner. traverse. They elute later.

Figure 3.13: Principles of GPC

As the name implies, all the SEC techniques are based on the principle of size exclusion. The fundamental idea is presented in Figure 3.13. A very low concentration polymer solution is passed through a column of porous particles. The molecules that are too large cannot enter the pores of the gel material and as such, they elute first. Smaller molecules that can penetrate or diffuse into the pores are detained in the column and elute 
at a later time. Thus a sample is fractioned based on molecular hydrodynamic volume and the resulting profile corresponds to the MWD. A concentration detector (e.g. differential refractometer (RI) or UV detector) is placed downstream of the columns to measure the concentration of each fraction as a function of time. The actual method for determining the MW averages and the MWD depends upon the presence of any accompanying detectors.

\subsubsection{Specifications and experimental procedure}

Polyolefins demand high temperature environment to be dissolved in a solvent. For this reason, the GPC used for them is called high temperature GPC. The lab GPC instrument that was used for the MWD analysis was a GPC 2000CV by Waters Alliance, equipped with a mixed bed GPC column (Polymer Labs mixed B-LS) and 1, 2, 4trichlorobenzene (TCB) as the mobile phase. The mobile phase was used at a nominal flow rate of $1.0 \mathrm{ml} / \mathrm{min}$ and a temperature of $145{ }^{\circ} \mathrm{C}$. No antioxidant was added to the mobile phase, but $800 \mathrm{ppm}$ of butylated hydroxytoluene (BHT) was added to the solvent used for sample dissolution. Polypropylene samples were heated at $175{ }^{0} \mathrm{C}$ for two hours with gentle agitation every 30 minutes and right before loading into the GPC carousel. Injection volume was $100 \mathrm{ml}$. Molecular weights were calculated using a narrow polystyrene calibration curve using appropriate Mark-Houwink constants and Waters Empower software. For polypropylene the Mark-Houwink constants, K and $\alpha$ (alpha), were 0.00041 and 0.657 respectively. 


\subsubsection{Capillary Rheometer}

\subsubsection{General}

A capillary rheometer is used for the rheological characterization and the flow chart of a material that is deformed in medium to high shear rates (Figure 3.5). As mentioned before, the capillary rheometer is used for the characterization of one CRPP polymer melt as power law fluid and the determination of the power law constants. This characterization allows the modeling of every CRPP in the Haake mixer according to existing models in bibliography (Bousmina et al., 1999).

The capillary rheometer (or viscometer) consists of the MFR apparatus described in section 3.2.2, but instead of a standard-weight piston, a piston of variable weight is used, and also instead of a standard die, different dies are applied. Indeed, the used piston is connected to a screw machine connected in its turn to a computer. The user has the ability to change the position - and as a result the weight (force) - of the piston in the sample through the screw machine. Pressure drop and flow rate through the tube are used to determine viscosity (Figure 3.14). This determination derives from the equations that follow.

The shear rate on the wall is given by the Rabinowitch equation:

$\dot{\gamma}_{\mathrm{W}}=\dot{\gamma}_{\text {app }}\left(\frac{3}{4}+\frac{1}{4} \frac{\mathrm{d} \ln \mathrm{Q}}{\mathrm{d} \ln \tau_{\mathrm{W}}}\right)$

where $\mathrm{Q}$ is the volumetric flow, $\tau_{\mathrm{w}}$ is the wall shear stress and $\dot{\gamma}_{\text {app }}$ is the apparent shear rate of a Non-Newtonian fluid which represents the true shear rate of a Newtonian fluid:

$\dot{\gamma}_{\text {app }}=\frac{4 \mathrm{Q}}{\pi \mathrm{R}^{3}}$

Then, the true viscosity of the material is given from:

$\eta=\frac{\tau_{\mathrm{w}}}{\dot{\gamma}_{\mathrm{w}}}$

For each position of the viscometer's piston, different $\tau_{\mathrm{w}}$ and $\dot{\gamma}_{\mathrm{w}}$ are received. These values of $\dot{\gamma}_{\mathrm{w}}$ and $\eta$ are plotted in a logarithmic scale (Figure 3.15). 
A power law fluid is described by the following equations:

$\tau=\mathrm{M} \dot{\gamma}^{\mathrm{n}}$ for the shear stress, and

$\eta=\mathrm{M} \dot{\gamma}^{\mathrm{n}-1}$ for the shear viscosity

with $\mathrm{M}$ (or $\mathrm{m}$ ) the consistency index and $\mathrm{n}$ the power-law index.

It is obvious that the logarithmic flow chart has to be a line with slope $n-1$ and intercept m. Figure 3.15 illustrates how some typical data approach that line.

One other thing that has to be clarified is the total pressure drop in the die. As can be seen from Figures 3.14 and 3.15, while the melted material is extruded from the die, three different pressure drops take place:

- The pressure drop in the reservoir, $\Delta \mathrm{P}_{\text {res }}$

- The pressure drop inside the capillary, $\Delta \mathrm{P}_{\text {cap }}$

- The pressure drop in the entrance of the capillary, $\Delta \mathrm{P}_{\mathrm{e}}$

The total pressure drop is the sum of the above three. The pressure drop in the reservoir can be considered negligible compared to the other two, as the reservoir has a much larger diameter than the die. That means the total pressure drop can be written as:

$$
\Delta \mathrm{P}=\Delta \mathrm{P}_{\mathrm{e}}+\Delta \mathrm{P}_{\text {cap }}
$$

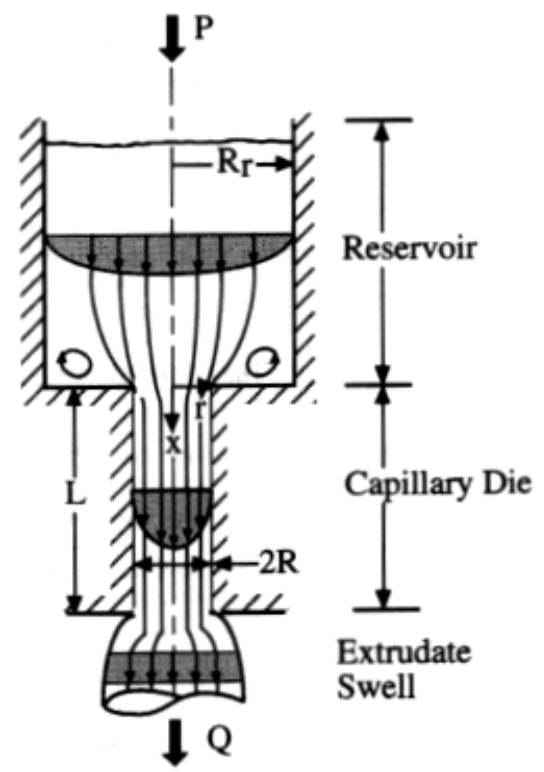

Figure 3.14: Flow inside the capillary rheometer 


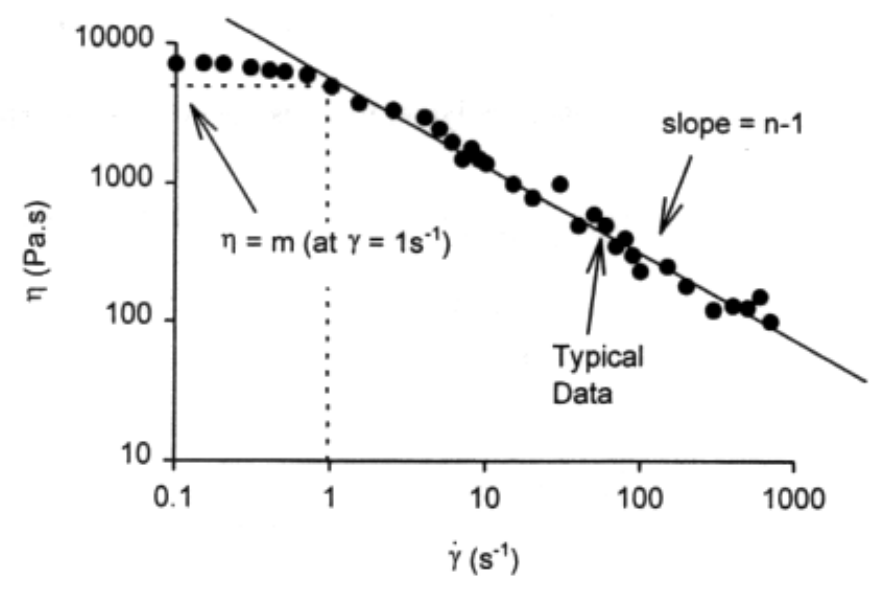

Figure 3.15: Flow chart in logarithmic scale of typical capillary rheometer results

In the theoretical analysis it has been assumed that the measured $\Delta \mathrm{P}$ by the instrument corresponds only to the pressure drop inside the capillary die, $\Delta \mathrm{P}_{\text {cap. }}$. According to that assumption, the wall shear stress is:

$\tau_{\mathrm{w}}=\frac{\Delta \mathrm{P}}{2(\mathrm{~L} / \mathrm{R})}$

If the pressure drop in the entrance of the capillary is not negligible compared to the pressure drop inside the capillary, the wall shear stress cannot be estimated from the above formula. In that case, the true wall shear stress is:

$\tau_{\mathrm{w}}=\frac{\Delta \mathrm{P}}{2\left(\frac{\mathrm{L}}{\mathrm{R}}+\mathrm{e}\right)}$

where the e factor is referred to as the Bagley correction.

For the calculation of the Bagley correction, data from at least two different dies must be provided. In case that the die happens to be really narrow compared to its length, something that means approximately $\mathrm{L} / \mathrm{R}>25$, the pressure drop inside the capillary is significantly larger than the pressure drop in its entrance and the Bagley correction may be neglected. 


\subsubsection{Specifications and experimental procedure}

As was mentioned in section 3.2.2.1, the type of the capillary rheometer is Galaxy V, model 8052a, provided by Kayeness Inc. The piston's screw machine of the capillary rheometer is manipulated by a pc via a series of gears. The general description of the heated reservoir is one that is given in section 3.2.2. After every experiment, $\tau_{\mathrm{w}}$ and $\dot{\gamma}_{\mathrm{w}}$ values are received and the flow chart ( $\eta$ vs. $\dot{\gamma}$ ) based on the Rabinowitch equation (or correction) is configured automatically.

In the experimental procedure, 2 different capillary dies were used: one of $0.03 "$ diameter and 0.60" length $(\mathrm{L} / \mathrm{D}=20)$, and a second of 0.03 " diameter and 1.20" length $(\mathrm{L} / \mathrm{D}=40)$. During the experiments, the temperature remained uniform inside the barrel, at $230{ }^{0} \mathrm{C}$. For every die, 9 different points in the flow chart (based on the 9 different positions of the piston inside the reservoir) were collected. From the experimental procedure, the consistency index and the power law index were obtained. 
Table 3.5 summarizes all the techniques used for the experimental procedure with their most important parameters.

Table 3.5: Techniques used with the most important parameters

\begin{tabular}{|c|c|c|c|}
\hline $\begin{array}{c}\text { Technique- } \\
\text { Instrument }\end{array}$ & Scope & Variables & Set Factors \\
\hline 1. Haake mixer & Production of CRPP & $\begin{array}{c}\text { Real temperature } \\
\text { Torque of rotors }\end{array}$ & $\begin{array}{c}\text { NOR/ perox. concentration } \\
\text { RPM } \\
\text { Duration of mixing } \\
\text { Nominal temperature }\end{array}$ \\
\hline 2. Grinder & $\begin{array}{c}\text { CRPP partition into granules } \\
\text { randomization of the expts }\end{array}$ & Orifice of grinder screen \\
\hline 3. MFR Apparatus & MFR Measurement & $\begin{array}{c}\text { Weight and duration } \\
\text { of CRPP's extrusion } \\
\text { from MFR die }\end{array}$ & $\begin{array}{c}\text { Temperature } \\
\text { Weight of piston } \\
\text { Die geometry }\end{array}$ \\
\hline 4. Hot Press & $\begin{array}{c}\text { Preparation of samples for } \\
\text { other instruments }\end{array}$ & $\begin{array}{c}\text { Temperature } \\
\text { Pressure }\end{array}$ \\
\hline $\begin{array}{c}\text { 5. Parallel plate } \\
\text { rheometer }\end{array}$ & $\begin{array}{c}\text { Determination of } \\
\text { viscoelastic properties }\end{array}$ & $\begin{array}{c}\text { Storage modulus } \\
\text { Loss modulus }\end{array}$ & $\begin{array}{c}\text { Percentage of strain } \\
\text { Angular frequency } \\
\text { Temperature }\end{array}$ \\
\hline $\begin{array}{c}\text { 6. FT-IR } \\
\text { spectroscopy }\end{array}$ & $\begin{array}{c}\text { Detection of molecular } \\
\text { structure }\end{array}$ & & $\begin{array}{c}\text { Temperature } \\
\text { Solvent }\end{array}$ \\
\hline 7. GPC & $\begin{array}{c}\text { Determination of MWD and } \\
\text { average molecular weights }\end{array}$ & & \\
\hline
\end{tabular}




\section{Results and Discussion}

Chapter 4 deals with the results of the experimental studies. As mentioned in the previous chapter, the experimental procedure consisted of the CRPP production and the CRPP characterization. From both of them, results are obtained for the 20 different CRPP samples produced in the Haake mixer. These results mainly include the torque values derived from the Haake mixer, the MFR indices, the rheological characteristics obtained by the parallel plate rheometer, the infrared spectra obtained by the FT-IR method and the MWD and molecular weight averages obtained by GPC. In addition, results from degradation studies of PP by using a tetra functional peroxide initiator are provided, giving a wider picture of NOR-mediated CRPP and peroxide-mediated CRPP. Moreover, according to the existing literature, results of modeling the rheological properties of every polymer melt sample inside the Haake mixer are provided.

All the results are accompanied by the appropriate comments and discussion. The most important conclusions are summarized in the next chapter in the form of final concluding remarks. 


\subsection{CRPP Production Results}

This section examines the experimental results that were derived from the production of CRPP in the Haake mixer.

\subsubsection{Haake Mixer Measurements}

The measurements that the Haake mixer produces are various. One of the most important measurements is the final instant torque at the end of every experiment. This value represents the instant torque of the rotors in order for the angular velocity to remain constant at $100 \mathrm{rpm}$. This value is recorded at the end of every experiment, exactly at the 300th second of the mixing, as each experiment lasts 5 minutes. For that reason it is called final torque. It can provide useful information about the polymer melt inside the batch mixer chamber.

Figure 4.1 illustrates that final torque of CRPP polymer melt in the Haake mixer as a function of the nominal temperature in the mixing chamber. The torque values of the CRPP that correspond to the same concentration of Irgatec CR76 or Luperox 101 or virgin PP are connected by a line to each other. As was previously said, the nominal temperature represents the temperature that is set to be maintained inside the mixing chamber. As the sample was introduced into the mixing chamber, the actual temperature decreased, and during the mixing increased again until it reached the set temperature. In this experimental procedure, the set temperature is rapidly approached before the end of the 5 minute period that each experiment lasts. All the graphs of torque vs. time for each sample that took place in the Haake mixer are presented in Appendix I of this thesis.

The main observations that can be made regarding the results that are shown at Figure 4.1, are:

As expected, a high percentage of initiator in the sample corresponds to a high level of degradation of the sample inside the Haake mixer. One can clearly see lower values of torque at higher concentrations of NOR (Irgatec CR76) or peroxide 
(Luperox 101).

As expected, at higher temperatures, the levels of degradation were higher, as indicated by lower values of torque at high temperatures.

- The lines for experiments with 0, 0.75, 1.5 and 3\% Irgatec CR76 are distinct at all temperatures. Only at $250{ }^{0} \mathrm{C}$ the values for $0.75 \%$ and $1.5 \%$ and at $290{ }^{0} \mathrm{C}$ the values for $0 \%$ and $0.75 \%$ come relatively close.

- The results for the polymer melt with $250 \mathrm{ppm}$ of peroxide and with $250 \mathrm{ppm}$ of NOR (0.75\% Irgatec CR76) are very close to each other (almost coincident). Only at $270{ }^{\circ} \mathrm{C}$ a separation appears between them. This indicates that the effects of peroxide and NOR addition are similar.

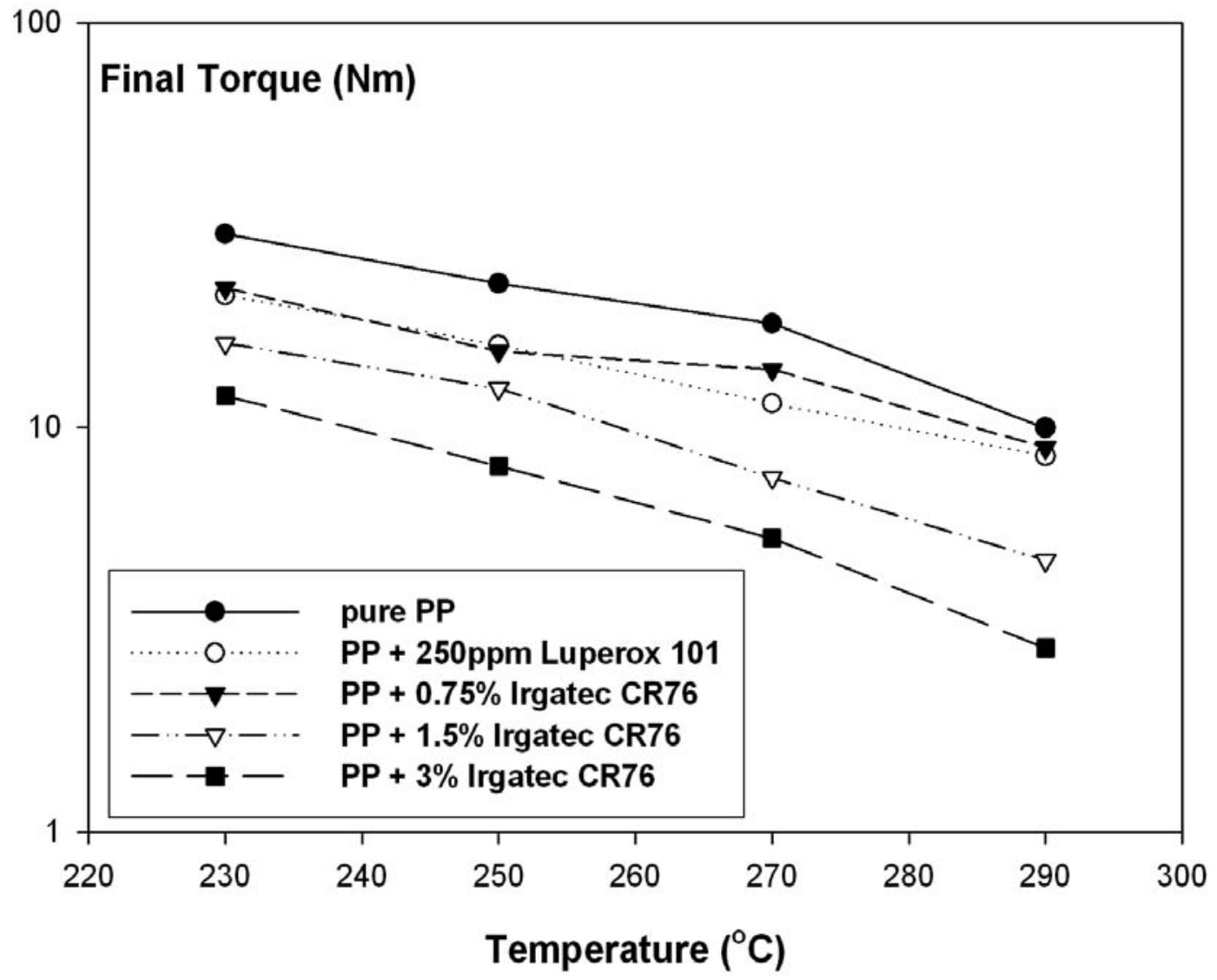

Figure 4.1: Final torque of CRPP polymer melt in the Haake mixer, as function of the nominal temperature in the mixing chamber 


\subsubsection{Modeling of the Polymer Melt in Haake Mixer}

The modeling of the rheological properties of the polymer melt inside the Haake mixer was done according to literature (Bousmina et al. (1999)). It is described analytically in Appendix II. For determination of the effective internal radius $R_{i}$ of the Haake Mixer, a reference melt tested in the Haake mixer was necessary. The CRPP that was produced from pure PP at $230{ }^{\circ} \mathrm{C}$ was chosen as the reference melt. That CRPP corresponds to the sample with the lowest level of degradation and as a result with the MFR closest to the MFR of the virgin PP. For the determination of the effective internal radius $\mathrm{R}_{\mathrm{i}}$ (see Appendix II), that CRPP was described as power law fluid with the power law parameters to be determined from experiments in the capillary rheometer.

For that reason, 2 different capillary dies were used: die 1 of 0.03 " diameter and 0.60 " length $(\mathrm{L} / \mathrm{D}=20)$ and die 2 of 0.03 " diameter and 1.20 " length $(\mathrm{L} / \mathrm{D}=40)$. The temperature used was $230{ }^{\circ} \mathrm{C}$. From these experiments in the capillary rheometer, and after the Rabinowitch equation, the values of the power law parameters are derived automatically from the software of the capillary rheometer, according to Figure 3.15.

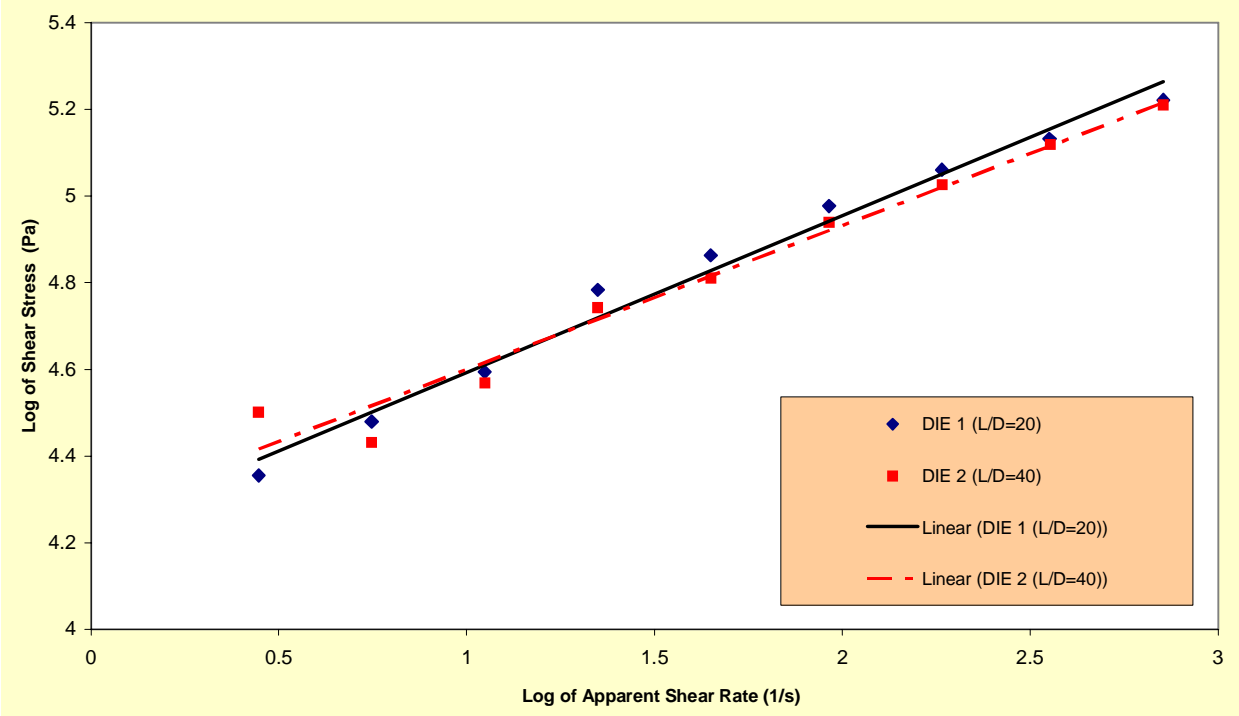

Figure 4.2: $\log$ of shear stress vs. $\log$ of shear rate for the two dies in the capillary $\underline{\text { rheometer }}$ 
From that software it was found that:

- For die $1: \mathrm{n}=0.3441$ and $\mathrm{M}=15,920 \mathrm{~Pa} \mathrm{~s}^{\mathrm{n}}$ (with trendline of $\mathrm{R}^{2}=0.9845$ )

- For die $2: \mathrm{n}=0.3596$ and $\mathrm{M}=13,750 \mathrm{~Pa} \mathrm{~s}^{\mathrm{n}}$ (with trendline of $\mathrm{R}^{2}=0.9716$ )

Figure 4.2 illustrates the experimental results for the two dies in the capillary rheometer.

Using the following data for equation (A.9), the effective internal radius was calculated to be $\mathrm{R}_{\mathrm{i}}=0.023 \mathrm{~m}$.

a. Power Law fluid: $\mathrm{n}=0.3441$ and $\mathrm{M}=15,920 \mathrm{~Pa} \mathrm{~s}^{\mathrm{n}}$

b. Haake mixer geometry: $\mathrm{L}=0.083 \mathrm{~m}$ and $\mathrm{R}_{\mathrm{e}}=0.034 \mathrm{~m}$

c. The rotation of the rotors: $\mathrm{N}=100 \mathrm{rpm}=1.667 \mathrm{~s}^{-1}$

d. The ratio of the rotation: $\mathrm{g}=\Omega_{2} / \Omega_{1}=2 / 3=0.6667$

e. The instantaneous torque of the Haake Mixer at the end of the experiment: $\Gamma=$ $30.01 \mathrm{Nm}$

With the above data, it was easy to calculate the instantaneous shear rate and shear viscosity for the polymer melt at the position $r_{1 / 2}$ by equations (A.11).

Using equation (A.11b), the shear rate was found:

$\left(\dot{\gamma}_{1 / 2}\right)_{\beta \rightarrow 1}=27.2 \mathrm{~s}^{-1}$

Using equation (A.11a), the shear rate was found:

$\left(\dot{\gamma}_{1 / 2}\right)_{\beta \rightarrow 1}=25.6 \mathrm{~s}^{-1}$

And by using the torque values of the Haake mixer presented in Figure 4.1, the instantaneous shear viscosity for the polymer melt at position $r_{1 / 2}$ using equation (A.14) can be calculated. The results are shown in Figure 4.3.

From the above analysis, the following remarks can be given:

- The two capillary dies give similar results, despite the fact that they have different $\mathrm{L} / \mathrm{D}$ ratio. That means that the pressure effect is not important.

- The modeling condition (A.10) for narrow gap is not satisfied. Particularly, it can be calculated:

$\frac{\mathrm{R}_{\mathrm{e}}-\mathrm{R}_{\mathrm{i}}}{\mathrm{R}_{\mathrm{i}}}=0.4783$ 
It is clear that 0.4783 is not $<<1$. In addition, the other condition for the simulation is that it has been assumed that no mixing happens between the two rotor areas of the mixing chamber. That condition is not practically possible, as the two rotor areas communicate with each other and mass transfer from the one to the other is unavoidable.

- The trend of the lines in Figure 4.3 is logical. High temperatures and high amount of initiator contribute to high degradation (translated to shorter chain lengths and low viscosity polymer melt). Figure 4.3 is in agreement with Figure 4.1, and no contradiction can be seen.

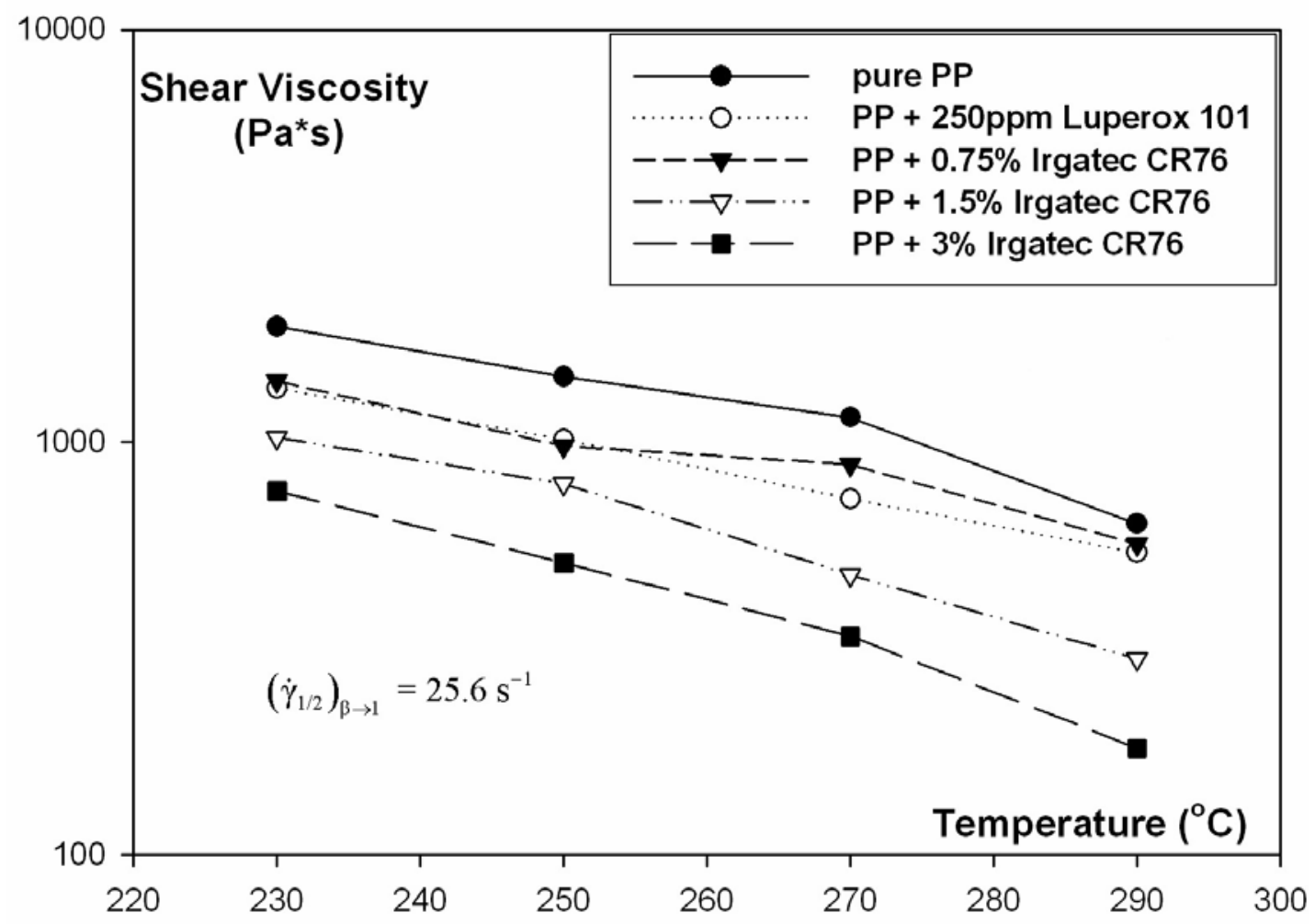

Figure 4.3: Analytical solution for shear viscosity of the CRPP melt in Haake mixer 


\subsection{CRPP Characterization results}

This section deals with the experimental results collected from the instruments that were used for characterization of CRPP. These measurements are: the MFR index, the viscoelastic characteristics derived from parallel plate rheometer, the IR spectra and molecular weights from GPC.

\subsubsection{Melt Flow Rate (MFR) Measurements}

\subsubsection{General results}

The MFR measurements took place in the capillary rheometer using the special die and conditions for the MFR, according to ASTM Protocol D 1238. As stated in the experimental section, for every CRPP, 5 independent experiments were done. That means that totally 100 measurements were done in the MFR apparatus.

After the 5 independent experiments for every CRPP were done, 5 independent values of MFR indices were determined for every sample. Using the numerical average of them, their MFR was calculated. The need for numerical average stems from the fact that individual MFR measurements are inherently noisy. Especially in our case the MFR indices are relatively high; this means the flows of the polymer melts that extruded through the MFR die were high and as a result were more difficult to measure.

The derived MFR chart is illustrated in Figure 4.4 and is analogous to that seen from the early research of Pfaendner (Figure 2.11). Figure 4.4 presents the measured MFR indices of the CRPP samples produced in the Haake mixer versus the nominal temperature that was used for their production. The points that result from the CRPP samples of the same mixture are connected with a line.

From Figure 4.4 the following remarks can be summarized:

The general trend of lines was as expected. The higher the temperature, the higher the degradation of the resin, the higher the level of decomposition of the carbon 
chain, and the higher the resulting MFR index. In the same way, a higher percentage of NOR contributes to higher levels of degradation and therefore to higher MFR values. The latter is not always true for high concentration of peroxide according to the existing literature, but cases of low concentration of peroxide initiator obey the general rule.

- The CRPP produced from experiments that have the same amount of peroxide (250 ppm Luperox 101) and NOR (0.75\% Irgatec CR76) give almost the same results for MFR. Only at high temperatures it appears that the peroxide caused slightly higher degradation than the NOR.

- The virgin PP (PDC 1280) that was used had an MFR index of $1.2 \mathrm{~g} / 10$ minutes. From Figure 4.4 it is can be seen that a small percentage of NOR (i.e., 3\% Irgatec CR76 that corresponds to $1000 \mathrm{ppm}$ of NOR) modifies the carbon chain significantly and increases the MFR by a factor of 100 at $290{ }^{\circ} \mathrm{C}$.

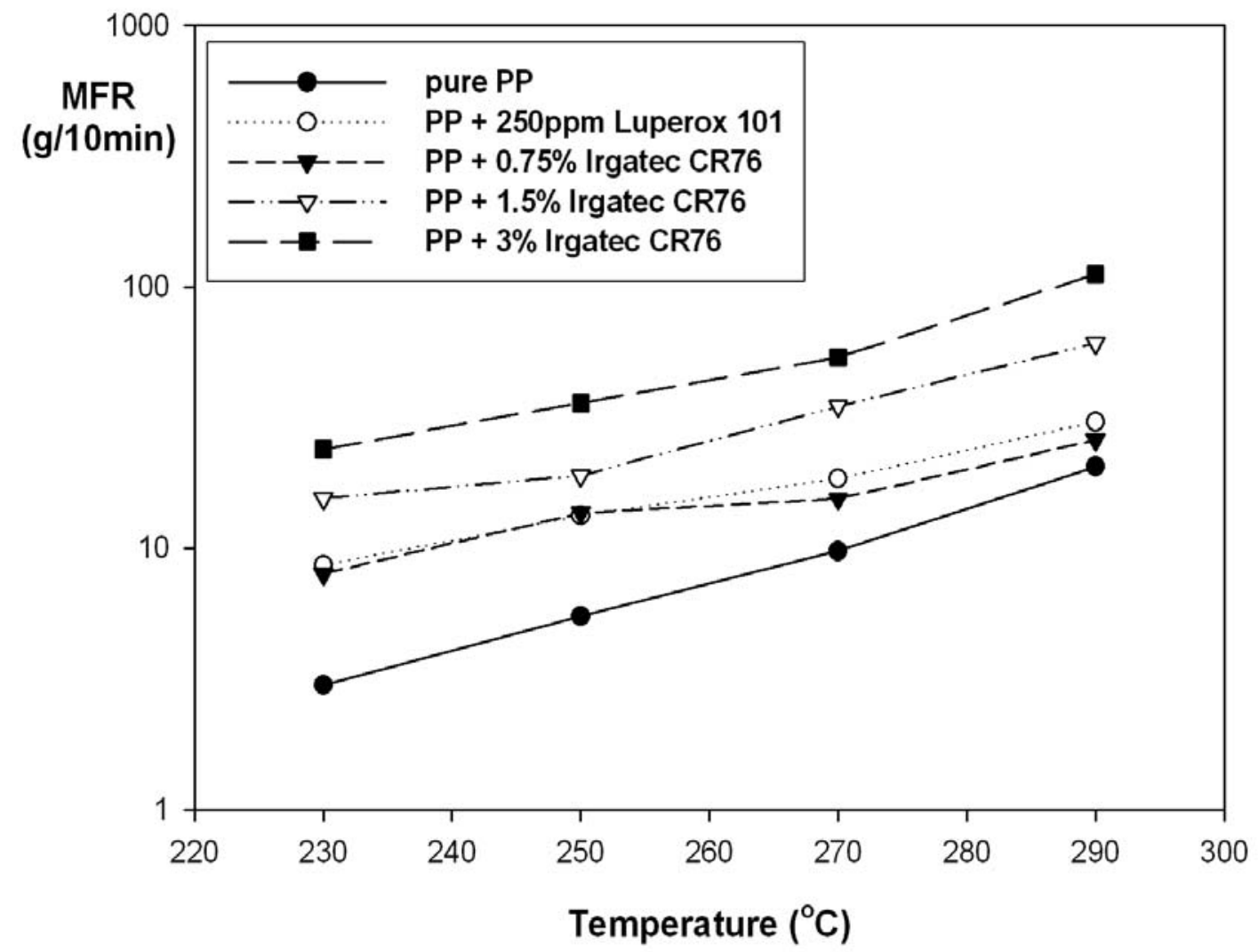

Figure 4.4: Performance of MFR index of the produced CRPP samples 


\subsubsection{Statistical analysis}

One other important aspect that has to be examined is the statistical analysis and interpretation of the MFR results. This is important because the MFR numerical average might give a false picture of the real trend of the MFR lines, so statistical analysis is needed. Particularly, confidence intervals are necessary to decide if the derived points are true and how large the statistical error is.

The classical method of confidence intervals necessitates the knowledge of each average MFR index (which is known from the data in Figure 4.4), and the standard deviation $\mathrm{s}$ which can be found easily as:

$\mathrm{s}=\sqrt{\frac{\sum_{\mathrm{i}=1}^{\mathrm{n}}\left(\mathrm{x}_{\mathrm{i}}-\overline{\mathrm{x}}\right)^{2}}{\mathrm{n}-1}}$

where $x_{i}$ is the MFR experimental value representing the $i^{\text {th }}$ - experiment, $\bar{x}$ is the numerical average of the experimental series, $n$ is the number of experiments $(n=5$ in our case), and $n-1$ represents the degrees of freedom of each experimental series.

Because the sample size is small, the t-Distribution has to be used (see, for instance, Milton et al. (1995), Walpole et al. (1998), Rawling et al. (1998)). The confidence interval that is used is the two-sided at $95 \%$. That means that with $95 \%$ confidence all the sample data will be in that confidence interval that is described via the equation:

$\overline{\mathrm{x}} \pm \frac{\mathrm{s}}{\sqrt{\mathrm{n}}} \cdot \mathrm{t}(\mathrm{n}-1, \mathrm{a})$

where $\mathrm{a}=(1-0.95)=0.05$, and from the $\mathrm{t}$-Distribution table:

$\mathrm{t}(\mathrm{n}-1, \mathrm{a})=\mathrm{t}(4,0.0 .5)=2.776$

This means that for every sample series, the $95 \%$ confidence interval has the form: $[\overline{\mathrm{x}}-1.2415 \mathrm{~s}, \overline{\mathrm{x}}+1.2415 \mathrm{~s}]$

where $\overline{\mathrm{x}}$ is the numerical average and $\mathrm{s}$ the standard deviation of the sample population.

According to the above, for the 20 experimental series corresponding to the 20 CRPP, their MFR indices with error bars are shown in Figure 4.5. As it can be seen, the error factor is not so large in order to be said that the trend of the MFR lines can be 
affected by statistical error. In other words, the chart in Figure 4.4 is accurate even considering the statistical error factor; the deviation is small and the average MFR index of each experimental series is not relatively far from the minimum and maximum values of that series. The inclusion of error bars does show that the trends for $250 \mathrm{ppm}$ peroxide and $0.75 \%$ Irgatec CR76 are essentially identical. The experimental values of different MFR series and for selected CRPP concentrations are illustrated in Figures 4.6 to 4.10. These experimental points verify the above observations.

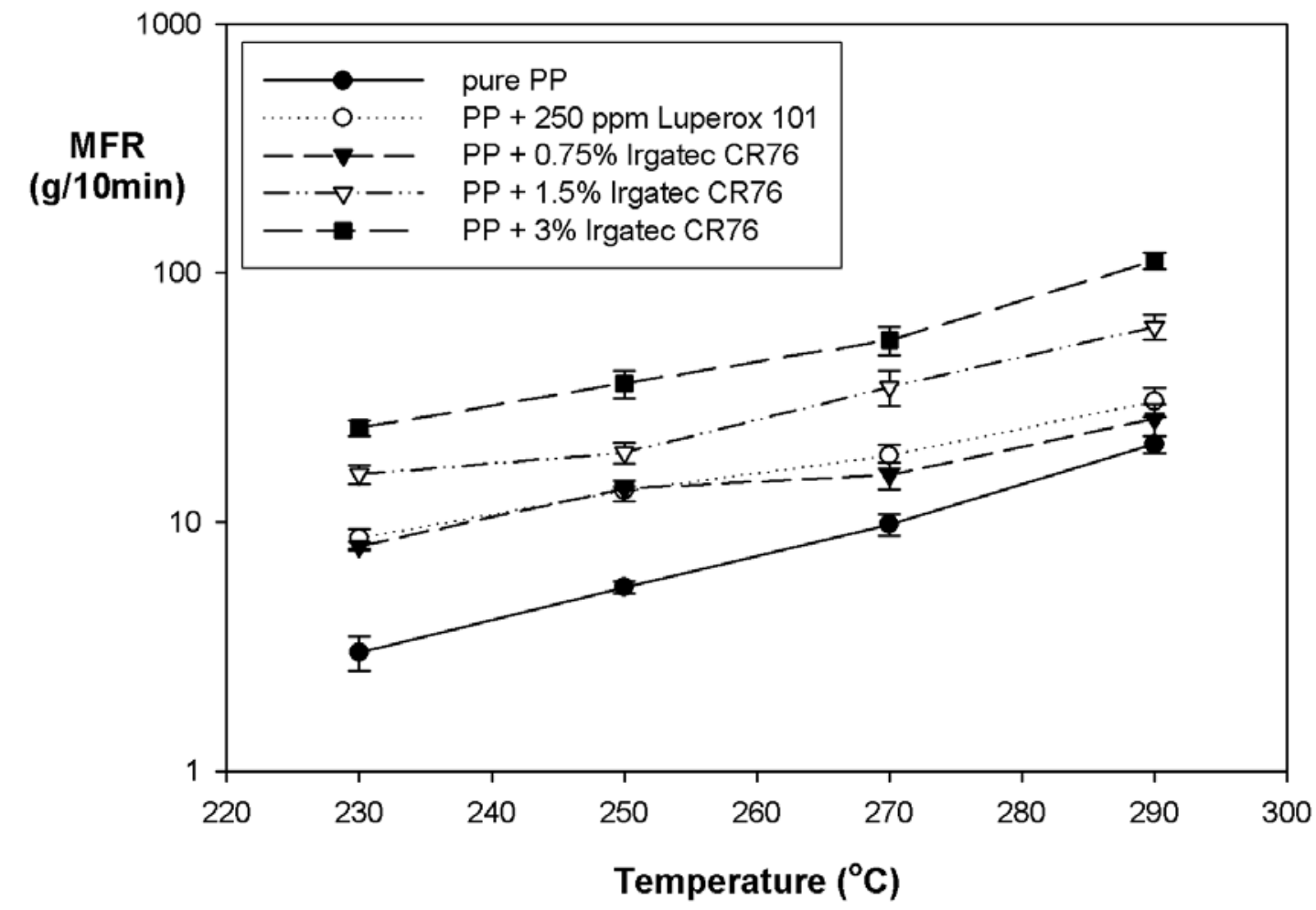

Figure 4.5: Performance of MFR index of the produced CRPP samples with error bars at $\underline{95 \% \text { confidence level }}$ 


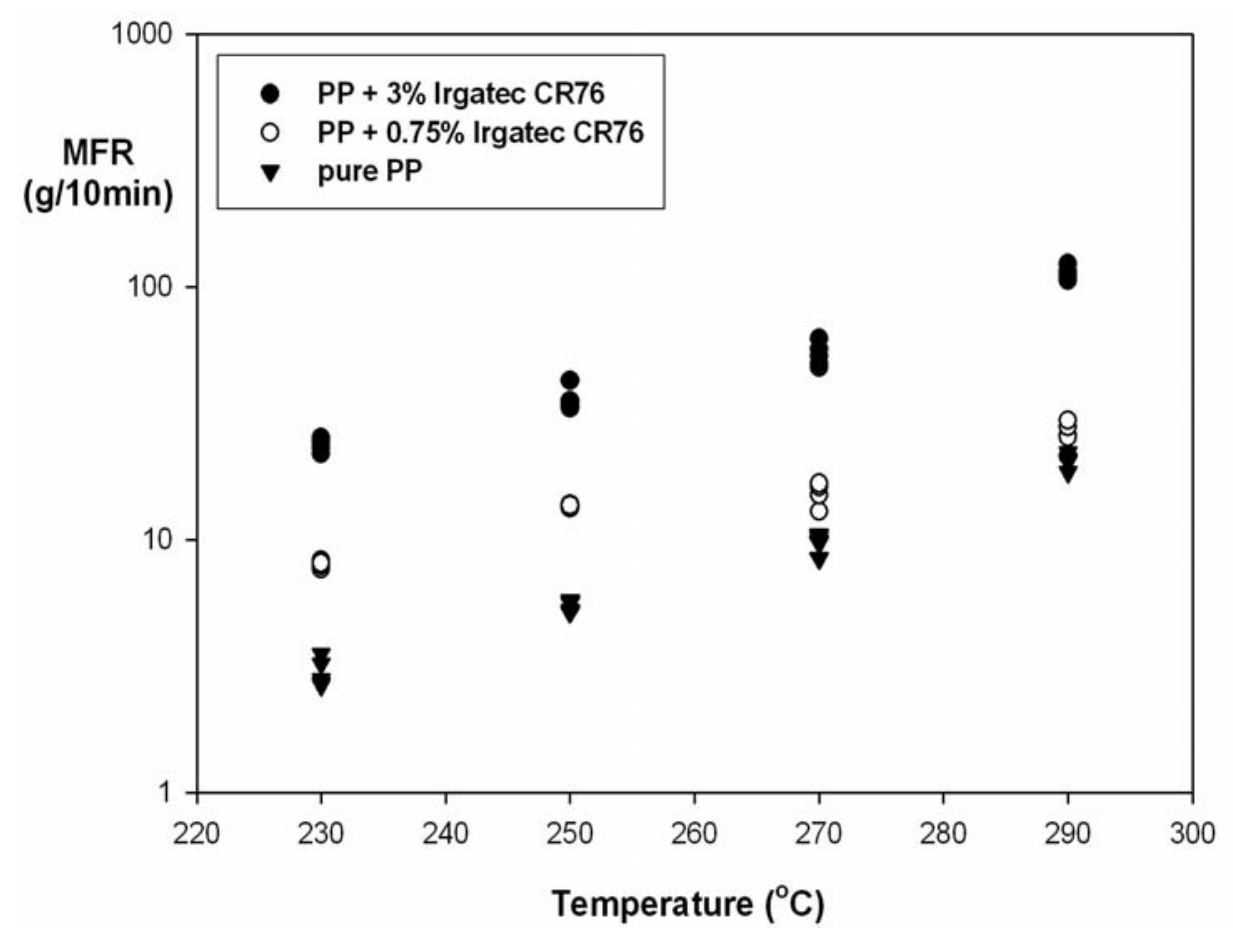

Figure 4.6: MFR experimental points for PP with 0, 0.75 and 3\% Irgatec CR76

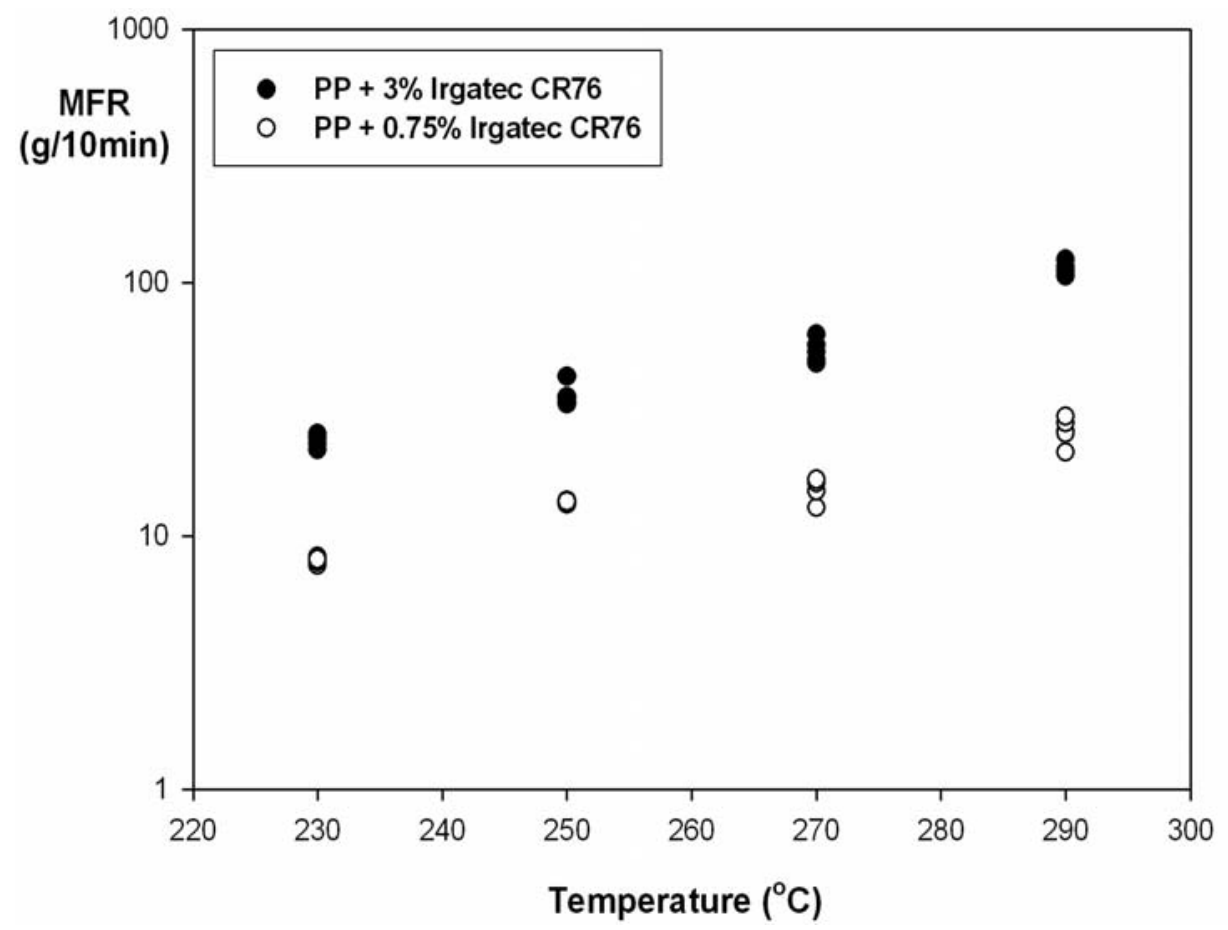

Figure 4.7: MFR experimental points for PP with 0.75 and 3\% Irgatec CR76 


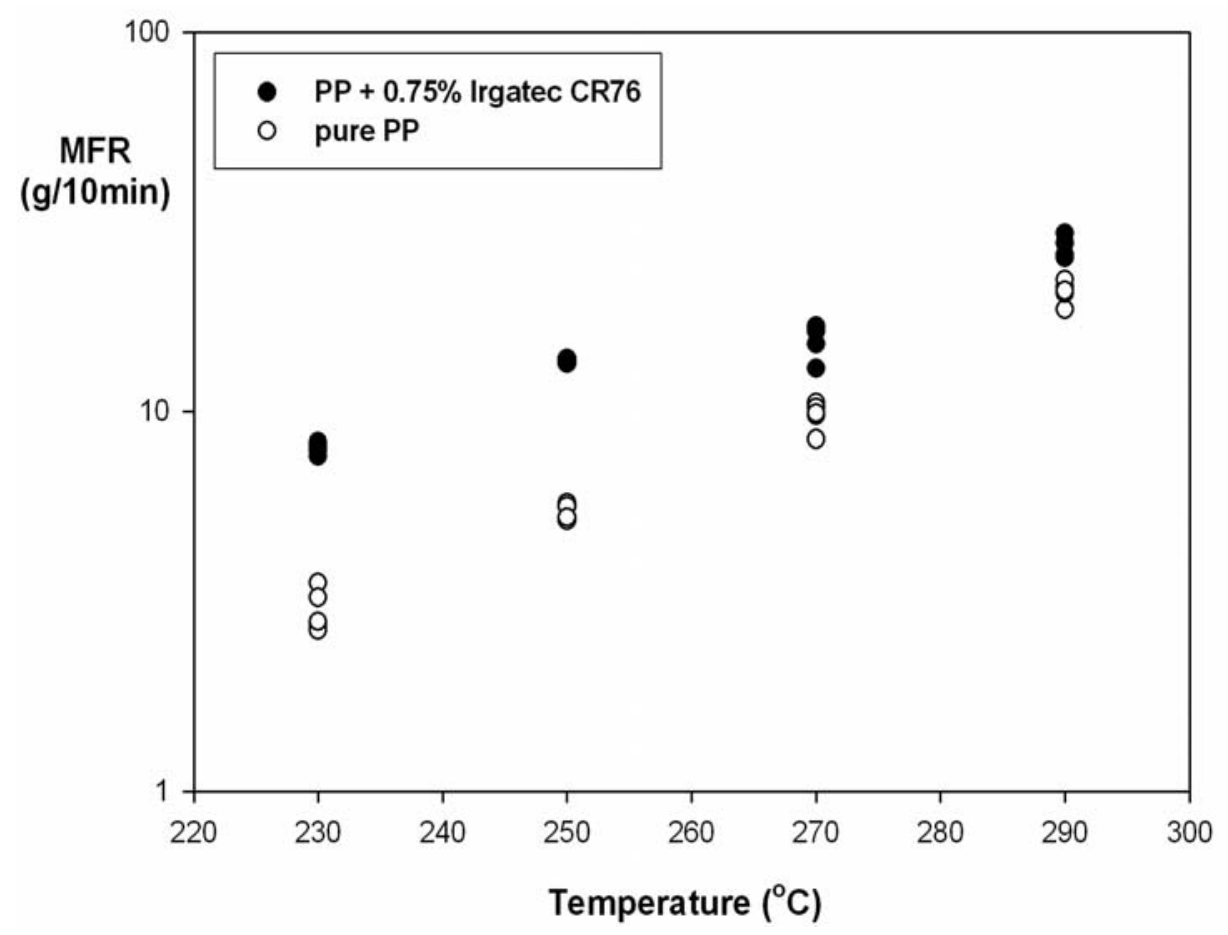

Figure 4.8: MFR experimental points for PP with 0 and $0.75 \%$ Irgatec CR76

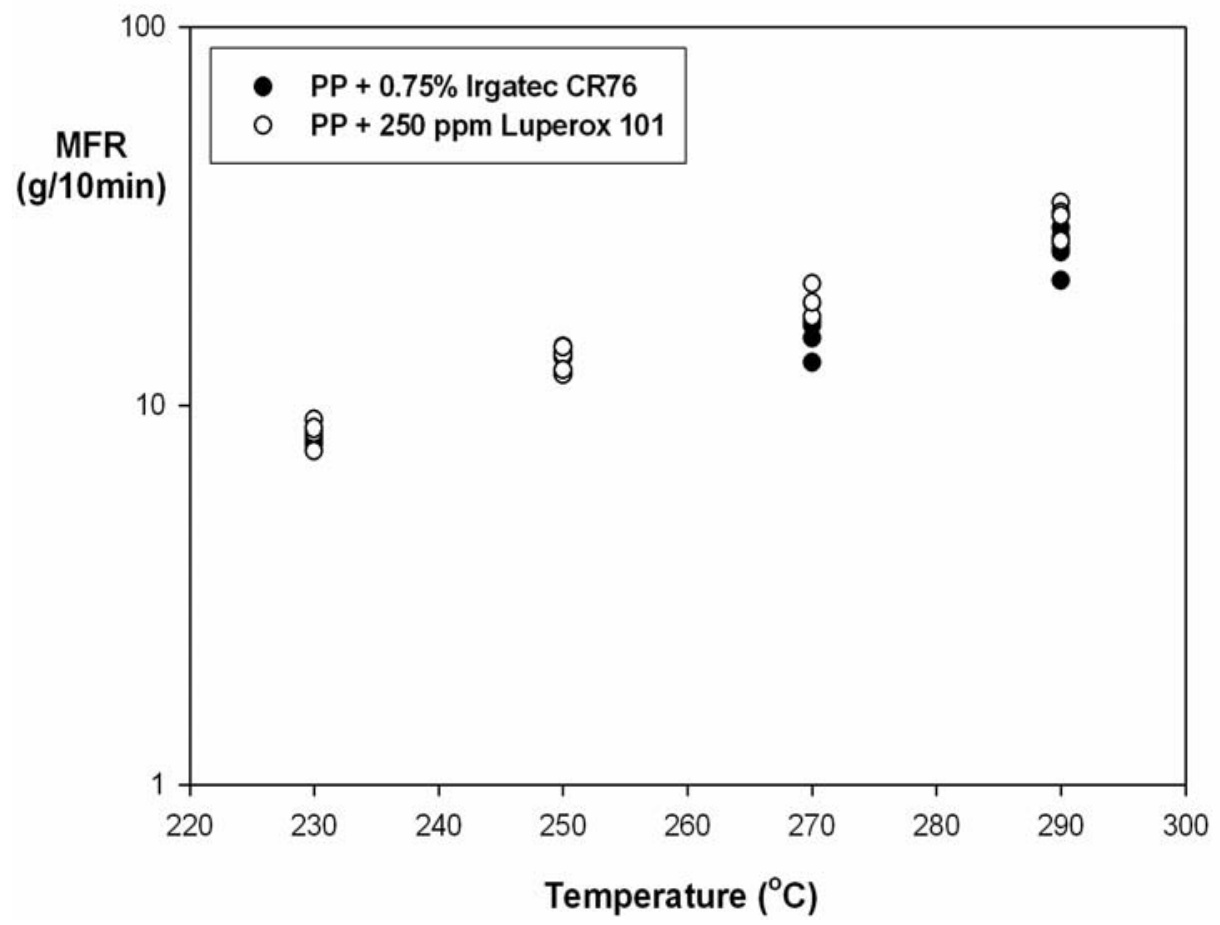

Figure 4.9: MFR experimental points for PP with $0.75 \%$ Irgatec CR76 and $250 \mathrm{ppm}$

Luperox101 


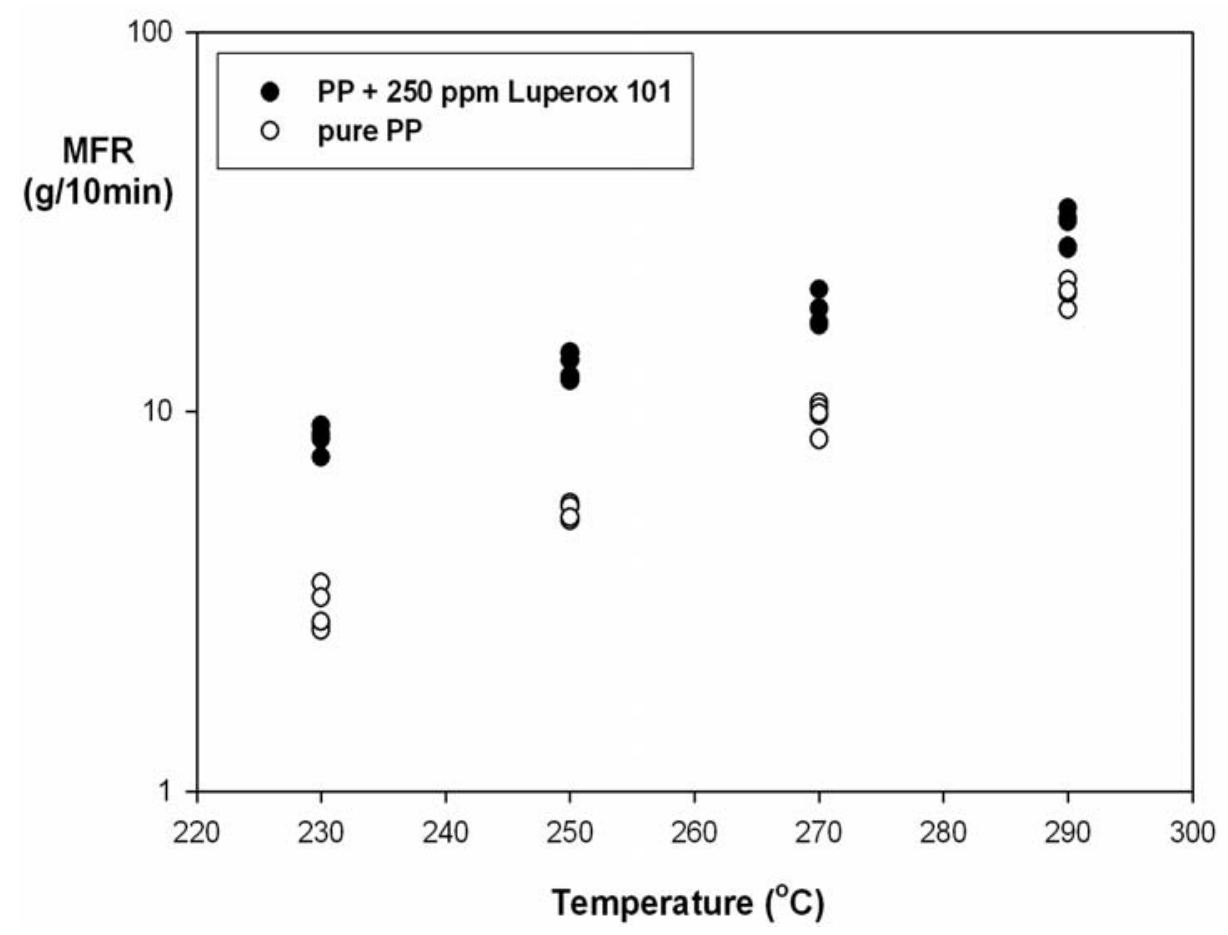

Figure 4.10: MFR experimental points for PP with 0 and 250 ppm Luperox 101

\subsubsection{MFR measurements for CRPP resins produced with $\mathrm{N}_{2}$ presence}

One other issue that had to be examined was whether the oxygen from air affected the degradation of the melt in the Haake mixer. In order to answer this question, some selected experiments were repeated in the Haake mixer under nitrogen $\left(\mathrm{N}_{2}\right)$ atmosphere. That means constant low flow of $\mathrm{N}_{2}$ was provided on the surface of the mixing chamber.

The selected experimental series repeated with $\mathrm{N}_{2}$, were the ones at nominal temperatures of $250{ }^{0} \mathrm{C}$ and $290{ }^{\circ} \mathrm{C}$. The resulting numerical average MFR indices compared to the numerical average MFR indices that were produced without $\mathrm{N}_{2}$ at the same nominal temperatures are illustrated in Figures 4.11 and 4.12. 


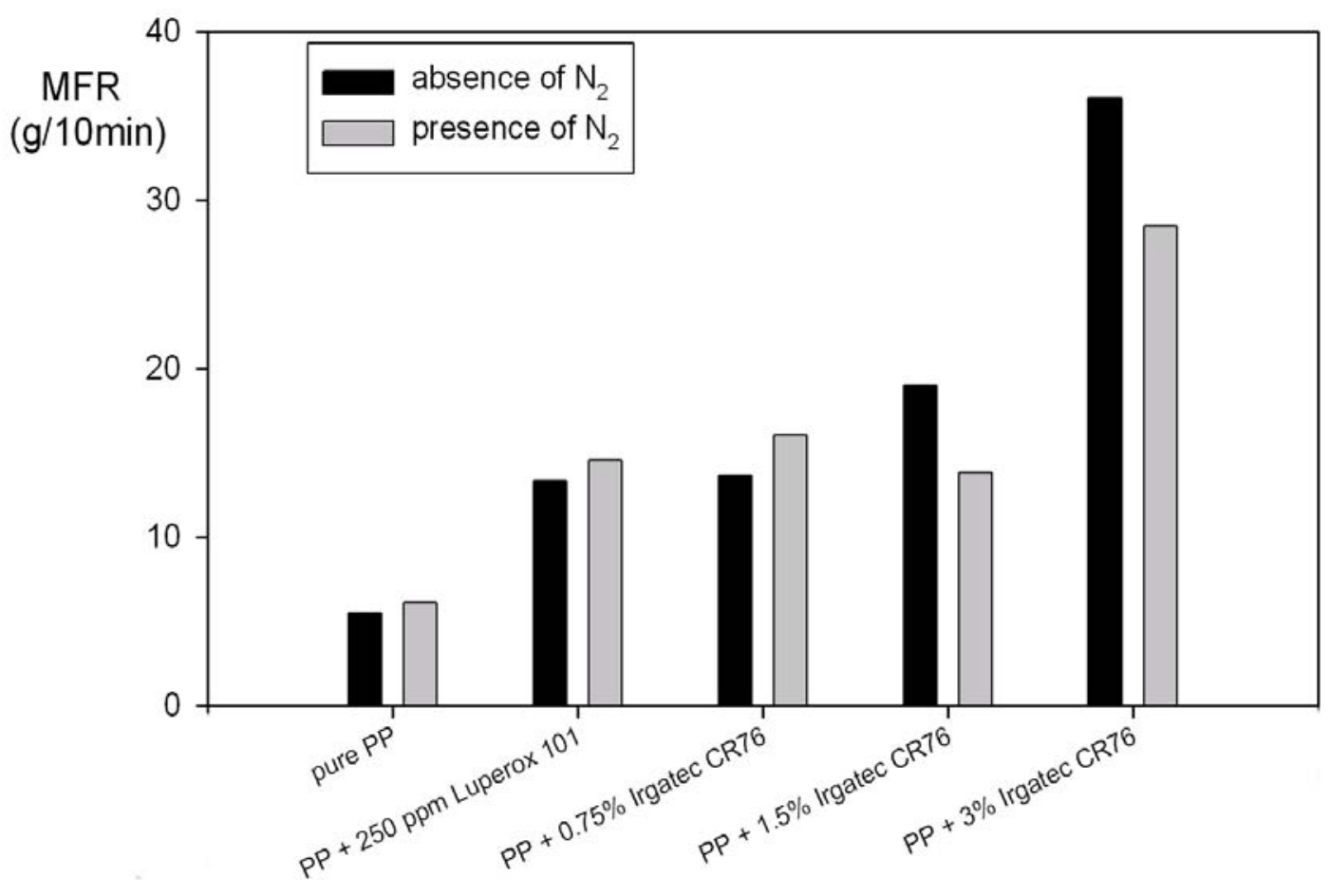

Figure 4.11: Bar chart with experimental results with and without $\mathrm{N}_{2}$ at $250{ }^{\circ} \mathrm{C}$

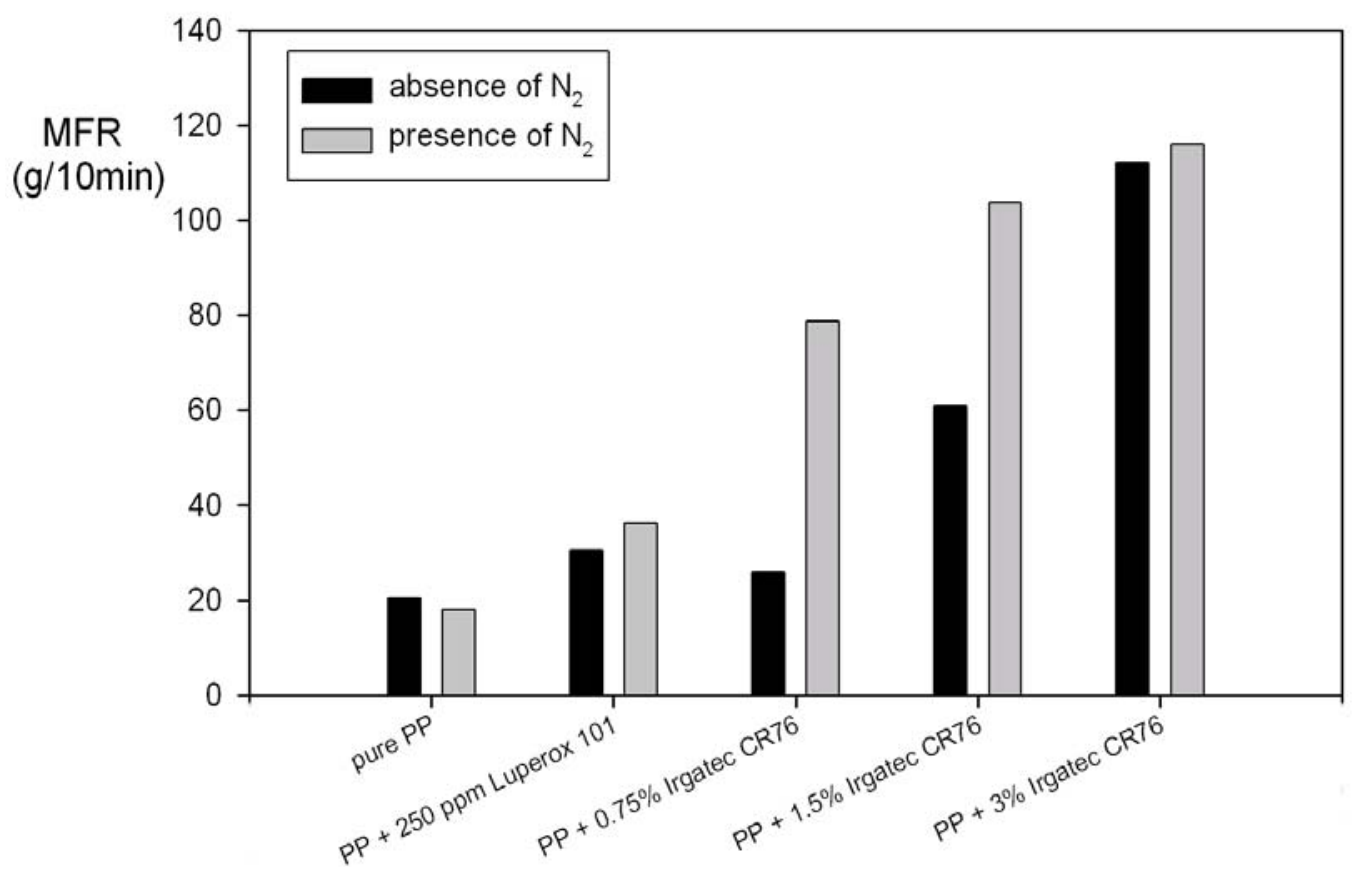

Figure 4.12: Bar chart with experimental results with and without $\mathrm{N}_{2}$ at $290{ }^{\circ} \mathrm{C}$ 
From Figures 4.11 and 4.12, it can be concluded that:

Most of the results are in agreement with the results of the CRPP resins produced without $\mathrm{N}_{2}$. Only 3 of them are significantly different from the original (PP with $3 \%$ Irgatec CR76 at $250{ }^{\circ} \mathrm{C}$, and PP with $0.75 \%$ and $1.5 \%$ Irgatec CR76 at 290 ${ }^{0} \mathrm{C}$ ). The fact that in some cases differences exist can be explained as a result of the unavoidable slight temperature changes in the mixing chamber, because of the nitrogen introduction.

The possibility of oxidization during the CRPP production seems minor. This is because in case we had significant oxidization during the CRPP production, then the degradation would be higher and the MFR indices would be larger without nitrogen. This means that the produced CRPP resins with $\mathrm{N}_{2}$ would have lower MFR indices, something that doesn't happen systematically according to these charts. Only in 3 cases (PP with $1.5 \%$ and $3 \%$ of Irgatec CR76 at $250{ }^{\circ} \mathrm{C}$ and pure PP at $290{ }^{\circ} \mathrm{C}$ ) the MFR of the CRPP produced without $\mathrm{N}_{2}$ is higher than the MFR of the CRPP produced with $\mathrm{N}_{2}$ presence. It also has to be taken into account that in some cases oxygen might act as inhibitor to radical processes (Odian (2004)).

Generally it can be claimed that oxidization of the CRPP doesn't happen or, if it happens, it is negligible. The short time of the experiment ( 300 seconds) and other factors of significant gravity (high temperatures, presence of radical initiators, high rotation of $100 \mathrm{rpm}$ ) point to that direction.

\subsubsection{Parallel Plate Rheometer Measurements}

The main experimental data collected from the parallel plate rheometer were the frequency sweeps for each CRPP sample. As described in section 3.2.4.1, these frequency sweeps illustrate the loss modulus $G^{\prime \prime}$ and storage modulus $G^{\prime}$ versus frequency $\omega$. The frequency sweeps were done at three different temperatures: 170,190 and $210{ }^{\circ} \mathrm{C}$. All these plots are presented in detail in Appendix III. From these charts, the plots of G" vs. $\mathrm{G}^{\prime}$ can be easily determined, as illustrated in Figures 4.13 to 4.24 . 


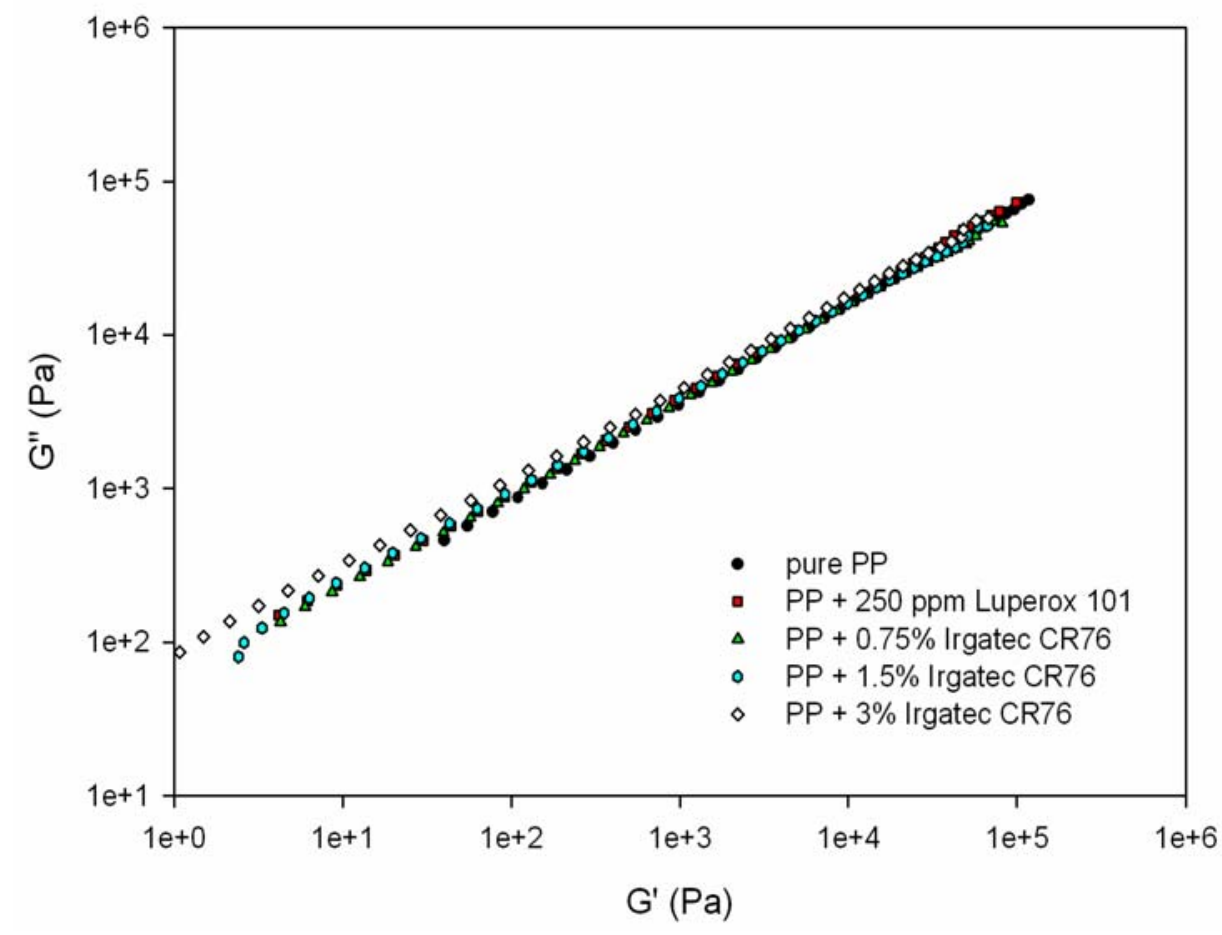

Figure 4.13: G" vs. $\mathrm{G}^{\prime}$ at $170{ }^{\circ} \mathrm{C}$ of CRPP produced in Haake Mixer at $230{ }^{\circ} \mathrm{C}$

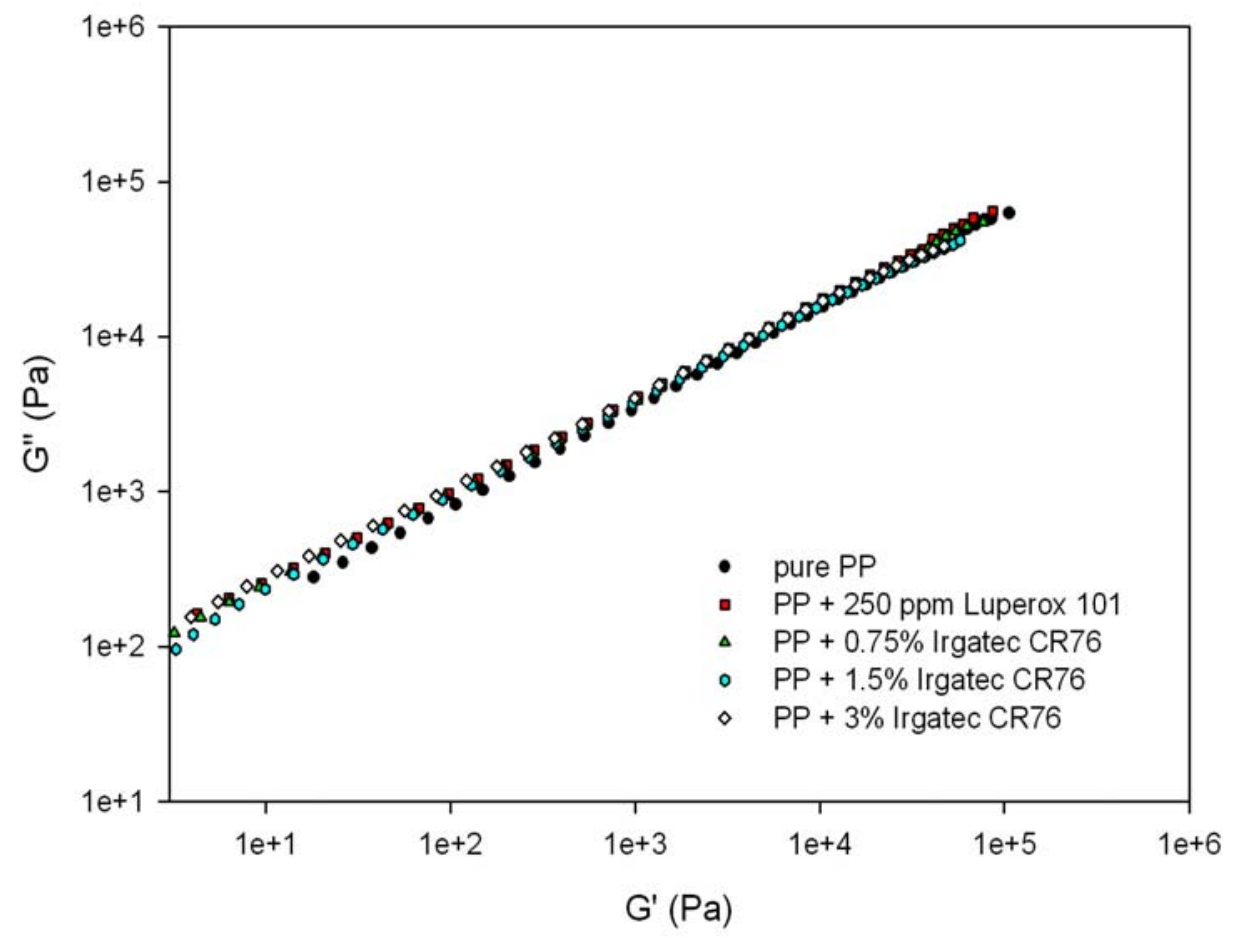

Figure 4.14: G" vs. $\mathrm{G}^{\prime}$ at $170{ }^{\circ} \mathrm{C}$ of CRPP produced in Haake Mixer at $250{ }^{\circ} \mathrm{C}$ 


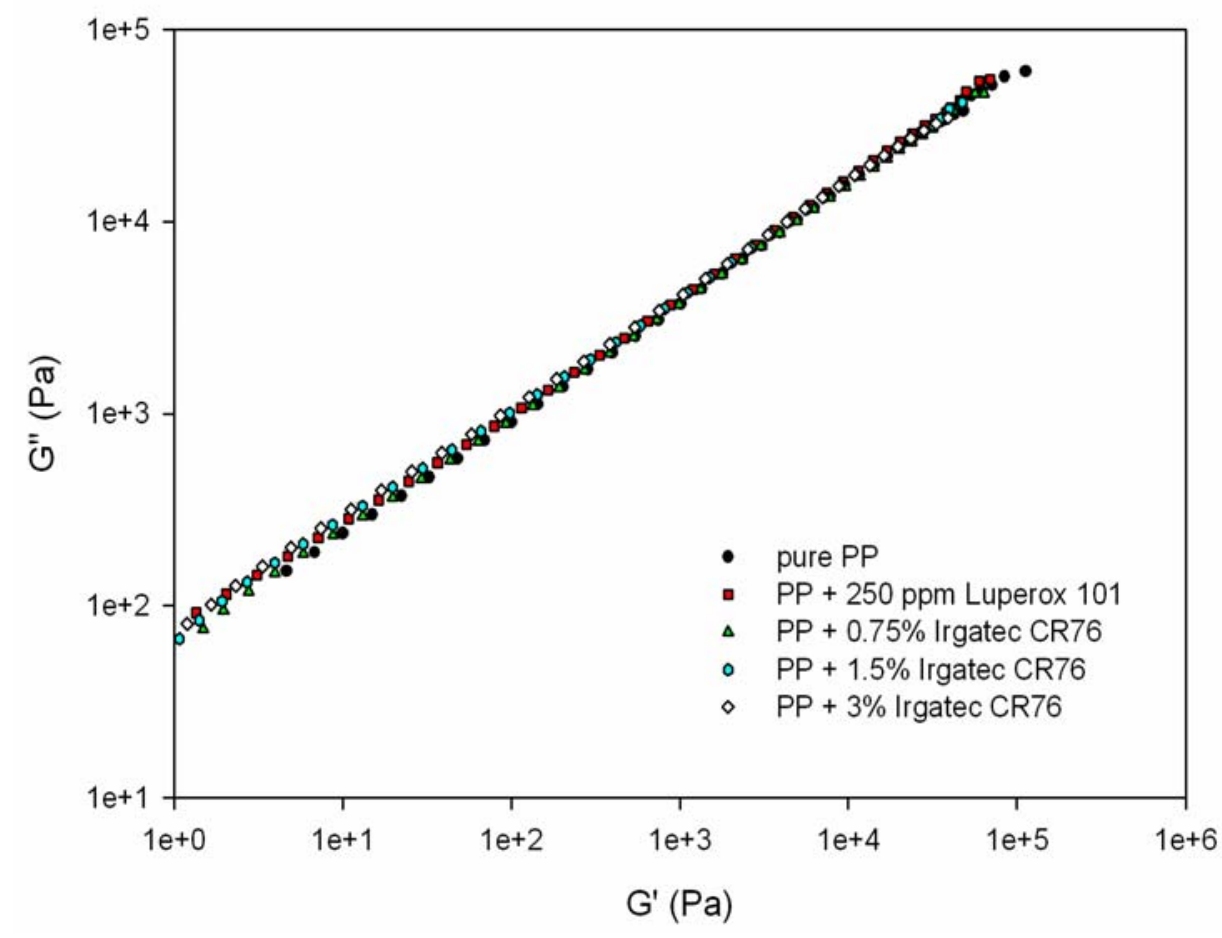

Figure 4.15: G" vs. $\mathrm{G}^{\prime}$ at $170{ }^{\circ} \mathrm{C}$ of CRPP produced in Haake Mixer at $270{ }^{\circ} \mathrm{C}$

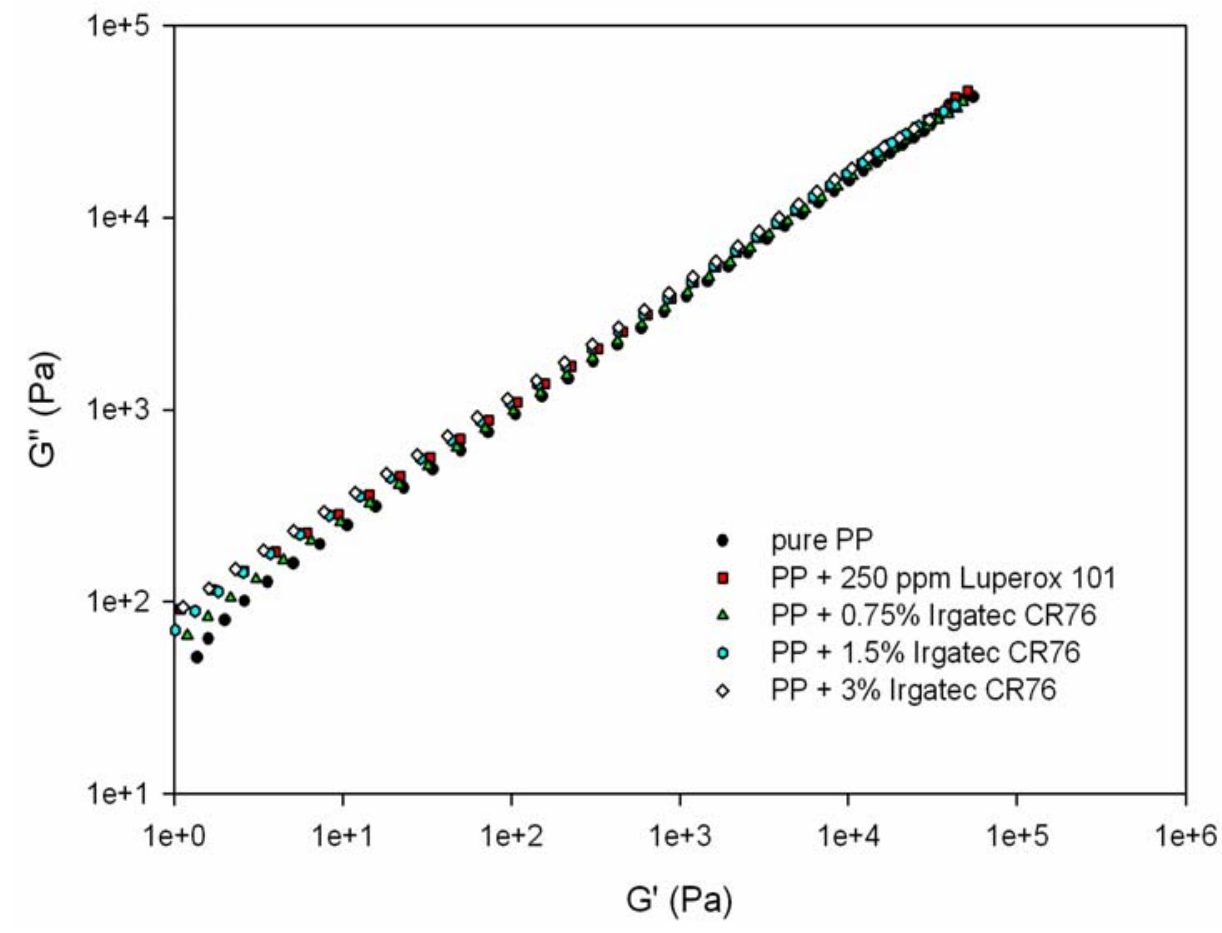

Figure 4.16: G" vs. G' at $170{ }^{\circ} \mathrm{C}$ of CRPP produced in Haake Mixer at $290{ }^{\circ} \mathrm{C}$ 


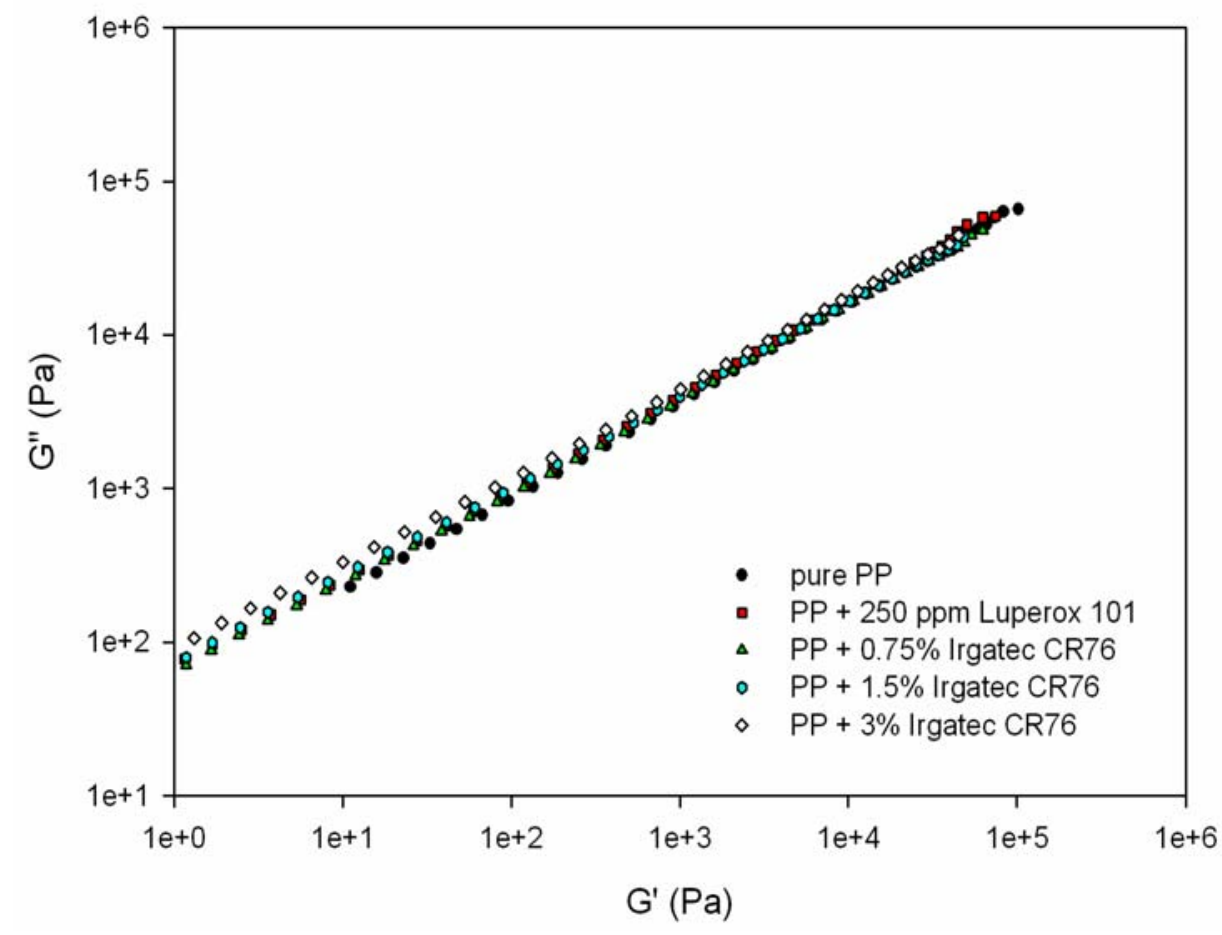

Figure 4.17: G" vs. $\mathrm{G}^{\prime}$ at $190{ }^{\circ} \mathrm{C}$ of CRPP produced in Haake Mixer at $230{ }^{\circ} \mathrm{C}$

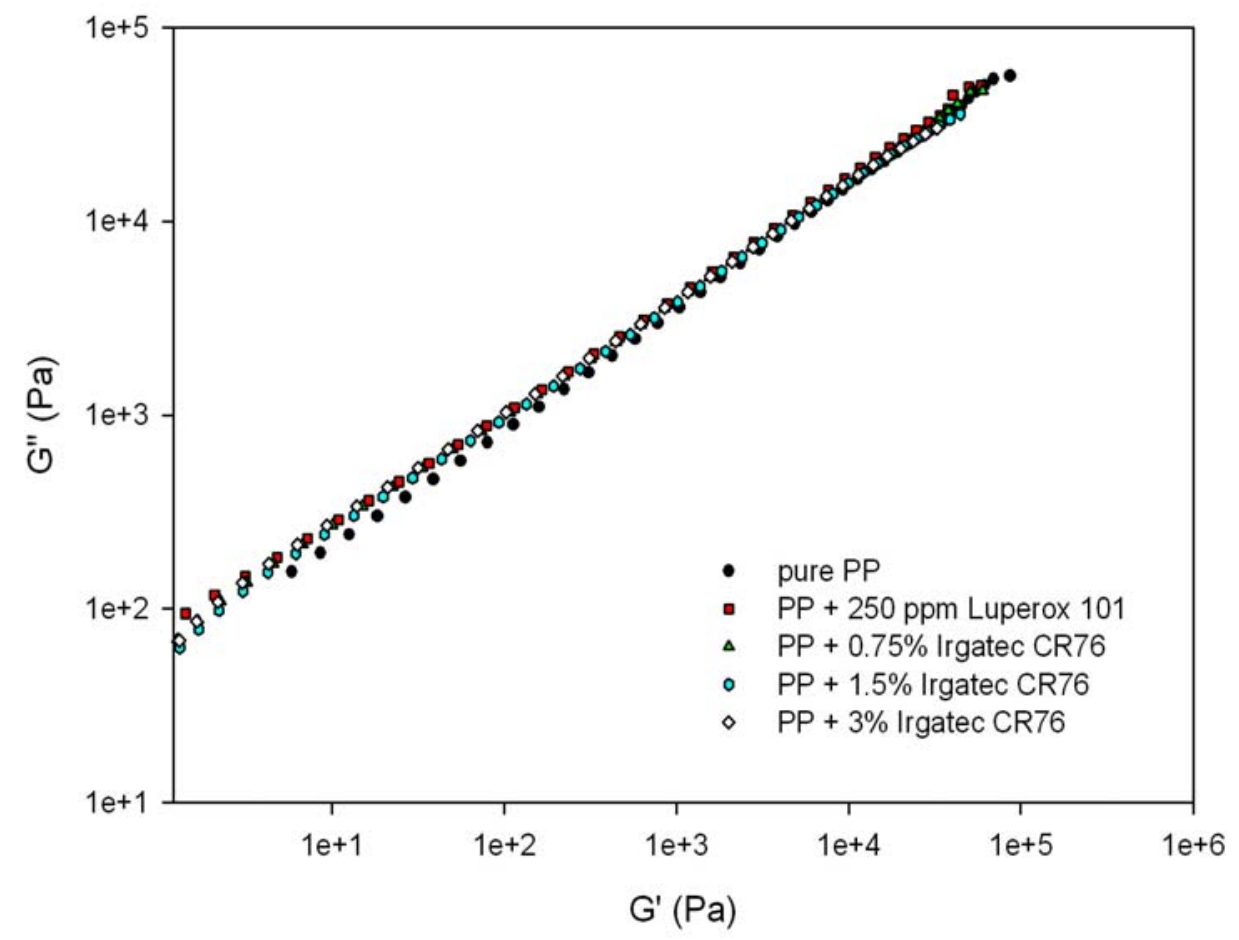

Figure 4.18: G" vs. G' at $190{ }^{\circ} \mathrm{C}$ of CRPP produced in Haake Mixer at $250{ }^{\circ} \mathrm{C}$ 


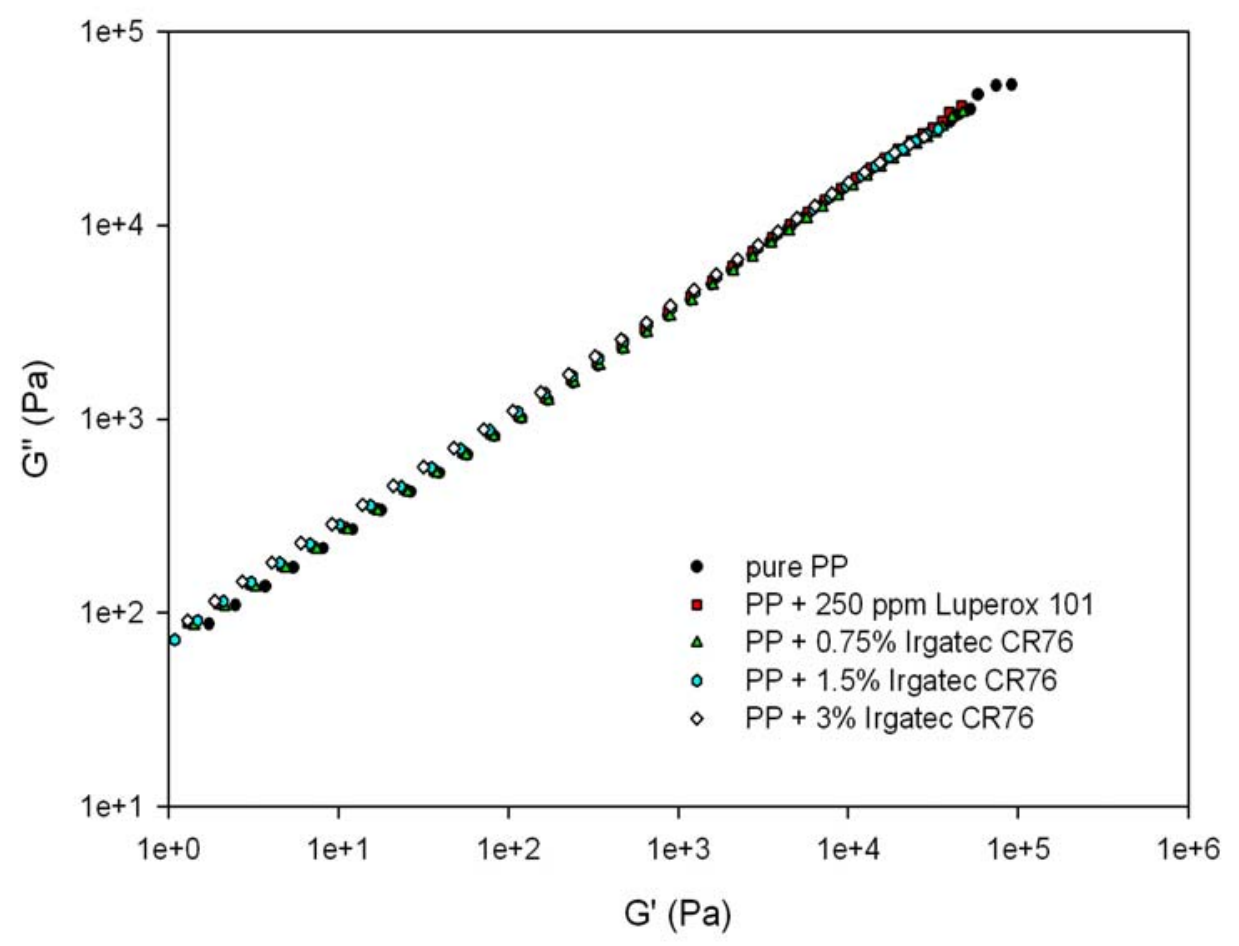

Figure 4.19: G" vs. $\mathrm{G}^{\prime}$ at $190{ }^{\circ} \mathrm{C}$ of CRPP produced in Haake Mixer at $270{ }^{\circ} \mathrm{C}$

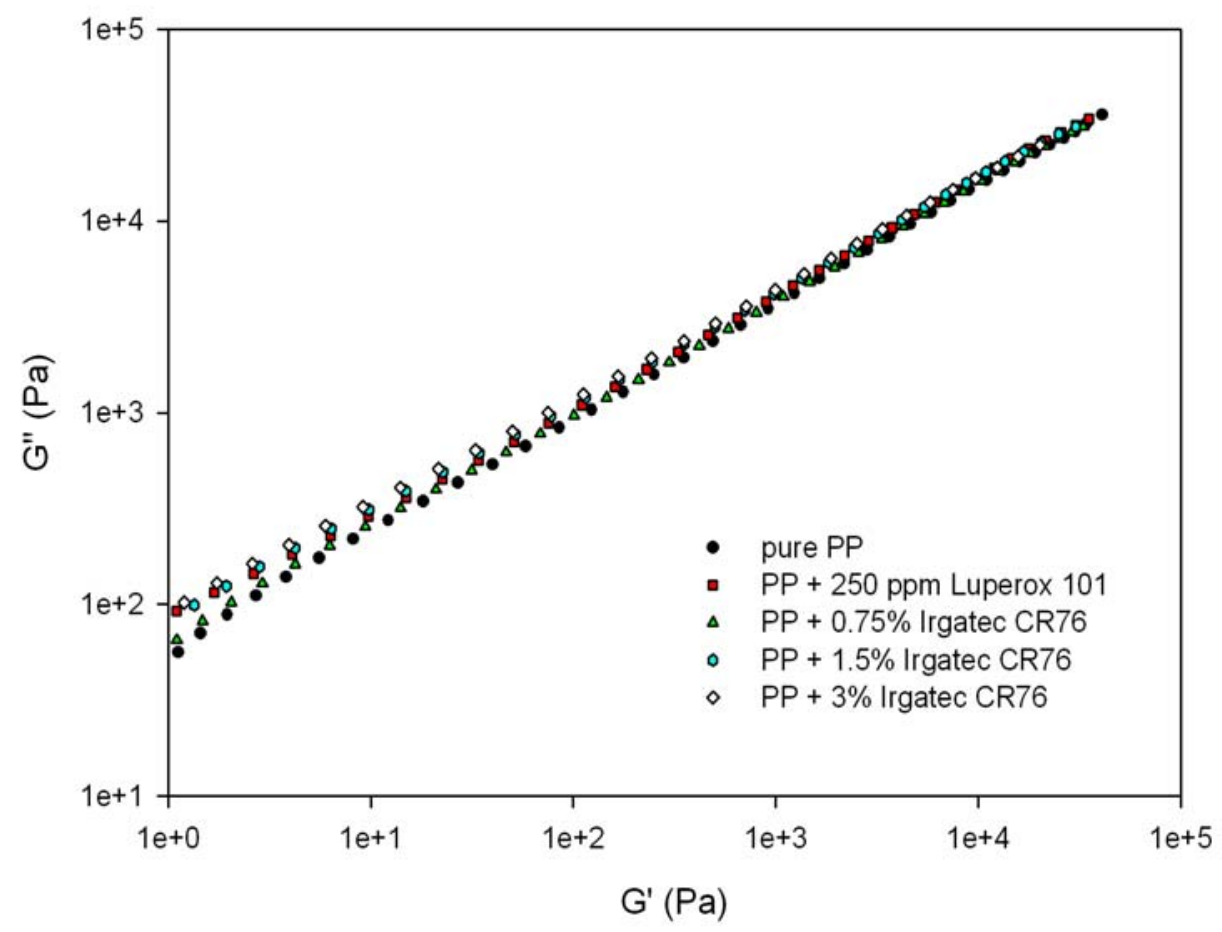

Figure 4.20: G" vs. G' at $190{ }^{\circ} \mathrm{C}$ of CRPP produced in Haake Mixer at $290{ }^{\circ} \mathrm{C}$ 


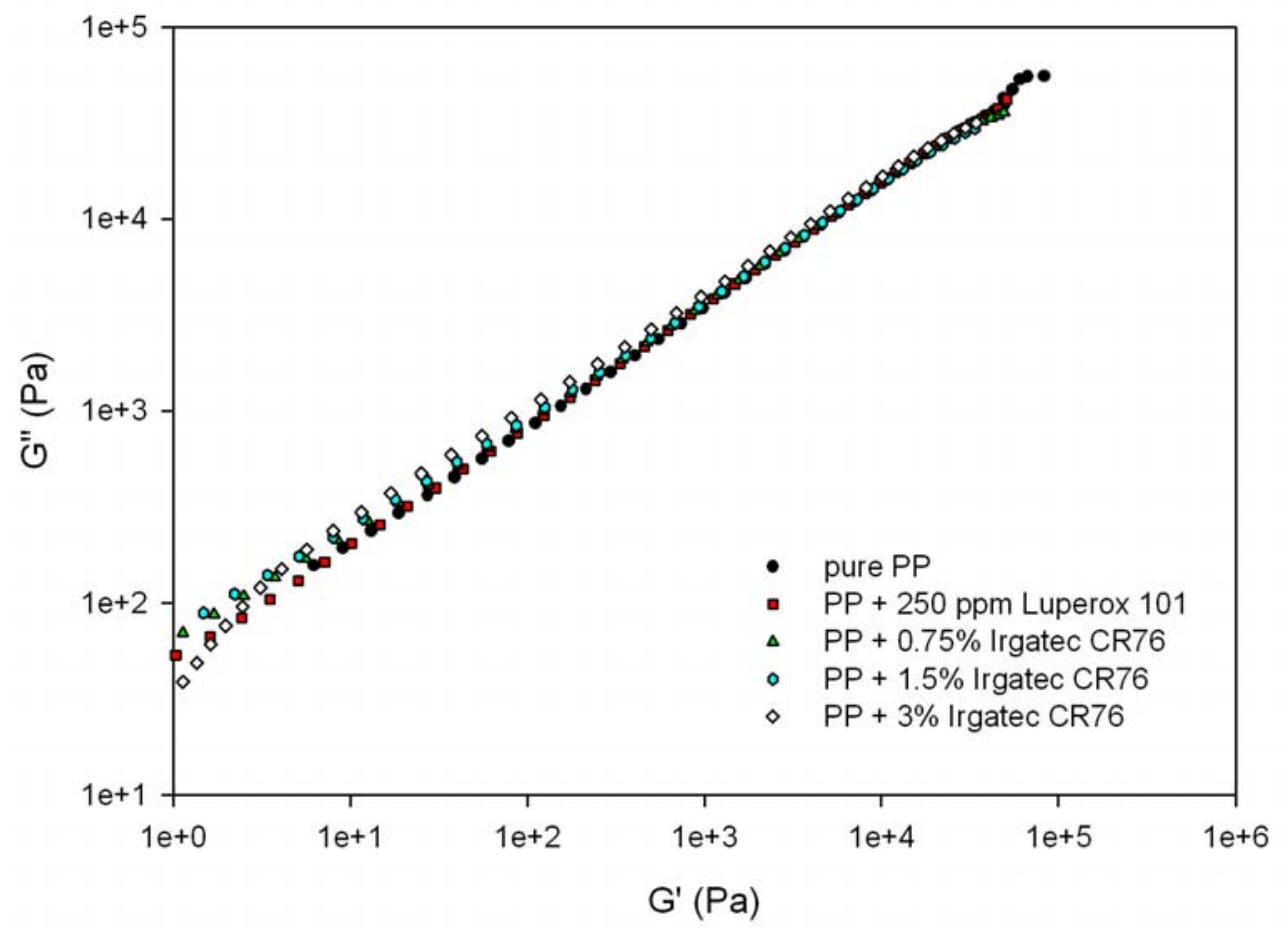

Figure 4.21: $\mathrm{G}^{\prime \prime}$ vs. $\mathrm{G}^{\prime}$ at $210^{\circ} \mathrm{C}$ of CRPP produced in Haake Mixer at $230{ }^{\circ} \mathrm{C}$

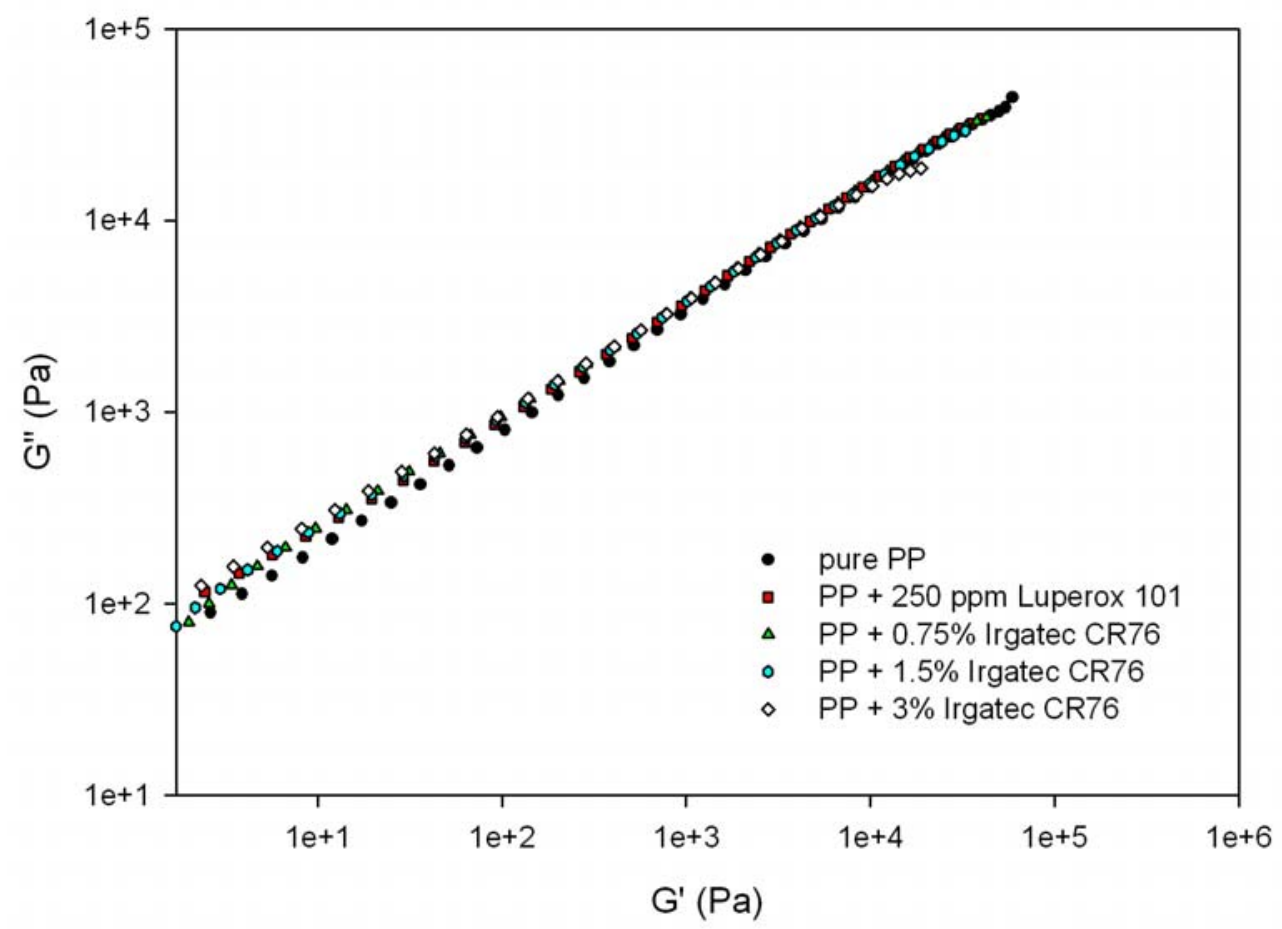

Figure 4.22: G" vs. $\mathrm{G}^{\prime}$ at $210^{\circ} \mathrm{C}$ of CRPP produced in Haake Mixer at $250{ }^{\circ} \mathrm{C}$ 


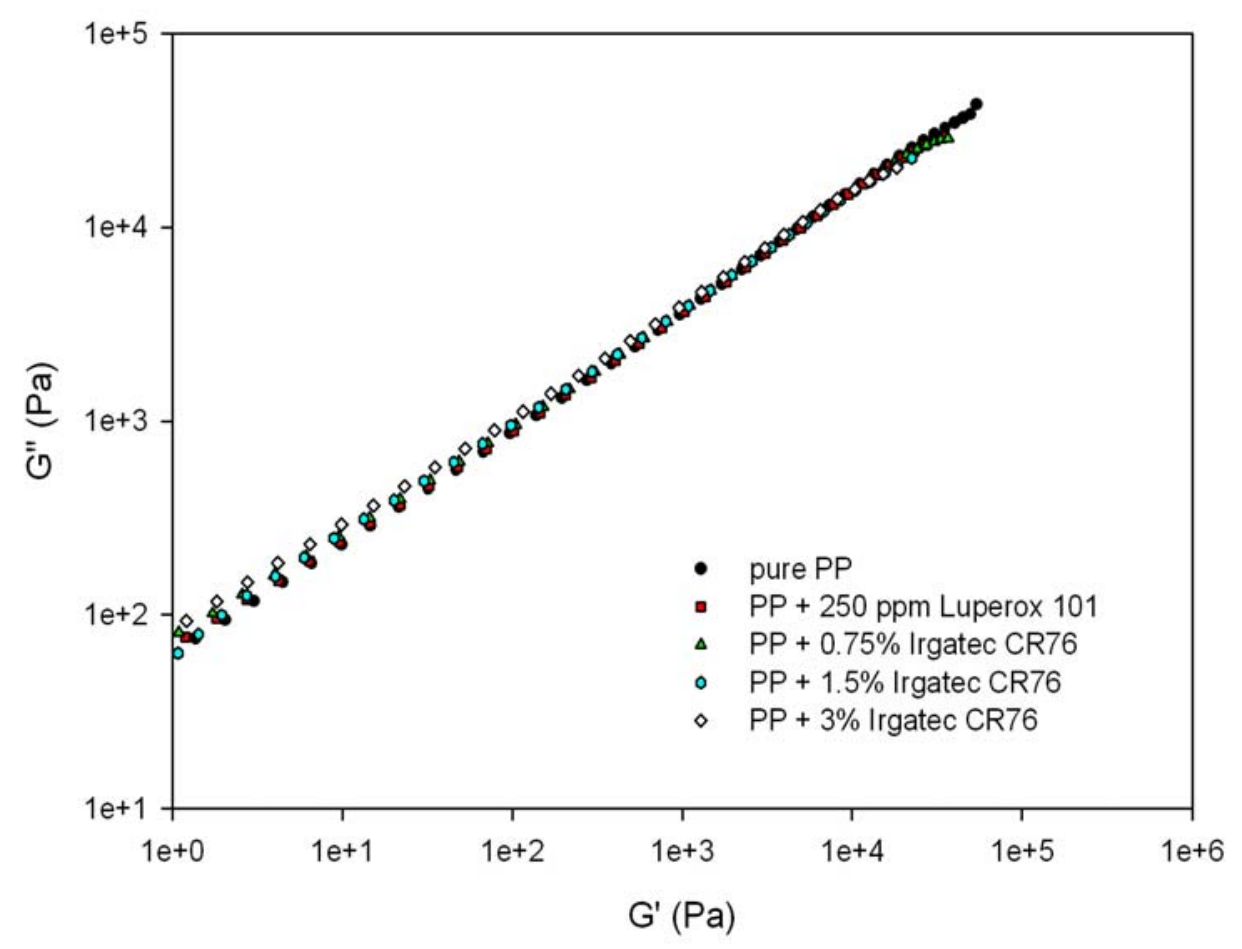

Figure 4.23: $\mathrm{G}^{\prime \prime}$ vs. $\mathrm{G}^{\prime}$ at $210^{\circ} \mathrm{C}$ of CRPP produced in Haake Mixer at $270{ }^{\circ} \mathrm{C}$

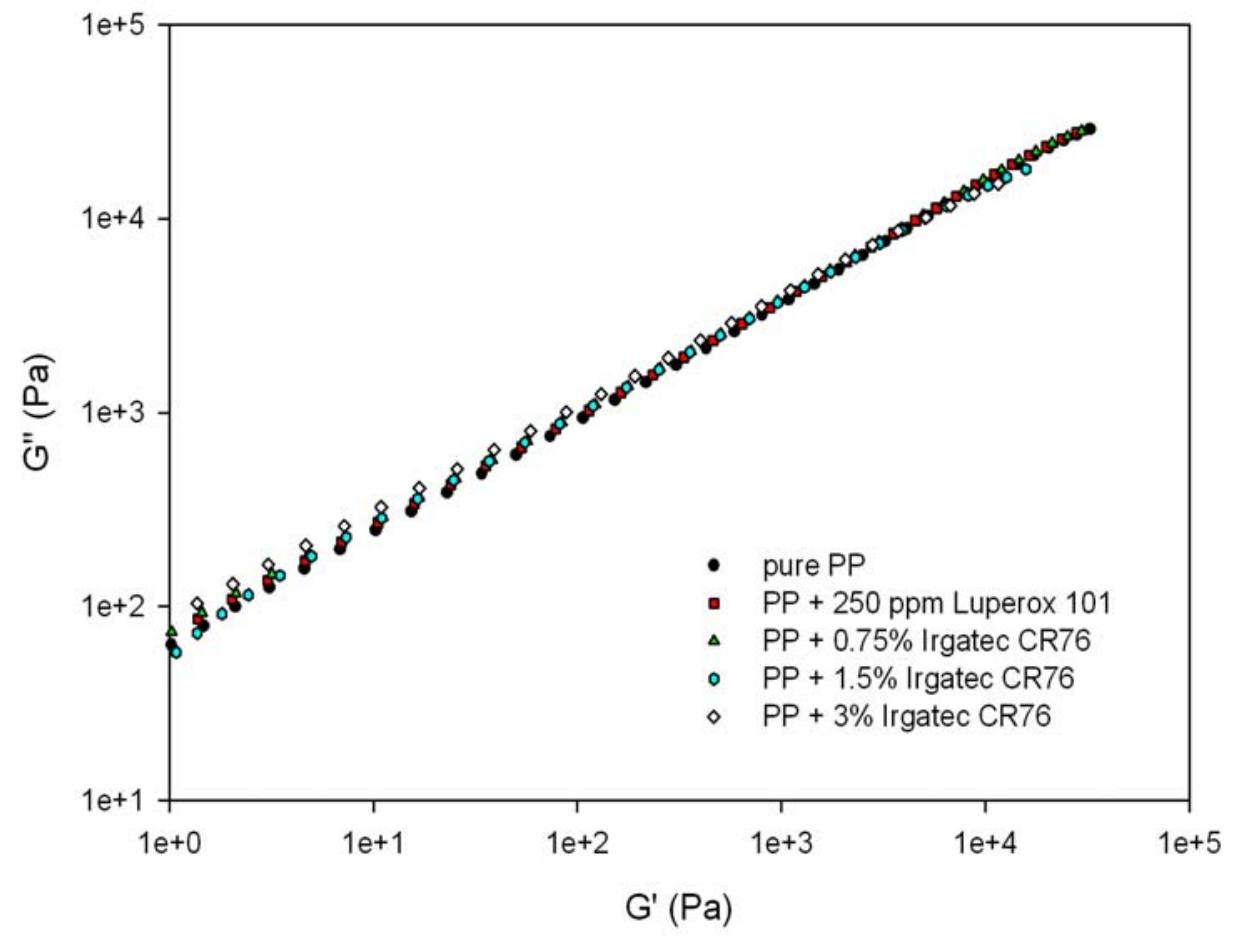

Figure 4.24: $\mathrm{G}^{\prime \prime}$ vs. $\mathrm{G}^{\prime}$ at $210^{\circ} \mathrm{C}$ of CRPP produced in Haake Mixer at $290{ }^{\circ} \mathrm{C}$ 
Figures 4.13 to 4.24 (plus the data given in Appendix III) exhibit relatively good measurements verifying the fact that the parallel plate rheometer measurements were successful. This was actually expected from the preliminary strain sweeps that exhibited a strong Linear Viscoelastic Region (LVR) that sometimes was extended for a percentage of strain up to $30 \%$. This verifies also that the samples were successfully prepared in the hot press, with no sign of air trapped inside. The linear correlation between $\mathrm{G}^{\prime \prime}$ and $\mathrm{G}^{\prime}$ shown in Figures 4.13 to 4.24 indicates that the produced CRPP are linear polymers with no evidence of Long Chain Branching (LCB).

One of the most important pieces of information that can be determinated from the frequency sweep plot is the zero shear viscosity. The zero shear viscosity can be found using the Cox - Merz rule (Cox and Merz (1958)), which states that the complex viscosity $\eta^{*}(\omega)$ is virtually identical to the shear viscosity $\eta(\dot{\gamma})$, with the angular frequency $\omega$ corresponding to shear rate $\dot{\gamma}$.

Using the Cox - Merz rule the zero shear viscosity can be determined in two ways:

- From the graph of $G^{\prime \prime} / \omega$ versus $\omega$, using the equation:

$$
\eta_{0}=\lim _{\omega \rightarrow 0}\left(\frac{G^{\prime \prime}}{\omega}\right)
$$

something that means that the $\eta_{0}$ is determined from $\mathrm{G}^{\prime \prime} / \omega$ values that correspond to $\omega$ values that are close to zero. If the frequency sweep ( $G^{\prime}$ and $G^{\prime \prime}$ versus $\left.\omega\right)$ is known, the construction of that graph is relatively easy.

- From the graph of complex viscosity $\eta^{*}(\omega)$ versus $\omega$ using a mathematical model. Using that model, the analytical solution for the zero shear viscosity is obtained through curve fitting of the experimental data. One well-known 5-parameter rheological model that can provide satisfactory results for the zero shear viscosity $\eta_{0}$ is the Carreau-Yasuda model:

$$
\frac{\eta-\eta_{\infty}}{\eta_{0}-\eta_{\infty}}=\left[1+(\lambda \dot{\gamma})^{\alpha}\right]^{\frac{\mathrm{n}-1}{\alpha}}
$$

where $\eta_{\infty}$ is the infinite viscosity, $\lambda$ is the relaxation time of the material, $n$ is the 
power law index and a is a constant for the simulation. Usually the infinite viscosity is considered zero, and equation (4.5) is modified to:

$$
\eta=\eta_{0}\left[1+(\lambda \dot{\gamma})^{\alpha}\right]^{\frac{\mathrm{n}-1}{\alpha}}
$$

which represents a 4-parameter Carreau-Yasuda expression.

By replacing $\eta$ and $\dot{\gamma}$ with $\eta^{*}$ and $\omega$ respectively, according to the Cox - Merz rule:

$$
\eta^{*}=\eta_{0}\left[1+(\lambda \omega)^{\alpha}\right]^{\frac{\mathrm{n}-1}{\alpha}}
$$

The values of $\eta^{*}$ and $\omega$ are defined from the experimental data.

The determination of the zero shear viscosity for each CRPP resin using these two methods is described in the following sections.

\subsubsection{Zero shear viscosity directly from experimental data}

Using the frequency sweep charts (see Appendix III), the G"/ $\omega$ vs. $\omega$ charts were constructed. These charts are illustrated in Figures 4.25 to 4.40. In the first group (Figures 4.25 to 4.28 ), the results for frequency sweep that were recorded at $170{ }^{\circ} \mathrm{C}$ are given. The second group (Figures 4.29 to 4.32 ) presents the results from frequency sweeps that were recorded at $190{ }^{\circ} \mathrm{C}$. The results from frequency sweeps that were recorded at $210{ }^{\circ} \mathrm{C}$ are shown in the third group (Figures 4.33 to 4.36). Finally, the fourth group (Figures 4.37 to 4.40), presents the experimental data as a result of the Time - Temperature Superimposition (TTS) considering the above-mentioned three temperatures, by using the $190{ }^{\circ} \mathrm{C}$ curve as reference. All the results are classified in the same plot according to the nominal temperature at which the CRPP were produced in the Haake mixer. The data of CRPP that contain the same chemical compound are connected with a line. As was mentioned in section 3.2.4.1, in the TTS superimposition charts, a factor $\mathrm{a}_{\mathrm{T}}$ is used. This factor represents the horizontal shift of each curve from the reference curve. 


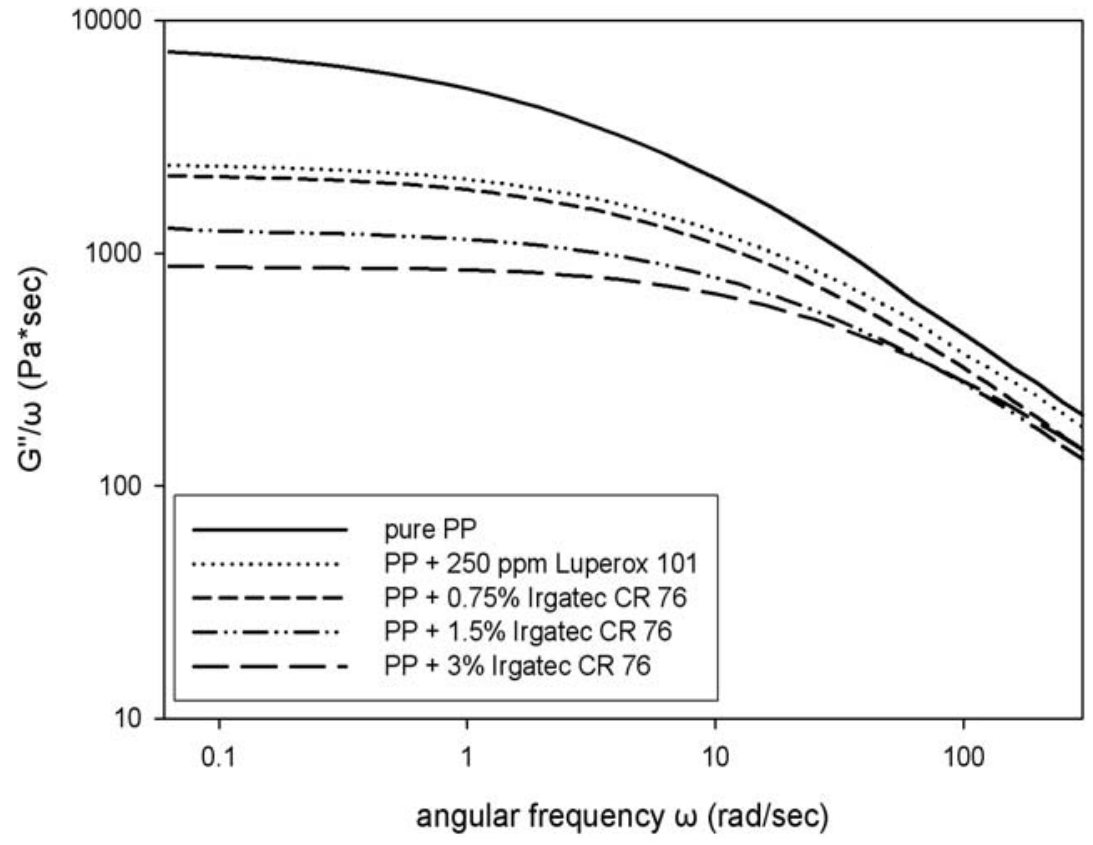

Figure 4.25: G" $/ \omega$ vs. $\omega$ at $170{ }^{\circ} \mathrm{C}$ of CRPP produced in Haake Mixer at $230{ }^{\circ} \mathrm{C}$

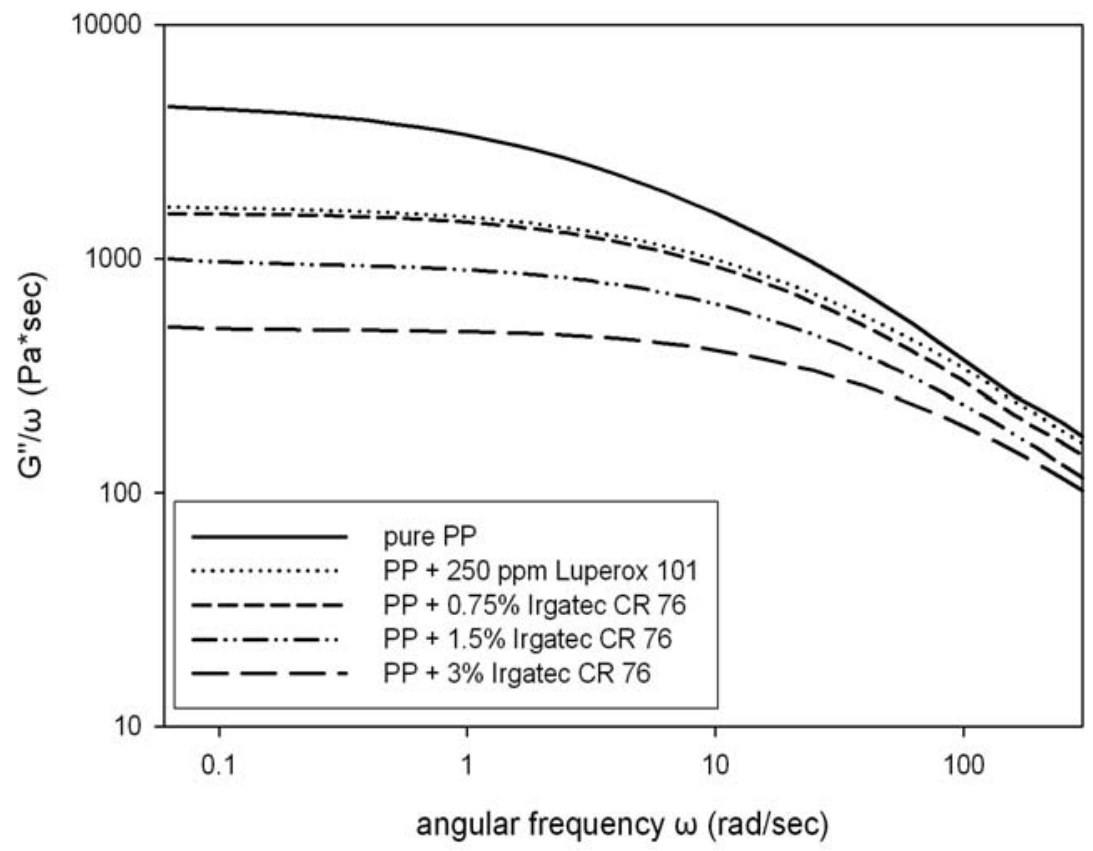

Figure 4.26: G" $/ \omega$ vs. $\omega$ at $170{ }^{\circ} \mathrm{C}$ of CRPP produced in Haake Mixer at $250{ }^{\circ} \mathrm{C}$ 


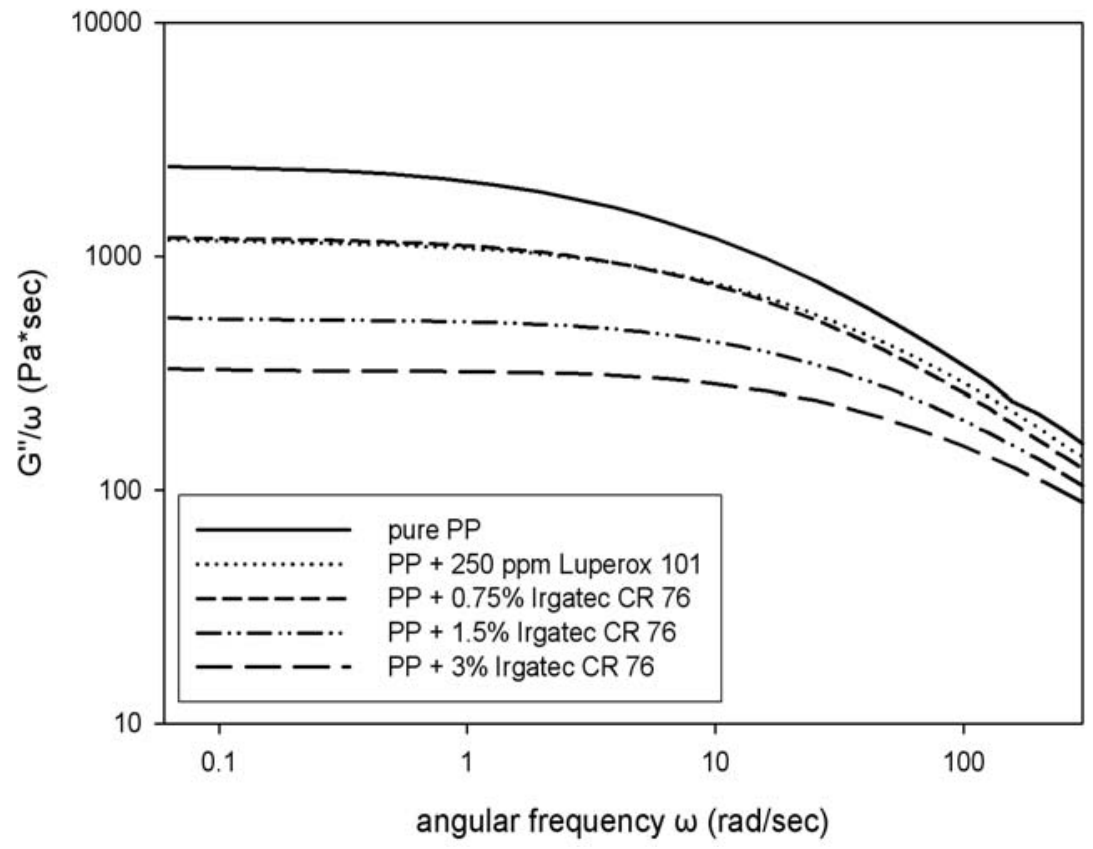

Figure 4.27: G" $/ \omega$ vs. $\omega$ at $170{ }^{\circ} \mathrm{C}$ of CRPP produced in Haake Mixer at $270{ }^{\circ} \mathrm{C}$

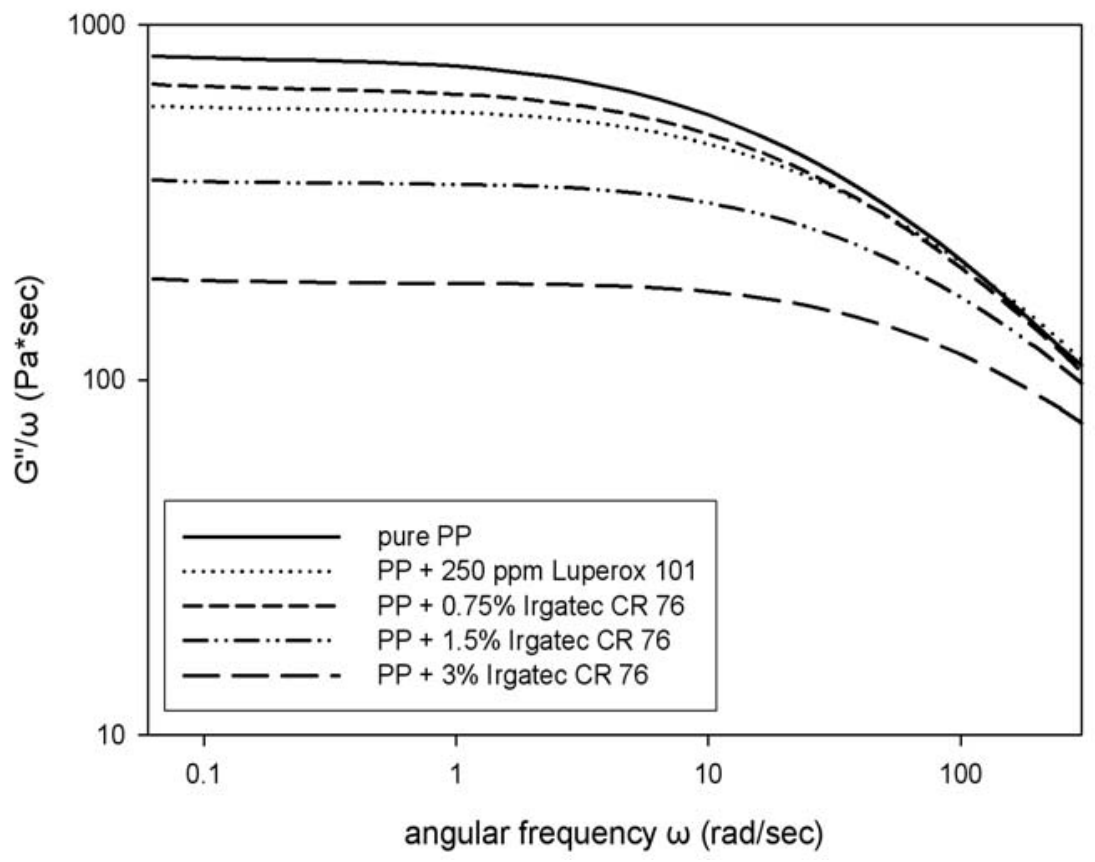

Figure 4.28: G"/ $\omega$ vs. $\omega$ at $170{ }^{\circ} \mathrm{C}$ of CRPP produced in Haake Mixer at $290{ }^{\circ} \mathrm{C}$ 


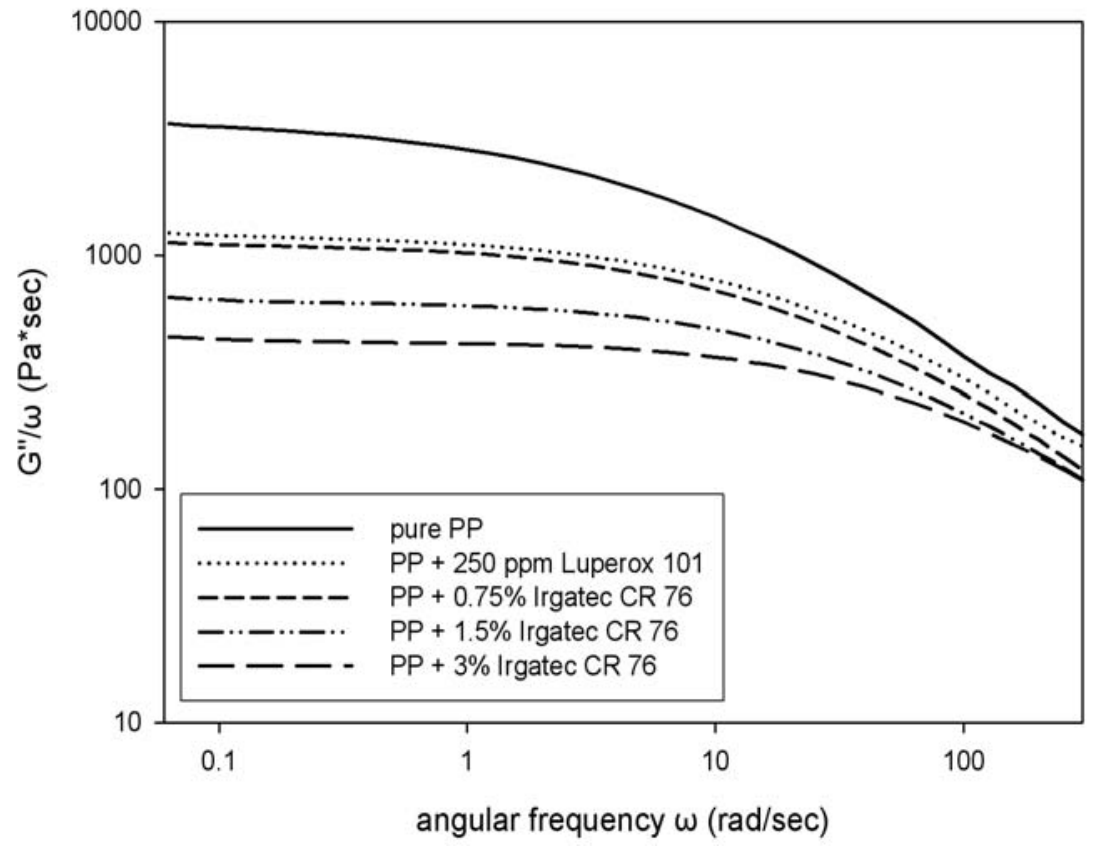

Figure 4.29: $\mathrm{G}^{\prime \prime} / \omega$ vs. $\omega$ at $190{ }^{\circ} \mathrm{C}$ of CRPP produced in Haake Mixer at $230{ }^{\circ} \mathrm{C}$

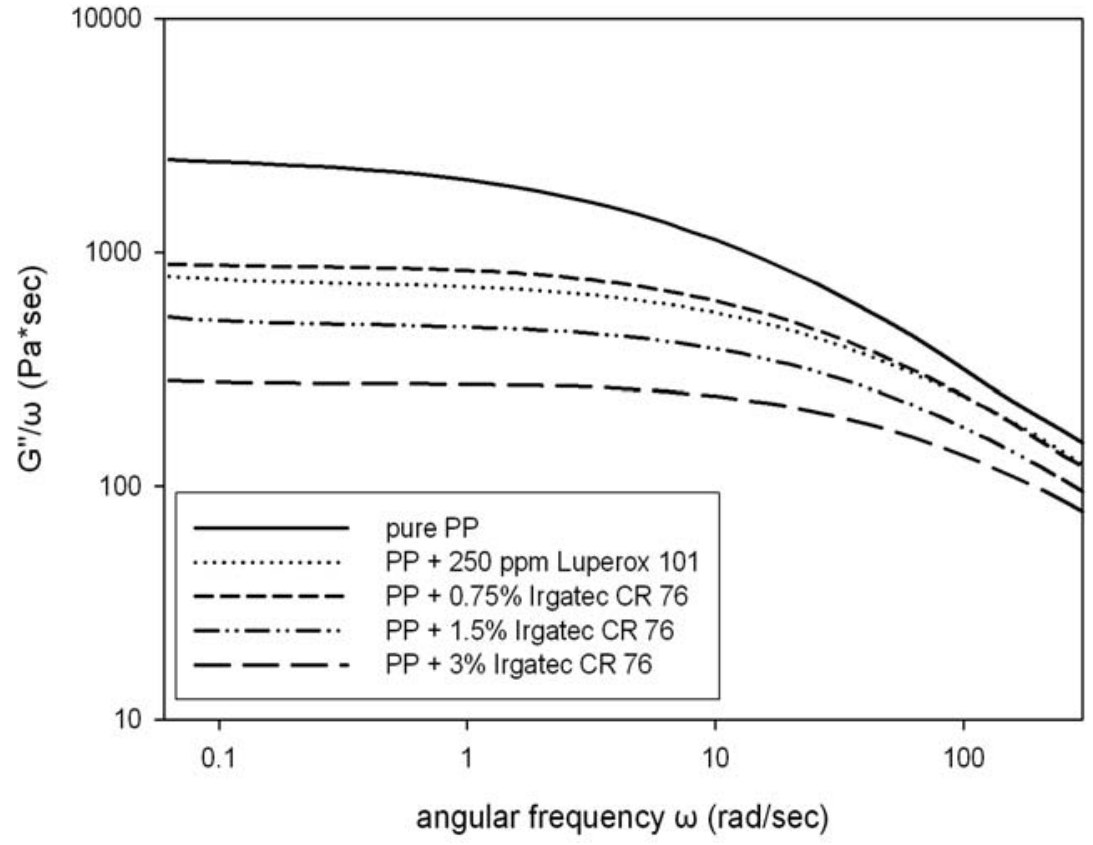

Figure 4.30: G" $/ \omega$ vs. $\omega$ at $190{ }^{\circ} \mathrm{C}$ of CRPP produced in Haake Mixer at $250{ }^{\circ} \mathrm{C}$ 


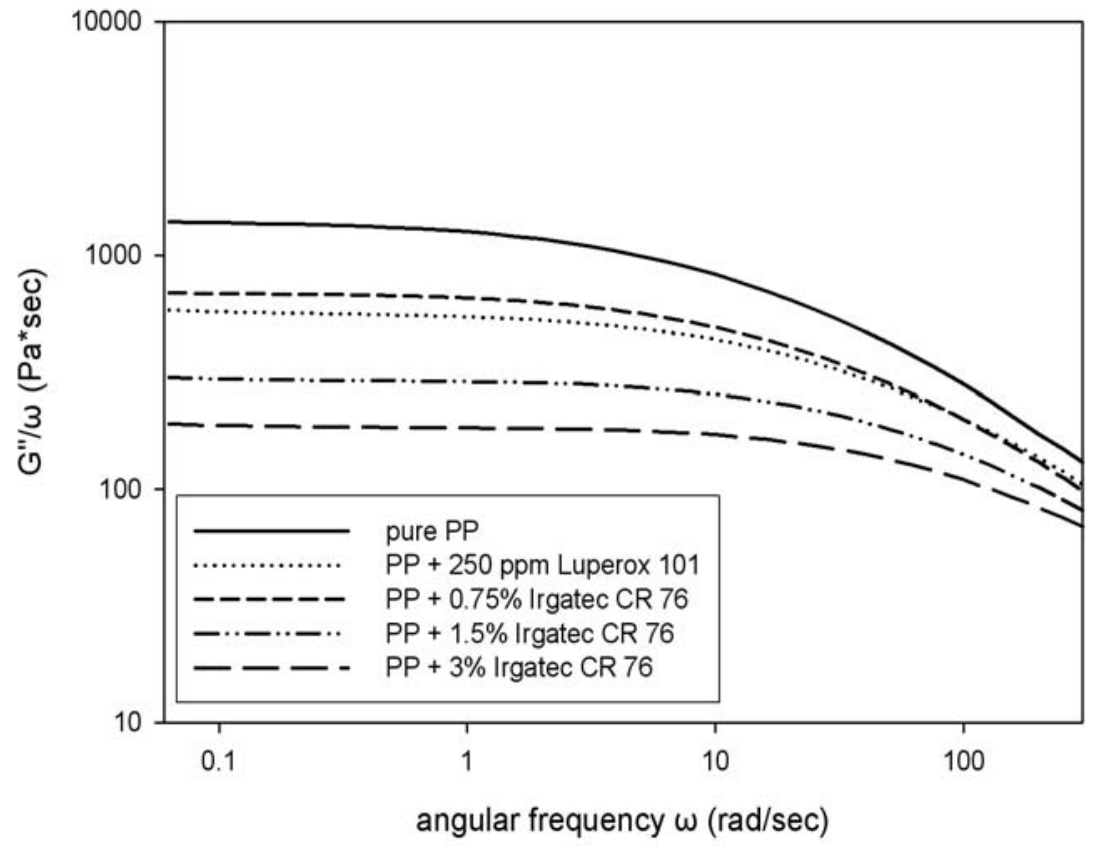

Figure 4.31: G"/ $\omega$ vs. $\omega$ at $190{ }^{\circ} \mathrm{C}$ of CRPP produced in Haake Mixer at $270{ }^{\circ} \mathrm{C}$

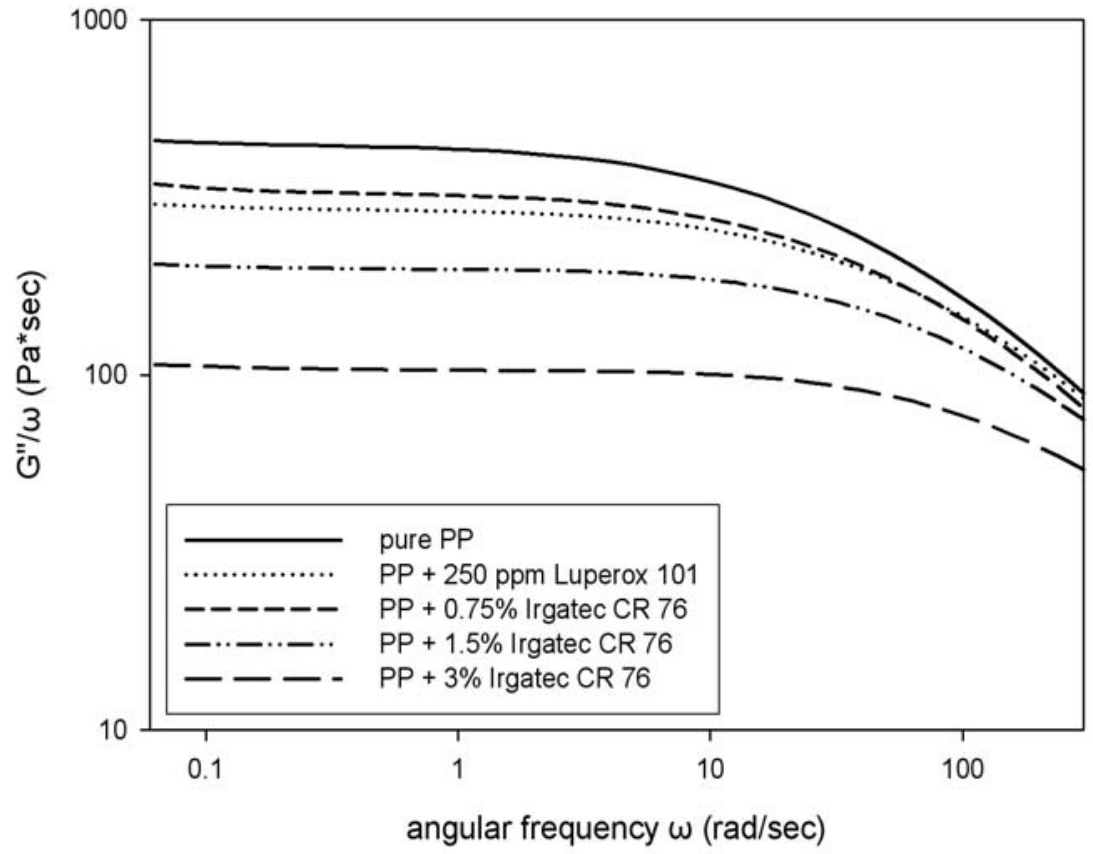

Figure 4.32: G"/ $\omega$ vs. $\omega$ at $190{ }^{\circ} \mathrm{C}$ of CRPP produced in Haake Mixer at $290{ }^{\circ} \mathrm{C}$ 


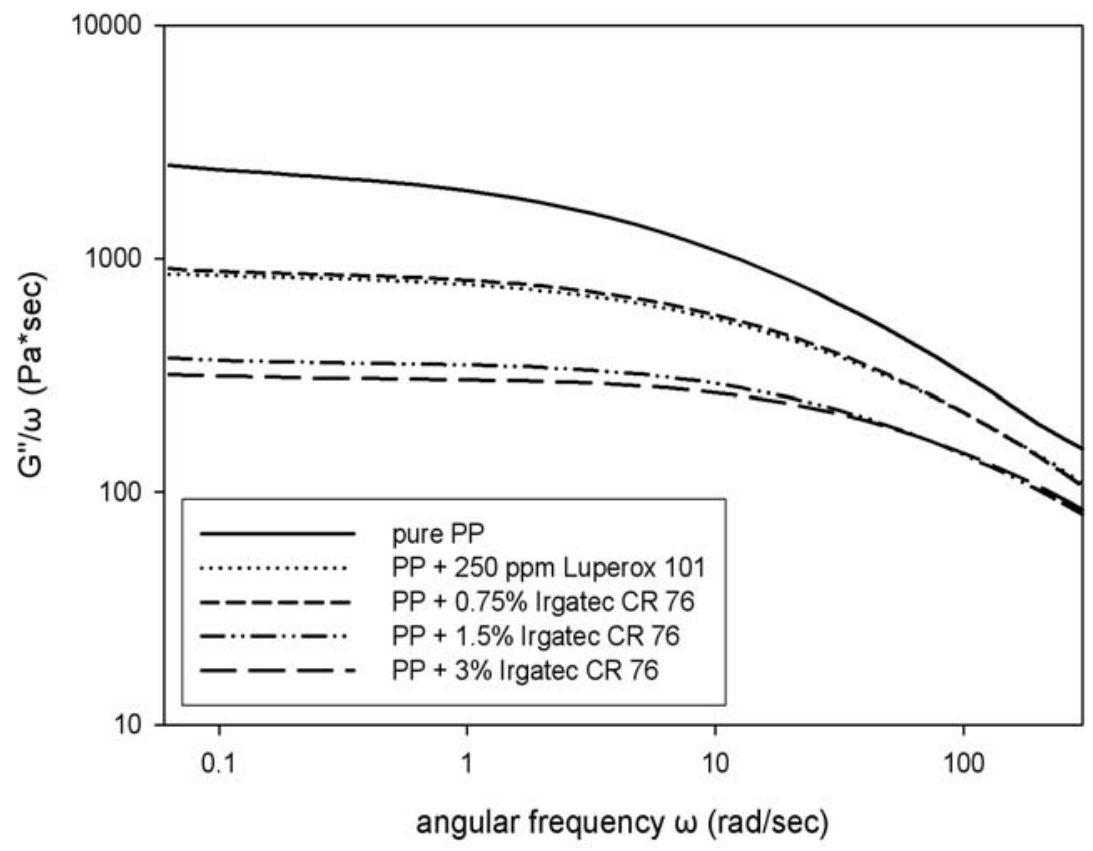

Figure 4.33: $\mathrm{G}^{\prime \prime} / \omega$ vs. $\omega$ at $210{ }^{\circ} \mathrm{C}$ of CRPP produced in Haake Mixer at $230{ }^{\circ} \mathrm{C}$

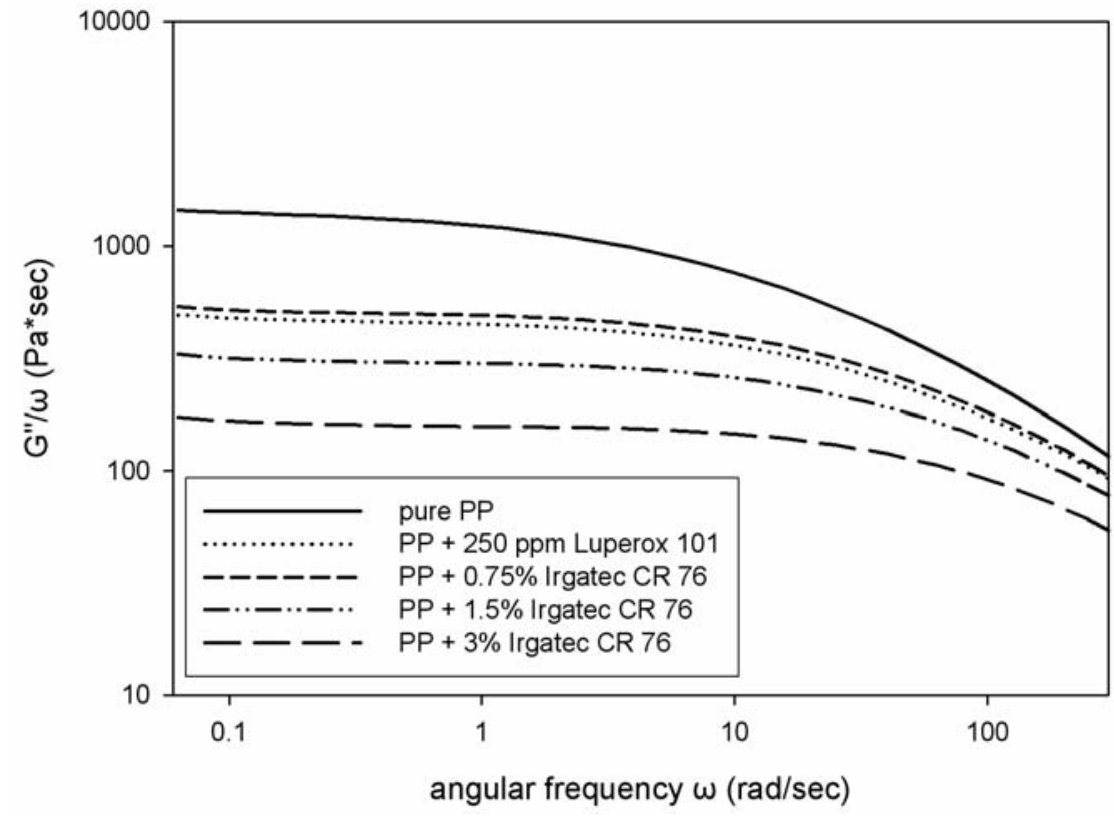

Figure 4.34: $\mathrm{G}^{\prime \prime} / \omega$ vs. $\omega$ at $210{ }^{\circ} \mathrm{C}$ of CRPP produced in Haake Mixer at $250{ }^{\circ} \mathrm{C}$ 


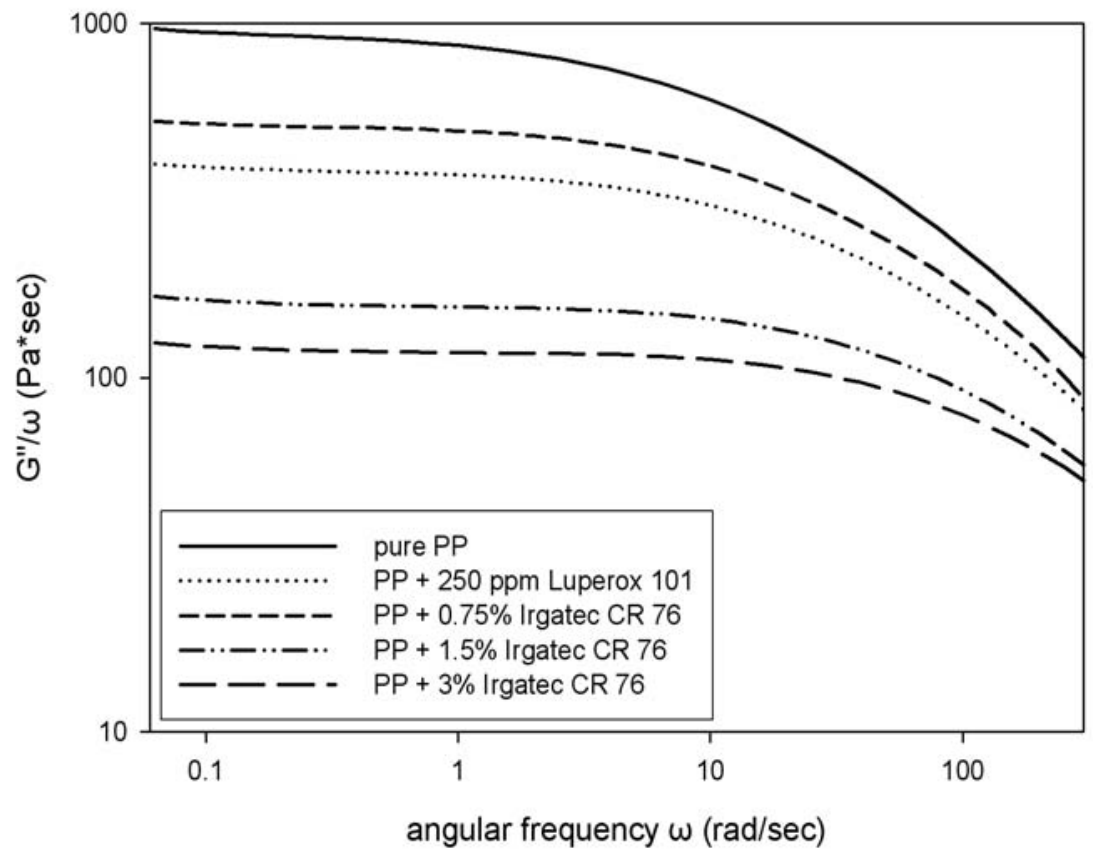

Figure 4.35: $\mathrm{G}^{\prime \prime} / \omega$ vs. $\omega$ at $210^{\circ} \mathrm{C}$ of CRPP produced in Haake Mixer at $270{ }^{\circ} \mathrm{C}$

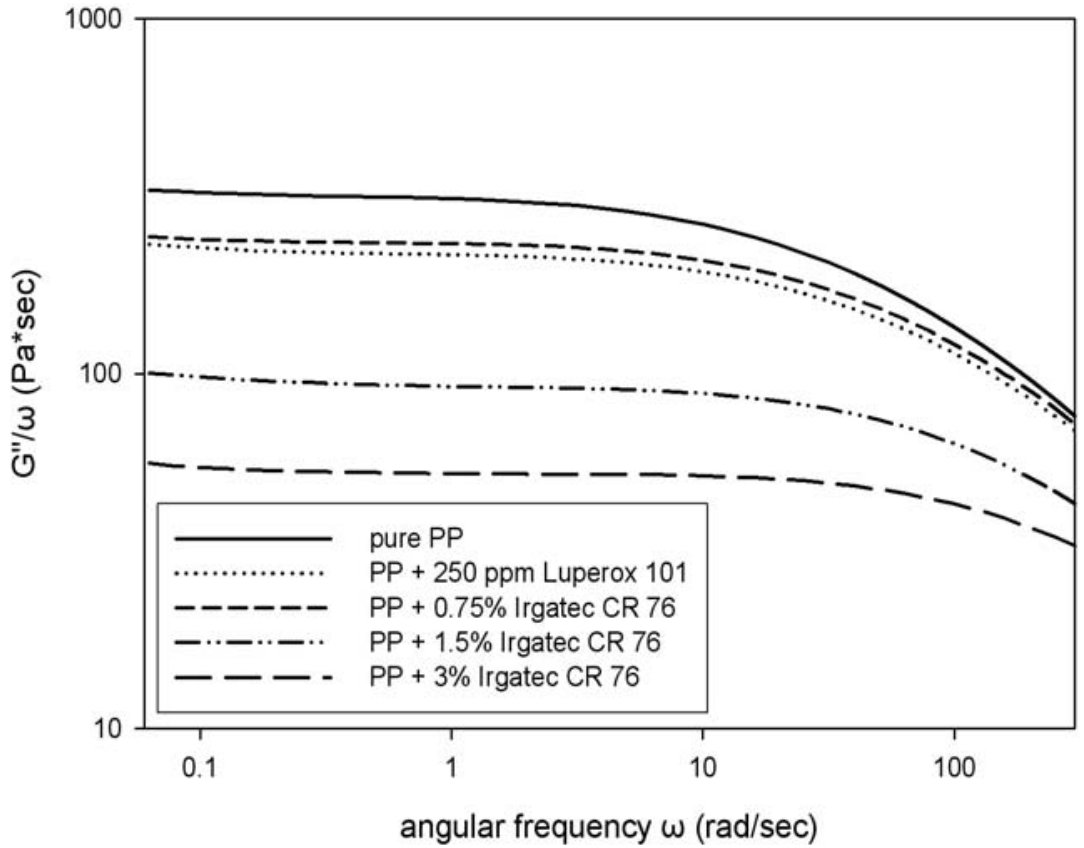

Figure 4.36: G"/ $\omega$ vs. $\omega$ at $210{ }^{\circ} \mathrm{C}$ of CRPP produced in Haake Mixer at $290{ }^{\circ} \mathrm{C}$ 


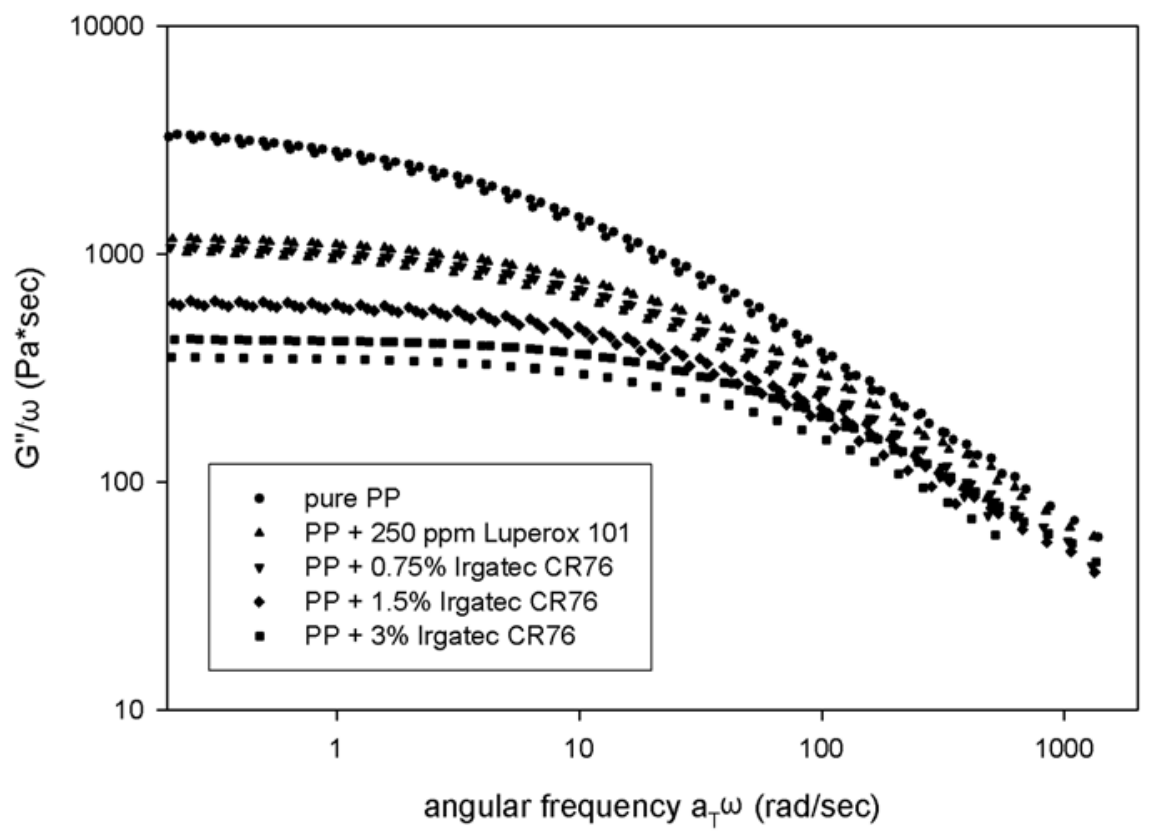

Figure 4.37: Superimposition of the results at 170,190 and $210^{\circ} \mathrm{C}$ (with $190{ }^{\circ} \mathrm{C}$ reference temperature) for CRPP produced in Haake Mixer at $230{ }^{\circ} \mathrm{C}$

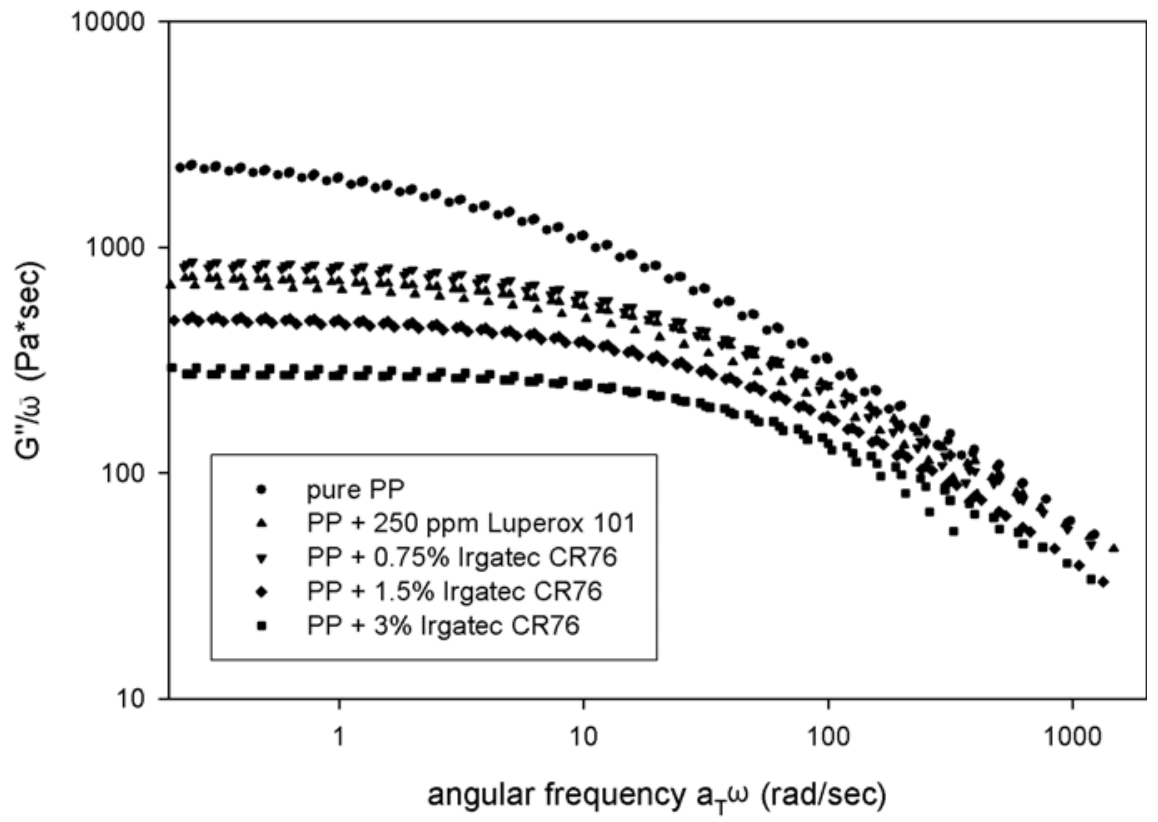

Figure 4.38: Superimposition of the results at 170,190 and $210^{\circ} \mathrm{C}$ (with $190{ }^{\circ} \mathrm{C}$ reference temperature) for CRPP produced in Haake Mixer at $250{ }^{\circ} \mathrm{C}$ 


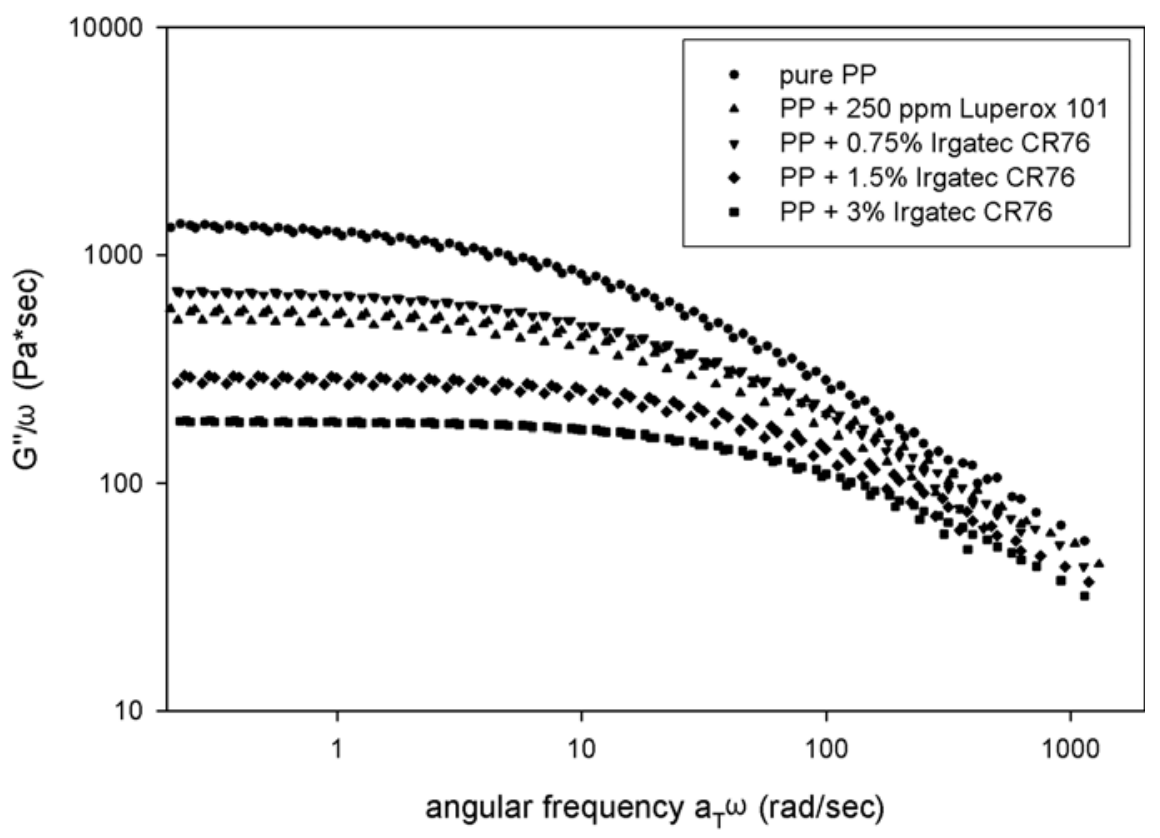

Figure 4.39: Superimposition of the results at 170,190 and $210{ }^{\circ} \mathrm{C}$ (with $190{ }^{\circ} \mathrm{C}$ reference temperature) for CRPP produced in Haake Mixer at $270{ }^{\circ} \mathrm{C}$

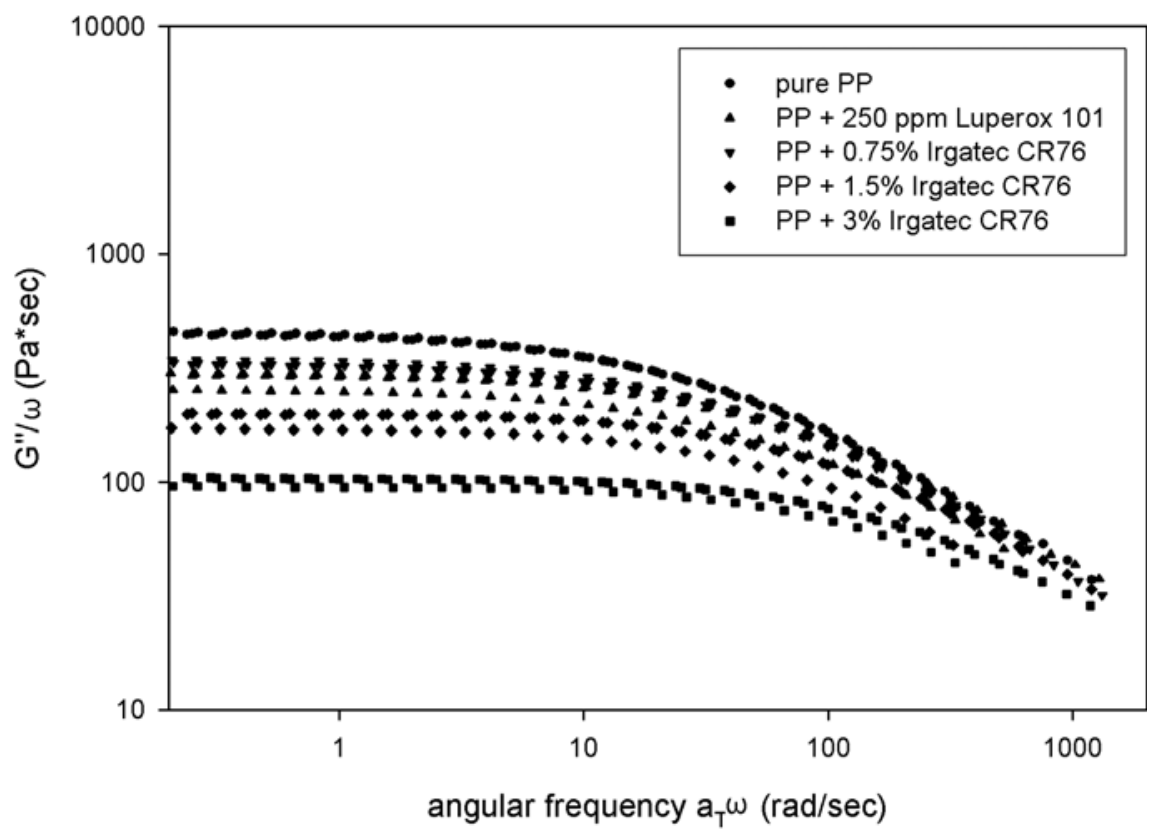

Figure 4.40: Superimposition of the results at 170,190 and $210^{\circ} \mathrm{C}$ (with $190{ }^{\circ} \mathrm{C}$ reference temperature) for CRPP produced in Haake Mixer at $290{ }^{\circ} \mathrm{C}$ 
In order to determine the zero shear viscosity, equation (4.4) was used. That means the values of $G^{\prime \prime} / \omega$ determine $\eta_{0}$ when $\omega$ approaches zero. Figures 4.25 to 4.40 can give an excellent idea of the value that zero shear viscosity approaches, but in addition to the visual inspection a numerical value can be obtained. For every CRPP sample and for every temperature $\left(170,190\right.$ and $\left.210{ }^{\circ} \mathrm{C}\right)$ the numerical value that represents the zero shear viscosity was determined from the numerical average of the 5 points of $\mathrm{G}^{\prime \prime} / \omega$ that correspond to the 5 points of $\omega$ closest to zero. Using this method, data presented in Tables 4.1, 4.2 and 4.3 were obtained from the charts of group A (Figures. 4.25 to 4.28), B (Figures. 4.29 to 4.32) and C (Figures. 4.33 to 4.36), which represent parallel plate experiments at 170,190 and $210{ }^{0} \mathrm{C}$, respectively. Using the values in Tables 4.1, 4.2 and 4.3, the determined zero shear viscosity of each CRPP sample was plotted vs. the production temperature of that sample (Figures 4.41, 4.42 and 4.43 , respectively).

Table 4.1: Zero shear viscosity (in Pa.sec) determined from G"/ $\omega$ vs. $\omega$ graphs at $170{ }^{0} \mathrm{C}$

\begin{tabular}{|c|c|c|c|c|}
\hline & $230{ }^{0} \mathrm{C}$ & $250{ }^{0} \mathrm{C}$ & $270{ }^{0} \mathrm{C}$ & $290{ }^{0} \mathrm{C}$ \\
\hline Pure PP & 7078.7105 & 4343.9407 & 2390.3068 & 808.02156 \\
\hline 250 ppm peroxide & 2356.3478 & 1640.2478 & 1156.4314 & 585.29173 \\
\hline 250 ppm NOR & 2125.5948 & 1545.728 & 1187.5474 & 671.26707 \\
\hline 500 ppm NOR & 1248.0648 & 969.4716 & 536.9761 & 362.04132 \\
\hline 1000 ppm NOR & 871.91968 & 501.26347 & 325.17538 & 190.62395 \\
\hline
\end{tabular}

Table 4.2: Zero shear viscosity (in Pa.sec) determined from G"/ $\omega$ vs. $\omega$ graphs at $190{ }^{\circ} \mathrm{C}$

\begin{tabular}{|c|c|c|c|c|}
\hline & $230{ }^{\circ} \mathrm{C}$ & $250{ }^{\circ} \mathrm{C}$ & $270{ }^{0} \mathrm{C}$ & $290{ }^{0} \mathrm{C}$ \\
\hline Pure PP & 3534.3626 & 2429.0162 & 1375.0589 & 451.18209 \\
\hline 250 ppm peroxide & 1213.9582 & 764.59667 & 572.3703 & 298.59644 \\
\hline 250 ppm NOR & 1107.8367 & 876.07954 & 683.42124 & 336.84547 \\
\hline $500 \mathrm{ppm}$ NOR & 642.82714 & 510.402 & 294.78136 & 202.61663 \\
\hline $1000 \mathrm{ppm}$ NOR & 436.31532 & 277.60363 & 187.92567 & 105.78028 \\
\hline
\end{tabular}


Table 4.3: Zero shear viscosity (in Pa.sec) determined from G"/ $\omega$ vs. $\omega$ graphs at $210^{\circ} \mathrm{C}$

\begin{tabular}{|c|c|c|c|c|}
\hline & $230{ }^{\circ} \mathrm{C}$ & $250{ }^{\circ} \mathrm{C}$ & $270{ }^{\circ} \mathrm{C}$ & $290{ }^{\circ} \mathrm{C}$ \\
\hline Pure PP & 2406.4591 & 1408.6477 & 947.61725 & 324.08731 \\
\hline 250 ppm peroxide & 841.98547 & 477.59549 & 393.92274 & 226.70557 \\
\hline $250 \mathrm{ppm}$ NOR & 879.99307 & 518.92002 & 521.12767 & 239.22125 \\
\hline $500 \mathrm{ppm}$ NOR & 366.13967 & 317.15281 & 165.77207 & 98.0197 \\
\hline $1000 \mathrm{ppm}$ NOR & 313.03453 & 167.09263 & 122.52207 & 54.55012 \\
\hline
\end{tabular}

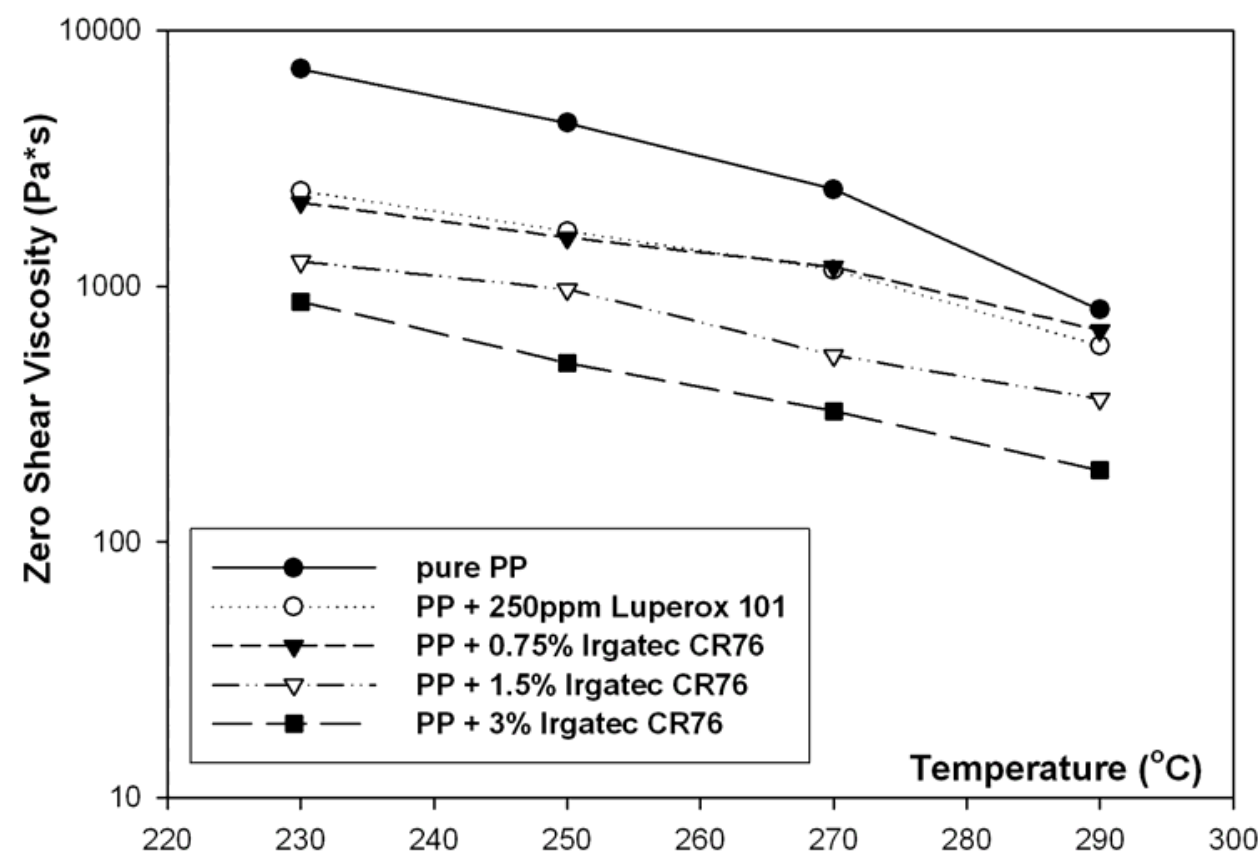

Figure 4.41: Zero shear viscosity $\eta_{0}$ of the CRPP determined at $170{ }^{\circ} \mathrm{C}$ from the $\mathrm{G}^{\prime \prime} / \omega$ graphs, vs. the production temperature of the CRPP 


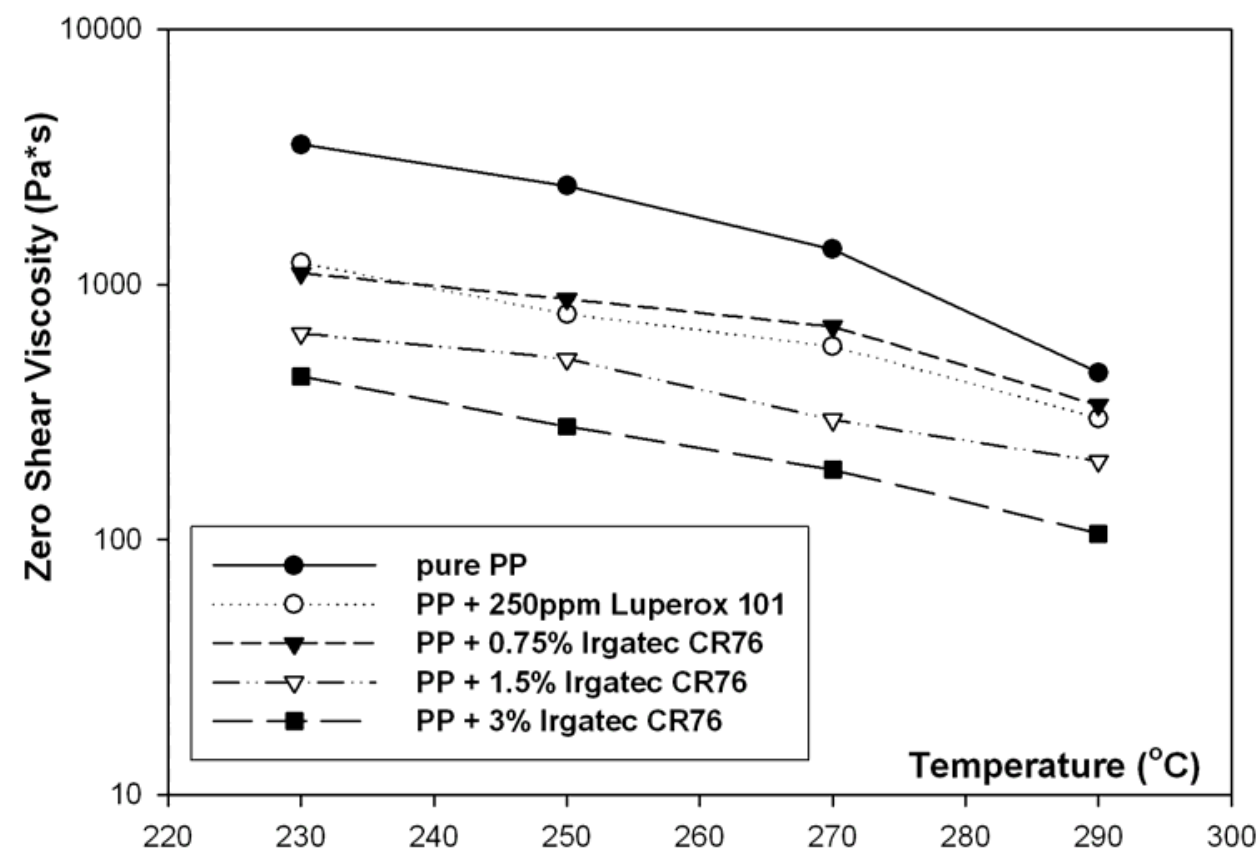

Figure 4.42: Zero shear viscosity $\eta_{0}$ of the CRPP determined at $190{ }^{\circ} \mathrm{C}$ from the $\mathrm{G} " / \omega$ graphs, vs. the production temperature of the CRPP

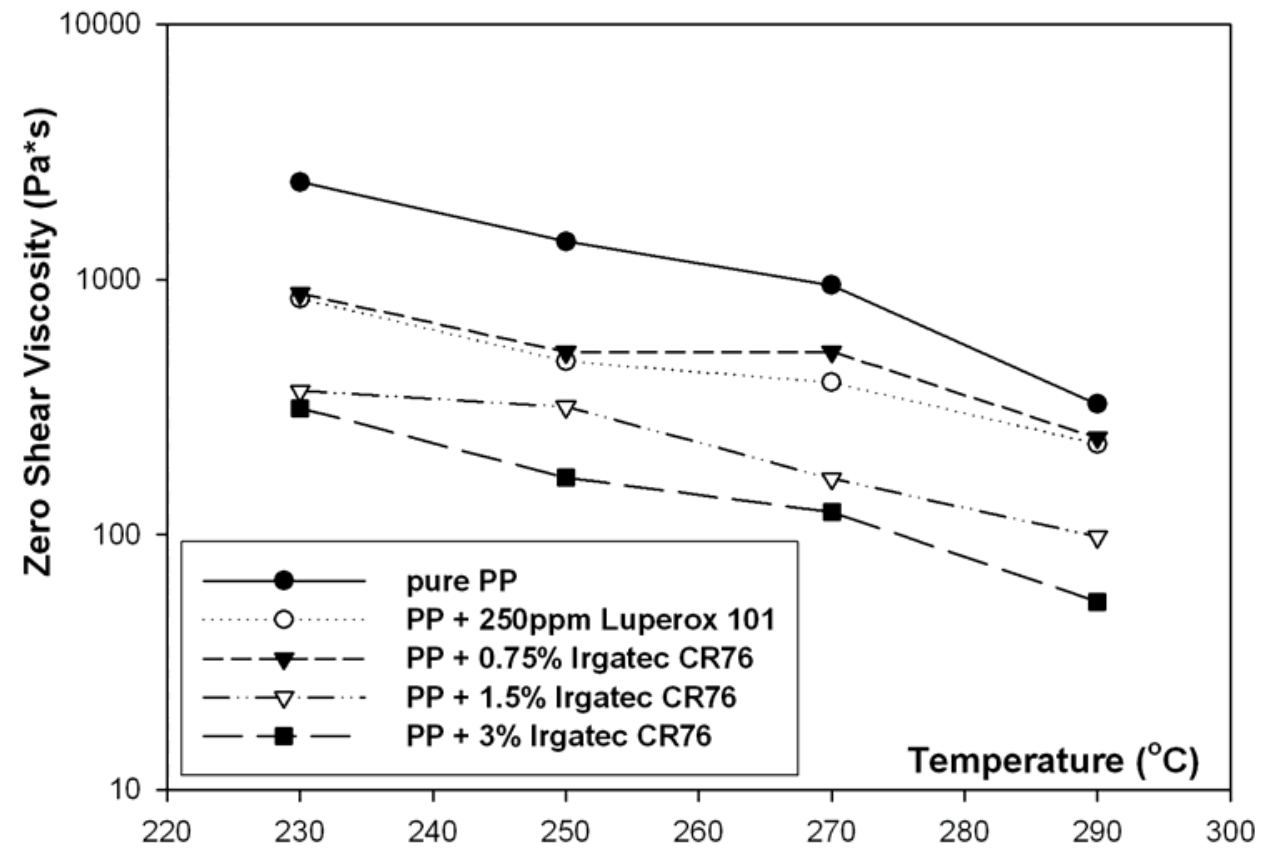

Figure 4.43: Zero shear viscosity $\eta_{0}$ of the CRPP determined at $210^{\circ} \mathrm{C}$ from the $\mathrm{G} / \omega$ graphs, vs. the production temperature of the CRPP 
Concluding section 4.2.2.1, the following arguments can be made:

Charts of Figures 4.25 to 4.40 show the expected trends for the different CRPP. For low values of frequency the lines are separated, but for high values of frequency they converge. The loss modulus G" (and as a result the $\mathrm{G}^{\prime \prime} / \omega$ ) is higher for the pure PP and lower for the more degraded samples. The higher percentage of NOR initiator in the sample, the lower the loss modulus G". This is expected, as the loss modulus $\mathrm{G}^{\prime \prime}$ represents the viscous part of the material.

- Especially at low frequency values, the separation of the curves in Figures 4.25 to 4.40 is significant. For resins produced at temperatures $250{ }^{\circ} \mathrm{C}, 270{ }^{\circ} \mathrm{C}$ and $290{ }^{\circ} \mathrm{C}$ the general trend of the curves is approximately the same. Starting from the higher and moving to the lower values of zero shear viscosity, the order of the curves is: pure PP, PP with 0.75\% Irgatec CR76 (250 ppm NOR), PP with 250 ppm Luperox 101 (250 ppm peroxide), PP with 1.5\% Irgatec CR76 and, finally, PP with 3\% Irgatec CR76. The only exception is for the $230{ }^{\circ} \mathrm{C}$. In that case the curve of PP with $0.75 \%$ Irgatec CR76 (250 ppm NOR) seems to give results of lower zero shear viscosity than the curve of PP with $250 \mathrm{ppm}$ Luperox 101 (250 ppm peroxide). But even in that case the difference is slight. In general, it can be said that the CRPP produced with $250 \mathrm{ppm}$ Luperox 101 give less viscous resins than the CRPP produced with $0.75 \%$ Irgatec CR76.

- The trends shown in Figures 4.41, 4.42 and 4.43, which represent the zero shear viscosity of the CRPP obtained from the G"/ $\omega$ vs. $\omega$ at 170,190 and $210{ }^{\circ} \mathrm{C}$, respectively, seem to be in general agreement with the trends of Figure 4.3, which represents the modeling of the instant shear viscosity of the polymer melt at the end of the experiment in the Haake mixer. Figure 4.3 and Figures 4.41, 4.42 and 4.43 also illustrate the curve of PP with Luperox 101 to give results of lower zero shear viscosity at high temperatures in comparison to the curve of PP with $0.75 \%$ Irgatec CR76. 


\subsubsection{Zero shear viscosity predicted from Carreau-Yasuda model}

As reported in section 4.2.2, aside from the experimental data of $\mathrm{G} " / \omega$ vs. $\omega$, one other way to determine the zero shear viscosity is by data modeling of complex viscosity $\eta^{*}$ vs. $\omega$, based on the Cox - Merz rule. That model is the Carreau-Yasuda model:

$\eta=\eta_{0}\left[1+(\lambda \dot{\gamma})^{\alpha}\right]^{\frac{\mathrm{n}-1}{\alpha}}$

and by replacing $\eta$ and $\dot{\gamma}$ with $\eta^{*}$ and $\omega$, respectively, according to the Cox - Merz rule:

$$
\eta^{*}=\eta_{0}\left[1+(\lambda \omega)^{\alpha}\right]^{\frac{\mathrm{n}-1}{\alpha}}
$$

From equation (4.7) it is obvious that when $\omega$ approaches zero, $\eta^{*}$ approaches $\eta_{0}$. In other words, by determining the parameters of (4.7), the zero shear viscosity of each sample can be derived. The curve fitting of the complex viscosity $\eta^{*}$ was done using the software Origin Pro v.7.0. The non-weighted Levenberg-Marquardt algorithm (cited at Marquardt (1963), Shrager (1970), Shrager (1972), Nash (1979), Press et al. (1986)) was used for the non-Linear curve fitting. 100 iterations were used for every fitting session. The tolerance was set at $10^{-9}$. The confidence bands were set at $95 \%$. For that level, the absolute error was calculated for every parameter.

The results of the numerical curve fitting with the experimental data are given in Figures 4.44 to 4.55 . Figures 4.44 to 4.47 illustrate the experimental and numerical results of the complex viscosity $\eta^{*}$ vs. $\omega$ for measurements that took place at $170{ }^{0} \mathrm{C}$ in the parallel plate rheometer. Figures 4.48 to 4.51 illustrate the experimental and numerical results of the complex viscosity $\eta^{*}$ vs. $\omega$ for measurements that took place at $190{ }^{\circ} \mathrm{C}$. Finally, Figures 4.52 to 4.55 illustrate the experimental and numerical results of the complex viscosity $\eta^{*}$ vs. $\omega$ for measurements that took place at $210{ }^{\circ} \mathrm{C}$. From the numerical simulation, the 4 parameters of the Carreau-Yasuda model (relaxation time $\lambda$, index a, power law index $\mathrm{n}$ and zero shear viscosity) are estimated for each CRPP sample and each temperature (Tables 4.4 to 4.15). In every table, the derived zero shear viscosity is compared to the respective zero shear viscosity as was determined from the $\mathrm{G} / \omega$ values in section 4.2.2.1. 


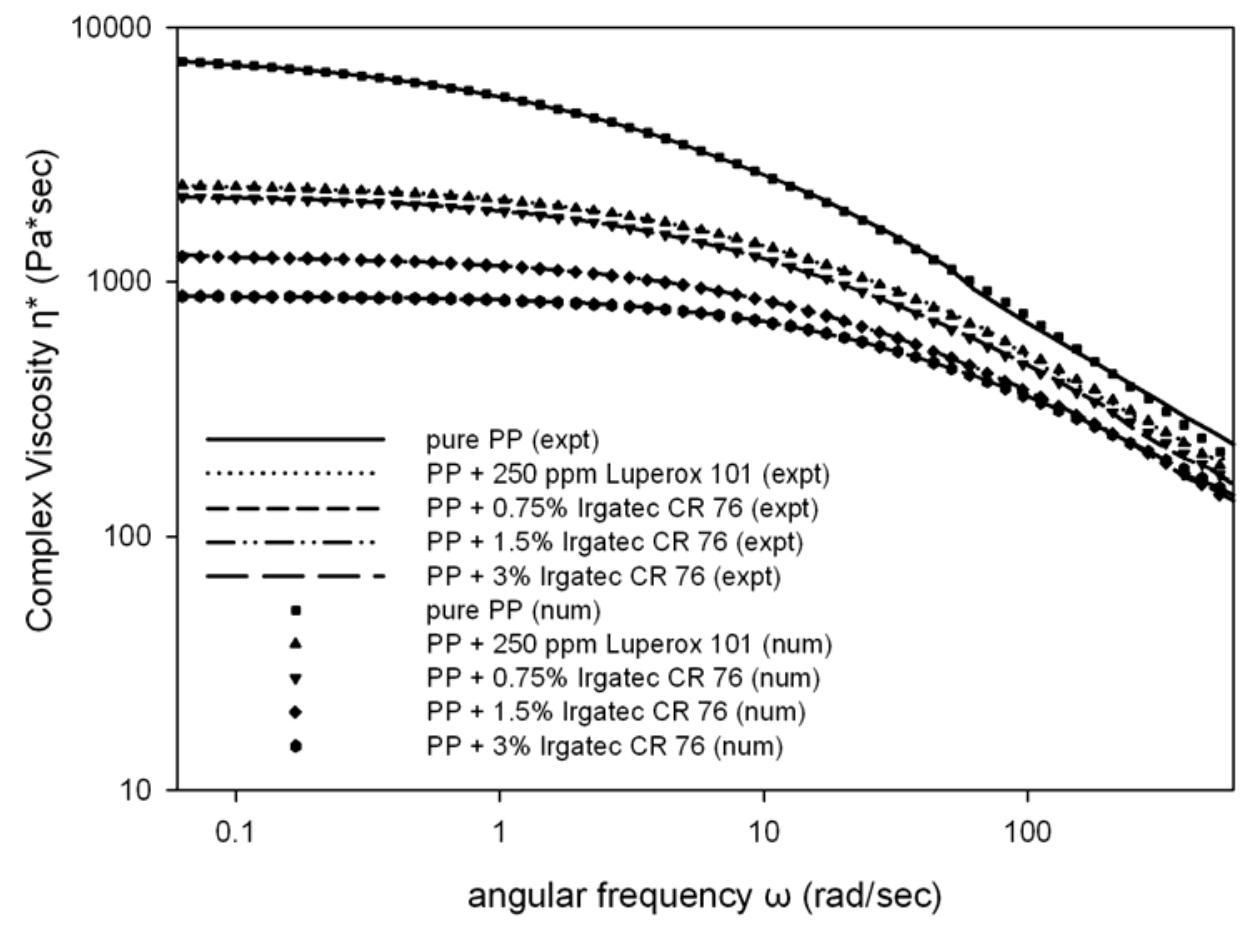

Figure 4.44: Complex viscosity vs. frequency of the CRPP determined at $170{ }^{\circ} \mathrm{C}$ for CRPP produced at $230{ }^{\circ} \mathrm{C}$

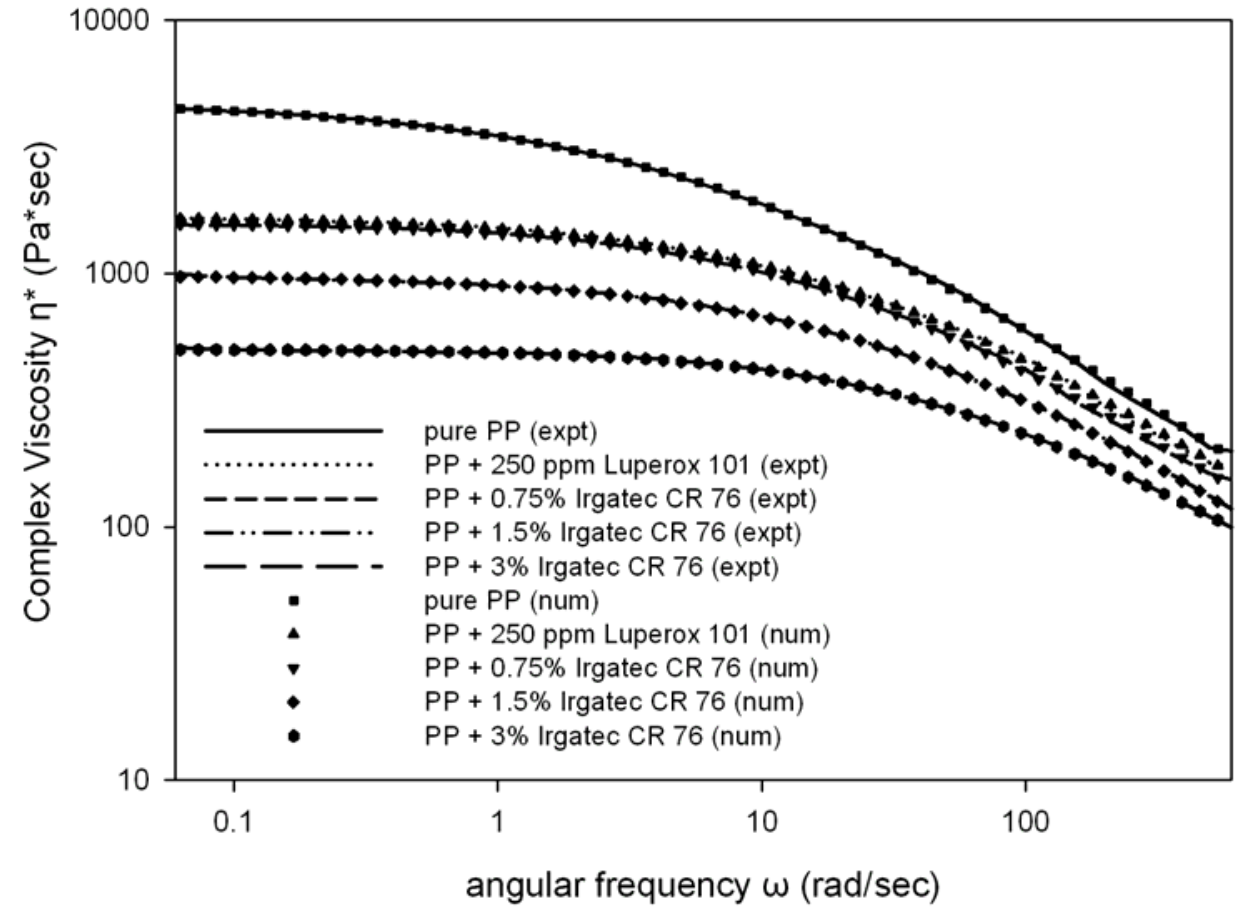

Figure 4.45: Complex viscosity vs. frequency of the CRPP determined at $170{ }^{\circ} \mathrm{C}$ for CRPP produced at $250{ }^{\circ} \mathrm{C}$ 


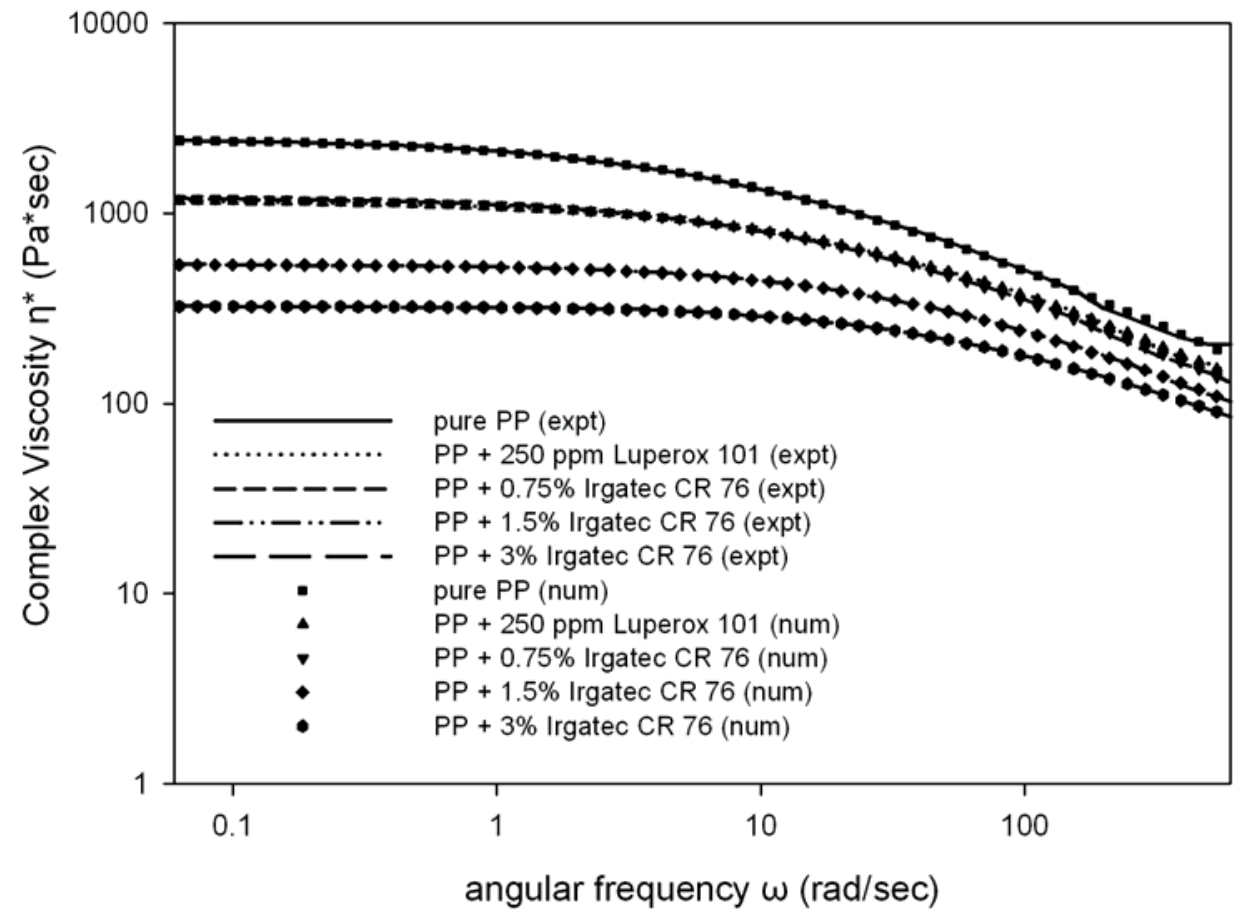

Figure 4.46: Complex viscosity vs. frequency of the CRPP determined at $170{ }^{\circ} \mathrm{C}$ for CRPP produced at $270{ }^{\circ} \mathrm{C}$

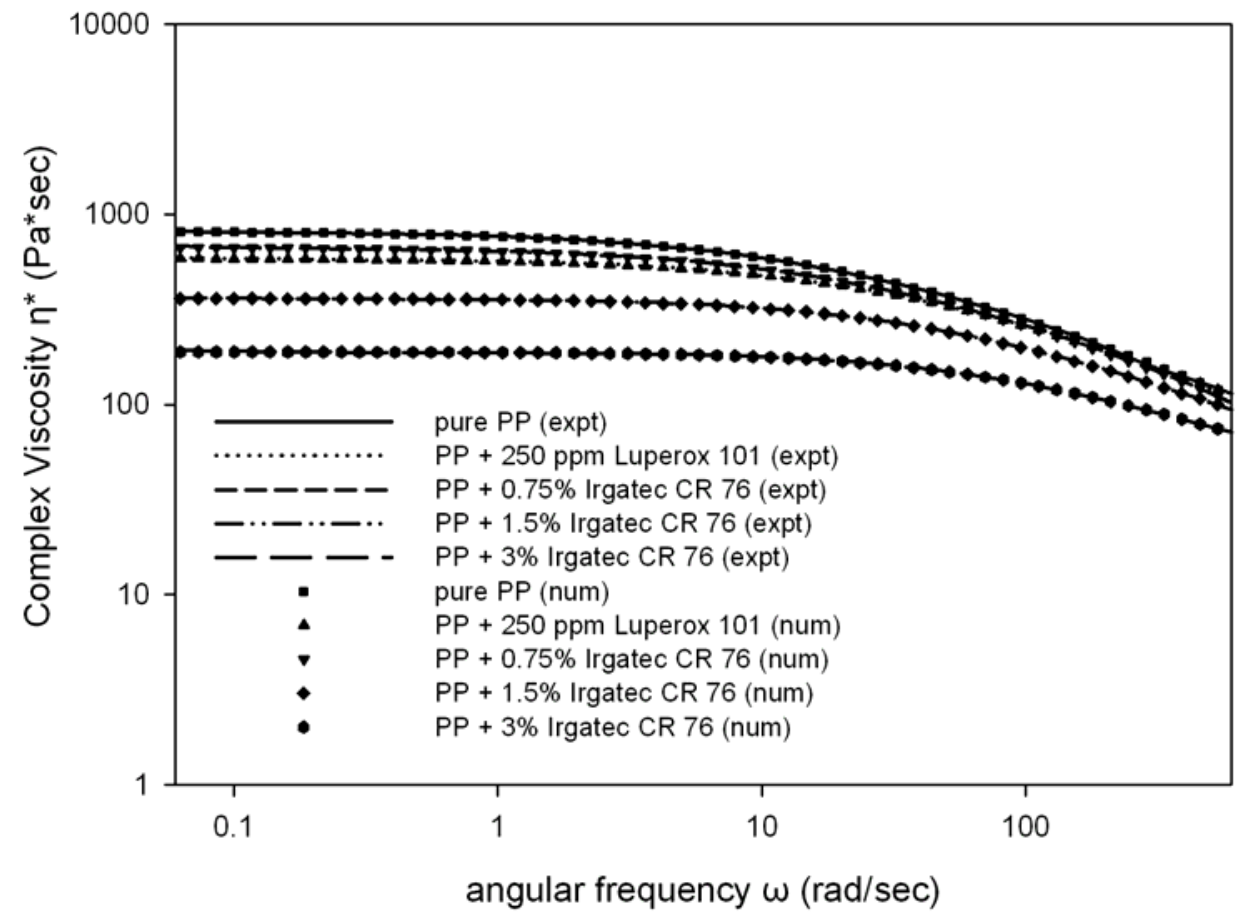

Figure 4.47: Complex viscosity vs. frequency of the CRPP determined at $170{ }^{\circ} \mathrm{C}$ for CRPP produced at $290{ }^{\circ} \mathrm{C}$ 


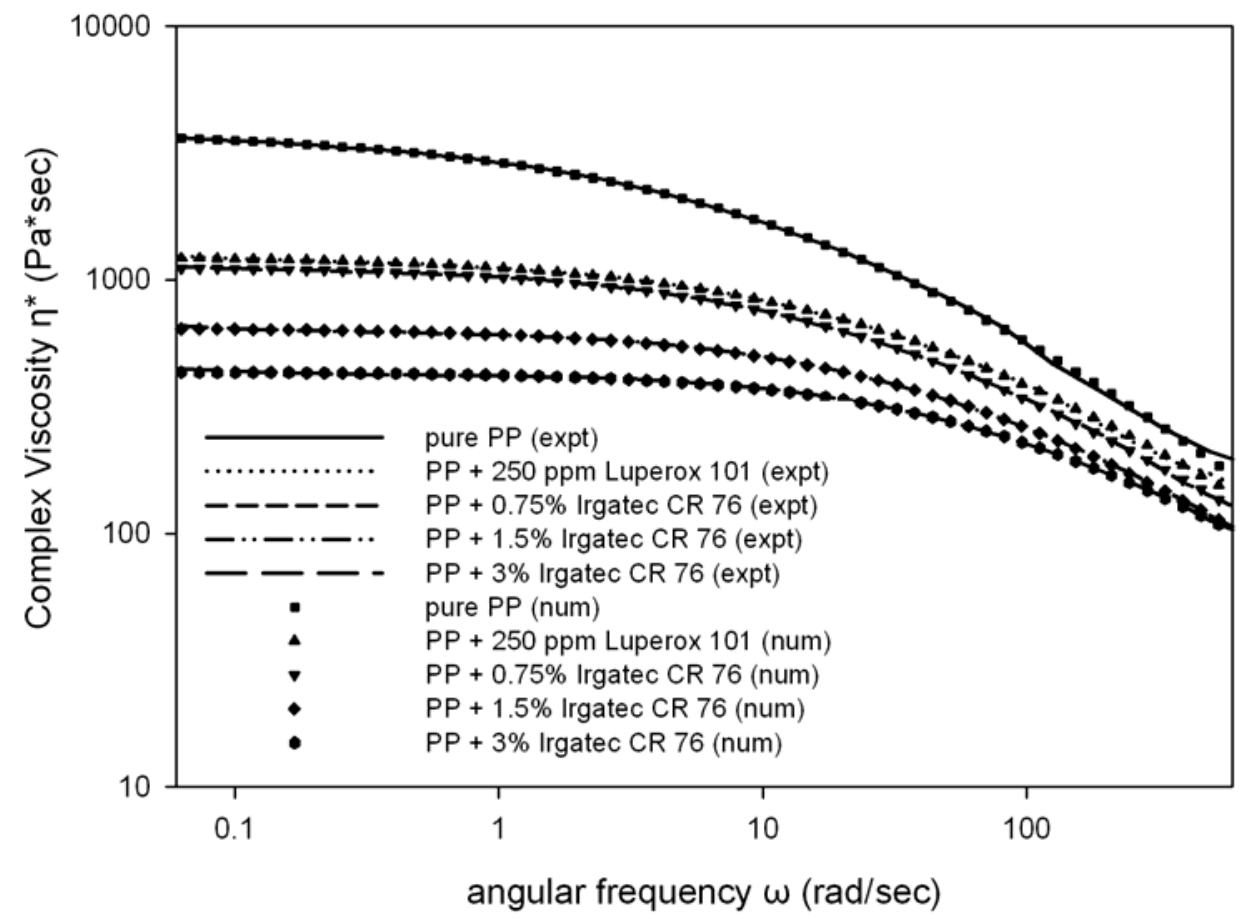

Figure 4.48: Complex viscosity vs. frequency of the CRPP determined at $190{ }^{\circ} \mathrm{C}$ for CRPP produced at $230{ }^{\circ} \mathrm{C}$

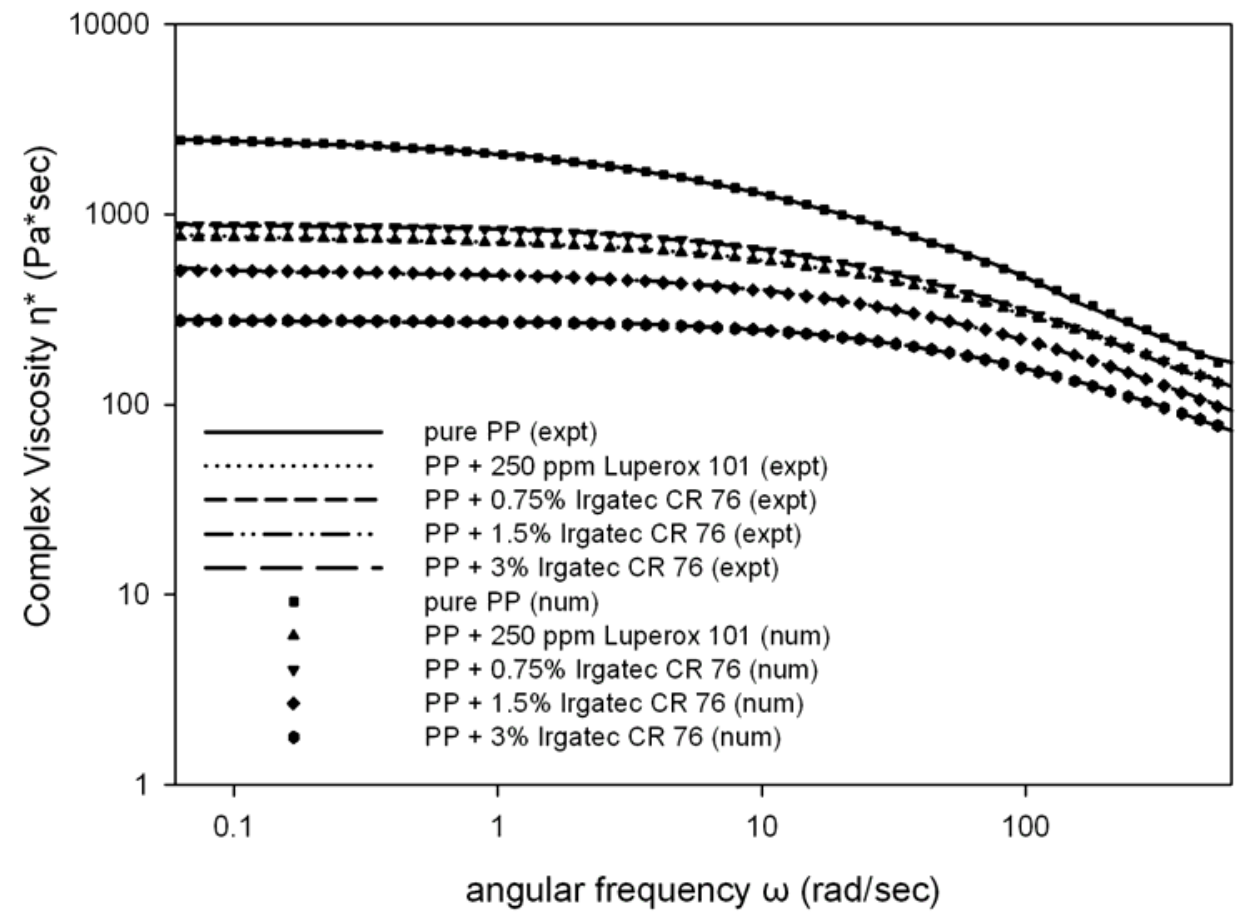

Figure 4.49: Complex viscosity vs. frequency of the CRPP determined at $190{ }^{\circ} \mathrm{C}$ for CRPP produced at $250{ }^{\circ} \mathrm{C}$ 


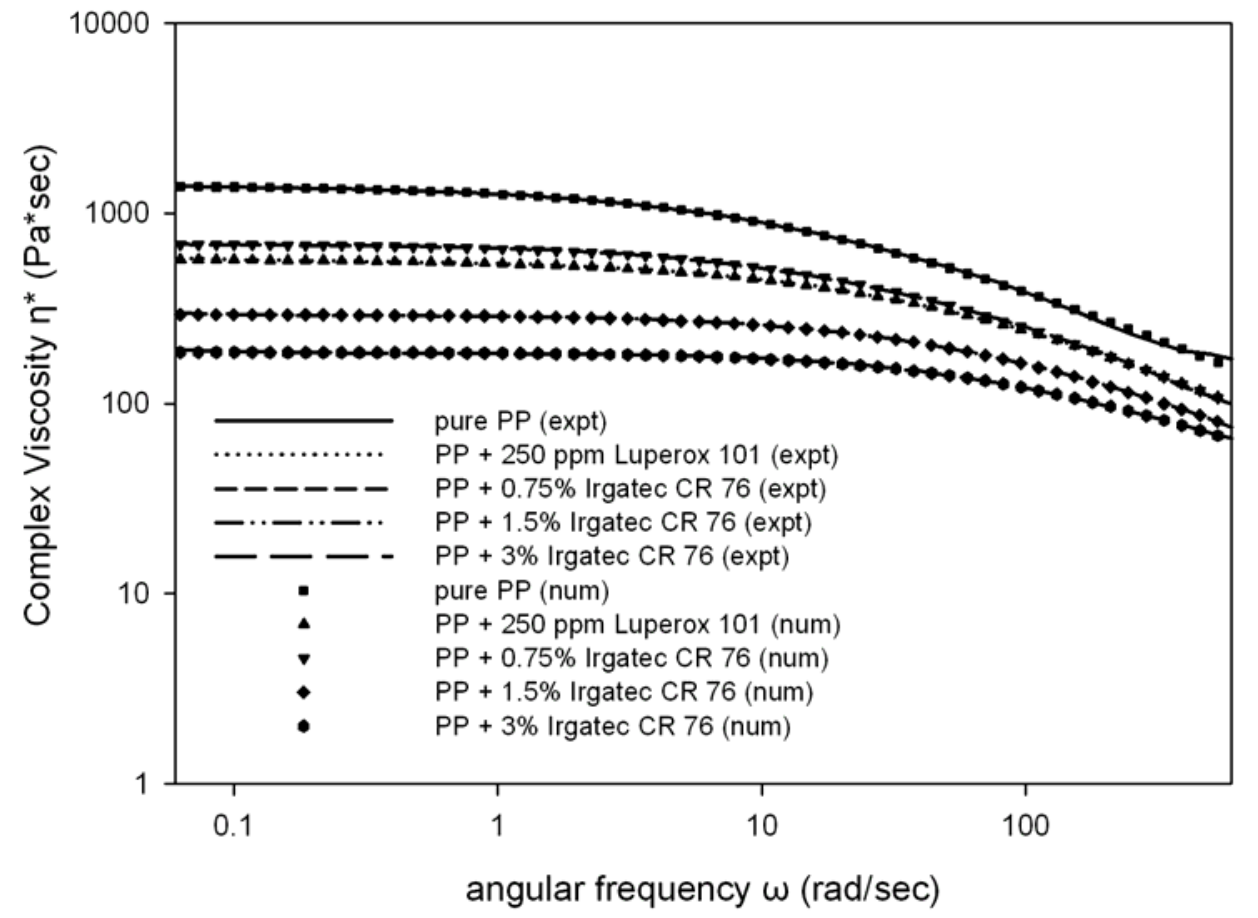

Figure 4.50: Complex viscosity vs. frequency of the CRPP determined at $190{ }^{\circ} \mathrm{C}$ for CRPP produced at $270{ }^{\circ} \mathrm{C}$

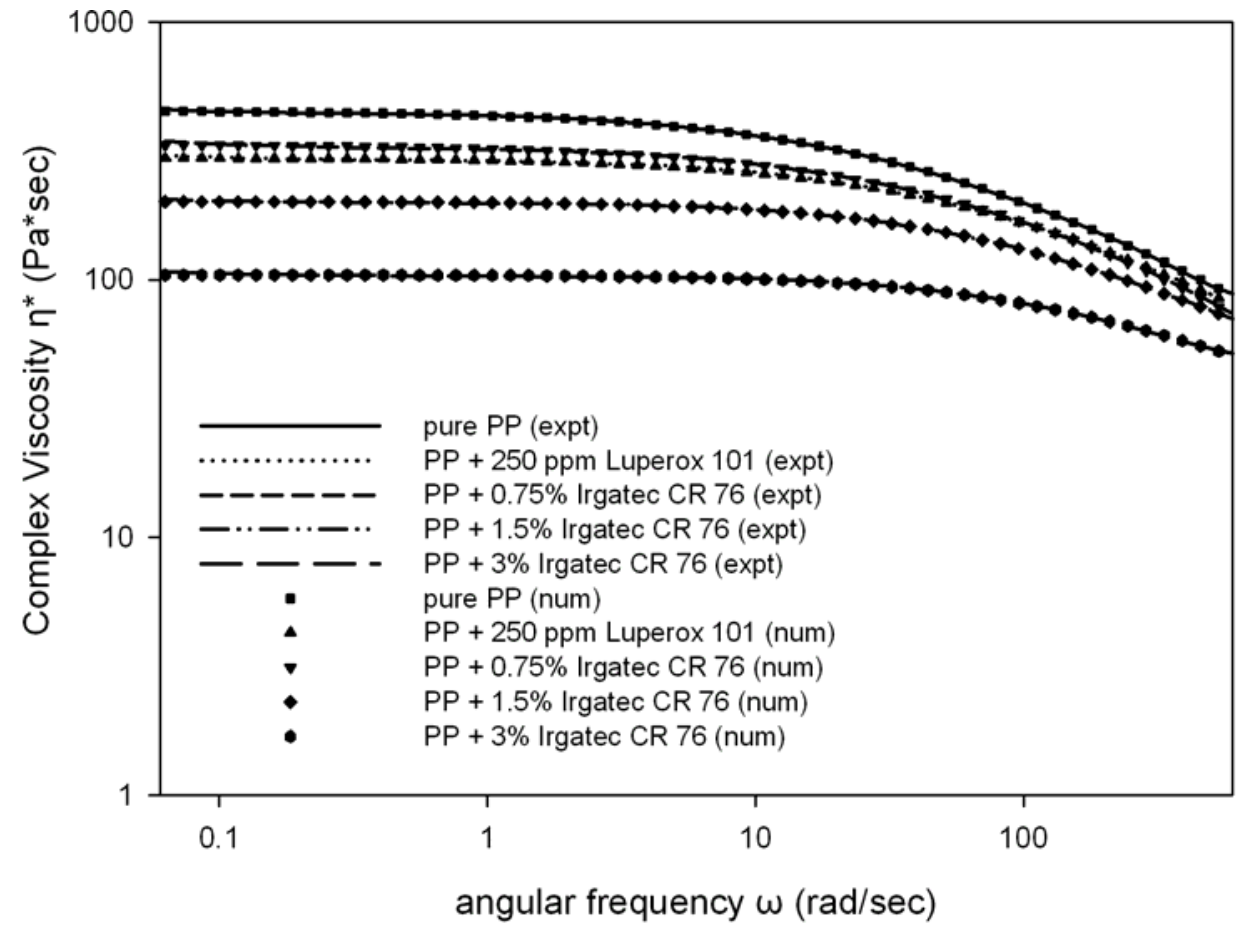

Figure 4.51: Complex viscosity vs. frequency of the CRPP determined at $190{ }^{\circ} \mathrm{C}$ for CRPP produced at $290{ }^{\circ} \mathrm{C}$ 


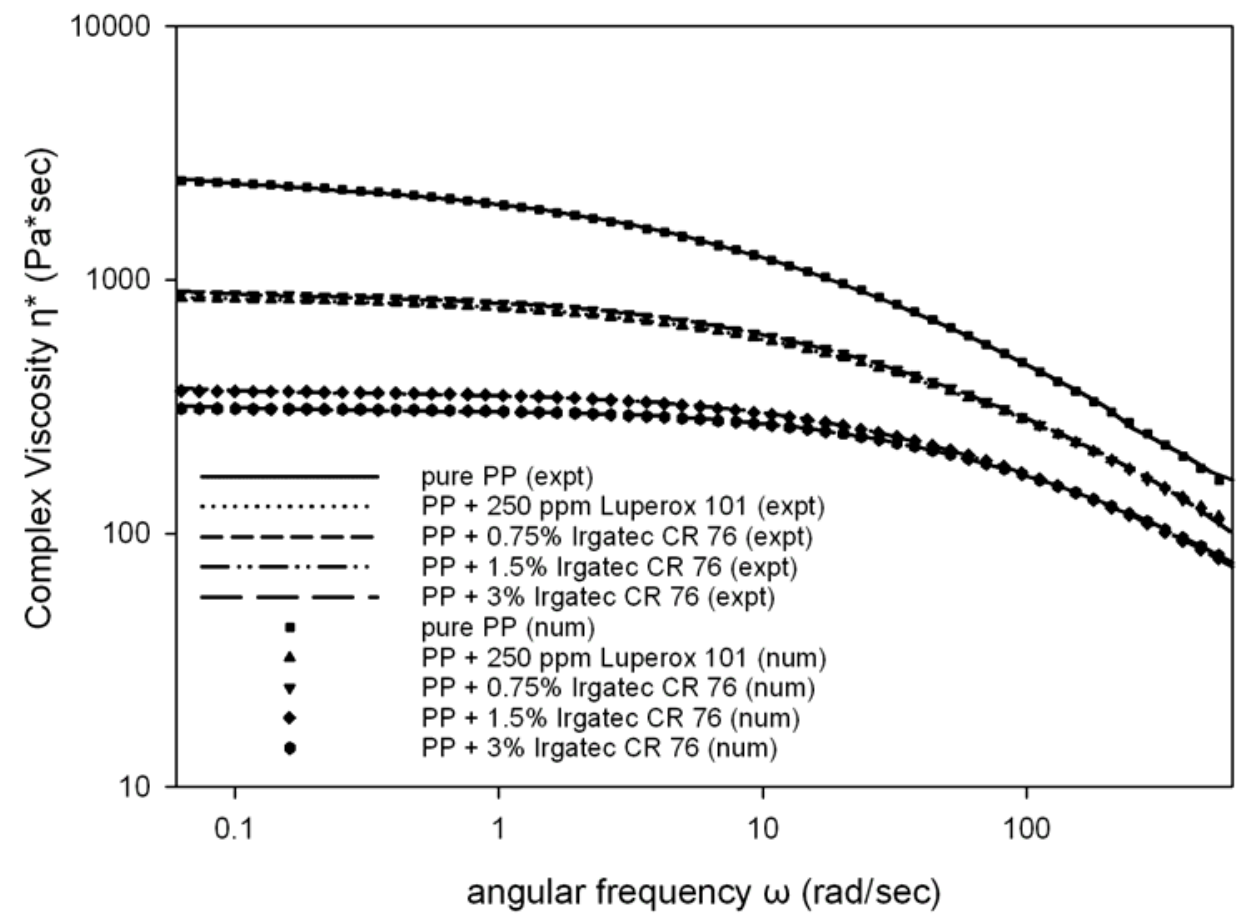

Figure 4.52: Complex viscosity vs. frequency of the CRPP determined at $210^{\circ} \mathrm{C}$ for CRPP produced at $230{ }^{\circ} \mathrm{C}$

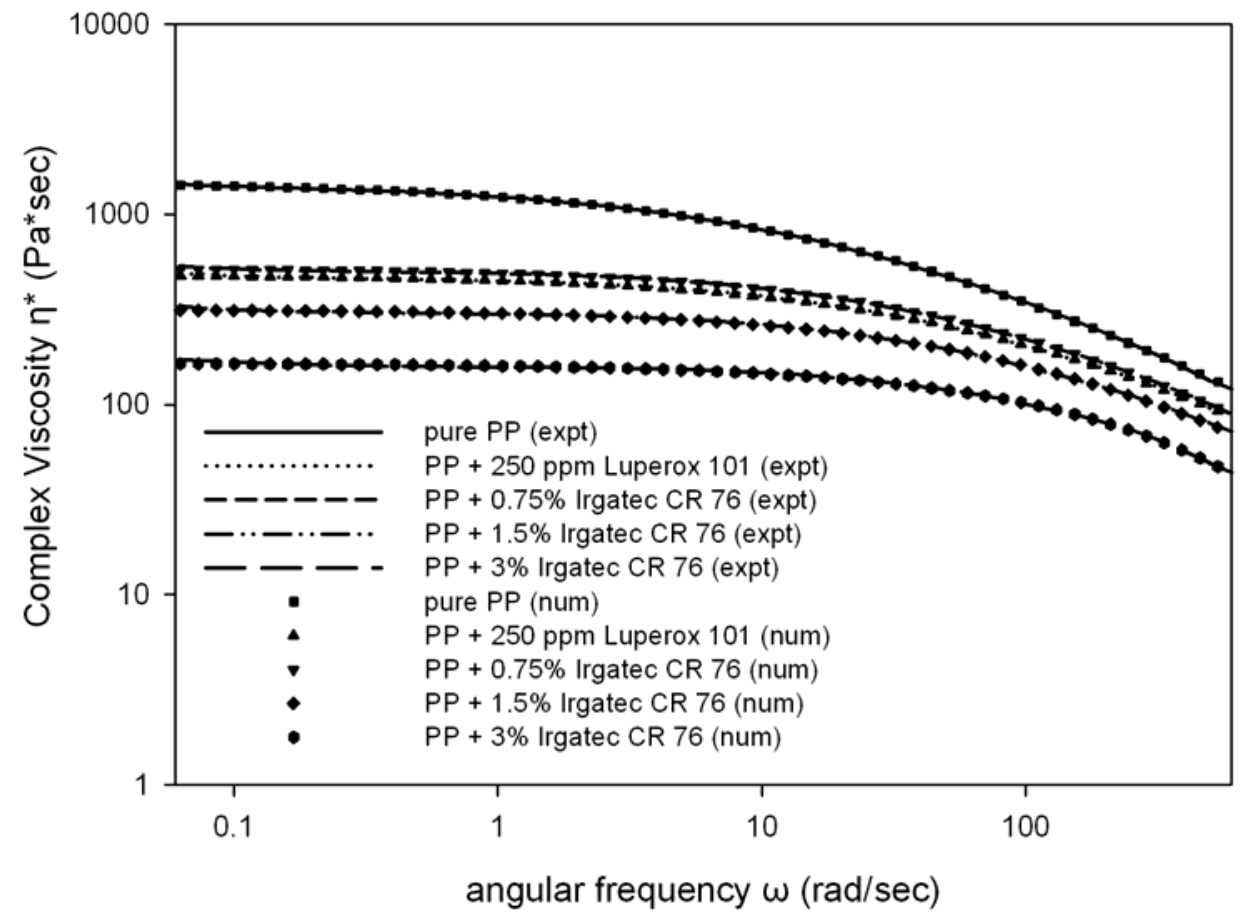

Figure 4.53: Complex viscosity vs. frequency of the CRPP determined at $210^{\circ} \mathrm{C}$ for CRPP produced at $250{ }^{\circ} \mathrm{C}$ 


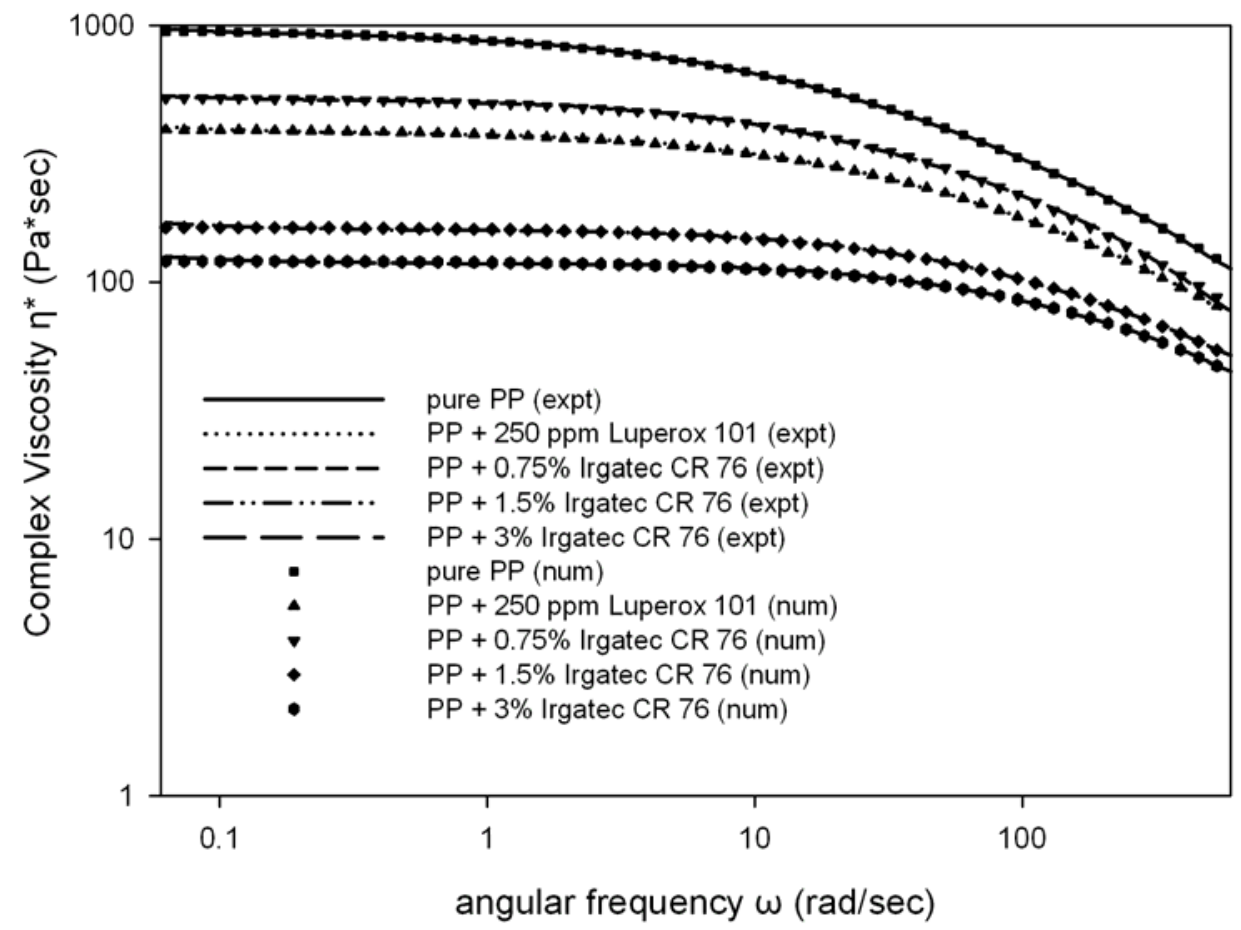

Figure 4.54: Complex viscosity vs. frequency of the CRPP determined at $210{ }^{\circ} \mathrm{C}$ for CRPP produced at $270{ }^{\circ} \mathrm{C}$

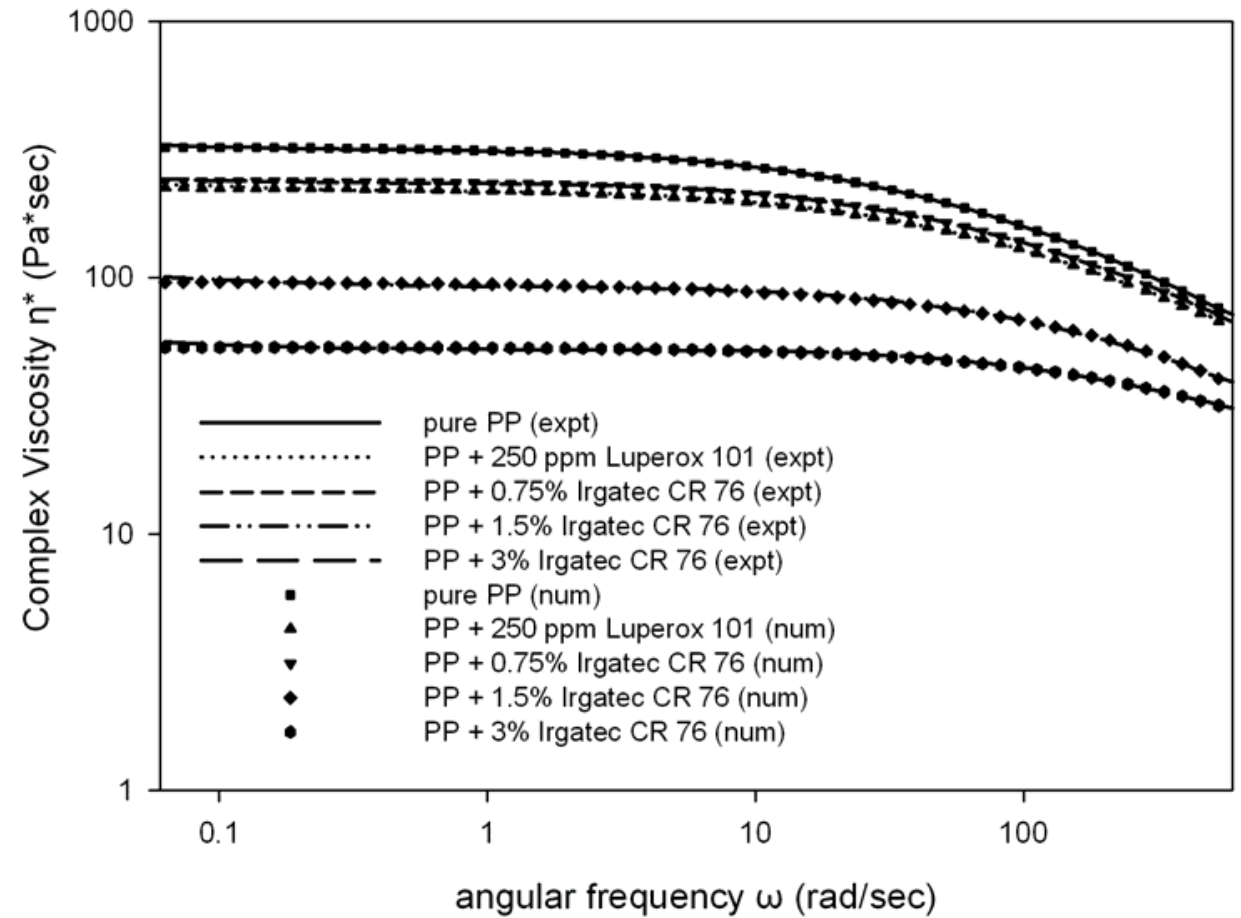

Figure 4.55: Complex viscosity vs. frequency of the CRPP determined at $210{ }^{\circ} \mathrm{C}$ for CRPP produced at $290{ }^{\circ} \mathrm{C}$ 
Table 4.4: Carreau-Yasuda model parameters from the numerical simulation of complex viscosity vs. frequency at $170{ }^{\circ} \mathrm{C}$ for CRPP produced at $230{ }^{\circ} \mathrm{C}$

\begin{tabular}{|c|c|c|c|c|c|}
\hline & $\lambda(\mathrm{sec})$ & Index a & index n & $\eta_{0}(\mathrm{~Pa} \cdot \mathrm{s})$ & $\eta_{0}$ from $\mathrm{G} " / \omega(\mathrm{Pa} \cdot \mathrm{s})$ \\
\hline Pure PP & 0.09673 & 0.5268 & 0.12618 & 8194.16838 & 7078.7105 \\
\hline $250 \mathrm{ppm}$ peroxide & 0.05263 & 0.64735 & 0.26858 & 2453.07286 & 2356.3478 \\
\hline $250 \mathrm{ppm}$ NOR & 0.07287 & 0.6805 & 0.3278 & 2207.14992 & 2125.5948 \\
\hline $500 \mathrm{ppm} \mathrm{NOR}$ & 0.03637 & 0.67923 & 0.31288 & 1274.1717 & 1248.0648 \\
\hline $1000 \mathrm{ppm}$ NOR & 0.03594 & 0.85443 & 0.43162 & 877.09797 & 871.91968 \\
\hline
\end{tabular}

Table 4.5: Carreau-Yasuda model parameters from the numerical simulation of complex viscosity vs. frequency at $170{ }^{\circ} \mathrm{C}$ for CRPP produced at $250{ }^{\circ} \mathrm{C}$

\begin{tabular}{|c|c|c|c|c|c|}
\hline & $\lambda(\mathrm{sec})$ & Index a & index $\mathrm{n}$ & $\eta_{0}(\mathrm{~Pa} \cdot \mathrm{s})$ & $\eta_{0}$ from $\mathrm{G} " / \omega(\mathrm{Pa} \cdot \mathrm{s})$ \\
\hline Pure PP & 0.11725 & 0.58656 & 0.2615 & 4780.53845 & 4343.9407 \\
\hline $250 \mathrm{ppm}$ peroxide & 0.04236 & 0.68313 & 0.30925 & 1683.55821 & 1640.2478 \\
\hline $250 \mathrm{ppm}$ NOR & 0.05665 & 0.75196 & 0.33968 & 1579.06089 & 1545.728 \\
\hline $500 \mathrm{ppm}$ NOR & 0.02606 & 0.65371 & 0.28662 & 987.10517 & 969.4716 \\
\hline $1000 \mathrm{ppm}$ NOR & 0.02208 & 0.81464 & 0.40821 & 501.90234 & 501.26347 \\
\hline
\end{tabular}

Table 4.6: Carreau-Yasuda model parameters from the numerical simulation of complex viscosity vs. frequency at $170{ }^{\circ} \mathrm{C}$ for CRPP produced at $270{ }^{\circ} \mathrm{C}$

\begin{tabular}{|c|c|c|c|c|c|}
\hline & $\lambda(\mathrm{sec})$ & Index a & index n & $\eta_{0}(\mathrm{~Pa} \cdot \mathrm{s})$ & $\eta_{0}$ from $\mathrm{G} / \omega(\mathrm{Pa} \cdot \mathrm{s})$ \\
\hline Pure PP & 0.09826 & 0.70931 & 0.36831 & 2479.42794 & 2390.3068 \\
\hline $250 \mathrm{ppm}$ peroxide & 0.03603 & 0.70579 & 0.34497 & 1177.01029 & 1156.4314 \\
\hline $250 \mathrm{ppm}$ NOR & 0.04972 & 0.74315 & 0.35979 & 1210.21339 & 1187.5474 \\
\hline $500 \mathrm{ppm}$ NOR & 0.02616 & 0.83043 & 0.42262 & 539.37623 & 536.9761 \\
\hline $1000 \mathrm{ppm}$ NOR & 0.02211 & 0.92275 & 0.50396 & 324.89727 & 325.17538 \\
\hline
\end{tabular}


Table 4.7: Carreau-Yasuda model parameters from the numerical simulation of complex viscosity vs. frequency at $170{ }^{\circ} \mathrm{C}$ for CRPP produced at $290{ }^{\circ} \mathrm{C}$

\begin{tabular}{|c|c|c|c|c|c|}
\hline & $\lambda(\mathrm{sec})$ & Index a & index n & $\eta_{0}(\mathrm{~Pa} \cdot \mathrm{s})$ & $\eta_{0}$ from $\mathrm{G} " / \omega(\mathrm{Pa} \cdot \mathrm{s})$ \\
\hline Pure PP & 0.04142 & 0.76421 & 0.40207 & 817.89015 & 808.02156 \\
\hline $250 \mathrm{ppm}$ peroxide & 0.02643 & 0.81129 & 0.42796 & 587.85359 & 585.29173 \\
\hline $250 \mathrm{ppm}$ NOR & 0.02715 & 0.7467 & 0.36706 & 676.18482 & 671.26707 \\
\hline $500 \mathrm{ppm}$ NOR & 0.02221 & 0.925 & 0.50132 & 361.69557 & 362.04132 \\
\hline $1000 \mathrm{ppm}$ NOR & 0.01324 & 0.96104 & 0.55694 & 189.24615 & 190.62395 \\
\hline
\end{tabular}

Table 4.8: Carreau-Yasuda model parameters from the numerical simulation of complex viscosity vs. frequency at $190{ }^{\circ} \mathrm{C}$ for CRPP produced at $230{ }^{\circ} \mathrm{C}$

\begin{tabular}{|c|c|c|c|c|c|}
\hline & $\lambda(\mathrm{sec})$ & Index a & index $\mathrm{n}$ & $\eta_{0}(\mathrm{~Pa} \cdot \mathrm{s})$ & $\eta_{0}$ from $\mathrm{G} / \mathrm{\omega}(\mathrm{Pa} \cdot \mathrm{s})$ \\
\hline Pure PP & 0.04799 & 0.53229 & 0.1425 & 3882.31924 & 3534.3626 \\
\hline $250 \mathrm{ppm}$ peroxide & 0.02426 & 0.62473 & 0.26977 & 1242.99539 & 1213.9582 \\
\hline $250 \mathrm{ppm}$ NOR & 0.03666 & 0.67634 & 0.32987 & 1131.07434 & 1107.8367 \\
\hline $500 \mathrm{ppm}$ NOR & 0.01762 & 0.68862 & 0.30973 & 646.14603 & 642.82714 \\
\hline $1000 \mathrm{ppm}$ NOR & 0.01192 & 0.75288 & 0.35589 & 433.3216 & 436.31532 \\
\hline
\end{tabular}

Table 4.9: Carreau-Yasuda model parameters from the numerical simulation of complex viscosity vs. frequency at $190{ }^{\circ} \mathrm{C}$ for CRPP produced at $250{ }^{\circ} \mathrm{C}$

\begin{tabular}{|c|c|c|c|c|c|}
\hline & $\lambda(\mathrm{sec})$ & Index a & index n & $\eta_{0}(\mathrm{~Pa} \cdot \mathrm{s})$ & $\eta_{0}$ from $\mathrm{G} / \omega(\mathrm{Pa} \cdot \mathrm{s})$ \\
\hline Pure PP & 0.06171 & 0.59483 & 0.25693 & 2583.3928 & 2429.0162 \\
\hline $250 \mathrm{ppm}$ peroxide & 0.01473 & 0.63 & 0.27188 & 772.34965 & 764.59667 \\
\hline $250 \mathrm{ppm}$ NOR & 0.03561 & 0.76942 & 0.37734 & 884.97905 & 876.07954 \\
\hline $500 \mathrm{ppm}$ NOR & 0.01227 & 0.64941 & 0.27169 & 511.96592 & 510.402 \\
\hline $1000 \mathrm{ppm}$ NOR & 0.01611 & 0.86393 & 0.45222 & 276.8722 & 277.60363 \\
\hline
\end{tabular}


Table 4.10: Carreau-Yasuda model parameters from the numerical simulation of complex viscosity vs. frequency at $190{ }^{\circ} \mathrm{C}$ for CRPP produced at $270{ }^{\circ} \mathrm{C}$

\begin{tabular}{|c|c|c|c|c|c|}
\hline & $\lambda(\mathrm{sec})$ & Index a & index n & $\eta_{0}(\mathrm{~Pa} \cdot \mathrm{s})$ & $\eta_{0}$ from $\mathrm{G} " / \omega(\mathrm{Pa} \cdot \mathrm{s})$ \\
\hline Pure PP & 0.0728 & 0.74302 & 0.42726 & 1403.40867 & 1375.0589 \\
\hline $250 \mathrm{ppm}$ peroxide & 0.01821 & 0.69868 & 0.34112 & 576.55133 & 572.3703 \\
\hline $250 \mathrm{ppm}$ NOR & 0.03612 & 0.77917 & 0.39575 & 691.37145 & 683.42124 \\
\hline $500 \mathrm{ppm}$ NOR & 0.0152 & 0.82421 & 0.43533 & 294.14737 & 294.78136 \\
\hline $1000 \mathrm{ppm}$ NOR & 0.01227 & 0.88043 & 0.51511 & 186.26121 & 187.92567 \\
\hline
\end{tabular}

Table 4.11: Carreau-Yasuda model parameters from the numerical simulation of complex viscosity vs. frequency at $190{ }^{\circ} \mathrm{C}$ for CRPP produced at $290{ }^{\circ} \mathrm{C}$

\begin{tabular}{|c|c|c|c|c|c|}
\hline & $\lambda(\mathrm{sec})$ & Index a & index $\mathrm{n}$ & $\eta_{0}(\mathrm{~Pa} \cdot \mathrm{s})$ & $\eta_{0}$ from $\mathrm{G} " / \omega(\mathrm{Pa} \cdot \mathrm{s})$ \\
\hline Pure PP & 0.0237 & 0.75614 & 0.41717 & 453.06459 & 451.18209 \\
\hline $250 \mathrm{ppm}$ peroxide & 0.0131 & 0.78331 & 0.42938 & 297.49866 & 298.59644 \\
\hline $250 \mathrm{ppm}$ NOR & 0.00939 & 0.69196 & 0.28269 & 335.75812 & 336.84547 \\
\hline $500 \mathrm{ppm}$ NOR & 0.0141 & 0.92841 & 0.53858 & 201.16383 & 202.61663 \\
\hline $1000 \mathrm{ppm}$ NOR & 0.00941 & 0.96821 & 0.62455 & 104.42269 & 105.78028 \\
\hline
\end{tabular}

Table 4.12: Carreau-Yasuda model parameters from the numerical simulation of complex viscosity vs. frequency at $210^{\circ} \mathrm{C}$ for CRPP produced at $230{ }^{\circ} \mathrm{C}$

\begin{tabular}{|c|c|c|c|c|c|}
\hline & $\lambda(\mathrm{sec})$ & Index a & index n & $\eta_{0}(\mathrm{~Pa} \cdot \mathrm{s})$ & $\eta_{0}$ from $\mathrm{G} / \omega(\mathrm{Pa} \cdot \mathrm{s})$ \\
\hline Pure PP & 0.0226 & 0.47172 & 0.08412 & 2675.4312 & 2406.4591 \\
\hline $250 \mathrm{ppm}$ peroxide & 0.02374 & 0.61402 & 0.29796 & 864.81471 & 841.98547 \\
\hline $250 \mathrm{ppm}$ NOR & 0.0195 & 0.61336 & 0.22561 & 901.31914 & 879.99307 \\
\hline $500 \mathrm{ppm}$ NOR & 0.01271 & 0.69432 & 0.32195 & 366.48647 & 366.13967 \\
\hline $1000 \mathrm{ppm}$ NOR & 0.0091 & 0.73858 & 0.31389 & 311.48239 & 313.03453 \\
\hline
\end{tabular}


Table 4.13: Carreau-Yasuda model parameters from the numerical simulation of complex viscosity vs. frequency at $210{ }^{\circ} \mathrm{C}$ for CRPP produced at $250{ }^{\circ} \mathrm{C}$

\begin{tabular}{|c|c|c|c|c|c|}
\hline & $\lambda(\mathrm{sec})$ & Index a & index n & $\eta_{0}(\mathrm{~Pa} \cdot \mathrm{s})$ & $\eta_{0}$ from $\mathrm{G} " / \omega(\mathrm{Pa} \cdot \mathrm{s})$ \\
\hline Pure PP & 0.03752 & 0.57746 & 0.26273 & 1481.22661 & 1408.6477 \\
\hline $250 \mathrm{ppm}$ peroxide & 0.01003 & 0.62131 & 0.23785 & 481.18994 & 477.59549 \\
\hline $250 \mathrm{ppm}$ NOR & 0.01237 & 0.66575 & 0.25517 & 521.03465 & 518.92002 \\
\hline $500 \mathrm{ppm}$ NOR & 0.00699 & 0.65686 & 0.23202 & 315.51517 & 317.15281 \\
\hline $1000 \mathrm{ppm}$ NOR & 0.00506 & 0.70838 & 0.26354 & 164.16135 & 167.09263 \\
\hline
\end{tabular}

Table 4.14: Carreau-Yasuda model parameters from the numerical simulation of complex viscosity vs. frequency at $210^{\circ} \mathrm{C}$ for CRPP produced at $270{ }^{\circ} \mathrm{C}$

\begin{tabular}{|c|c|c|c|c|c|}
\hline & $\lambda(\mathrm{sec})$ & Index a & index $\mathrm{n}$ & $\eta_{0}(\mathrm{~Pa} \cdot \mathrm{s})$ & $\eta_{0}$ from $\mathrm{G} / /(\mathrm{\omega}$ (Pas) \\
\hline Pure PP & 0.02819 & 0.63881 & 0.30589 & 969.70688 & 947.61725 \\
\hline $250 \mathrm{ppm}$ peroxide & 0.01225 & 0.67386 & 0.29227 & 395.82185 & 393.92274 \\
\hline $250 \mathrm{ppm}$ NOR & 0.01184 & 0.68594 & 0.1861 & 526.19034 & 521.12767 \\
\hline $500 \mathrm{ppm}$ NOR & 0.00517 & 0.7262 & 0.28946 & 163.74343 & 165.77207 \\
\hline $1000 \mathrm{ppm}$ NOR & 0.00251 & 0.7444 & 0.13506 & 120.77703 & 122.52207 \\
\hline
\end{tabular}

Table 4.15: Carreau-Yasuda model parameters from the numerical simulation of complex viscosity vs. frequency at $210{ }^{\circ} \mathrm{C}$ for CRPP produced at $290{ }^{\circ} \mathrm{C}$

\begin{tabular}{|c|c|c|c|c|c|}
\hline & $\lambda(\mathrm{sec})$ & Index a & index $\mathrm{n}$ & $\eta_{0}(\mathrm{~Pa} \cdot \mathrm{s})$ & $\eta_{0}$ from $\mathrm{G} " / \omega(\mathrm{Pa} \cdot \mathrm{s})$ \\
\hline Pure PP & 0.01552 & 0.74137 & 0.38815 & 324.27388 & 324.08731 \\
\hline $250 \mathrm{ppm}$ peroxide & 0.00879 & 0.71573 & 0.38136 & 224.76649 & 226.70557 \\
\hline $250 \mathrm{ppm}$ NOR & 0.01411 & 0.82062 & 0.46005 & 238.19992 & 239.22125 \\
\hline $500 \mathrm{ppm}$ NOR & 0.00767 & 0.85659 & 0.50708 & 94.86666 & 98.0197 \\
\hline $1000 \mathrm{ppm}$ NOR & 0.00172 & 0.75399 & 0.40163 & 53.41961 & 54.55012 \\
\hline
\end{tabular}


From the Carreau-Yasuda model curve fitting of complex viscosity vs. frequency, the following statements can be made:

As it can be seen from Figures 4.44 to 4.55 , the modified 4 parameter CarreauYasuda model and its numerical curve fitting seem to give very good results. All the numerical solutions are in agreement with the experimental curves.

- The importance of reliable simulation lies on the fact that the numerical method can give a value for the zero shear viscosity exactly at $\omega=0$. This doesn't happen for the experimental solution (section 4.2.2.1), as the closest frequency value to zero is the $0.0628 \mathrm{sec}^{-1}$, and all the other frequency values that were used for the determination of zero viscosity were greater than that value.

- The zero shear viscosity values determined from Carreau-Yasuda modeling are generally in good agreement with the respective values that were determined from G"/ $\omega$ vs. $\omega$ charts. Only for very viscous samples (typically produced from pure PP at low temperatures) there is disagreement. In every other case the divergence is negligible.

- Except for $\eta_{0}$, other important parameters were determined from Carreau-Yasuda modeling. These parameters were determined at three different temperatures for each CRPP sample (Tables 4.4 to 4.15 ).

- In all cases the power law index was found to be between 0.1 and 0.5 . The variation of the parameters $\lambda$, $a$, and $n$ can be explained by the fact that the curve fitting of the model covers the linear and the non-linear viscoelastic region of the sample. In all cases the algorithm converged. Generally, it can be said that four parameters were adequate for the curve fitting of the experimental data. 


\subsubsection{Fourier Transform Infrared (FT-IR) Spectroscopy}

Fourier Transform Infrared (FT-IR) spectroscopy was used as a tool for identifying if there were differences in molecular structure of the produced CRPP resins. Literature results (Thompson et al., 1997) have shown that in the case of PP degraded with peroxide (particularly Luperox 101) the peroxide radical initiator causes a peak in the IR spectrum of the CRPP, at the point of $888 \mathrm{~cm}^{-1}$. The peak at that point is due to terminal double bonds (see Figure 2.3). It was reported in the same reference that the peak in the IR spectra increases incrementally when the level of the peroxide concentration increases from $0.01 \mathrm{wt} \%$ up to $2 \mathrm{wt} \%$ because relatively more terminal double bonds are formed.

The scope of the FT-IR spectroscopy in this research was to investigate if something similar takes place for CRPP produced using NOR. In case a similar peak appears at the same wavenumber for the nitroxide-mediated CRPP, then the molecular structure of the produced NOR-mediated CRPP samples can be compared with the molecular structure of the produced peroxide-mediated CRPP samples. In addition, a peak at the same point would confirm the formation of terminal double bonds for CRPP produced with NOR, as shown in Figure 2.12.

For each of the 20 CRPP samples, two independent FT-IR measurements were made. For each sample, 2 spectra are shown (in Appendix IV). The first is the general area that the FT-IR instrument provides (wavenumbers between 400 and $4,000 \mathrm{~cm}^{-1}$ ), while the second is an expansion of the area for wavenumbers between 800 and $900 \mathrm{~cm}^{-1}$, the area that includes the wavenumber of $888 \mathrm{~cm}^{-1}$.

One point that has to be highlighted is that IR spectroscopy gives absorbance relative to the thickness of the tested film. For this reason in order to have clear picture of the absorbance of each point, that absorbance has to be compared to the absorbance of one other point in the same spectrum. For the experimental procedure, the selected peak at $888 \mathrm{~cm}^{-1}$ was compared to two reference points: the $841 \mathrm{~cm}^{-1}$ point which represents a relatively high peak in the spectrum, and the $459 \mathrm{~cm}^{-1}$ point which represents a relatively low peak (the C-C-C bending peak). Using these points, the relative absorbance at 888 $\mathrm{cm}^{-1}$ of each CRPP sample is given in Figures 4.56 and 4.57. Each data point in Figures 
4.56 and 4.57 was the average of two independent measurements done for each sample.

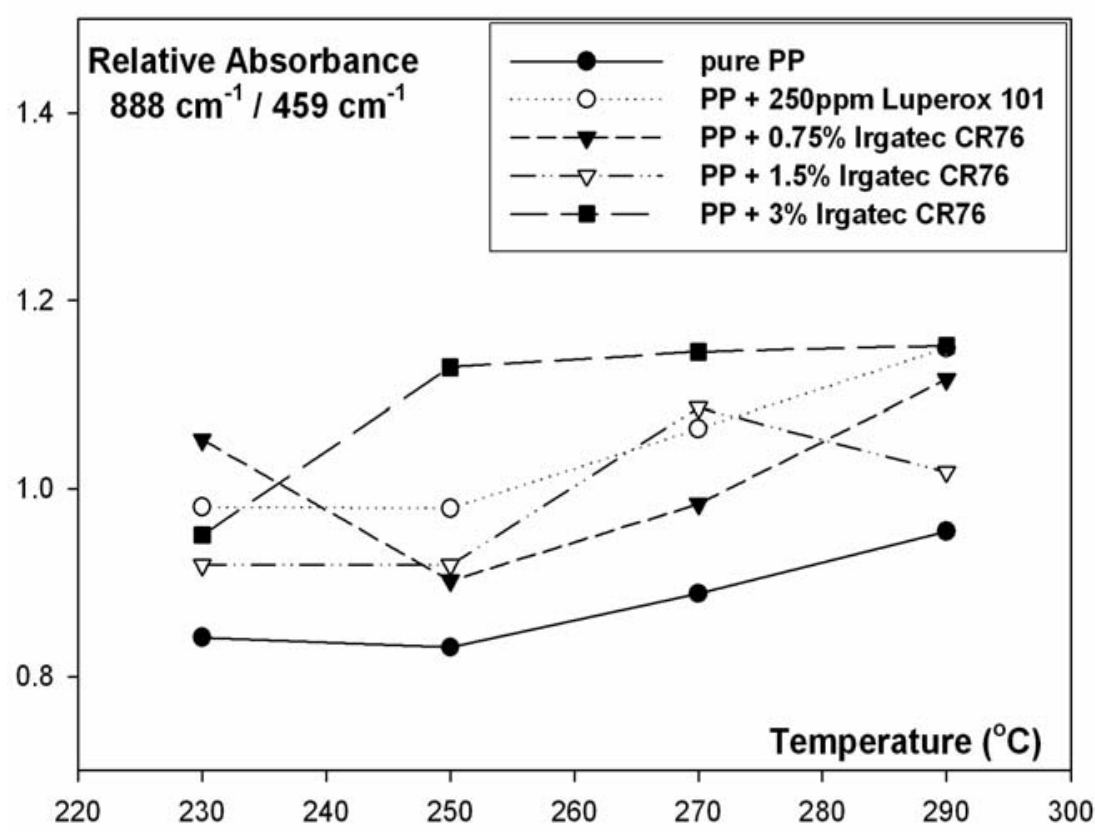

Figure 4.56: Relative absorbance $\left(888 \mathrm{~cm}^{-1} / 459 \mathrm{~cm}^{-1}\right)$ of each CRPP vs. temperature of production

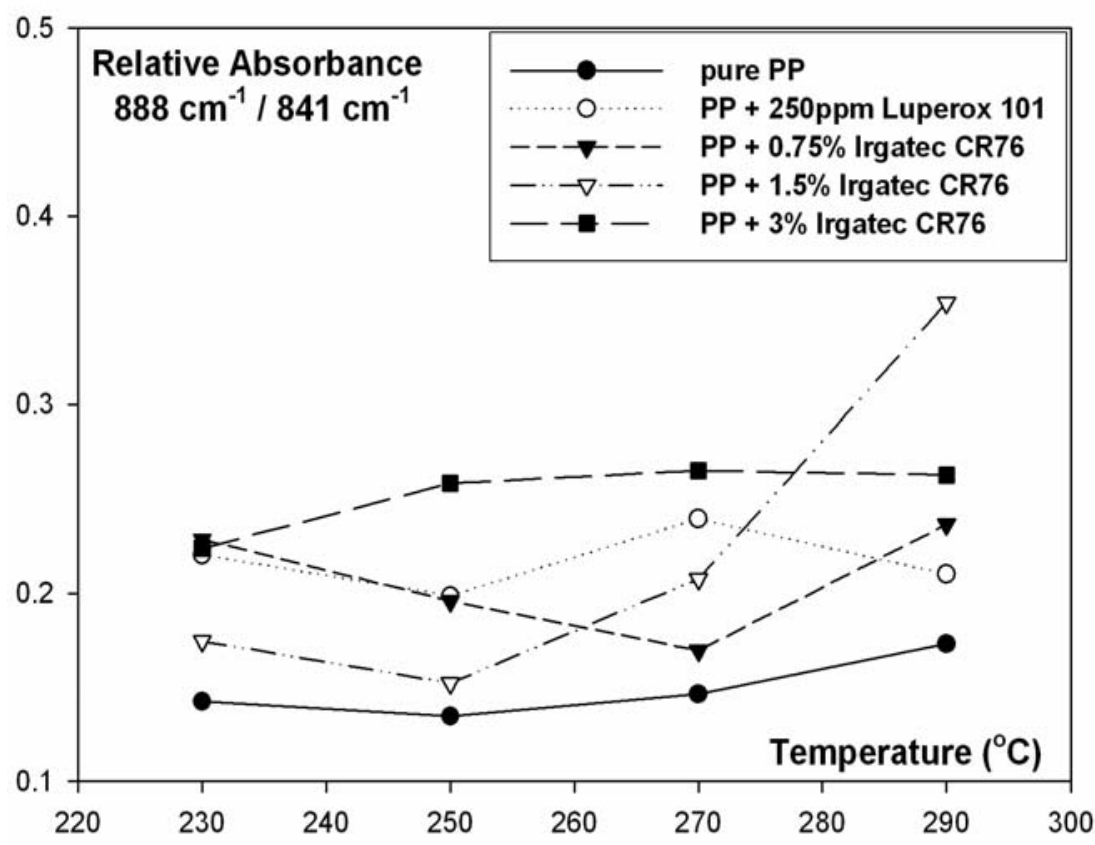

Figure 4.57: Relative absorbance $\left(888 \mathrm{~cm}^{-1} / 841 \mathrm{~cm}^{-1}\right)$ of each CRPP vs. temperature of production 
From the data presented in Figures 4.56 and 4.57 the following can be observed:

- It is clear from these charts that for CRPP produced by both of the initiators, NOR or peroxide, the relative absorbance at $888 \mathrm{~cm}^{-1}$ is higher than the relative absorbance of CRPP produced by pure PP at the same point, revealing the formation of terminal double bonds. This also verifies previous literature results, and the fact that the nitroxide initiator affects the PP in the same way the peroxide does, as both of the initiators contribute in the formation of terminal double bonds.

- By comparing the lines of PP with 250 ppm Luperox 101 and PP with $0.75 \%$ Irgatec CR76, the first is generally higher than the second one. That means that peroxide causes the formation of more terminal double bonds than the NOR.

- While the peroxide line trend exhibits an expected and normal behaviour in comparison to the virgin PP line, the NOR-lines do not. This might be explained by the fact that during PP's degradation, the NOR initiator is responsible for other side reactions that can result in slightly modified products.

\subsubsection{Gel Permeation Chromatography Analysis}

A number of selected CRPP samples were tested by Gel Permeation Chromatography (GPC) to determine average molecular weights. These samples were:

- CRPP produced from virgin PP at $230{ }^{\circ} \mathrm{C}$

- CRPP produced from virgin PP at $250{ }^{\circ} \mathrm{C}$

- CRPP produced from virgin PP at $290{ }^{\circ} \mathrm{C}$

- CRPP produced from PP with 250 ppm Luperox 101 at $290{ }^{0} \mathrm{C}$

- CRPP produced from PP with $0.75 \%$ Irgatec CR76 at $290{ }^{\circ} \mathrm{C}$

- CRPP produced from PP with $1.5 \%$ Irgatec CR76 at $250{ }^{\circ} \mathrm{C}$

- CRPP produced from PP with 1.5\% Irgatec CR76 at $290{ }^{0} \mathrm{C}$

- CRPP produced from PP with 3\% Irgatec CR76 at $290{ }^{\circ} \mathrm{C}$ 
Figures 4.58 and 4.59 illustrate the MWD, while Table 4.16 lists the number average MW $\left(M_{n}\right)$, weight average MW $\left(M_{w}\right)$, viscosity average MW $\left(M_{v}\right)$, z average MW $\left(M_{z}\right)$, and $\mathrm{z}^{+1}$ average $\mathrm{MW}\left(\mathrm{M}_{\mathrm{z}+1}\right)$ of the selected samples, all determined by the GPC analysis.

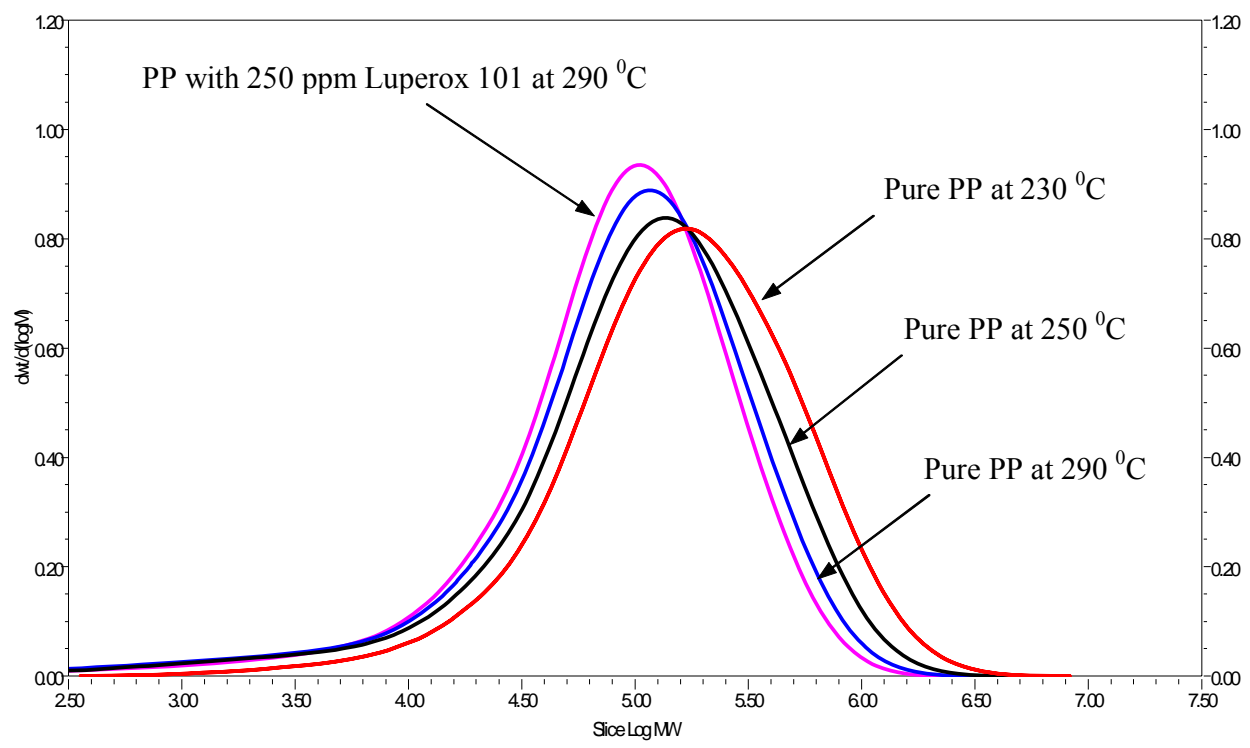

Figure 4.58: MWD for CRPP resins produced from pure PP at $230{ }^{\circ} \mathrm{C}$, pure PP at $250^{\circ} \mathrm{C}$, pure $\mathrm{PP}$ at $290{ }^{\circ} \mathrm{C}$ and PP with $250 \mathrm{ppm}$ Luperox 101 at $290{ }^{\circ} \mathrm{C}$

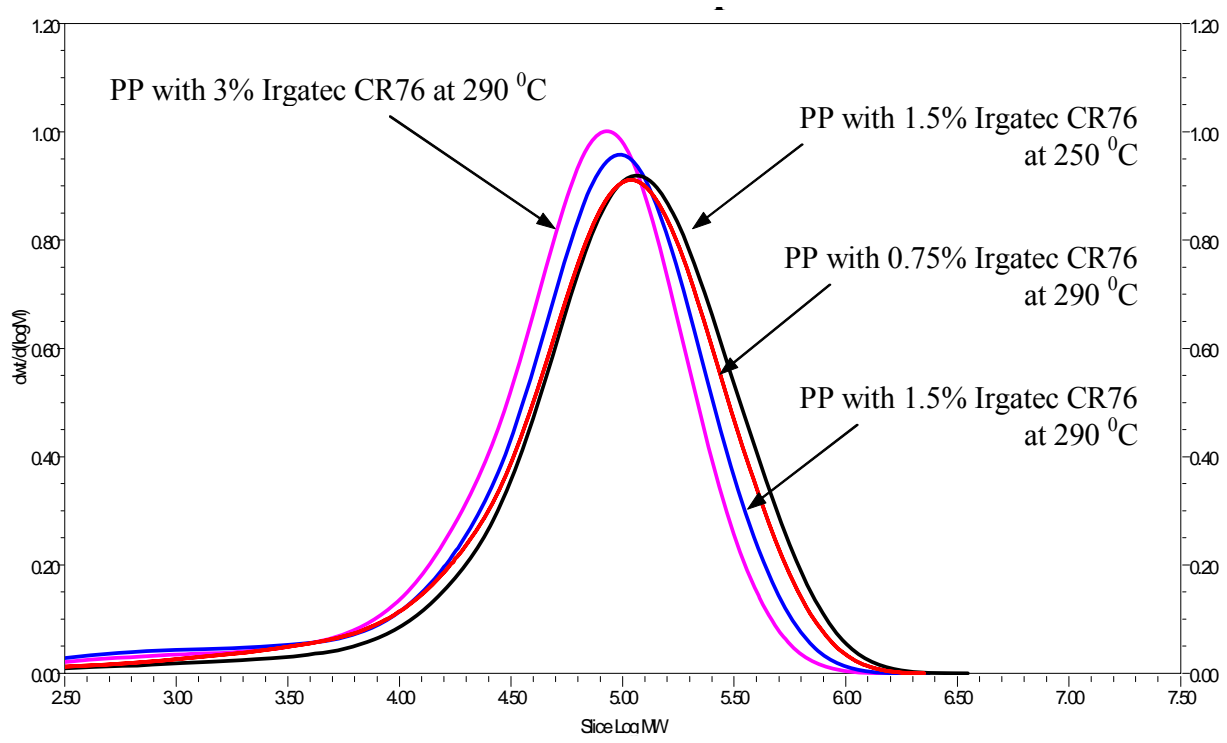

Figure 4.59: MWD for CRPP resins produced from PP with 0.75\% Irgatec CR76 at 290 ${ }^{0} \mathrm{C}$, PP with $1.5 \%$ Irgatec CR76 at $250{ }^{\circ} \mathrm{C}$, PP with $1.5 \%$ Irgatec CR76 at $290{ }^{\circ} \mathrm{C}$ and PP with $3 \%$ Irgatec CR76 at $290{ }^{\circ} \mathrm{C}$ 
Table 4.16: Molecular Weights determined from GPC analysis for selected CRPP resins

\begin{tabular}{|c|c|c|c|c|c|c|}
\hline Sample & $\mathrm{M}_{\mathrm{w}} / \mathrm{M}_{\mathrm{n}}$ & $\mathrm{M}_{\mathrm{n}}$ & $\mathrm{M}_{\mathrm{w}}$ & $\mathrm{M}_{\mathrm{v}}$ & $\mathrm{M}_{\mathrm{z}}$ & $\mathrm{M}_{\mathrm{z}+1}$ \\
\hline Pure PP, $230{ }^{\circ} \mathrm{C}$ & 5.14 & 56,120 & 286,333 & 236,935 & 731,932 & $1,392,408$ \\
\hline Pure PP, $250{ }^{\circ} \mathrm{C}$ & 7.79 & 30,161 & 222,261 & 184,959 & 545,046 & $1,012,884$ \\
\hline Pure PP, $290{ }^{\circ} \mathrm{C}$ & 8.57 & 18,354 & 157,315 & 132,676 & 356,994 & 631,510 \\
\hline $\mathrm{PP}+250$ ppm peroxide, $290{ }^{\circ} \mathrm{C}$ & 7.11 & 20,607 & 145,337 & 123,743 & 318,110 & 552,881 \\
\hline $\mathrm{PP}+0.75 \%$ Irgatec CR76, $290{ }^{\circ} \mathrm{C}$ & 8.56 & 17,331 & 147,483 & 124,775 & 325,734 & 561,953 \\
\hline $\mathrm{PP}+1.5 \%$ Irgatec $\mathrm{CR} 76,250{ }^{\circ} \mathrm{C}$ & 6.07 & 28,697 & 170,003 & 145,220 & 370,963 & 647,693 \\
\hline $\mathrm{PP}+1.5 \% \operatorname{Irgatec} \mathrm{CR} 76,290{ }^{\circ} \mathrm{C}$ & 9.73 & 12,113 & 117,508 & 100,242 & 245,817 & 408,288 \\
\hline $\mathrm{PP}+3 \%$ Irgatec $\mathrm{CR} 76,290{ }^{\circ} \mathrm{C}$ & 6.01 & 18,751 & 105,084 & 91,242 & 208,782 & 345,127 \\
\hline
\end{tabular}

Using the logarithmic values of $\mathrm{M}_{\mathrm{w}}$ of each sample and the logarithmic values of the respective zero shear viscosity $\eta_{0}$, as derived from the $\mathrm{G}^{\prime \prime} / \omega$ experimental data and the numerical simulation of $\mathrm{G}^{*}$, the charts in Figures 4.60 and 4.61 were constructed. Figure 4.60 illustrates $\eta_{0}$ versus $M_{w}$ for $\eta_{0}$ determined from the experimental data (section 4.2.2.1) and Figure 4.61 illustrates $\eta_{0}$ versus $M_{w}$ for $\eta_{0}$ determined from the curve fitting (section 4.2.2.2). In every chart, the zero viscosity data are given at the three temperatures tested in the parallel plate rheometer $\left(170,190\right.$ and $\left.210{ }^{\circ} \mathrm{C}\right)$, and for every group of data the linear regression model is given, accompanied with the $\mathrm{R}^{2}$ values for each regression line.

The importance of these charts lies in the fact that according to the Fox and Flory theory, the zero shear viscosity $\eta_{0}$ of polymer melts is found to increase with increasing molecular weight $\mathrm{M}$ or with decreasing temperature. Especially for linear polymers the dependence of $\eta_{0}$ on $M$ can be described via the following equations:

$\eta_{0}=\mathrm{k}_{\mathrm{n}}^{\prime \prime} \mathrm{M} \quad$ when $\mathrm{M}<\mathrm{M}_{\mathrm{C}}$

$\eta_{0}=\mathrm{k}_{\mathrm{n}}^{\prime \prime} \mathrm{M}^{3.4}$ when $\mathrm{M}>\mathrm{M}_{\mathrm{C}}$

where $\mathrm{k}_{\mathrm{n}}^{\prime}, \mathrm{k}_{\mathrm{n}}^{\prime \prime}$ are constants and the transition marked by $\mathrm{M}_{\mathrm{C}}$ (a critical MW) represents in some sense a division between low molecular weight and high molecular weight polymers. 


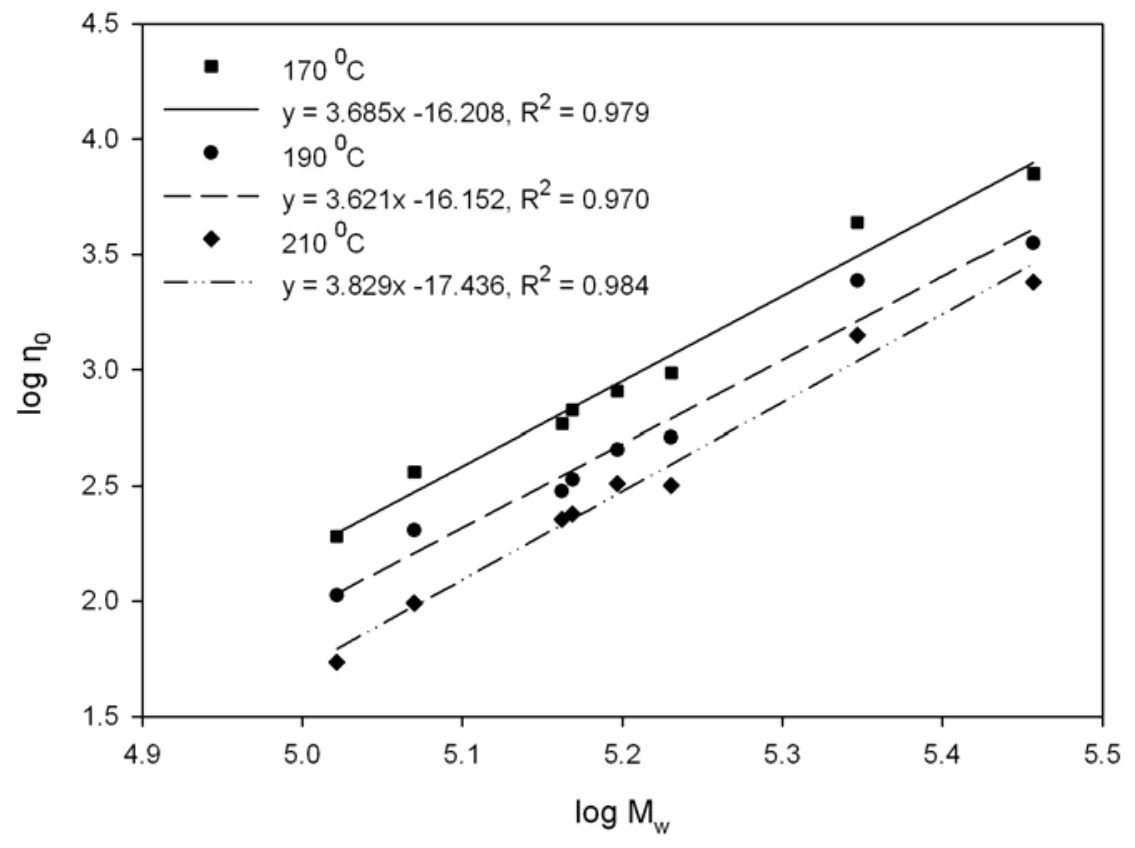

Figure 4.60: Zero shear viscosity, as determined for 170,190 and $210{ }^{\circ} \mathrm{C}$ using the $\mathrm{G}^{\prime \prime} / \omega$ experimental data vs. the determined $\mathrm{M}_{\underline{w}}$ for the 8 tested CRPP resins including linear regression models for each data set

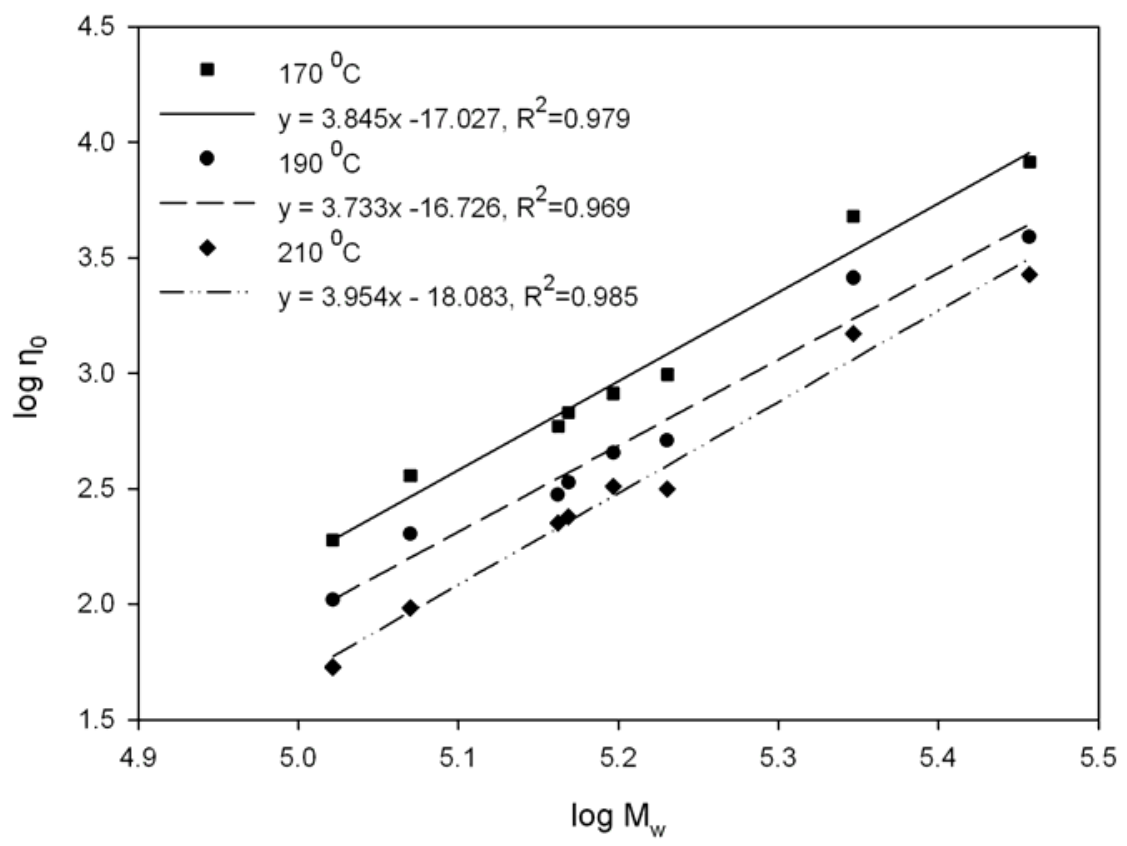

Figure 4.61: Zero shear viscosity, as determined for 170,190 and $210^{\circ} \mathrm{C}$ using numerical simulation vs. the determined $\mathrm{M}_{\underline{\mathrm{w}}}$ for the 8 tested CRPP resins including linear regression $\underline{\text { models for each data set }}$ 
Fox and Flory theory has been confirmed by numerous investigations (Fox and Loshaek (1955), Fox et al. (1956), Baumann and Steingiser (1963), Gruver et al. (1964), Kraus and Gruver (1965), Minoshima et al. (1980)). Generally, it was found that for polydisperse systems that molecular weight which should be used is the weight average MW $\left(\mathrm{M}_{\mathrm{w}}\right)$. Using equation (4.8b), for high molecular weight polymers, it is easily proved that:

$$
\log \left(\eta_{0}\right)=3.4 \log \left(M_{w}\right)+\log k_{n}^{\prime \prime}
$$

Equation (4.9) means that for the $\log \left(\eta_{0}\right)-\log \left(M_{w}\right)$ chart, the data must be located on a line of slope 3.4, which is close to the slopes of the data trends shown in Figures 4.60 and 4.61.

Apart from the conventional $\mathrm{M}_{\mathrm{w}} / \mathrm{M}_{\mathrm{n}}$ polydispersity index (PDI), other polydispersity indices can be examined and compared to the PDI values. These indices are based on rheological data. This may be useful, since rheological data may be more sensitive (than GPC results) to small differences between resins. The connection between GPC and rheological results has always been an issue for polymer processing engineering.

Polydispersity indices derived from rheological data have been discussed in the literature. Two of the most important have been introduced by Shroff and Mavridis (1995). These are:

a. Polydispersity at the High MW End (ER). ER is extracted from G' vs. G" data as:

$$
\mathrm{ER}=\left.\mathrm{C}_{1} \cdot \mathrm{G}^{\prime}\right|_{\text {at } \mathrm{G}_{\mathrm{ref}}^{\prime \prime}}
$$

where $\mathrm{G}^{\prime \prime}$ ref is selected to be at low modulus value (corresponding to low frequencies) and $\mathrm{C}_{1}$ is a normalization constant. Typically for polyolefin melts, $\mathrm{C}_{1}=1.871 \cdot 10^{-3}$ and $\mathrm{G}_{\text {ref }}^{\prime \prime}=500 \mathrm{~Pa}$. In case the available data do not extend to $G^{\prime \prime}{ }_{\text {ref, }}$ a numerical linear extrapolation to $\mathrm{G}^{\prime \prime}$ ref is possible because the log plot of $\mathrm{G}^{\prime} \mathrm{vs}$. $\mathrm{G}^{\prime \prime}$ is almost linear.

b. Overall Polydispersity Measure (PDR). The PDR index is defined as: 
$\operatorname{PDR}=\frac{\eta_{1}^{*}}{\eta_{3}^{*}} \cdot \frac{\left(\eta_{1}^{*} \cdot \eta_{3}^{*}\right)^{1 / 2}}{\eta_{2}^{*}}$

$\eta_{1}^{*}, \eta_{2}^{*}$ and $\eta_{3}^{*}$ represent three complex viscosities that are calculated at three complex modulus values: $\mathrm{G}_{\mathrm{ref}, 1}^{*}, \mathrm{G}_{\mathrm{ref}, 2}^{*}=\left(\mathrm{G}_{\mathrm{ref}, 1}^{*} \cdot \mathrm{G}_{\mathrm{ref}, 3}^{*}\right)^{1 / 2}$ and $\mathrm{G}_{\mathrm{ref}, 3}^{*} \cdot$ The first part in equation (4.11) is a measure of shear viscosity, while the second term is a measure of curvature of the viscosity curve with a larger curvature corresponding to smaller polydispersity. Usually for linear polyolefins the selected reference complex modulus values are $\mathrm{G}_{\mathrm{ref}, 1}^{*}=$ $1950 \mathrm{~Pa}$ and $\mathrm{G}_{\mathrm{ref}, 3}^{*} / \mathrm{G}_{\mathrm{ref}, 1}^{*}=2$, and for Long Chain Branched (LCB) polyolefins $\mathrm{G}_{\mathrm{ref}, 1}^{*}=$ $1000 \mathrm{~Pa}$ and $\mathrm{G}_{\mathrm{ref}, 3}^{*} / \mathrm{G}_{\mathrm{ref}, 1}^{*}=1.5$.

Table 4.17 illustrates the measured ER and PDR values for the selected samples. In addition, typical values for the complex viscosity at $\mathrm{G}^{*}=2 \cdot 10^{4} \mathrm{~Pa}$ are given. The last column shows the approximate increase of the $\eta^{*}$ at $\mathrm{G}^{*}=2 \cdot 10^{4} \mathrm{~Pa}$, something that shows by what factor the complex viscosity at $\mathrm{G}^{*}=2 \cdot 10^{4} \mathrm{~Pa}$ of each CRPP is reduced by using as reference value the complex viscosity at $\mathrm{G}^{*}=2 \cdot 10^{4} \mathrm{~Pa}$ for CRPP produced from pure PP at $230{ }^{\circ} \mathrm{C}$.

Table 4.17: Polydispersity indices ER and PDR derived from rheological data, complex viscosity $\eta^{*}$ at $\mathrm{G}^{*}=2 \cdot 10^{4} \mathrm{~Pa}$ and its approximate increase for the selected CRPP resins

\begin{tabular}{|c|c|c|c|c|}
\hline Sample & ER & PDR & $\eta^{*}$ at $\mathrm{G}^{*}=2 \cdot 10^{4} \mathrm{~Pa}$ & $\begin{array}{c}\text { Approx. increase of } \eta^{*} \\
\text { at } \mathrm{G}^{*}=2 \cdot 10^{4} \mathrm{~Pa}\end{array}$ \\
\hline Pure PP, $230{ }^{\circ} \mathrm{C}$ & 0.79 & 3.05 & $2.06 \cdot 10^{4}$ & 1.0 \\
\hline Pure PP, $250{ }^{\circ} \mathrm{C}$ & 0.73 & 2.95 & $1.15 \cdot 10^{4}$ & 1.8 \\
\hline Pure PP, $290{ }^{\circ} \mathrm{C}$ & 0.56 & 2.47 & $2.60 \cdot 10^{3}$ & 7.9 \\
\hline $\mathrm{PP}+250$ ppm peroxide, $290{ }^{\circ} \mathrm{C}$ & 0.52 & 2.31 & $1.94 \cdot 10^{3}$ & 10.6 \\
\hline $\mathrm{PP}+0.75 \%$ Irgatec $\mathrm{CR} 76,290^{\circ} \mathrm{C}$ & 0.48 & 2.27 & $2.55 \cdot 10^{3}$ & 8.1 \\
\hline $\mathrm{PP}+1.5 \%$ Irgatec $\mathrm{CR} 76,250{ }^{\circ} \mathrm{C}$ & 0.50 & 2.36 & $3.55 \cdot 10^{3}$ & 20.6 \\
\hline $\mathrm{PP}+1.5 \% \operatorname{Irgatec} \mathrm{CR} 76,290^{\circ} \mathrm{C}$ & 0.44 & 2.10 & $9.99 \cdot 10^{2}$ & 35.0 \\
\hline $\mathrm{PP}+3 \%$ Irgatec $\mathrm{CR} 76,290^{\circ} \mathrm{C}$ & 0.41 & 1.81 & $5.89 \mathrm{E}+02$ & \\
\hline
\end{tabular}


From the data given in section 4.2.4, the following observations can be made:

The MWD and MW were studied for 8 selected CRPP samples. These CRPP correspond to the most extreme production conditions of temperature and concentration of radical generator.

- Generally, by increasing the temperature or the concentration of the radical generator the MWD curve moves to lower molecular weights. In addition, the weight average MW $\left(\mathrm{M}_{\mathrm{w}}\right)$ decreases, but the PDI does not show a clear trend, something that can be explained by the fact that in some cases the decrease of the PDI denominator $\left(M_{n}\right)$ is larger than the decrease of the PDI numerator $\left(M_{w}\right)$.

A clear trend of polydispersity index can be shown in the case of the rheological polydispersity indices ER and PDR. By increasing the temperature or the concentration of the radical generator, both of them decrease.

Figures 4.60 and 4.61 illustrate good correlations for the zero shear viscosity versus $M_{w}$. The $\log \left(\eta_{0}\right)-\log \left(M_{w}\right)$ data strongly approach linear profiles with their slope close to 3.4, confirming the literature results (something that also indicates linear polymers). In addition, $\eta_{0}$ was found to decrease with increasing temperature.

As a final observation, it can be said that high concentrations of the nitroxyl radical generator are responsible for linear materials of reduced rheological polydispersities. No evidence of LCB has been detected. 


\subsection{CRPP Produced with Tetrafunctional Peroxide Initiator}

The peroxide initiator Luperox 101 by Aldrich, which was used as a typical peroxide radical generator for comparison to the new nitroxyl radical generator, is a monofunctional initiator. A new tetrafunctional peroxide initiator Luperox JWEB50 (Figure 2.2) by Atofina was used in a parallel study to compare its CRPP results with results of CRPP produced with the monofunctional Luperox 101. These results have a special importance because the two peroxides potentially can have the same qualitative but different quantitative effect in the polymer degradation process.

Multifunctional initiator's main advantage was claimed to be the improved polymerization productivity without sacrificing the molecular weight (Luperox JWEB50, technical bulletin, Atofina, 2001). Recent research (Scorah et al. (2004), Scorah (2005), Scorah et al. (2005)) on styrene, methyl methacrylate (MMA) and a-methyl styrene has shown that this particular benefit of the multifunctional initiator is limited to certain monomer and comonomer feeds. In addition, the polymer products have shown evidence of branching for all cases except for the homopolymerization of MMA.

This section, which studies the effects of Luperox JWEB50 on CRPP, can be considered as an extension of the research about the novel multifunctional peroxide initiator. The experimental sequence was almost the same as in the case of CRPP produced with NOR: production in Haake mixer, characterization in rheometer and GPC, and comparison with CRPP produced with Luperox 101 at the same concentrations. In addition to the basic comparison of CRPP produced with the two peroxides, the characterization of CRPP produced with Luperox JWEB50 focuses on the investigation of possible branching, something that according to the existing literature was found to happen with other polymer materials (Scorah et al. (2005)).

Production of CRPP samples with Luperox JWEB50 and Luperox 101 was done at equivalent peroxide concentrations. That means at concentrations which contain the same number of moles of the -O-O- group. The CRPP production was done in the Haake Mixer and the PP used was PP34RY01 by Equistar (Table 4.18). The 
concentrations used were $0.01,0.03$, and $0.1 \mathrm{wt} \%$ of peroxide A1 (Luperox 101) while the equivalent concentrations used were $0.0166,0.055$, and $0.166 \mathrm{wt} \%$ for peroxide A2 (Luperox JWEB 50). To facilitate homogeneous distribution of the peroxides among PP, these two kinds of peroxides were dissolved in acetone before mixing with PP. After evaporation of the acetone, the PP pellets with peroxides were added to the Haake batch mixer at 200 and $230{ }^{\circ} \mathrm{C}$ for 20 minutes. Considering the peroxide concentrations and the production temperature, 14 CRPP were produced. The produced CRPP were milled into small chunks for further analysis, and a portion of each of them was pressed into disk specimens for rheological measurements.

Rheological data were collected on the rheometer (AR 2000, TA instruments) with a cone-and-plate fixture $\left(40 \mathrm{~mm}\right.$ diameter, angle $\left.1^{\circ}\right)$. The tests were run under a nitrogen purge at a flow rate of $10 \mathrm{ml} / \mathrm{min}$. Time sweeps were conducted to make sure there was no further degradation during testing. Strain sweep was used to determine the linear region for the frequency sweep testing. The frequency sweep tests were performed at 190 and $210{ }^{\circ} \mathrm{C}$. The results are shown in Figures 4.62 to 4.73 . The legends refer to data received from PP pellets (without Haake mixer processing), and CRPP processed at $200{ }^{0} \mathrm{C}$ or $230{ }^{0} \mathrm{C}$ in the Haake mixer: received from pure PP, from PP with $0.01 \mathrm{wt} \%$ peroxide A1, from PP with 0.1 wt \% peroxide A1, from PP with 0.0166 wt \% peroxide A2 and from PP with 0.166 wt \% peroxide A2, respectively.

Table 4.18: Materials used for production of CRPP with monofunctional and $\underline{\text { tetrafunctional peroxide initiator }}$

\begin{tabular}{|c|c|c|c|}
\hline $\begin{array}{c}\text { Commercial } \\
\text { name }\end{array}$ & Physical status & Chemical nature & Provider \\
\hline PP34RY01 & pellets & PP resin from industry (MFR $=57)$ & Equistar \\
\hline Luperox JWEB50 & liquid & $\begin{array}{c}\text { Tetrafunctional peroxide } \\
(50 \% \text { peroxide, } 50 \% \text { ethylbenzene })\end{array}$ & Atofina \\
\hline Luperox 101 & liquid & $\begin{array}{c}\text { Monofunctional peroxide } \\
(90 \% \text { peroxide })\end{array}$ & Aldrich \\
\hline
\end{tabular}




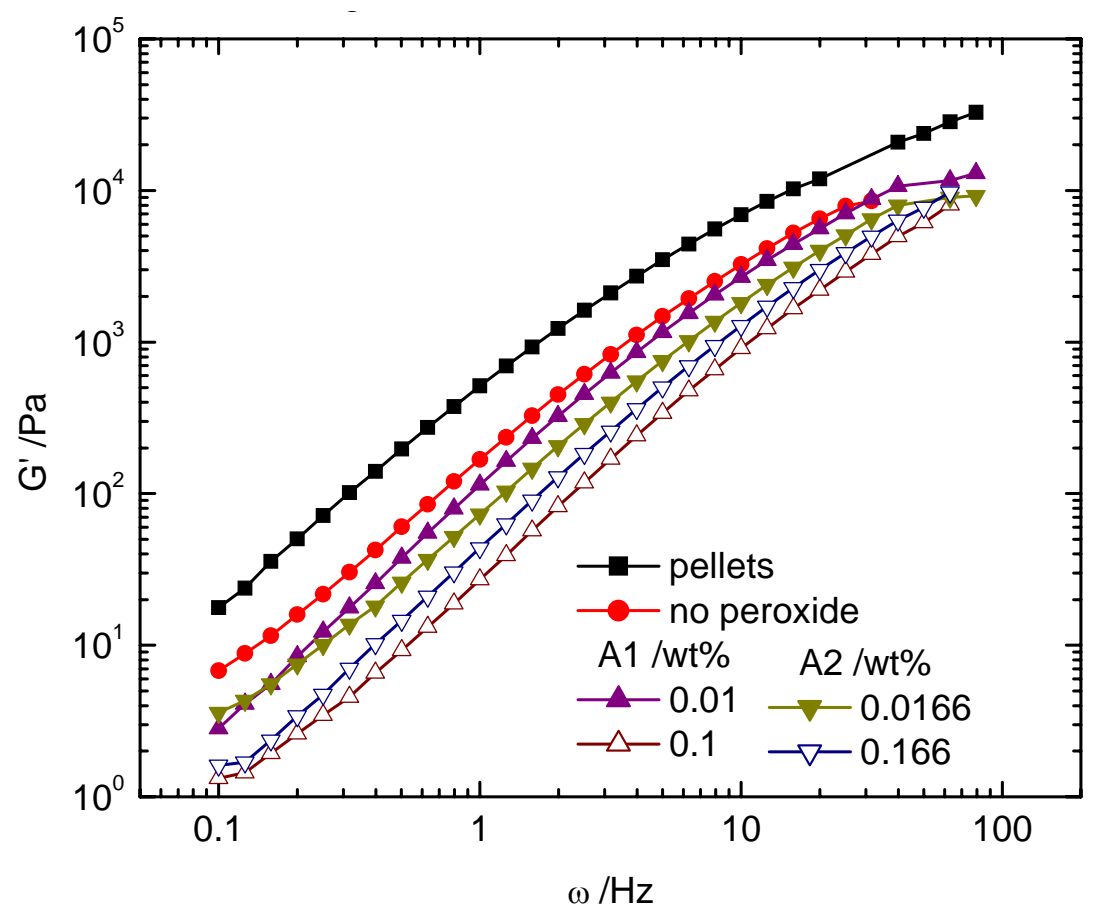

Figure 4.62: Storage modulus $\mathrm{G}^{\prime}$ vs. $\omega$ for CRPP produced at $200{ }^{\circ} \mathrm{C}$ and tested at $190{ }^{\circ} \mathrm{C}$ $\underline{\text { in the cone and plate viscometer }}$

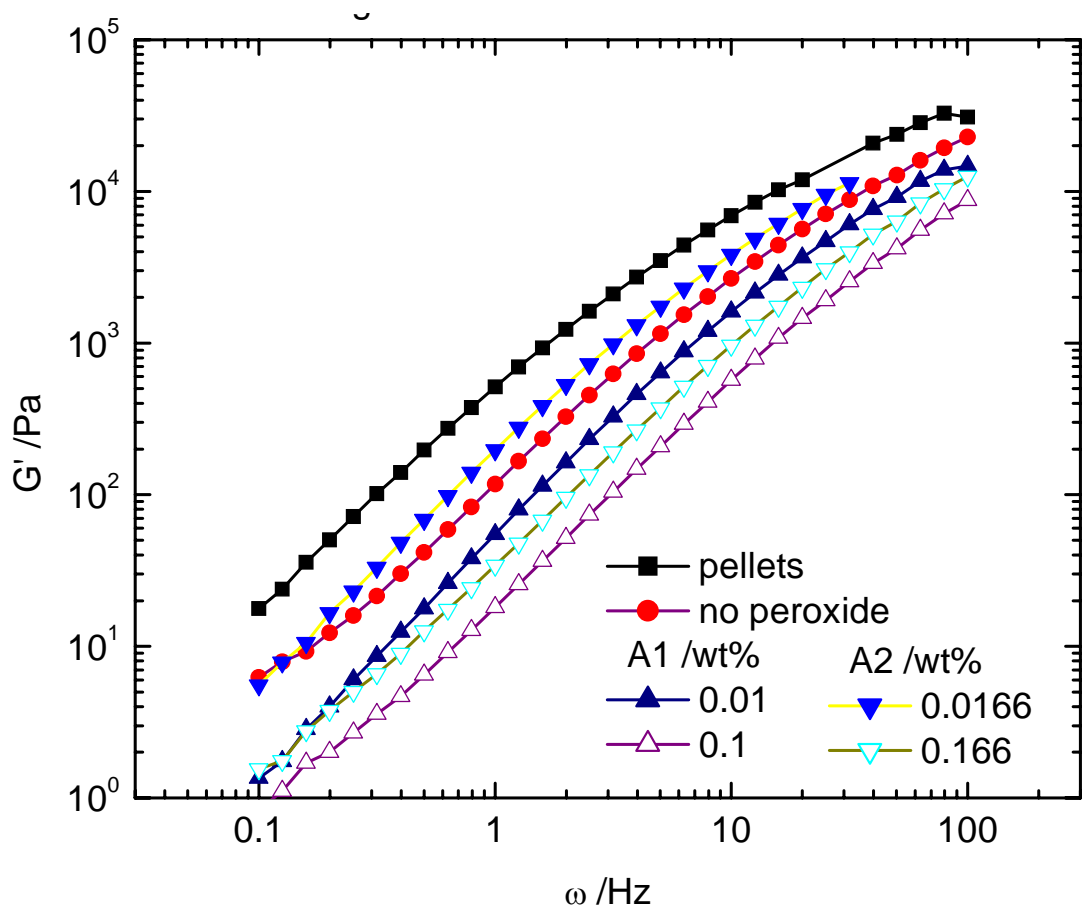

Figure 4.63: Storage modulus $\mathrm{G}^{\prime}$ vs. $\omega$ for CRPP produced at $230{ }^{\circ} \mathrm{C}$ and tested at $190{ }^{\circ} \mathrm{C}$ in the cone and plate viscometer 


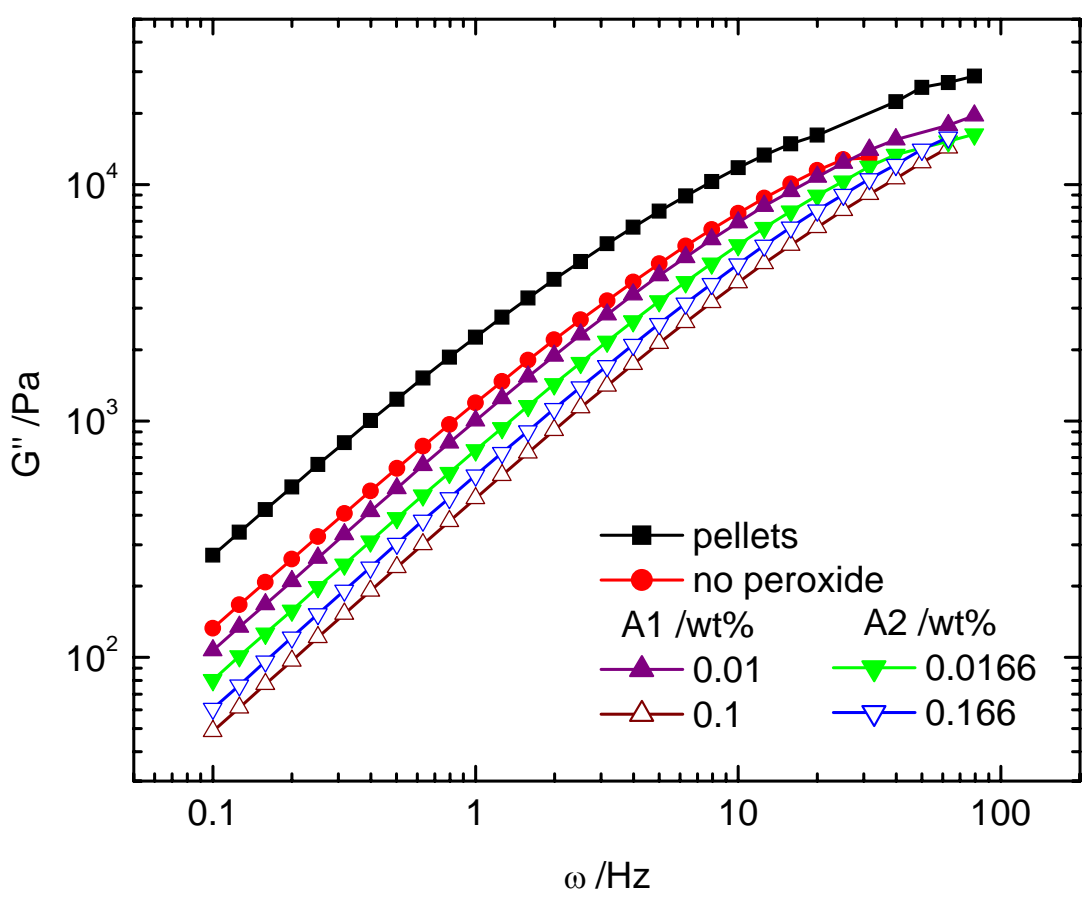

Figure 4.64: Loss modulus G" vs. $\omega$ for CRPP produced at $200{ }^{\circ} \mathrm{C}$ and tested at $190{ }^{\circ} \mathrm{C}$ in the cone and plate viscometer

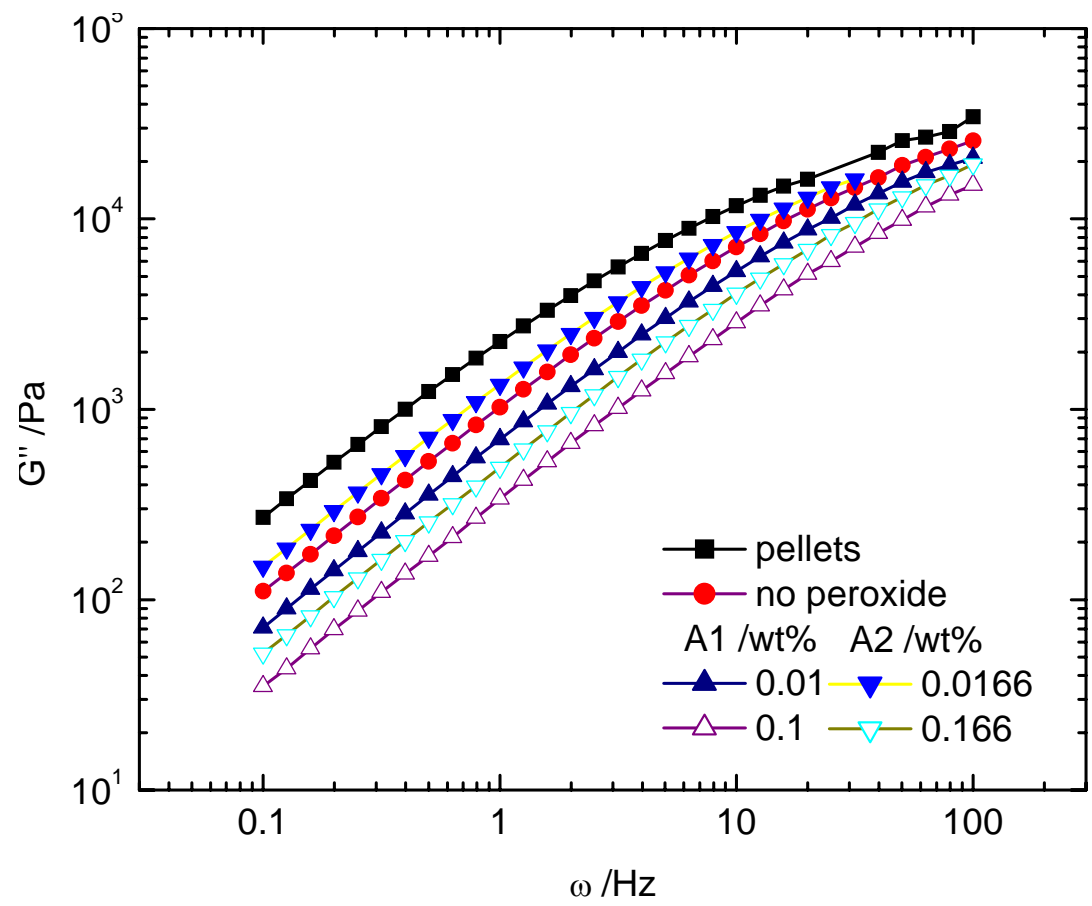

Figure 4.65: Loss modulus G" vs. $\omega$ for CRPP produced at $230{ }^{\circ} \mathrm{C}$ and tested at $190{ }^{\circ} \mathrm{C}$ in the cone and plate viscometer 


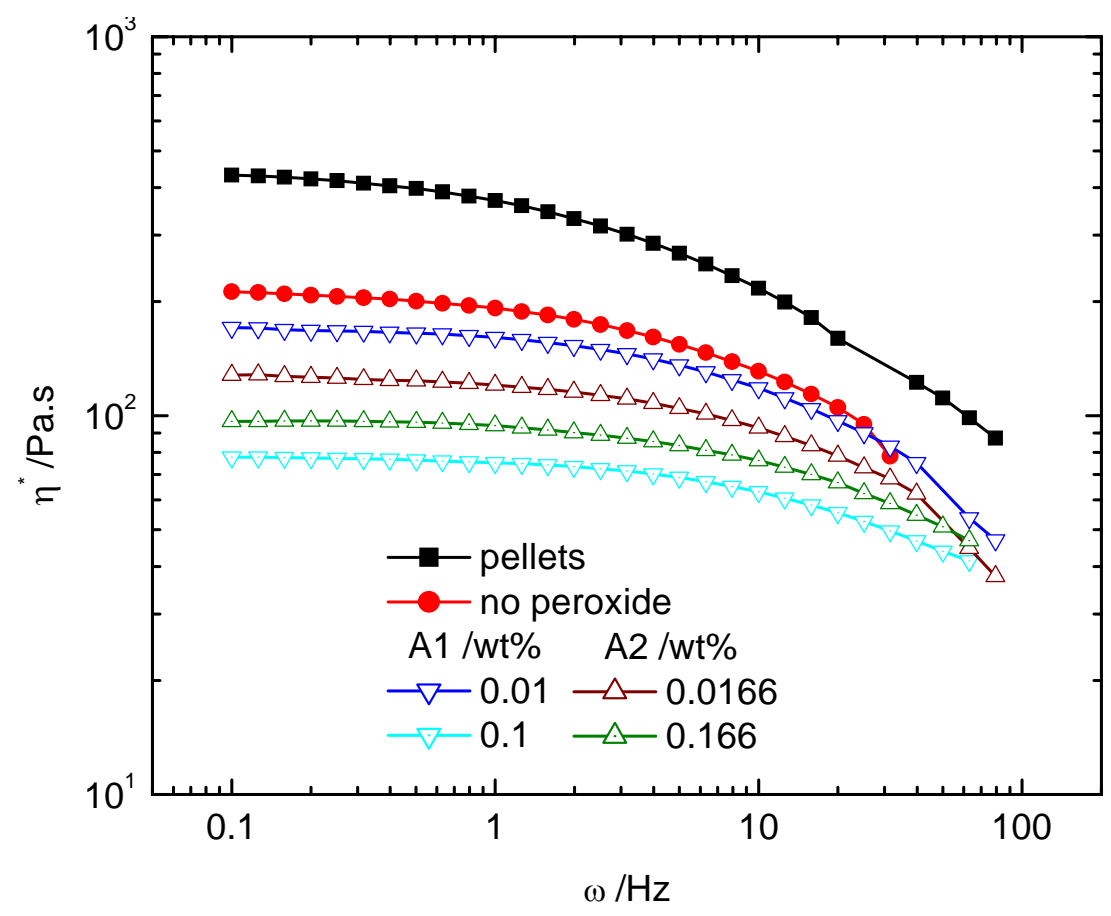

Figure 4.66: Complex viscosity $\eta^{*}$ vs. $\omega$ for CRPP produced at $200{ }^{\circ} \mathrm{C}$ and tested at 190 ${ }^{0} \mathrm{C}$ in the cone and plate viscometer

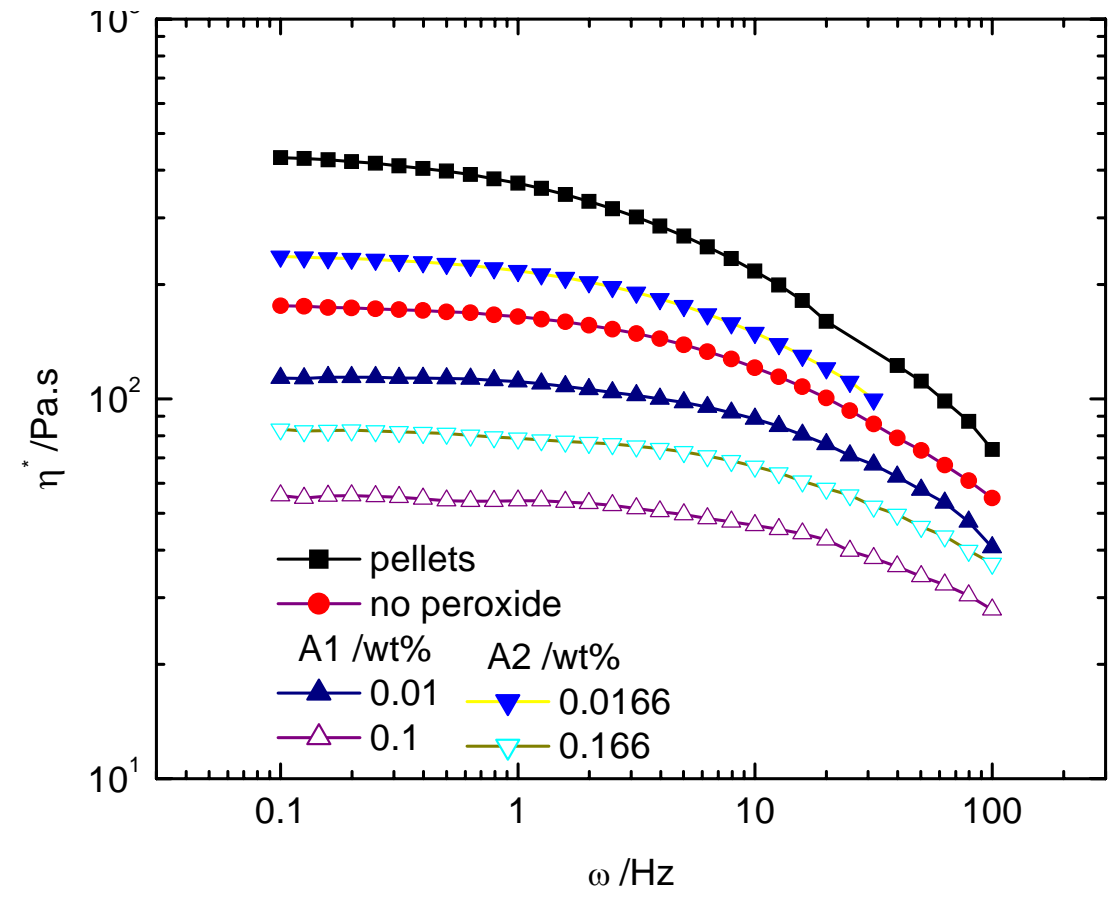

Figure 4.67: Complex viscosity $\eta^{*}$ vs. $\omega$ for CRPP produced at $230{ }^{\circ} \mathrm{C}$ and tested at 190

${ }^{0} \mathrm{C}$ in the cone and plate viscometer 


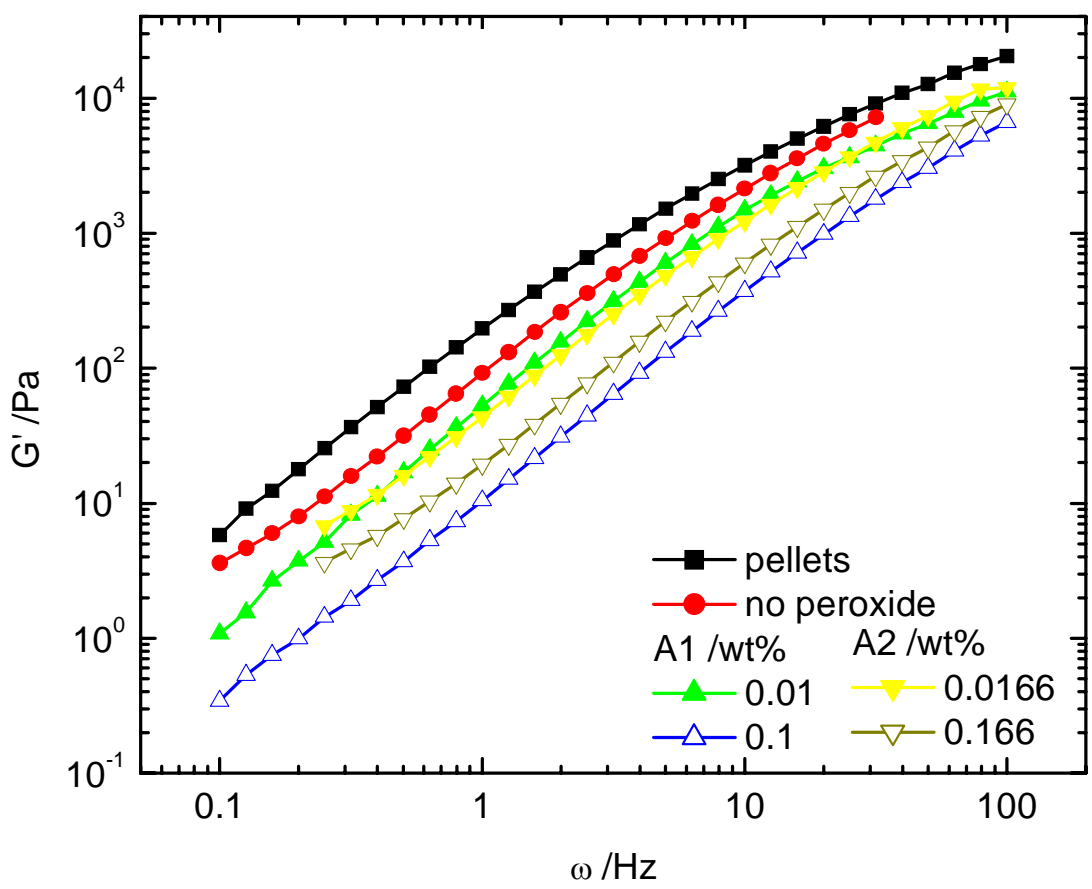

Figure 4.68: Storage modulus $\mathrm{G}^{\prime}$ vs. $\omega$ for CRPP produced at $200{ }^{\circ} \mathrm{C}$ and tested at $210^{\circ} \mathrm{C}$ in the cone and plate viscometer

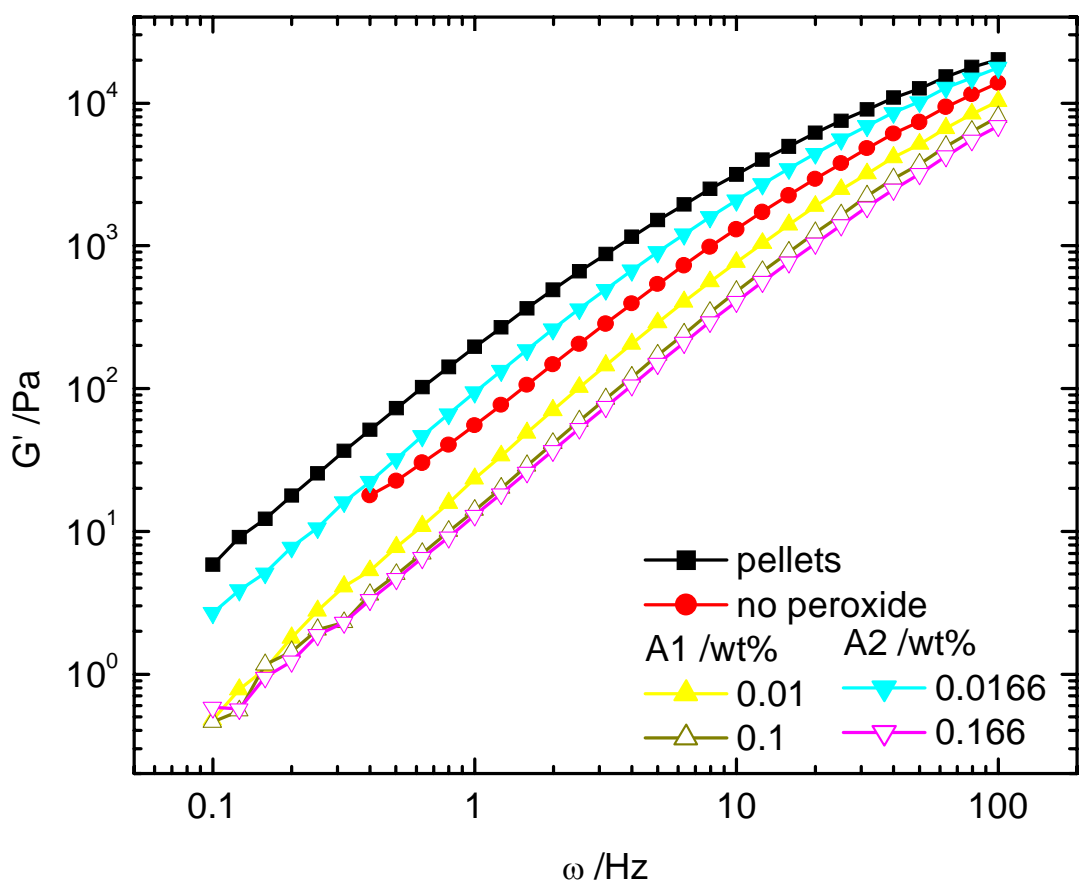

Figure 4.69: Storage modulus $\mathrm{G}^{\prime}$ vs. $\omega$ for CRPP produced at $230{ }^{\circ} \mathrm{C}$ and tested at $210^{\circ} \mathrm{C}$ in the cone and plate viscometer 


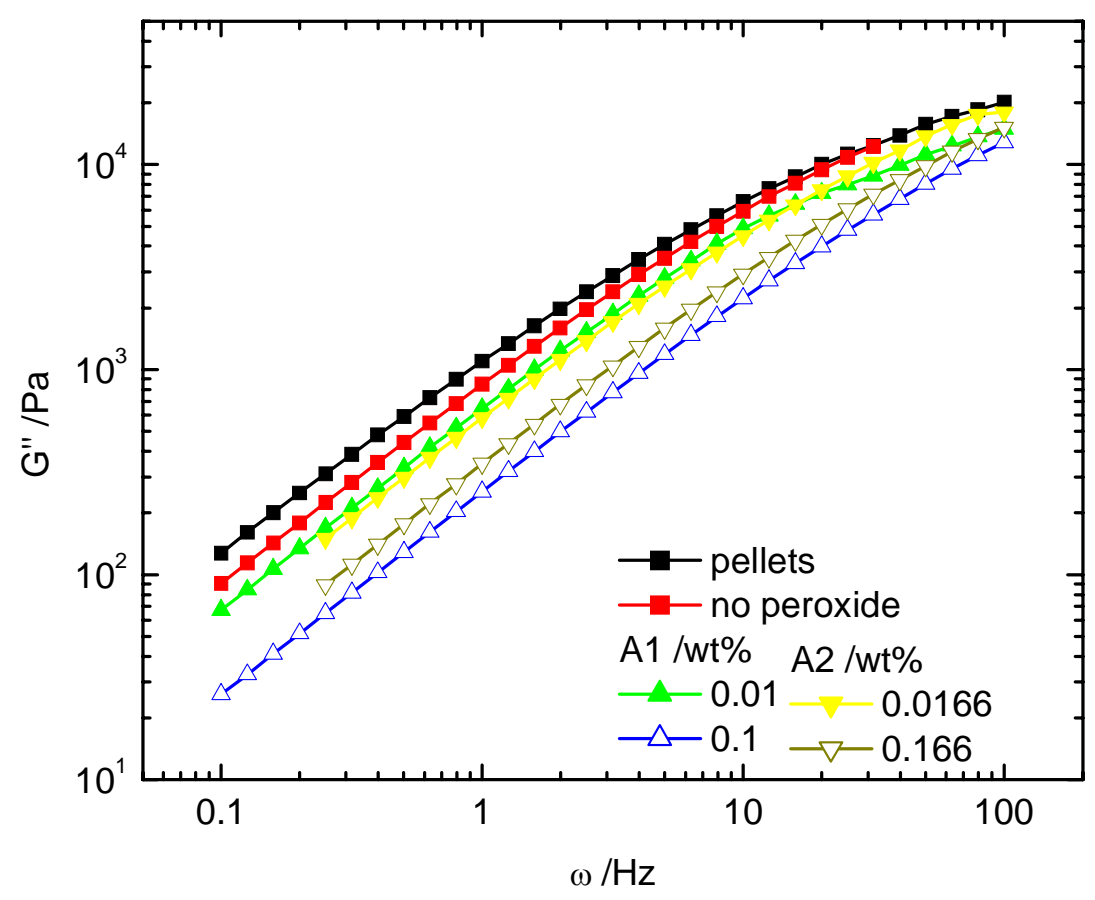

Figure 4.70: Loss modulus G" vs. $\omega$ for CRPP produced at $200^{\circ} \mathrm{C}$ and tested at $210^{\circ} \mathrm{C}$ in the cone and plate viscometer

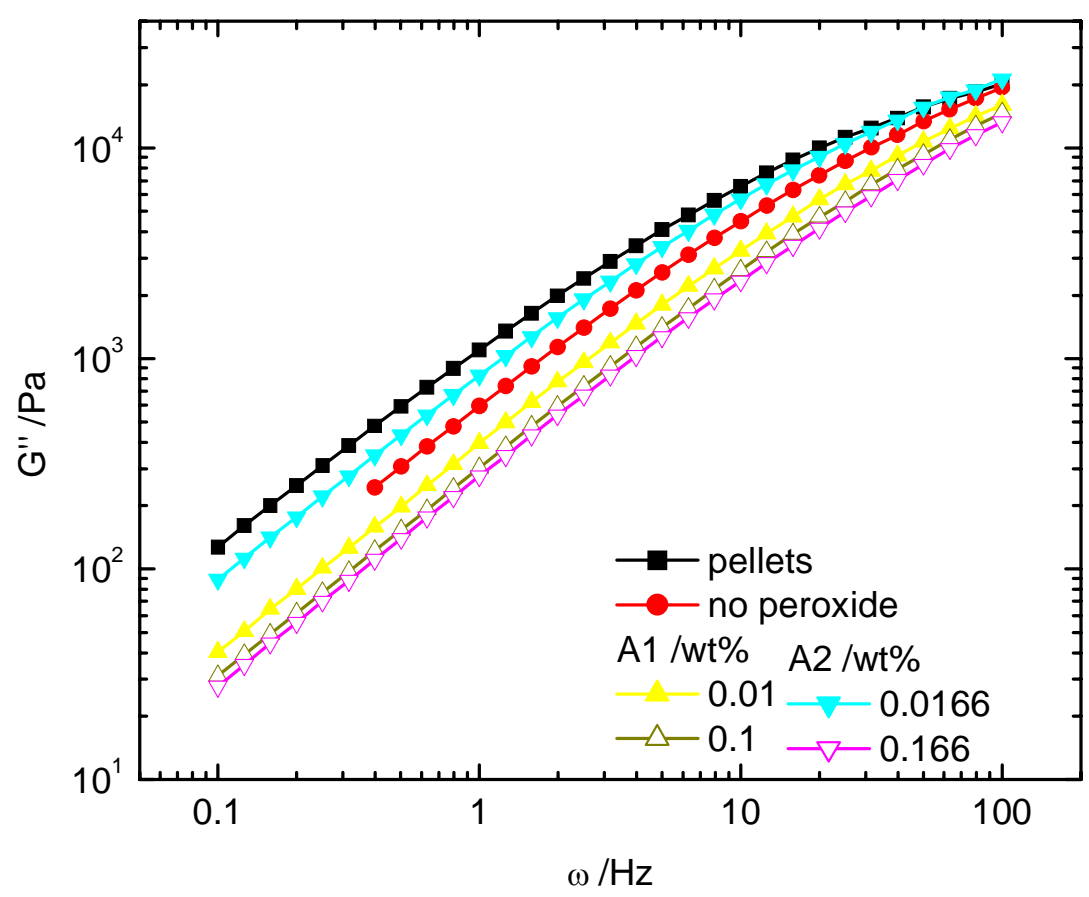

Figure 4.71: Loss modulus G" vs. $\omega$ for CRPP produced at $230{ }^{\circ} \mathrm{C}$ and tested at $210^{\circ} \mathrm{C}$ in the cone and plate viscometer 


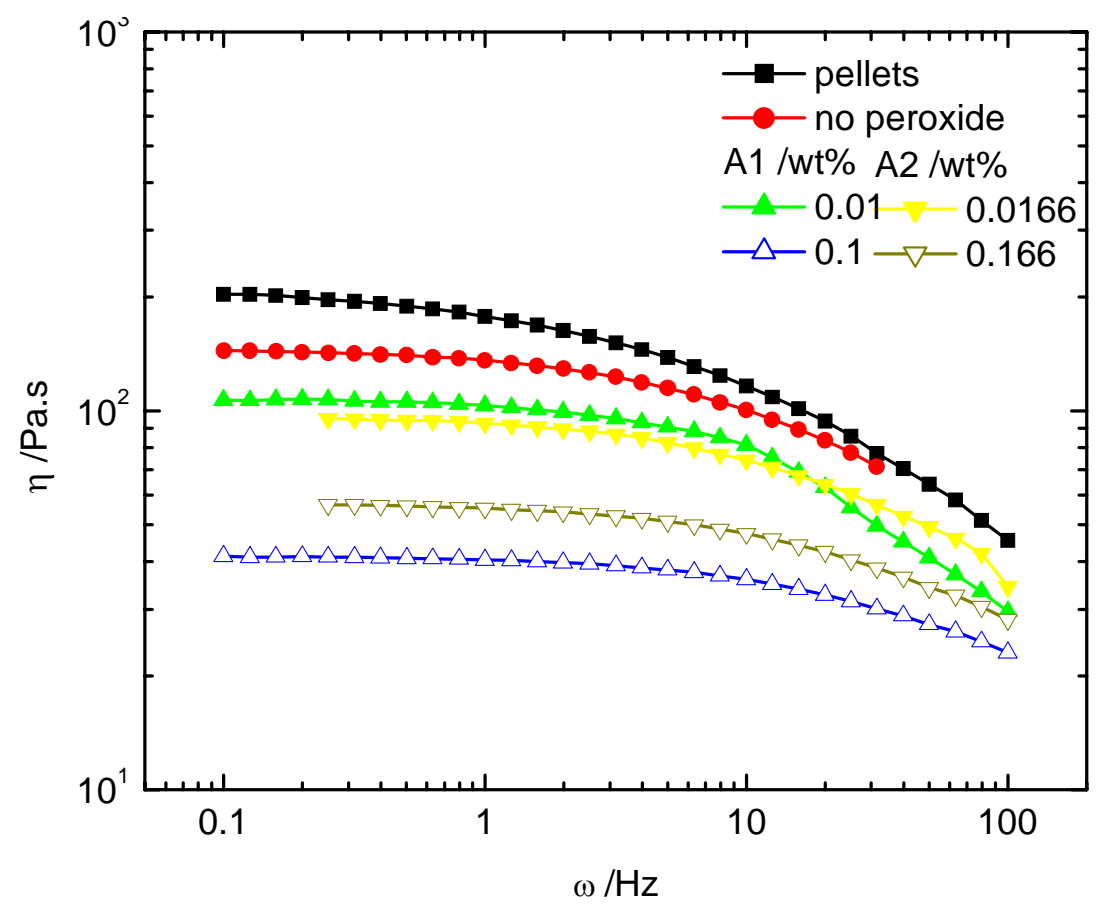

Figure 4.72: Complex viscosity $\eta^{*}$ vs. $\omega$ for CRPP produced at $200{ }^{\circ} \mathrm{C}$ and tested at 210 ${ }^{0} \mathrm{C}$ in the cone and plate viscometer

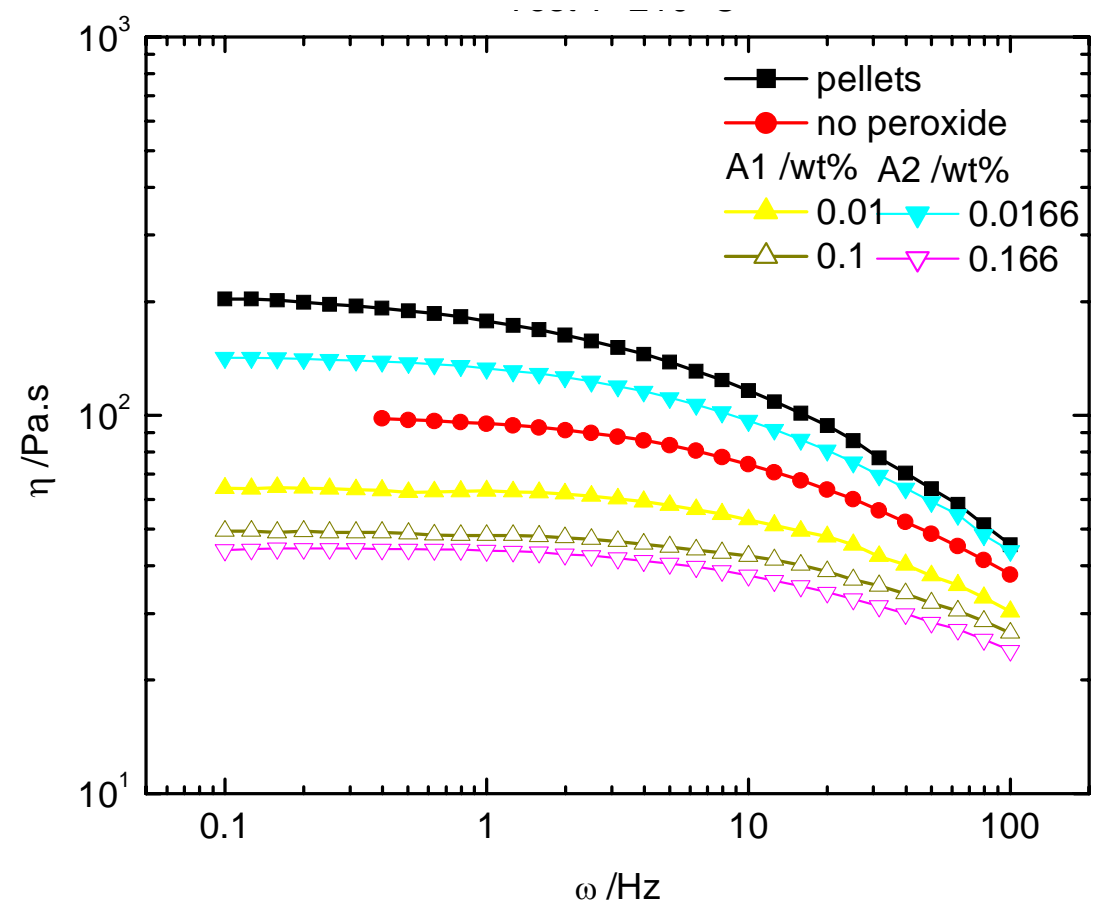

Figure 4.73: Complex viscosity $\eta^{*}$ vs. $\omega$ for CRPP produced at $230{ }^{\circ} \mathrm{C}$ and tested at 210 ${ }^{0} \mathrm{C}$ in the cone and plate viscometer 
In addition to the rheological testing, selected CRPP were tested with high temperature GPC. The experimental procedure used two injections for each sample. These injections are noted as "experiment 1" and "experiment 2" in the legend of every chart. The MWD of the samples are illustrated in Figures 4.74 to 4.80. The results are grouped according to the temperature of production $\left(200\right.$ or $\left.230{ }^{\circ} \mathrm{C}\right)$ and the peroxide concentration. In every chart, the MWD of the virgin PP in pellets is given as the reference curve. In addition, Figure 4.74 illustrates the temperature effect for the PP material. CRPP produced from pure PP at 200 and $230{ }^{\circ} \mathrm{C}$ are compared to the reference curve of the virgin PP pellets.

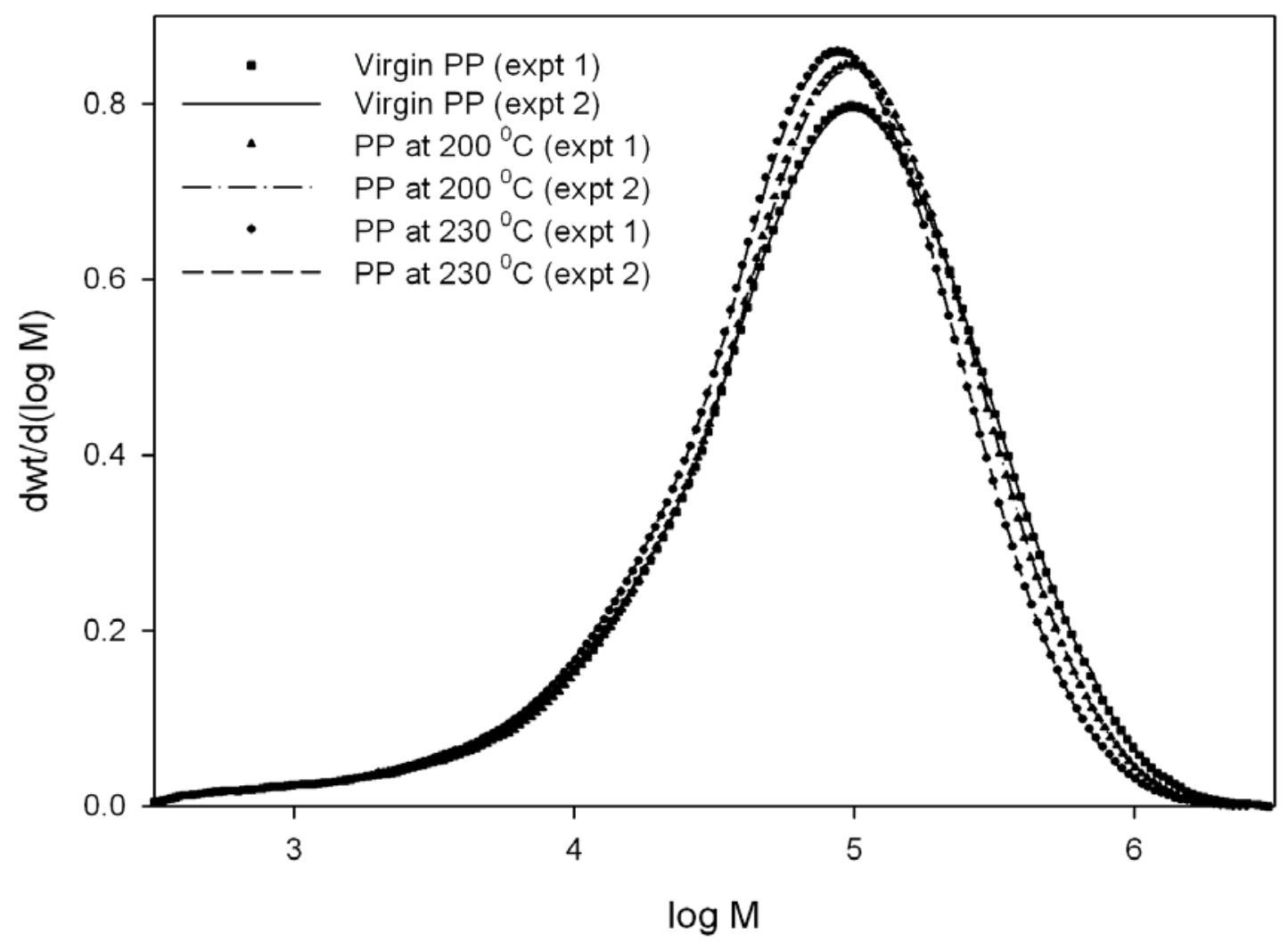

Figure 4.74: The temperature effect: MWD for virgin PP (pellets), CRPP produced from virgin $\mathrm{PP}$ at $200{ }^{\circ} \mathrm{C}$ and $\mathrm{CRPP}$ produced from virgin $\mathrm{PP}$ at $230{ }^{\circ} \mathrm{C}$ 


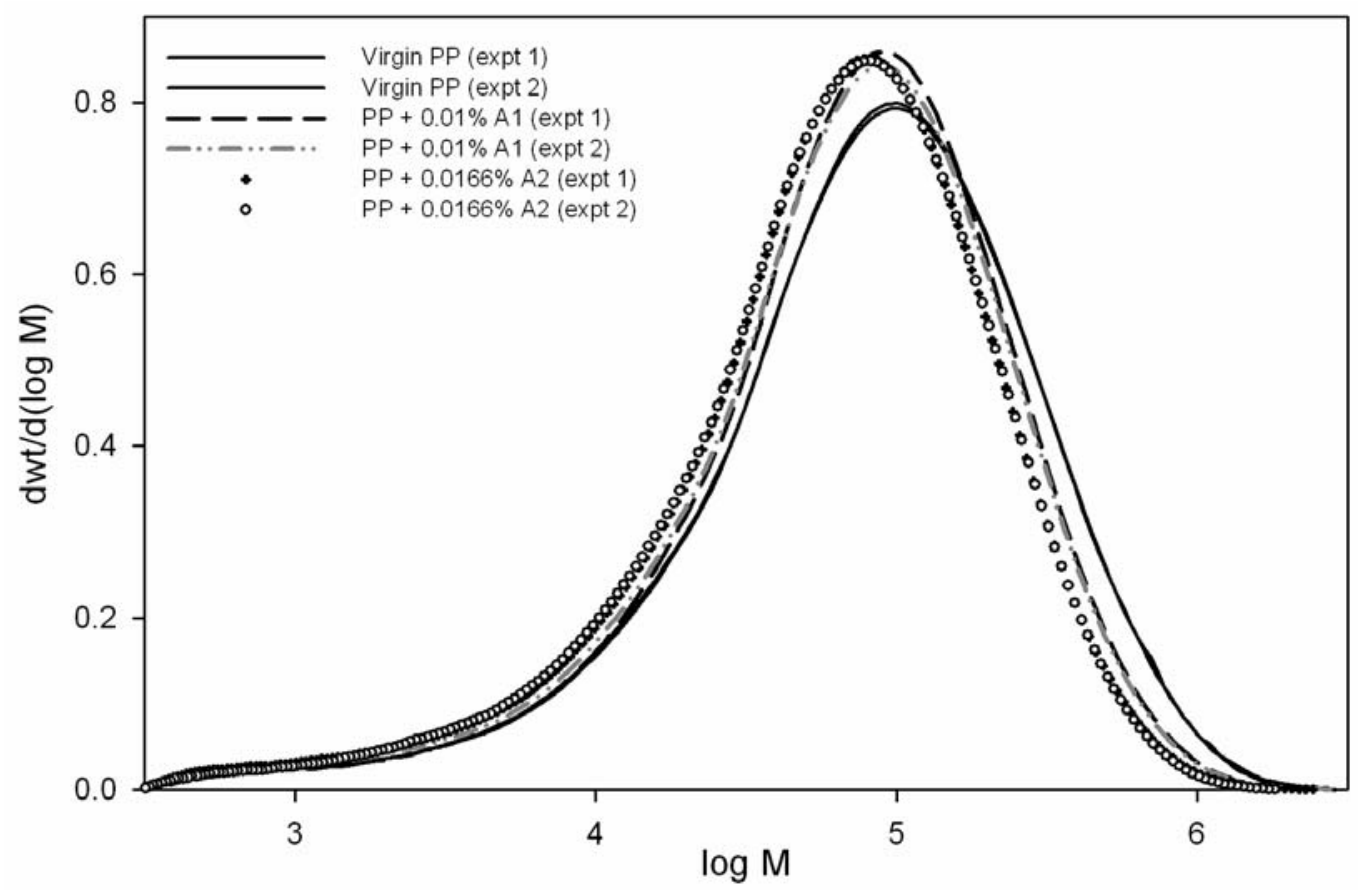

Figure 4.75: MWD for CRPP produced at $200{ }^{\circ} \mathrm{C}$ from PP with $0.01 \% \mathrm{~A} 1$ and from PP with $0.0166 \% \mathrm{~A} 2$

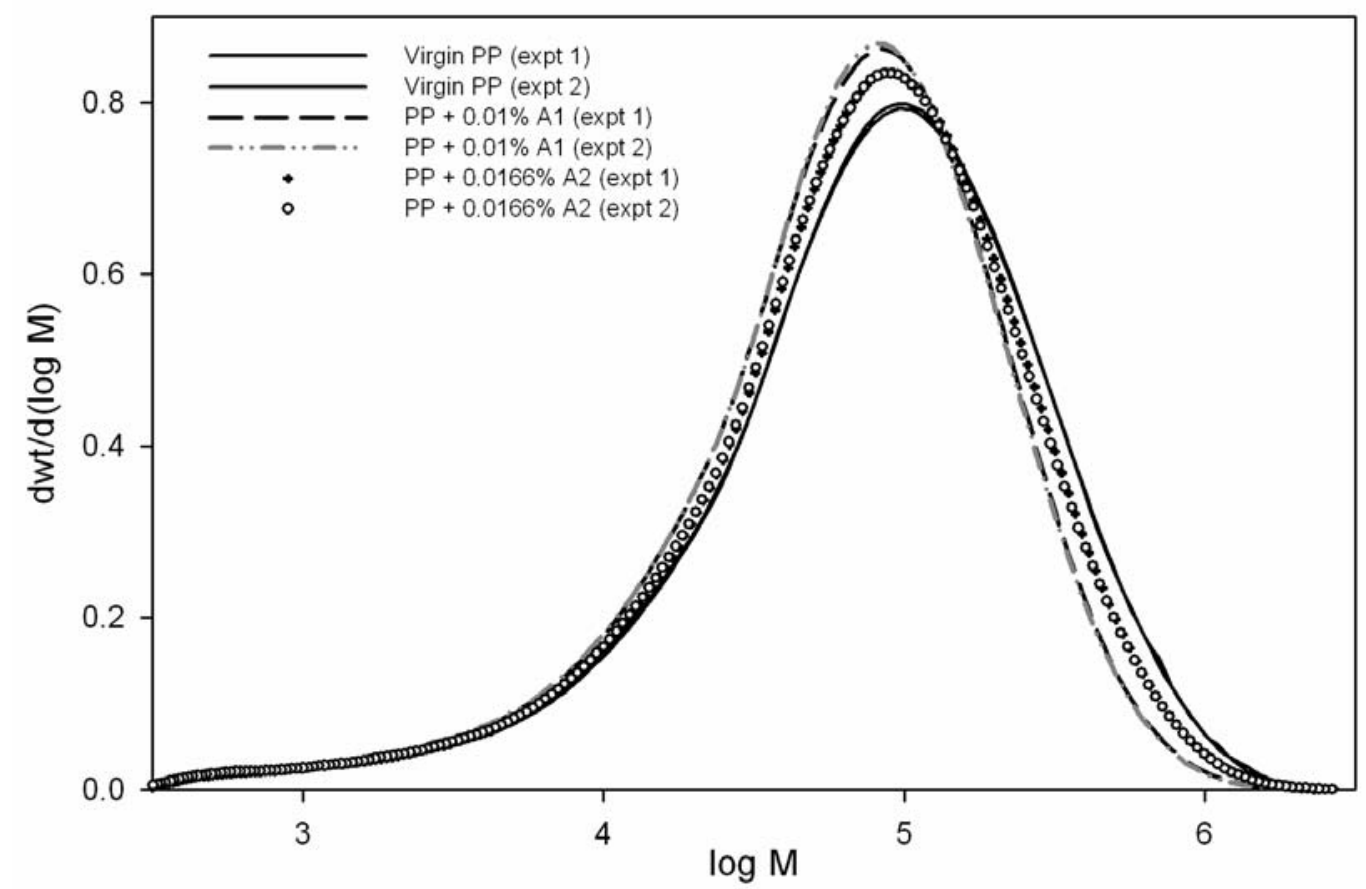

Figure 4.76: MWD for CRPP produced at $230{ }^{\circ} \mathrm{C}$ from $\mathrm{PP}$ with $0.01 \% \mathrm{~A} 1$ and from PP with $0.0166 \% \mathrm{~A} 2$ 


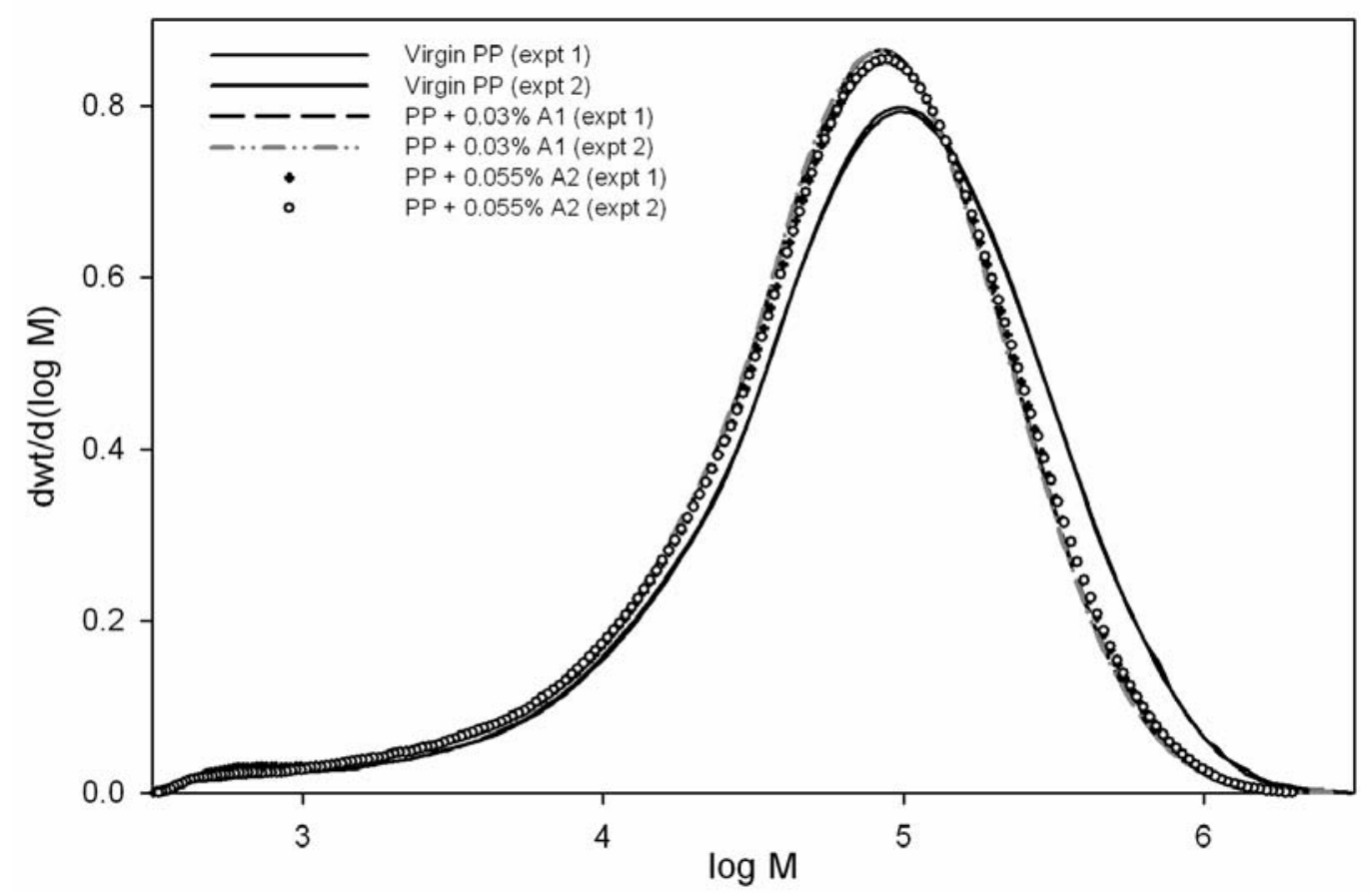

Figure 4.77: MWD for CRPP produced at $200{ }^{\circ} \mathrm{C}$ from $\mathrm{PP}$ with $0.03 \% \mathrm{~A} 1$ and from $\mathrm{PP}$ with $0.055 \% \mathrm{~A} 2$

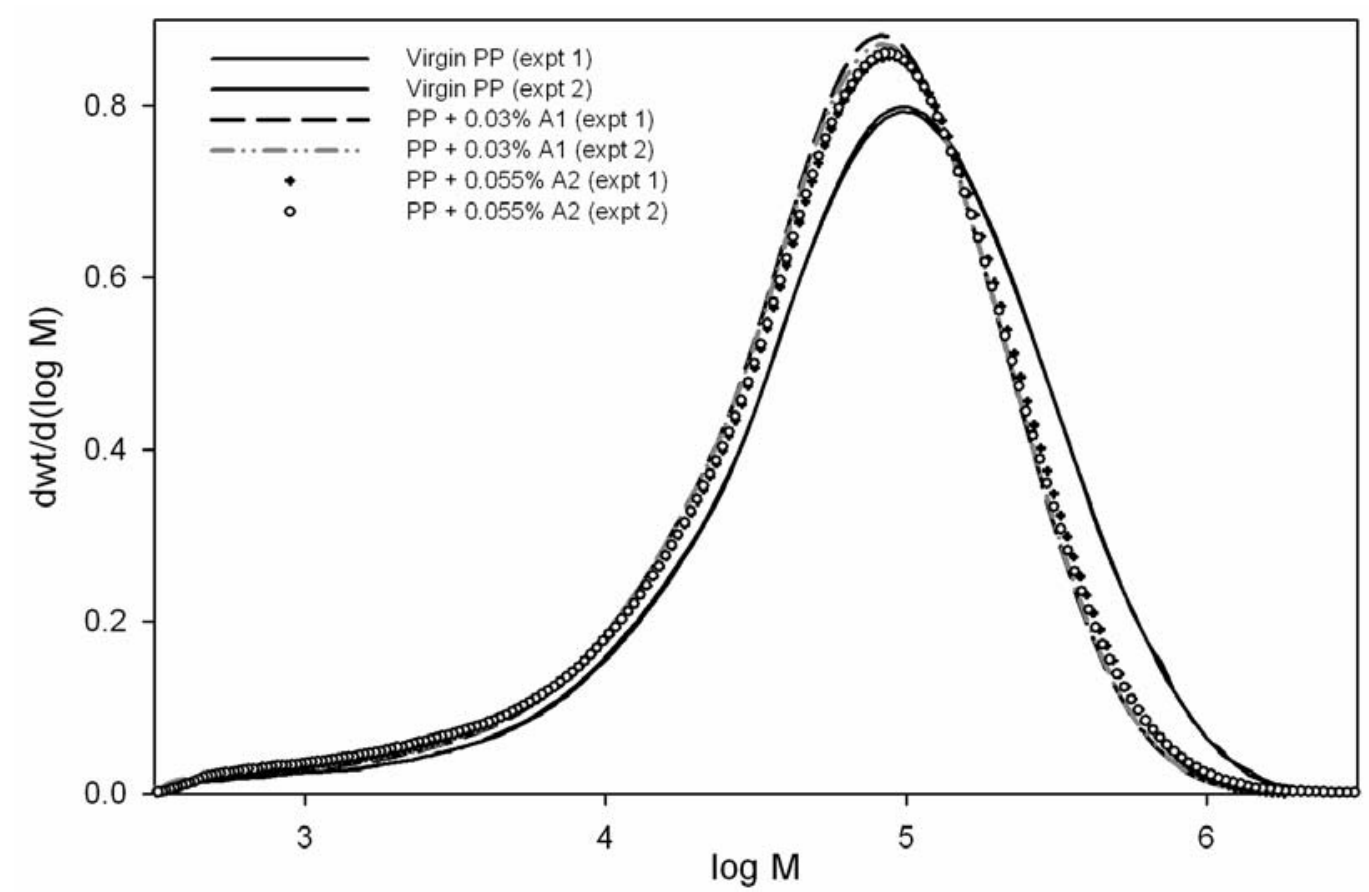

Figure 4.78: MWD for CRPP produced at $230{ }^{\circ} \mathrm{C}$ from $\mathrm{PP}$ with $0.03 \% \mathrm{~A} 1$ and from $\mathrm{PP}$ with $0.055 \% \mathrm{~A} 2$ 


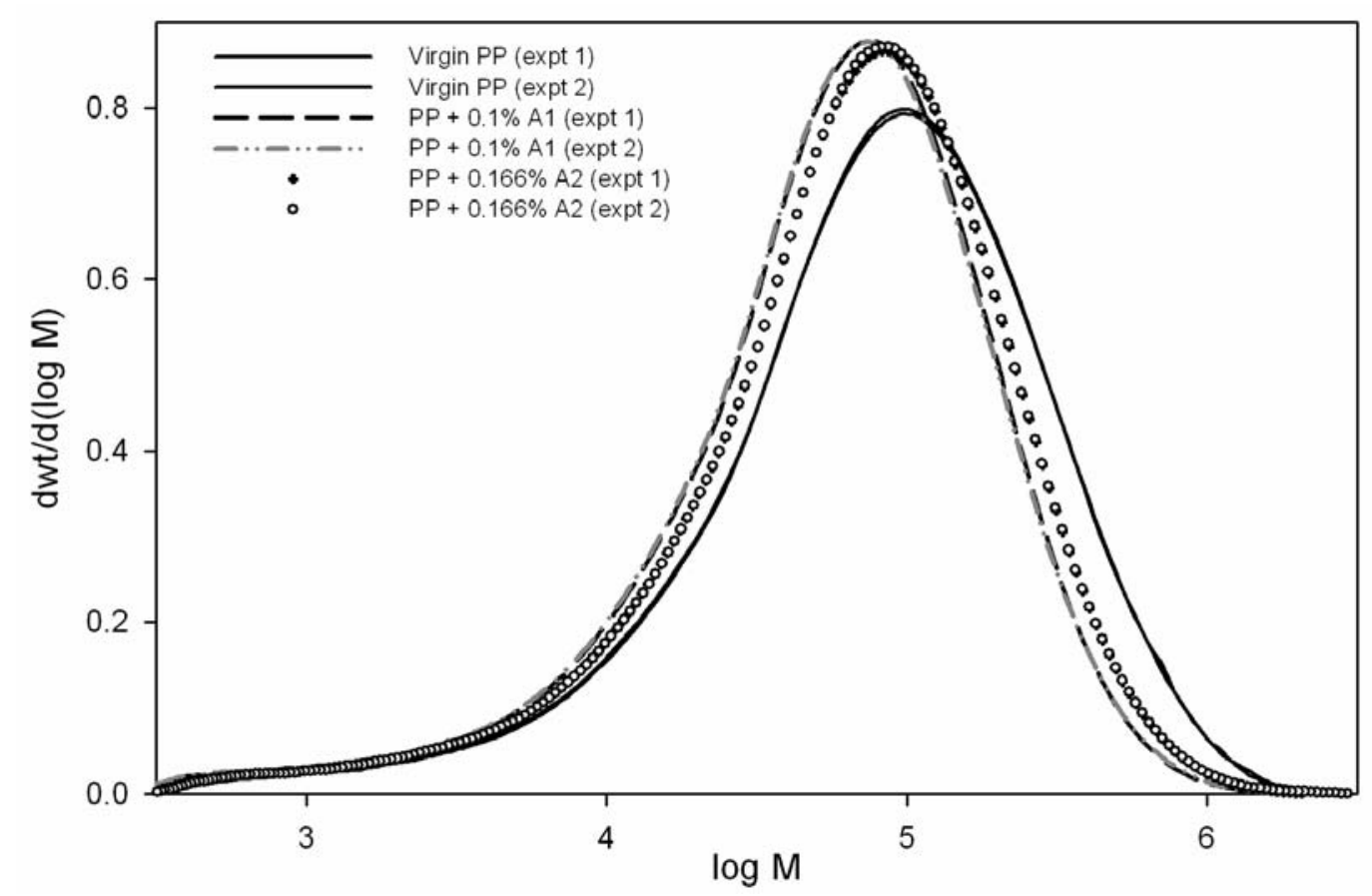

Figure 4.79: MWD for CRPP produced at $200{ }^{\circ} \mathrm{C}$ from PP with $0.1 \% \mathrm{~A} 1$ and from PP with $0.166 \% \mathrm{~A} 2$

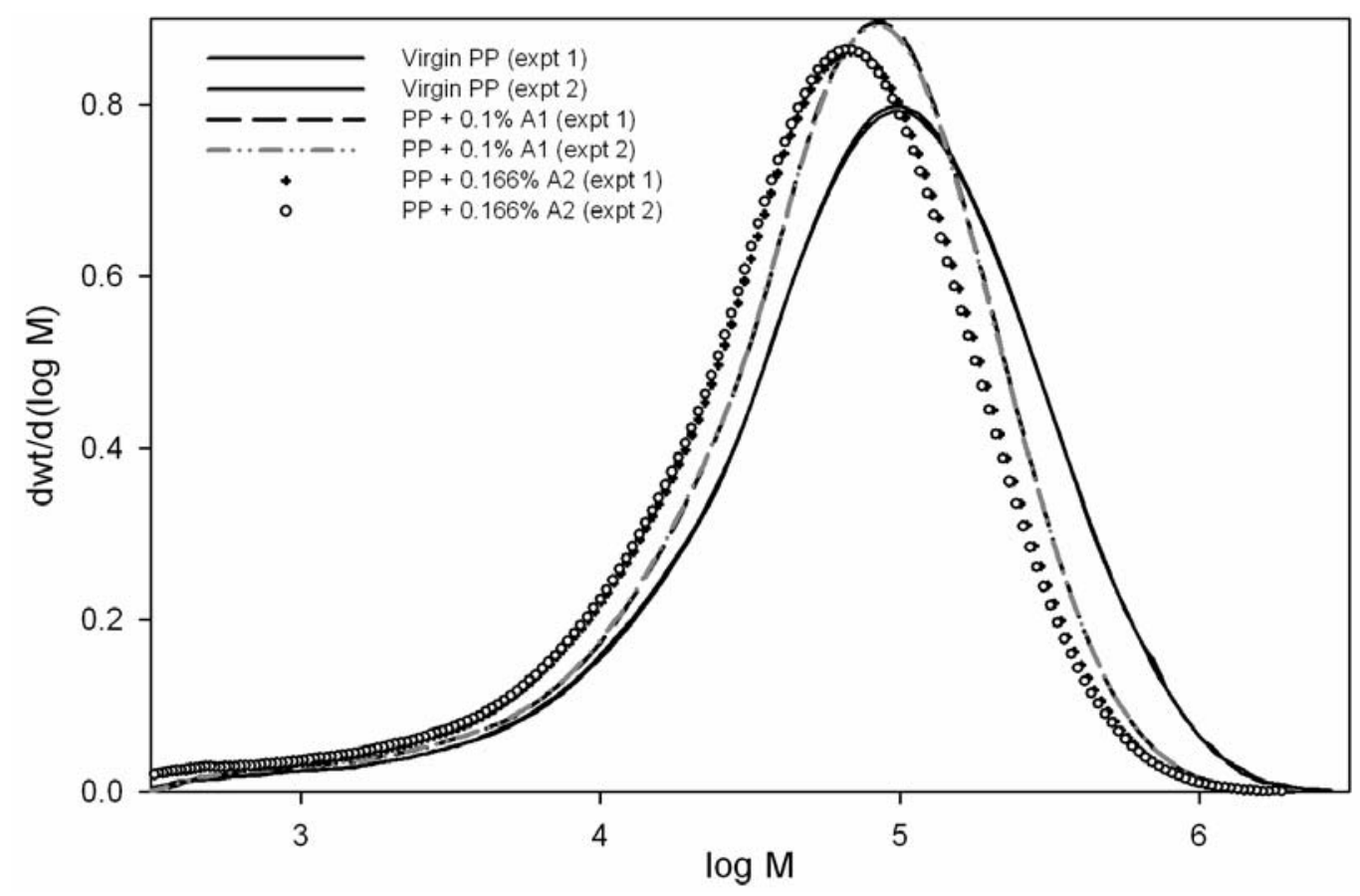

Figure 4.80: MWD for CRPP produced at $230{ }^{\circ} \mathrm{C}$ from PP with $0.1 \% \mathrm{~A} 1$ and from PP with $0.166 \% \mathrm{~A} 2$ 
The data from the GPC analyses are summarised in Table 4.19. Every value in Table 4.19 represents the numerical average of the values that were obtained by two injections. $\mathrm{M}_{\mathrm{N}}, \mathrm{M}_{\mathrm{W}}, \mathrm{M}_{\mathrm{Z}}$ and $\mathrm{M}_{\mathrm{V}}$ represent the number-average $\mathrm{MW}$, weight-average $\mathrm{MW}$, $\mathrm{z}$-average MW, and viscosity-average MW respectively. PDI is the polydispersity index and $\mathrm{g}^{\prime}$ is the intrinsic viscosity (I.V.) contraction factor. $\mathrm{K}$ and $\alpha$ (alpha) are the KuhnMark-Houwink-Sakurada parameters (McCrackin (1987)).

Plotting the measured values of intrinsic viscosity versus $\log \mathrm{M}$, Figures 4.81 to 4.86 were created. These plots should exhibit a linear profile according to the MarkHouwink equation (Goldberg et al (1948), Debye and Bueche (1948)):

$[\eta]=\mathrm{K} \cdot \mathrm{M}^{\alpha}$

which gives:

$\log [\eta]=\log \mathrm{K}+\alpha \log \mathrm{M}$

In equations (4.12) \& (4.13), index $\alpha$ remains constant for linear and changes for branched polymers.

$\underline{\text { Table 4.19: GPC analysis for CRPP samples }}$

\begin{tabular}{|c|c|c|c|c|c|c|c|c|c|c|}
\hline $\mathbf{T}$ & Concentration & $\mathbf{M n}$ & $\mathbf{M w}$ & $\mathbf{M z}$ & $\mathbf{M v}$ & $\mathbf{P D I}$ & $\mathbf{g}^{\prime}$ & $\mathbf{K}$ & $\boldsymbol{\alpha}$ & $\mathbf{I . V} \mathbf{.}$ \\
\hline & virgin PP & 21,368 & 151,594 & 398,203 & 130,278 & 7.10 & 0.978 & 0.000163 & 0.739 & 0.948 \\
\hline 200 & 0 & 22,500 & 139,117 & 337,318 & 123,160 & 6.19 & 0.942 & 0.000105 & 0.769 & 0.808 \\
\hline 230 & 0 & 21,045 & 124,572 & 306,189 & 109,950 & 5.92 & 0.915 & 0.000124 & 0.763 & 0.773 \\
\hline 200 & $0.01 \%$ A1 & 20,480 & 125,715 & 309,293 & 111,573 & 6.16 & 0.914 & 0.000110 & 0.773 & 0.791 \\
\hline 200 & $0.0166 \%$ A2 & 17,730 & 109,433 & 264,502 & 96,018 & 6.18 & 0.929 & 0.000161 & 0.751 & 0.808 \\
\hline 230 & $0.01 \%$ A1 & 18,271 & 112,780 & 270,214 & 98,665 & 6.18 & 0.924 & 0.000162 & 0.741 & 0.740 \\
\hline 230 & $0.0166 \%$ A2 & 20,048 & 132,490 & 334,973 & 115,406 & 6.61 & 0.944 & 0.000151 & 0.749 & 0.874 \\
\hline 200 & $0.03 \%$ A1 & 18,266 & 114,781 & 280,946 & 100,849 & 6.29 & 0.932 & 0.000147 & 0.751 & 0.791 \\
\hline 200 & $0.055 \%$ A2 & 18,548 & 119,352 & 286,532 & 105,452 & 6.45 & 0.928 & 0.000124 & 0.763 & 0.777 \\
\hline 230 & $0.03 \%$ A1 & 17,685 & 107,797 & 249,797 & 93,515 & 6.11 & 0.964 & 0.000194 & 0.717 & 0.683 \\
\hline 230 & $0.055 \%$ A2 & 17,545 & 115,086 & 287,259 & 100,369 & 6.57 & 0.937 & 0.000149 & 0.742 & 0.697 \\
\hline 200 & $0.1 \%$ A1 & 15,706 & 99,693 & 237,390 & 86,222 & 6.35 & 0.973 & 0.000223 & 0.717 & 0.745 \\
\hline 200 & $0.166 \%$ A2 & 19,024 & 115,695 & 287,283 & 100,344 & 6.09 & 0.957 & 0.000170 & 0.730 & 0.718 \\
\hline 230 & $0.1 \%$ A1 & 19,067 & 109,498 & 253,559 & 96,449 & 5.75 & 0.970 & 0.000128 & 0.743 & 0.621 \\
\hline 230 & $0.166 \%$ A2 & 13,264 & 91,626 & 222,930 & 78,383 & 6.91 & 0.966 & 0.000286 & 0.705 & 0.777 \\
\hline
\end{tabular}




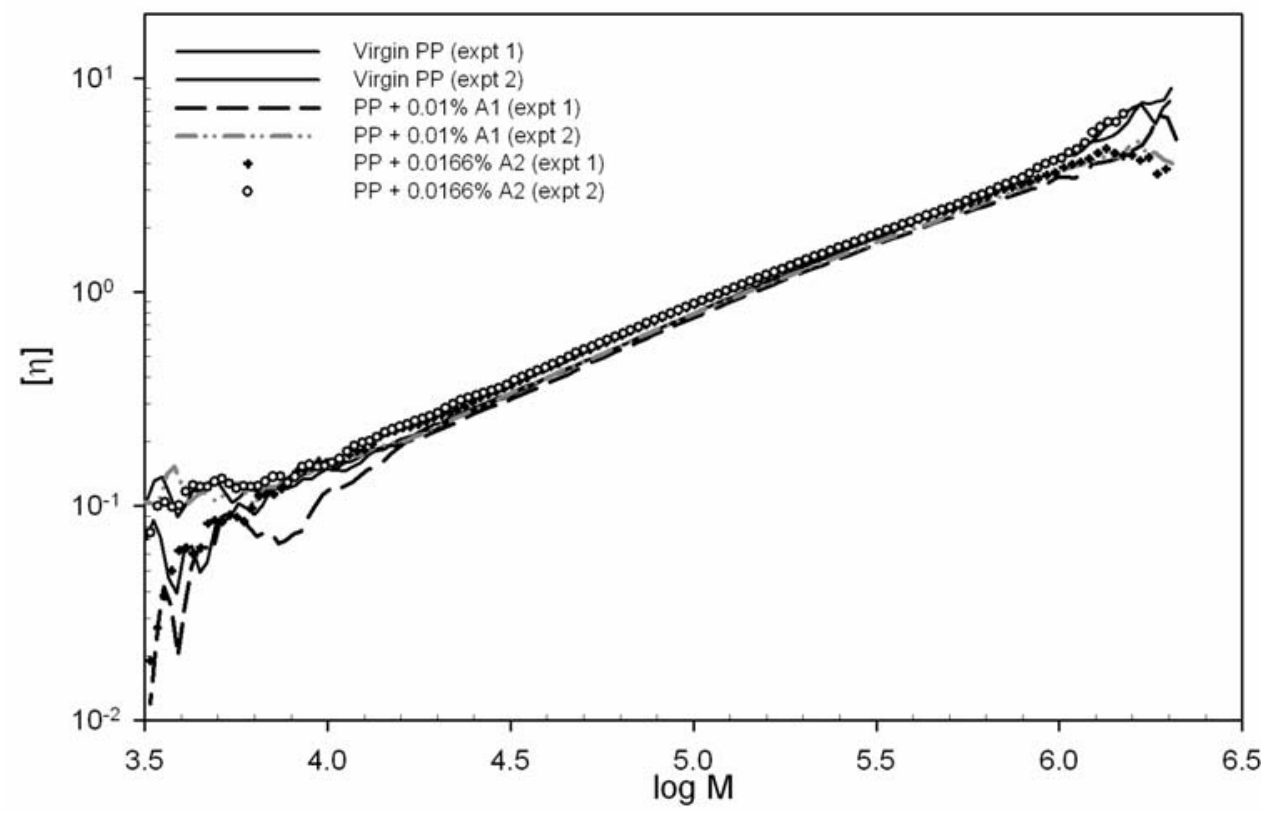

Figure 4.81: Intrinsic viscosity vs. $\log \mathrm{M}$ for CRPP produced at $200{ }^{\circ} \mathrm{C}$ from PP with $\underline{0.01 \% \mathrm{~A} 1 \text { and from PP with } 0.0166 \% \mathrm{~A} 2}$

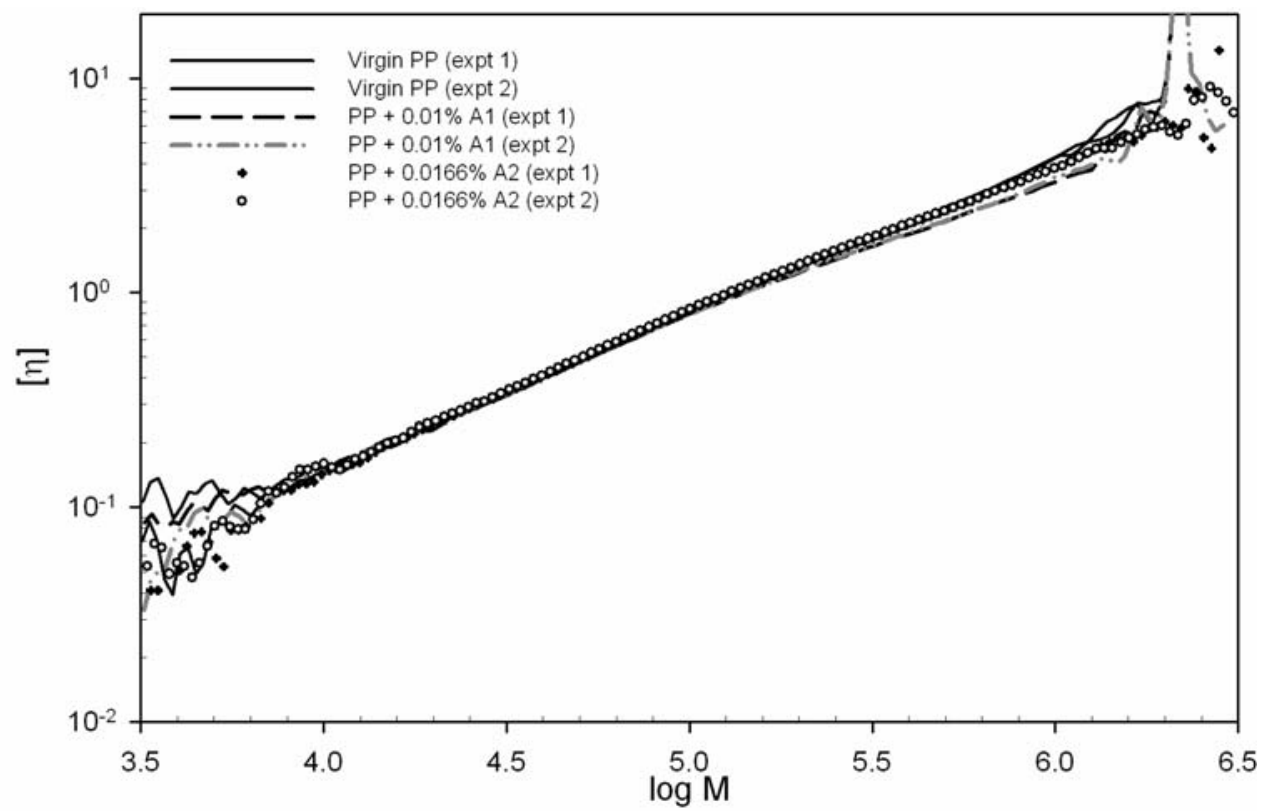

Figure 4.82: Intrinsic viscosity vs. $\log \mathrm{M}$ for CRPP produced at $230{ }^{\circ} \mathrm{C}$ from PP with $\underline{0.01 \% \mathrm{~A} 1 \text { and from PP with } 0.0166 \% \mathrm{~A} 2}$ 


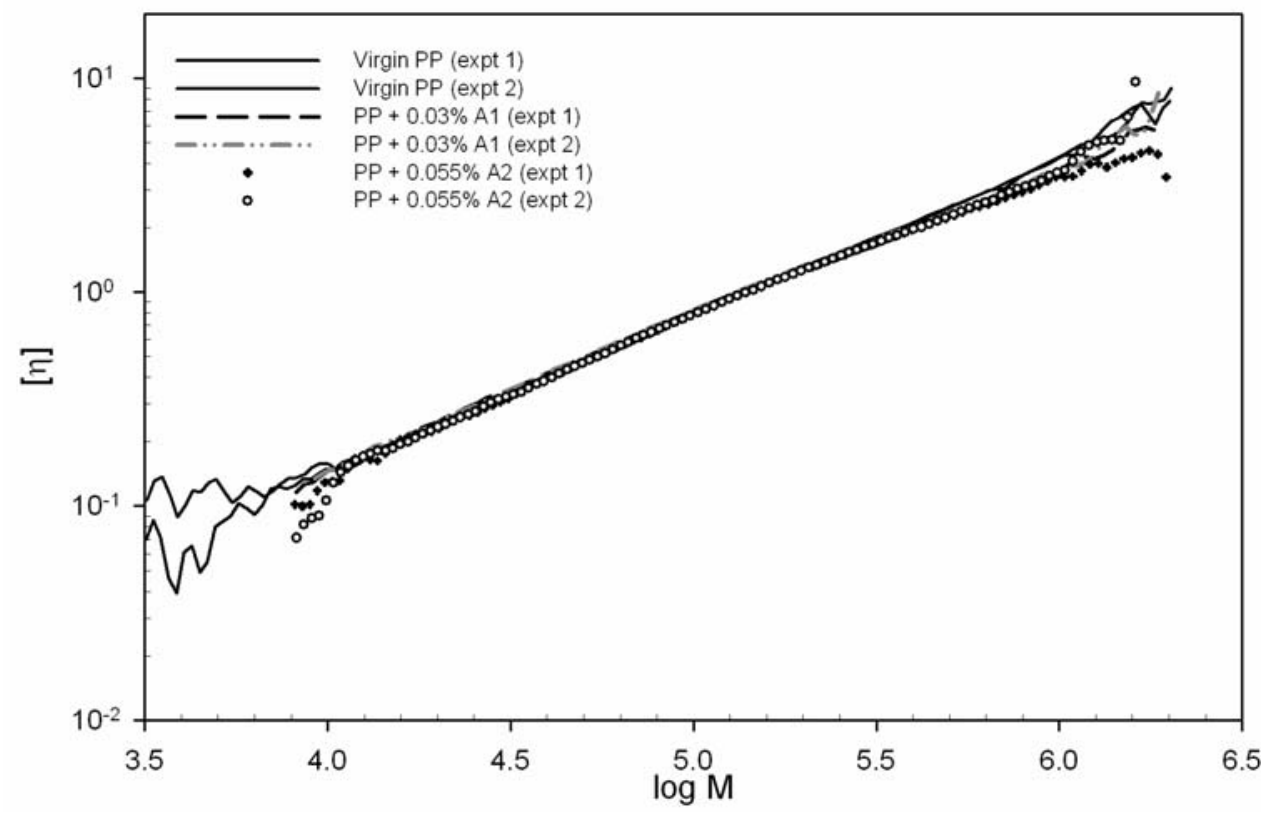

Figure 4.83: Intrinsic viscosity vs. $\log \mathrm{M}$ for CRPP produced at $200{ }^{\circ} \mathrm{C}$ from PP with $\underline{0.03 \% \mathrm{~A} 1 \text { and from PP with } 0.055 \% \mathrm{~A} 2}$

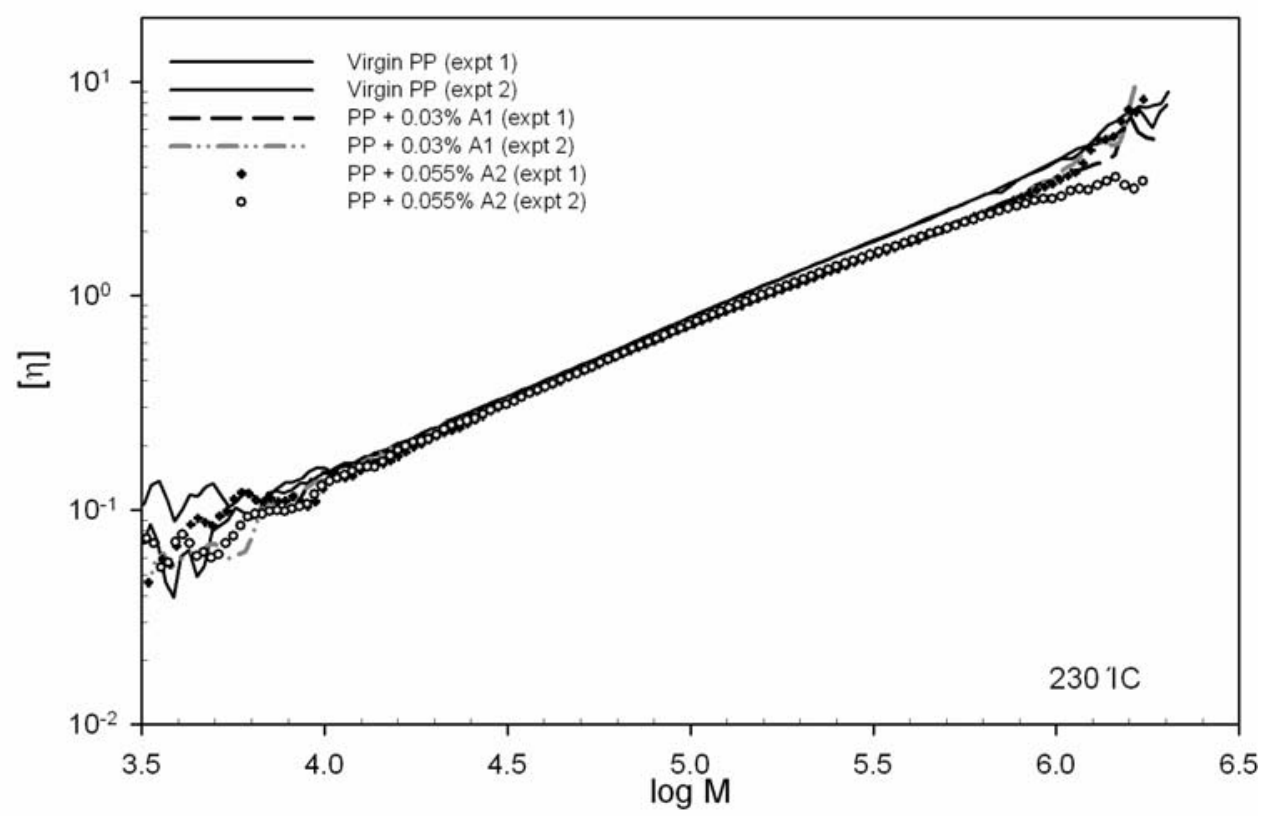

Figure 4.84: Intrinsic viscosity vs. $\log \mathrm{M}$ for CRPP produced at $230{ }^{\circ} \mathrm{C}$ from PP with $\underline{0.03 \% \mathrm{~A} 1 \text { and from } \mathrm{PP} \text { with } 0.055 \% \mathrm{~A} 2}$ 


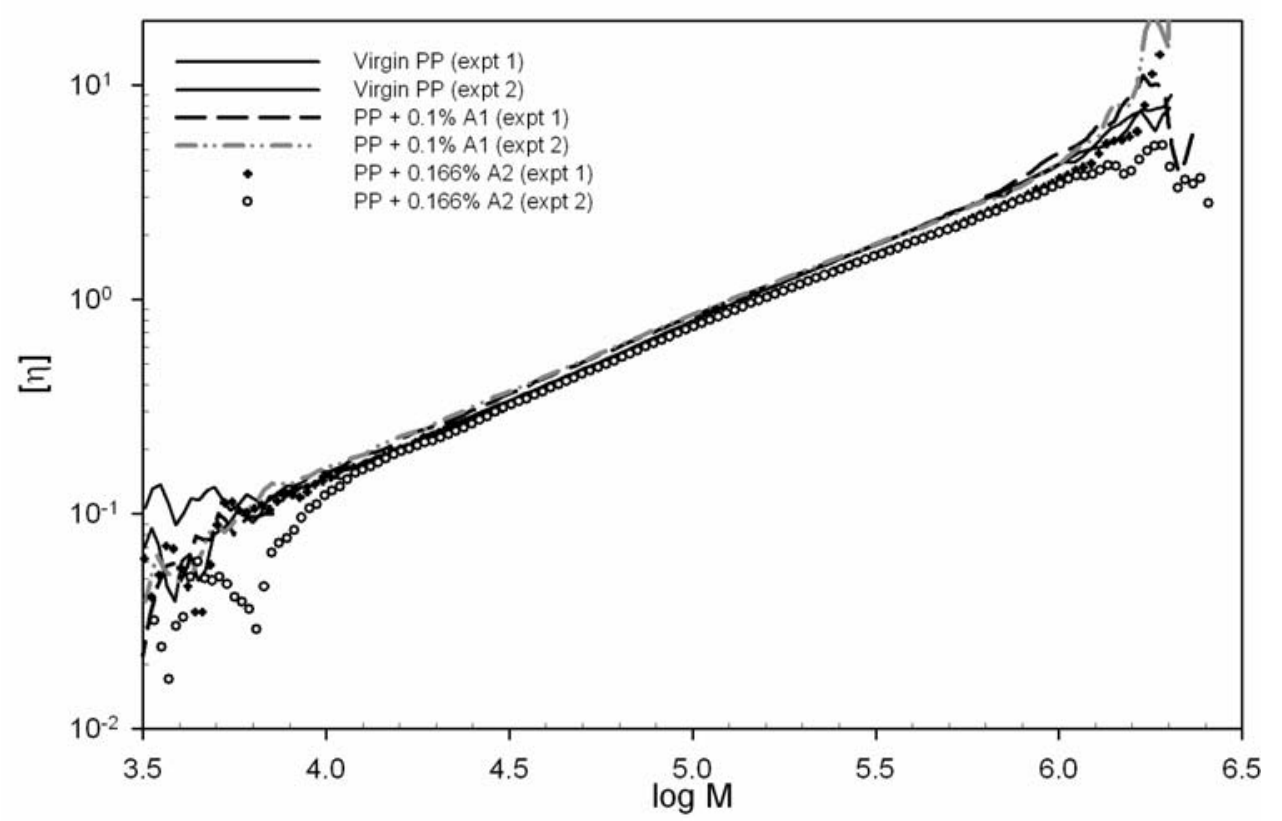

Figure 4.85: Intrinsic viscosity vs. $\log \mathrm{M}$ for CRPP produced at $200{ }^{\circ} \mathrm{C}$ from PP with $\underline{0.1 \% \mathrm{~A} 1 \text { and from } \mathrm{PP} \text { with } 0.166 \% \mathrm{~A} 2}$

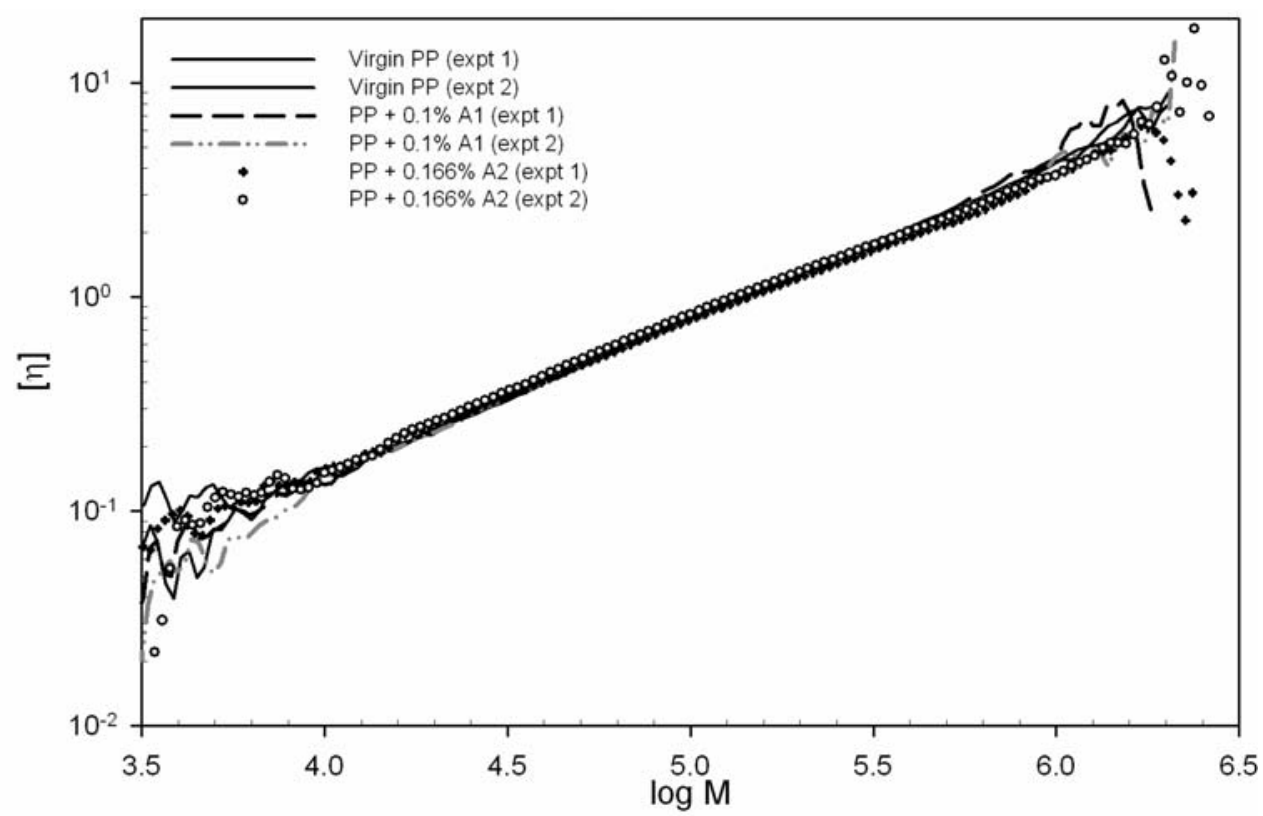

Figure 4.86: Intrinsic viscosity vs. $\log \mathrm{M}$ for CRPP produced at $230{ }^{\circ} \mathrm{C}$ from PP with $\underline{0.1 \% \mathrm{~A} 1 \text { and from } \mathrm{PP} \text { with } 0.166 \% \mathrm{~A} 2}$ 
From all the above data, the observations that can be made are the following:

The effect on PP of two peroxides, A1 (Luperox 101) and A2 (Luperox JWEB 50), was studied. The two peroxides differ in functionality. The reference peroxide that was used, Luperox 101, is mono-functional while the other, Luperox JWEB 50, is tetra-functional. The two peroxides were compared to each other at concentrations that contain the same number of moles of the $-\mathrm{O}-\mathrm{O}-$ group. These concentrations were at three levels: low, middle and high. The first corresponds to $0.01 \mathrm{wt} \% \mathrm{~A} 1$ and $0.0166 \mathrm{wt} \% \mathrm{~A} 2$, the second corresponds to $0.03 \mathrm{wt} \% \mathrm{~A} 1$ and $0.055 \mathrm{wt} \% \mathrm{~A} 2$, and the third to $0.1 \mathrm{wt} \% \mathrm{~A} 1$ and $0.166 \mathrm{wt} \% \mathrm{~A} 2$. From an overall consideration of the results, it can be said that there is no clear evidence of significant difference between the two peroxides when they are used at "equivalent" concentrations.

- The graphs of the measured intrinsic viscosity versus $\log \mathrm{M}$ are rather linear. This implies that the produced CRPP are linear polymers regardless of the type of radical generator or the conditions of production. There is no clear indication for LCB.

- From the graphs of the rheological analysis (Figures 4.62 to 4.73 ), it is observed that the curves of CRPP produced at high temperature $\left(230{ }^{0} \mathrm{C}\right)$ from PP with tetrafunctional initiator at low concentration, are higher than the curves that correspond to CRPP produced by pure PP at the same temperature. Upon first glance, that should not happen as the additive should cause higher degradation to the CRPP. Crosslinking which may take place at high temperatures with the multifunctional peroxide is a reasonable explanation for that. 
Chapter V: Conclusions and Recommendations for Future Work

\section{Conclusions and Recommendations for Future Work}

In this thesis, a novel nitroxyl radical generator was studied. Nitroxide-mediated CRPP was produced and compared to peroxide-mediated CRPP and pure PP, all of them produced and processed using the same procedures. The main parameters were the concentration $(0,250,500,1000 \mathrm{ppm}$ NOR and $250 \mathrm{ppm}$ peroxide) and the temperature $\left(230{ }^{0} \mathrm{C}, 250,270{ }^{0} \mathrm{C}, 290{ }^{0} \mathrm{C}\right)$. The rheological properties and the MWD of the CRPP products were evaluated. It was found that the produced CRPP are linear materials of reduced rheological polydispersities at higher concentrations of the nitroxyl radical generator. No significant difference between the nitroxyl and the peroxy radical generator was found.

Highlighting the most important points of the CRPP characterization, the CRPP polymer melt in a Haake mixer was modeled according to existing models. The MFR of the CRPP samples was measured and compared to the chart of MFR vs. production temperature given in the literature (Pfaendner (2003)). A statistical analysis showed that the obtained MFR indices were quite accurate. In addition, selected CRPP experiments were carried out with the presence of nitrogen in order to investigate the possibility for oxidization.

The viscoelastic properties of the CRPP samples were measured in a parallel plate rheometer. These results showed that the zero shear viscosity of each sample could be derived in two ways: directly from the $\mathrm{G}^{\prime \prime} / \omega$ vs. $\omega$ chart and from the modeling of the complex viscosity data with the Carreau model.

Each CRPP sample was examined with FT-IR spectroscopy. The results were compared to literature results about the peroxide influence on PP. It was found that the nitoxyl radical generator affects PP in the same way the regular peroxide does. Peak at 
$888 \mathrm{~cm}^{-1}$ was observed for the CRPP produced with NOR too, revealing formation of terminal double bond and thus lending more credence to the suggested NOR degradation mechanism shown in Figure 2.12.

Selected CRPP samples were examined in GPC analysis. Their MWD and molecular weight averages were determined. The log of zero shear viscosity vs. the log of the $\mathrm{M}_{\mathrm{w}}$ for the CRPP was found linear with slopes close to 3.5, verifying the Fox and Flory equation and indicating linear polymers. Then, their rheological polydispersities were determined. It was found that high nitroxide concentrations are responsible for reduced rheological polydispersities.

Aside from CRPP produced with NOR and CRPP produced with monofunctional peroxide, CRPP produced with a tetrafunctional peroxide generator was studied and compared to the CRPP produced with monofunctional peroxide generator at the same peroxy group concentration. No evident difference between the two peroxides was observed on the CRPP.

Summarizing, the objective of this research was to investigate if this novel nitroxide initiator could act as a potential substitution in the CRPP engineering, dominated by peroxides. Nitroxides are already well-known for being powerful stabilizers protecting plastics from light and heat and potentially easier in handling during processing.

Despite the fact that the novel nitroxyl radical generator, Irgatec CR76, contributes in significant degradation of PP, it can be said in general terms that the experimental results do not verify preliminary industrial literature for spectacular performance, especially at high temperatures, of this new initiator in comparison to a typical peroxide one. This might be because of other factors, since in this thesis the production of the CRPP took place under different conditions than the experimental procedure in the literature. In addition, the virgin PP resin used was different, and the CRPP production experiments took place without any special additives.

The industrial literature experimental results (Pfaendner (2003)) and the results of this research show that the new radical initiator performs an important role in degradation of PP. This can lead to the conclusion that Irgatec CR76 and other hindered amines may be able to exhibit a better performance under special conditions, which might not be far 
from the industrial ones. This can be an object of future research. Useful conditions for CRPP production are many, and the researcher can selectively change some of them with the purpose to obtain products with a range of different properties.

The most important factors are:

- The type of the reactor and process. Different types of reactor may give different results (i.e. Haake mixer (batch process), extruder (continuous process)).

- Type of virgin PP. The MFR and the rheological properties of the produced CRPP are strongly dependent on the type of the original virgin PP, its MFR and its molecular weight.

- Concentration of the initiators. In this research, only low concentrations of radical generators were used. Higher concentrations of nitroxyl radical initiator will unveil more information. Possibly an optimum NOR concentration can be found.

- Temperature and duration of the experiment. Both of them contribute significantly in the degradation of the polymer melt. Experiments at lower temperatures can approach industrial conditions for CRPP, while longer experimental duration contributes in Haake mixer conditions close to steady state.

- Rotation speed. This is one of the most important Haake mixer parameters, especially if the time of the experiment is short. High rpm corresponds to high level of degradation of the polymer and low torque values at the end of the experiment.

- $\quad$ Presence of other special additives (antioxidants, lubricants, etc.).

- Replicates for different conditions.

In addition to the above, other nitroxyls can be studied as radical generators. The field of NORs as radical generators in a new field and the relative research can expand to many other new NORs or NOR compounds. These new nitroxyl radical generators can be studied and compared with different peroxide radical generators; monofunctional or multifunctional. Moreover, the polymer reaction engineering part of nitroxyls as radical generators can be studied in-depth. Detailed kinetic models can be obtained based on selective kinetic studies. 


\section{References}

Aklonis J. J., MacNight W. J., Shen M., Introduction to Polymer Viscoelasticity, Wiley, New York (1972)

Asteasuain M., Sarmoria C., Brandolin A., Controlled Rheology of Polypropylene: Modeling of Molecular Weight Distribution, Journal of Applied Polymer Science, v. 88, pp 1676-1685 (2003)

ASTM, Standard Test Method for Melt Flow Rates of Thermoplastics by Extrusion Plastometer, D 1238, 04c, pp 271-284 (2004)

Azizi H., Ghasemi I., Reactive Extrusion of Polypropylene: Production of Controlled-Rheology Polypropylene (CRPP) by Peroxide-promoted Degradation, Polymer Testing, v. 23, pp 137-143 (2004)

Balke S. T., Suwanda D., Lew R., A Kinetic Model for the Degradation of Polypropylene, Journal of Polymer Science, Part C, v. 25, pp 313-320 (1987)

Baumann G., Steingiser S., Rheological Measurements on Polycarbonate, Journal of Polymer Science Part A: General Papers, v. 1, n. 11, pp 3395-3406 (1963)

Berger L., Meissner J., Linear Viscoelasticity, Simple and Planar Melt Extension of Linear Polyboutadienes with Bimodal Molar Mass Distributions, Rheologica Acta, v. 31, pp 63-74 (1992)

Bonilla - Rios J., Darby R., Sosa J. M., Effects of Temperature, Peroxide Concentration and Peroxide Addition Technique on the Molecular Weight Distribution of Controlled Rheology Polypropylene Resins, Annual Technical Conference - ANTEC, 1625-1629 (1995)

Bonilla - Rios J., Darby R., Sosa J. M., Changes in the Viscosity, Relaxation Spectra and the Molecular Weight Distribution of Polypropylene Resins due to the Addition of Peroxide during Extrusion, Annual Technical Conference - ANTEC, 1001-1005 (1998)

Bousmina M., Ait-Kadi A., Faisant J. B., Determination of shear rate and viscosity from batch mixer data, Journal of Rheology, v. 43, n. 2, pp 415-433 (1999) 
Braun D., Controlled Free Radical Polymerization of Vinyl Chloride, Journal of Vinyl and Additive Technology (2005)

Bulsari M. P., Hydrosilylation of Polypropylene through Reactive Extrusion, MASc Thesis, Department of Chemical Engineering, University of Waterloo (2004)

Carlsson D. J., Chan K. H., Durmis J., Wiles D.M., Decomposition of Polypropylene Hydroperoxide by Hindered Amines, Journal of Polymer Science, v. 20, pp 575-582 (1982)

Carrot C., Revenu P., Guillet J., Rheological Behavior of Degraded Polypropylene Melts: From MWD to Dynamic Moduli, Journal of Applied Polymer Science, v. 61, pp 1887-1897 (1996)

Catterton A. J., Fourier Transform Infrared Spectroscopy (FT-IR), Drug Enforcement Administration, Southeast Laboratory, Miami, Florida (2004)

Cheremisinoff N. P., An Introduction to Polymer Rheology and Processing, CRC Press, Boca Raton (1993)

Cox W. P., Merz E. H., Correlation of Dynamic and Steady State Flow Viscosities, Journal of Polymer Science, v. 28, pp 619-622 (1958)

Debye P., Bueche A. M., Intrinsic Viscosity, Diffusion and Sedimentation Rate of Polymers in Solution, Journal of Chemical Physics, v. 16, pp 573-579 (1948)

Denisov E. T., International Symposium on Degradation and Stability of Polymers, Preprints, Brussels, $\mathrm{p}$ 137 (1974)

Ferry J. D., Viscoelastic Properties of Polymers, Wiley \& Sons Inc., New York, $3^{\text {rd }}$ edition (1980)

Fink J., Roth M., Pfaendner R., Grafting of Nitroxyl Terminated Oligomers or Polymers onto Thermoplastic Polymers, US Patent application publication, 2005/0215720 A1 (2005)

Fox T. G. Jr., Flory P. J., Intrinsic Viscosity - Molecular Weight Relationships for Polyisobutylene, Journal of Physical and Colloid Chemistry, v. 53, pp 197-212 (1949)

Fox T. G. Jr., Flory P. J., Molecular Configuration and Thermodynamic Parameters from Intrinsic Viscosities, Journal of Polymer Science, Part B, v. 34, pp 207-209 (1996) 
Fox T. G. Jr., Loshaek S., Isothermal viscosity-Molecular Weight Dependence for Long Polymer Melts, Journal of Applied Physics, v. 26, n. 9, pp 1080-1083 (1955)

Fritz H. G., Stohrer B., Polymer Compounding Process for Controlled Peroxide Degradation of Polypropylene, International Polymer Processing, v. 1, pp 31-41 (1986)

Fukuda T., Terauchi T., Goto A., Ohno K., Tsujii Y., Miyamoto T., Kobatake S., Yamada B., Mechanisms and Kinetics of Nitroxide-Controlled Free Radical Polymerization, Macromolecules, v. 29, n. 20, pp 6393 6398 (1996)

Georges M. K., Quinlan M., Keoshkerian B., Odell P. G., Stable Free Radical Polymerization Process (SFRP) - Limitations?, American Chemical Society, Polymer Preprints Division of Polymer Chemistry, v. 37, n. 2, pp 507-508 (1996)

Georges M. K., Odell P. G., Veregin R. P. N., Keoshkerian B., Nitroxide-Mediated Stable Free Radical Polymerization Process - Mechanistic Considerations, American Chemical Society, Polymer Preprints Division of Polymer Chemistry, v. 38, n. 1, pp 721-722 (1997)

Georges M. K., Hamer G. K., Listigovers N. A., Block Copolymer Synthesis by a Nitroxide-Mediated Living Free Radical Polymerization Process, Macromolecules, v. 31, n. 25, pp 9087-9089 (1998)

Goldberg A. I., Hohenstein W. P., Mark H., Intrinsic Viscosity - Molecular Weight Relationship for Polystyrene, Journal of Polymer Science, v. 2, n. 5, pp 503-510 (1947)

Goodrich J. E., Porter R. S., a Rheological Interpretation of Torque-Rheometer Data, Polymer Engineering Science, v. 7, pp 45-51 (1967)

Kowalski R. C., Harrison; J. W., Staton J. C., Keller J. P., Controlled Degradation of Polypropylene in Extruder - Reactor, US Patent 3,608,001 (1971)

Kraus G., Gruver J. T., Rheological Properties of Cis-Polybutadiene, Journal of Applied Polymer Science, v. 9, n. 2, pp 739-755 (1965)

Malz H., Hydrosilylation of terminal double bonds in degraded Polypropylene, Diploma in Chemical Engineering Thesis, University of Waterloo (1995) 
Marquardt D.W., An Algorithm for Least Squares Estimation of Parameters, Journal of the Society of Industrial and Applied Mathematics, v. 11, pp 431-441 (1963)

Matyjaszewski K., Davis T. P., Handbook of Radical Polymerization, Wiley \& Sons Inc., Hoboken, New Jersey, $1^{\text {st }}$ edition (2002)

McCrackin F. L., Relationship of Intrinsic Viscosity of Polymer Solutions to Molecular Weight, Polymer, v. 28, n. 11, pp 1847-1850 (1987)

Micallef A. S., Blinco J. P., George G. A., Reid D. A., Rizzardo E., Thang S. H., Bottle S. E, The application of a novel profluorescent nitroxide to monitor thermo-oxidative degradation of polypropylene, Polymer Degradation and Stability, v. 89, n. 3, pp 427-435 (2005)

Milton J. S., Arnold J. C., Introduction to Probability and Statistics, McGraw-Hill Inc., New York, $3^{\text {rd }}$ edition (1995)

Minoshima W., White J. L., Spruiell J. E., Experimental Investigation of the Influence of Molecular Weight Distribution on the Rheological Properties of Polypropylene Melts, Polymer Engineering and Science, v. 20, n. 17, pp 1166-1674 (1980)

Nash J.C., Compact Numerical Methods for Computers: Linear Algebra and Function Minimization, John Wiley \& Sons Inc., New York (1979)

Nilsen A., Braslau R., Nitroxide Decomposition: Implications toward Nitroxide Design for Applications in Living Free-Radical Polymerization, Journal of Polymer Science Part A: Polymer Chemistry, v. 44, pp 697-717 (2006)

Odian G., Principles of Polymerization, Wiley \& Sons Inc., Hoboken, New Jersey, $4^{\text {th }}$ edition (2004)

Pfaendner Rudolf, Hindered amines beyond stabilization: radical generators for efficient polymer modification, presentation, Polymer Processing Society 2003, Athens (2003)

Pirrung F. O. H., Auschra C., Nitroxide-mediated Synthesis of Acrylic Block Copolymers and their use as Coating Additives, Polymer Preprints, v. 46, n. 2, pp 316-317 (2005)

Press W. H., Flannery B. P., Teukolsky S. A., Vetterling W. T., Numerical Recipes. Cambridge: Cambridge University Press (1986) 
Pyun J., Matyjaszewski K., Synthesis of Nanocomposite Organic/Inorganic Hybrid Materials Using Controlled/“Living” Radical Polymerization, Chemical Materials, v. 13, pp 3436-3448 (2001)

Rawling J. O., Sastry G. P., Dickey D. A., Applied Regression Analysis: A Research Tool, Springer, Verlag (1998)

Ryu S. H., Gogos C. G., Xanthos M., Parameters Affecting Process Efficiency of Peroxide-initiated Controlled Degradation of Polypropylene, Advances in Polymer Technology, v. 11, n. 2, pp 121-131 (1992)

Scorah M. J., Dhib R., Penlidis A., Free-Radical Polymerization of Methyl Methacrylate with a Tetrafunctional Peroxide Initiator, Journal of Polymer Science, v 42, n. 22, pp 5647-5661 (2004)

Scorah M. J., Dhib R., Penlidis A., Use of a Novel Tetrafunctional Initiator in the Free Radical Homo-and Copolymerization of Styrene, Methyl Methacrylate and a-Methyl Styrene, Journal of Macromolecular Science - Pure and Applied Chemistry, v. 42 A, n. 4, pp 403-426 (2005)

Scorah M. J., Experimental and Modeling Investigation of a Novel Tetrafunctional Initiator in Free Radical Polymerization, PhD Thesis, Department of Chemical Engineering, University of Waterloo (2005)

Shrager R.I., Regression with Linear Constraints: An Extension of the Magnified Diagonal Method, Journal of the Association for Computing Machinery, v. 17, pp 446-452 (1970)

Shrager, R.I., Quadratic Programming for N., Communications of the ACM, v. 15, pp 41-45 (1972)

Shroff R., Mavridis H., New Measures of Polydispersity from Rheological Data on Polymer Melts, Journal of Applied Polymer Science, v. 57, pp 1605-1626 (1995)

Suwanda D., Lew R., Balke S. T., Reactive Extrusion of Polypropylene I: Controlled Degradation, Journal of Applied Polymer Science, v. 35, pp 1019-1032 (1988a)

Suwanda D., Lew R., Balke S. T., Reactive Extrusion of Polypropylene II: Degradation Kinetic Modeling, Journal of Applied Polymer Science, v. 35, pp 1033-1048 (1988b)

Thompson M. R., Tzoganakis C., Rempel G. L., Evaluation of Vinylidene Group Content in Degraded Polypropylene, Journal of Polymer Science: Part A: Polymer Chemistry, v. 35, pp 3083-3086 (1997) 
Tozzi A., Cantatore G., Masina F., Recent Progress in the Stabilization of Polypropylene Fibers, Textile Research Journal, v. 48, n. 8, pp 433-436 (1978)

Triacca V. J., Gloor P. E., Zhu S., Hrymak A. N., Hamielec A. E., Free Radical Degradation of Polypropylene: Random Chain Scission, Polymer Engineering Science, v. 33, n. 8, pp 445-454 (1994)

Tzoganakis C., Vlachopoulos J., Hamielec A. E., Controlled Degradation of Polypropylene, Chemical Engineering Progress, v. 84, n. 11, pp 47-49 (1988)

Tzoganakis C., Peroxide Degradation of Polypropylene During Reactive Extrusion, PhD Thesis, Department of Chemical Engineering, McMaster University (1988)

Tzoganakis C., Vlachopoulos J., Hamielec A. E., Controlled Degradation of Polypropylene: A Comprehensive Experimental and Theoretical Investigation, Polymer Plastics Technology and Engineering, v. 28, n. 3, pp 319-350 (1989a)

Tzoganakis C., Vlachopoulos J., Hamielec A. E., Effect of Molecular Weight Distribution on the Rheological and Mechanical Properties of Polypropylenes, Polymer Engineering Science, v. 29, n. 6, pp 390-396 (1989b)

Walpole R. E., Myers R. H., Myers S. L., Probability and Statistics for Engineers and Scientists, Prentice Hall, New Jersey, $6^{\text {th }}$ edition (1998)

Wannemacher T., Braun D., Pfaendner R., Novel Copolymers via Nitroxide Mediated Controlled Free Radical Polymerization of Vinyl Chloride, Macromol. Symp., v. 202, pp 11-23 (2003)

White J. L., Principles of Polymer Engineering Rheology, Wiley \& Sons Inc., New York (1990)

Website: Science of Spectroscopy, http://scienceofspectroscopy.info 


\section{Appendices}

Appendix I presents the torque vs. time charts that were derived from the Haake mixer experiments. These charts present the values of the instant torque, which was necessary for the machine to work at a constant rotation (100 rpm), as a function of the experimental time. The $\mathrm{x}$-axis corresponds to real time (of the experiment).

Appendix II presents an analytical solution of the rheological characteristics of the instant polymer melt in the Haake Mixer. Mathematical models were derived for its description according to the existing literature (Bousmina et al. (1999)).

Appendix III presents the charts of storage modulus $\left(\mathrm{G}^{\prime}\right)$ and loss modulus $\left(\mathrm{G}^{\prime \prime}\right)$ of the produced CRPP materials vs. the imposed angular frequency $\omega$. These charts represent the frequency sweep obtained from the parallel plate rheometer experiments. The charts are given in three parts according to the temperature used.

Finally, Appendix IV deals with the Fourier Transform Infrared (FT-IR) spectra of the produced CRPP samples. For each sample, four plots are given. This is because two independent experiments for each sample took place and, in addition, two areas of the derived spectra were given for each sample. The first is the typical IR spectrum (wavenumber between 400 and 4,000 $\mathrm{cm}^{-1}$ ) and the second is an expansion for wavenumbers between 800 and $900 \mathrm{~cm}^{-1}$. 


\section{Appendix I}

\section{Charts of Torque vs. Time in Haake Mixer}

This section presents the charts for instant torque versus time (of the experiment) for each CRPP production in the Haake mixer. Each plot shows the progress of the torque that was necessary for the device to work in a constant rotation speed $(100 \mathrm{rpm})$ for every CRPP production. The importance of the instant torque lies on the fact that it represents a measure of resistance of the polymer melt inside the mixing chamber. The charts are grouped according to the nominal temperature at which the mixing chamber was set.

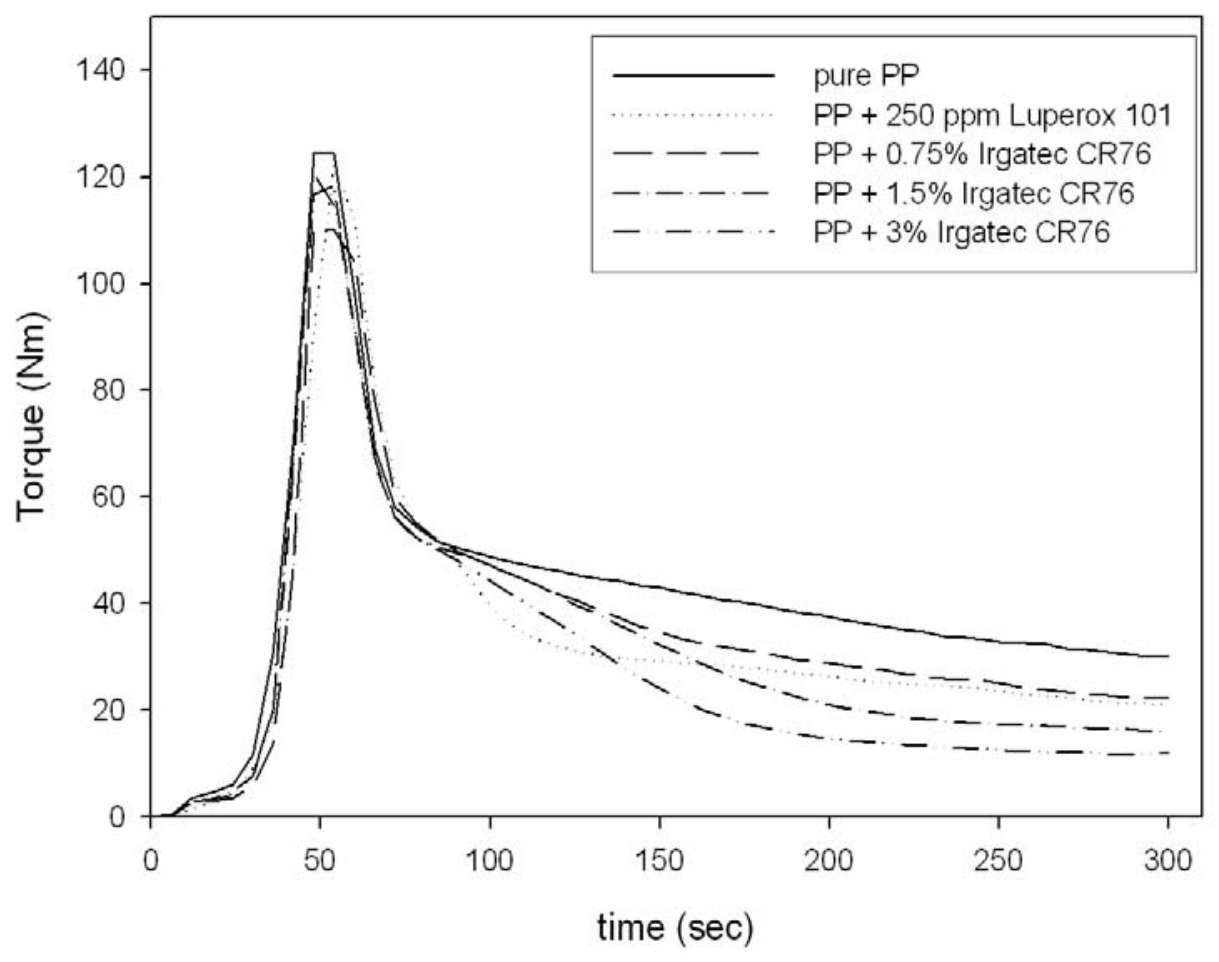

Figure AI.1: Torque vs. time for $230{ }^{\circ} \mathrm{C}$ in Haake mixer 


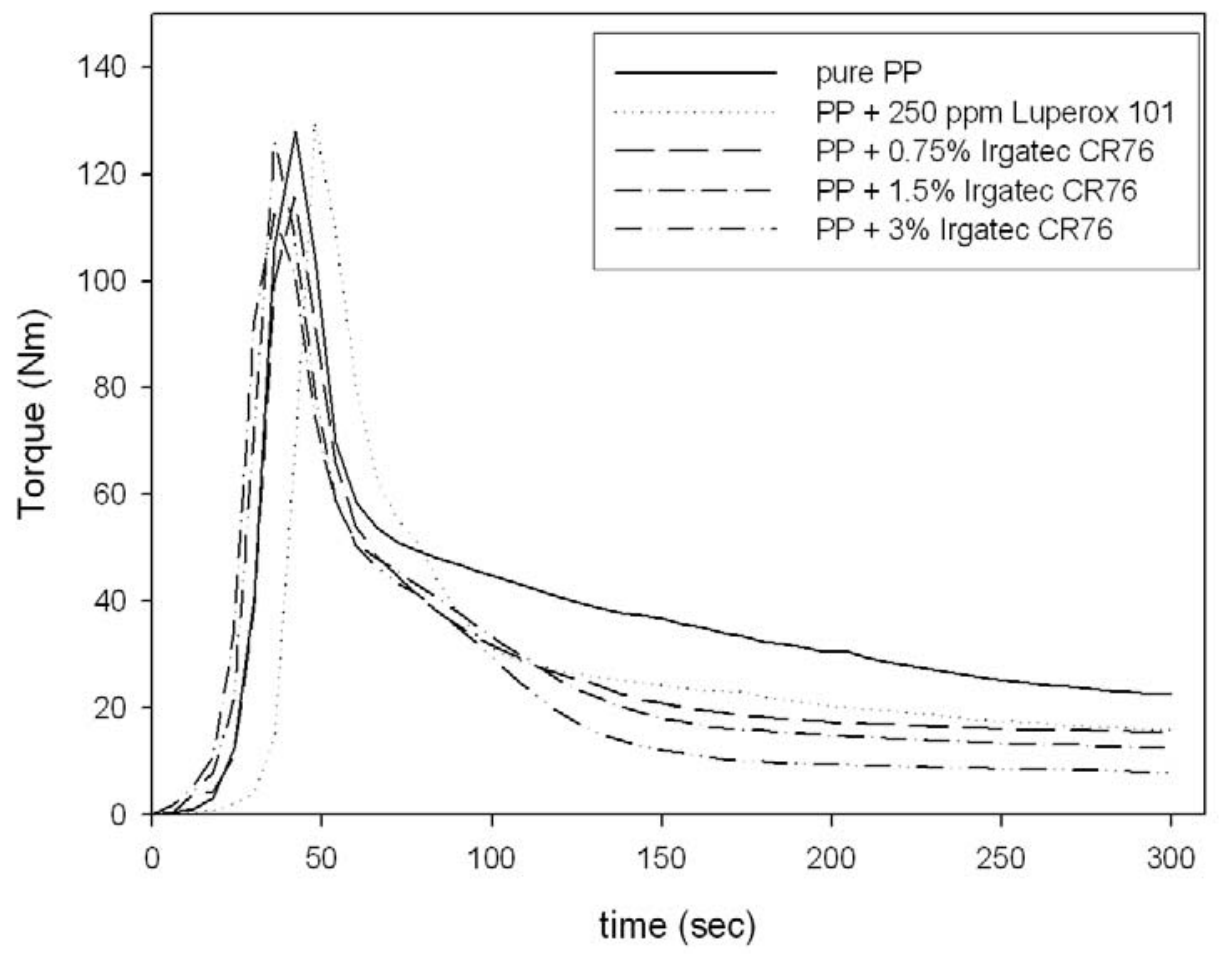

Figure AI.2: Torque vs. time for $250{ }^{\circ} \mathrm{C}$ in Haake mixer

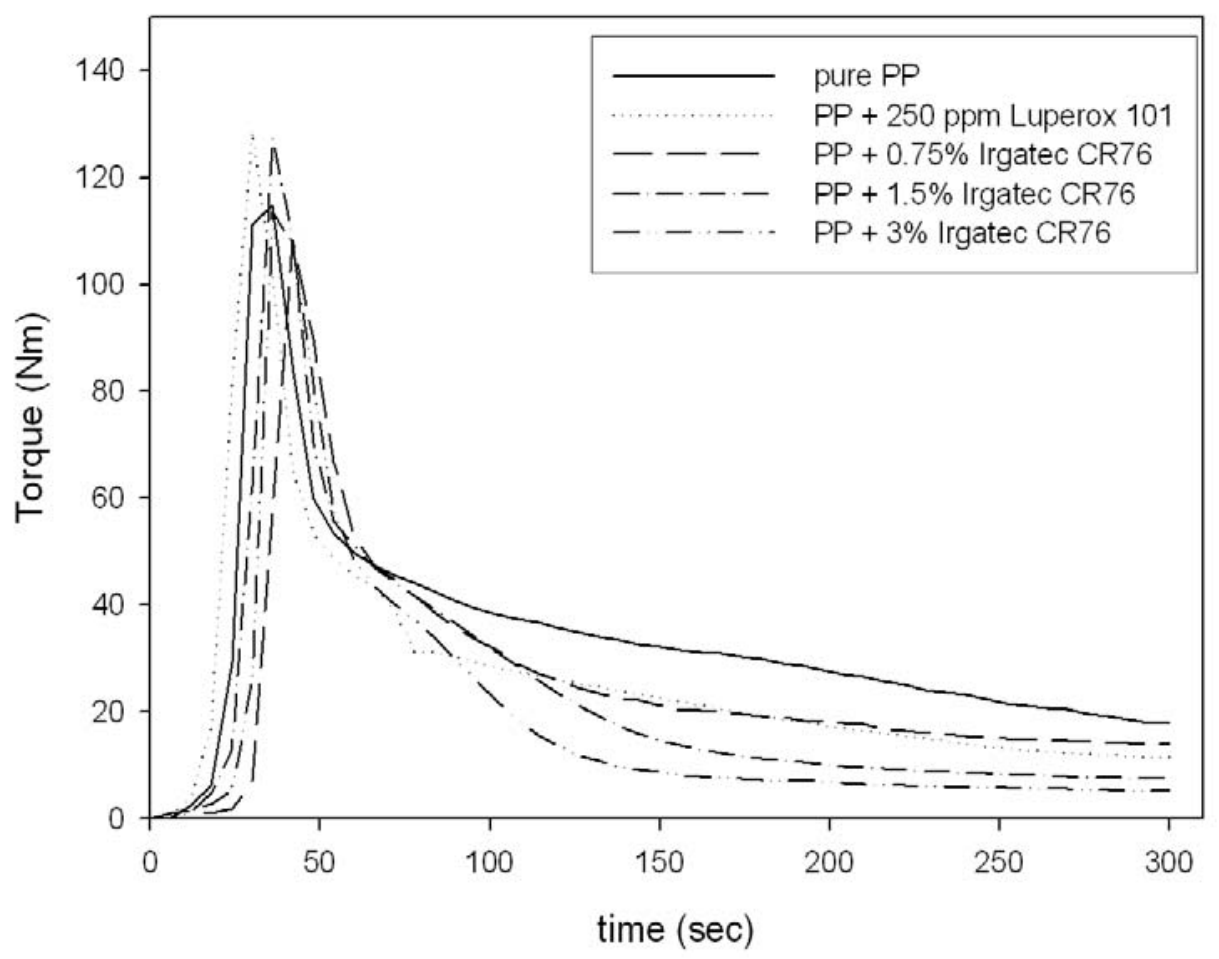

Figure AI.3: Torque vs. time for $270{ }^{\circ} \mathrm{C}$ in Haake mixer 


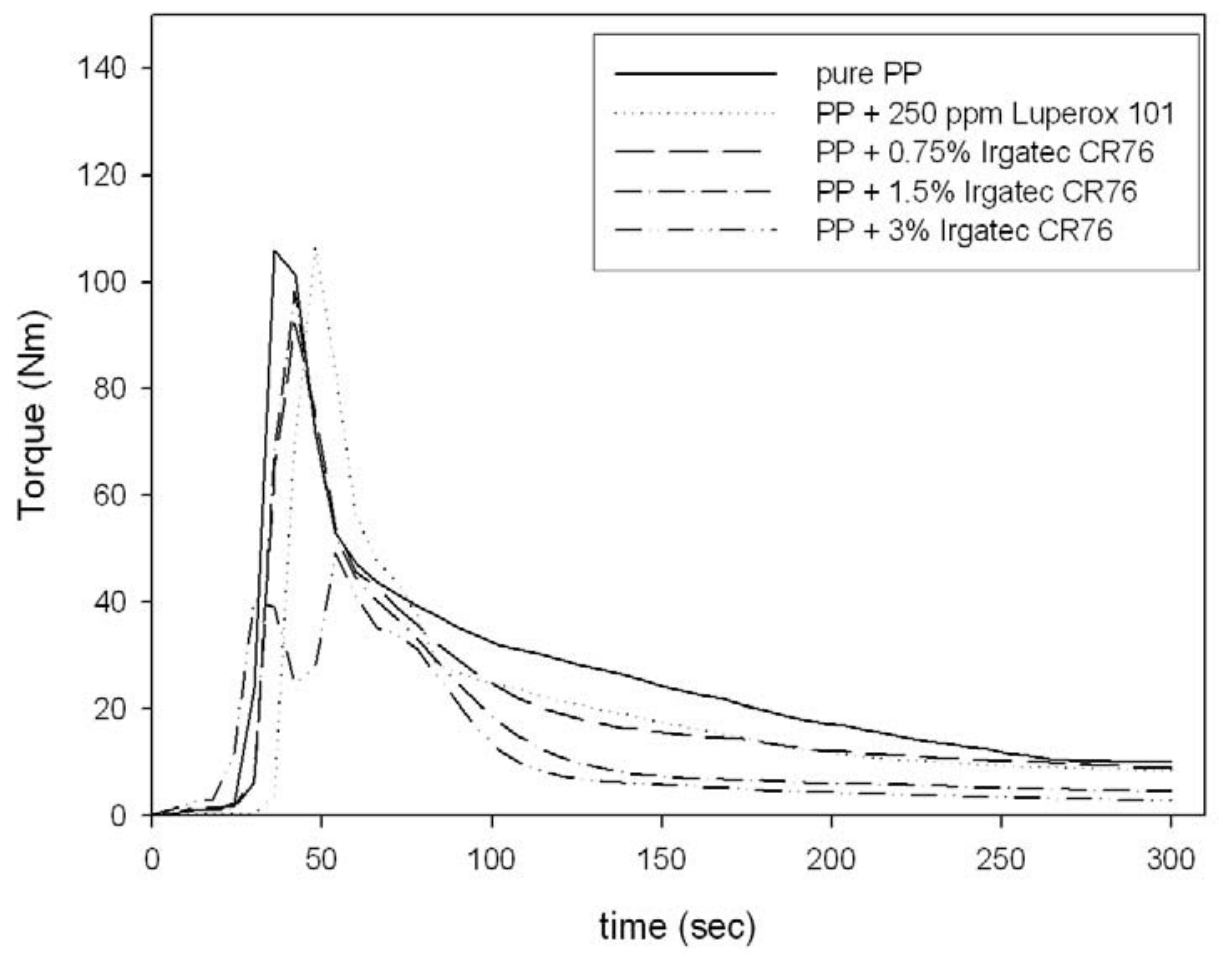

Figure AI.4: Torque vs. time for $290{ }^{\circ} \mathrm{C}$ in Haake mixer 


\section{Appendix II}

\section{Modeling of Polymer Melt in Haake Mixer}

The modeling of the rheological properties of polymer melt inside the Haake mixer follows a concept according to studied by Bousmina et al. (1999). The rheological parameters that can be calculated by this method are the shear viscosity and shear rate inside the mixing chamber. These represent the instant values of shear viscosity and shear rate of the polymer melt that is located in the middle of the space between each rotor and its correspondent circular wall of the chamber. In other words, according to Figure 3.1, the modeling has the purpose of estimating the instant values of shear viscosity and shear rate for the position:

$\mathrm{r}_{1 / 2}=\frac{\mathrm{R}_{\mathrm{e}}+\mathrm{R}_{\mathrm{i}}}{2}$

Generally, according to fluid mechanics, if we consider two coaxial cylinders, one of smaller ( $\mathrm{Ri}$ ) and one of larger radius ( $\mathrm{Re})$, where the large one is static and the small one can rotate with $\mathrm{N}$ rpm angular velocity, and between the inner and outer cylinder there is fluid that obeys the power law:

$$
\tau=\mathrm{M} \dot{\gamma}^{\mathrm{n}}
$$

$\tau_{\mathrm{r} \theta}=\mathrm{M} \dot{\gamma}_{\theta \mathrm{r}}{ }^{\mathrm{n}}$

(In cylindrical coordinates)

where $\tau$ is the shear stress, $\dot{\gamma}$ the shear rate, $\mathrm{M}$ the consistency index and $\mathrm{n}$ the power law index, then the shear rate (as function of the distance $r$ from the coaxial axis) is calculated as:

$\dot{\gamma}=\frac{4 \pi \mathrm{N}}{\mathrm{n}} \frac{\left(\frac{\mathrm{R}_{\mathrm{e}}}{\mathrm{r}}\right)^{2 / \mathrm{n}}}{\left(\frac{\mathrm{R}_{\mathrm{e}}}{\mathrm{R}_{\mathrm{i}}}\right)^{2 / \mathrm{n}}-1}$

At position (A.1) it is easy to calculate:

$\dot{\gamma}=\dot{\gamma}_{1 / 2}=\frac{2^{2(1+1 / n)} \pi \mathrm{N}}{\mathrm{n}} \frac{\beta^{2 / \mathrm{n}}}{(1+\beta)^{2 / \mathrm{n}}\left(\beta^{2 / \mathrm{n}}-1\right)}$ 
where $\beta$ is the ratio $R_{e} / R_{i}$.

In the case of a Haake mixer, this methodology can be applied for each circular cross section of the mixing chamber, but instead of an inner cylinder of flat surface there is a rotor (blade) of spiral cross section, something that complicates this application. In other words, all the parameters in equation (A.4) are known except $\beta$. For this reason, Bousmina et al. (1999) simulated the rotor radius via an apparent effective internal radius $\mathrm{R}_{\mathrm{i}}$ as if there was an internal cylinder that caused the same results as the rotor.

Generally, the torque is given by:

$\Gamma=(2 \pi \mathrm{rL}) \tau_{\mathrm{r} \theta} \mathrm{r}$

where $\mathrm{L}$ is the width of the surface. The total mechanical power is:

$\Omega \Gamma=\Omega_{1} \Gamma_{1}+\Omega_{2} \Gamma_{2}$

where $\Omega$ is the angular velocity (rpm) and 1 and 2 represent rotor 1 (main blade) and rotor 2 (secondary blade), respectively. In the case of the Haake mixer: $\Omega=\Omega_{1}$, so we can divide by $\Omega$ and obtain the total torque:

$\Gamma=\Gamma_{1}+\mathrm{g} \Gamma_{2}$

where $\mathrm{g}$ is the ratio $\Omega_{2} / \Omega_{1}$.

Combining (A.2), (A.3), (A.5) and (A.7), it is derived:

$$
\Gamma=2^{2 \mathrm{n}+1} \pi^{\mathrm{n}+1} \operatorname{MLR}_{\mathrm{e}}^{2} \frac{\mathrm{N}^{\mathrm{n}}\left(1+\mathrm{g}^{\mathrm{n}+1}\right)}{\left\{\mathrm{n}\left[(\beta)^{2 / \mathrm{n}}-1\right]\right\}^{\mathrm{n}}}
$$

Additionaly, using equations (A.2), (A.3), (A.5), and (A.7) and solving for the radius Ri:

$$
\mathrm{R}_{\mathrm{i}}=\frac{\mathrm{R}_{\mathrm{e}}}{\left[1+\frac{4 \pi \mathrm{N}}{\mathrm{n}}\left(2 \pi \mathrm{MLR}_{\mathrm{e}}{ }^{2} \frac{1+\mathrm{g}^{\mathrm{n}+1}}{\Gamma}\right)^{1 / \mathrm{n}}\right]^{\mathrm{n} / 2}}
$$

According to Bousmina et al. (1999), equation (A.9) can be used for the calculation of the effective internal radius of the rotors. The same study supports that, unlike the case of Goodrich et al. (1967), in this case the effective internal radius is independent of the nature of the fluid under mixing and the processing conditions: rotation, speed and temperature. That means that regardless of the material and the conditions inside the mixing chamber, the denominator in equation (A.9) remains 
constant. In other words, one experiment with a power law fluid in the Haake mixer is enough for the determination of the effective internal radius.

In addition, Bousmina et al. (1999) support that when the internal gap is narrow:

$\frac{\mathrm{R}_{\mathrm{e}}-\mathrm{R}_{\mathrm{i}}}{\mathrm{R}_{\mathrm{i}}}<<1$

then the shear rate evaluated at position (A.1) is independent of the power law index n. This means that in this position and under assumption (A.10), the shear rate can be approximated by Newtonian behaviour $(\mathrm{n}=1)$.

In that case, equation (A.4) becomes:

$$
\dot{\gamma}=\left(\dot{\gamma}_{1 / 2}\right)_{\beta \rightarrow 1}=16 \pi \mathrm{N} \frac{\beta^{2}}{(1+\beta)^{2}\left(\beta^{2}-1\right)}
$$

which can be approximated by:

$\dot{\gamma}=\left(\dot{\gamma}_{1 / 2}\right)_{\beta \rightarrow 1} \approx 2 \pi \mathrm{N} / \ln \beta$

And equation (A.8) becomes:

$$
\Gamma=8 \pi^{2} \operatorname{MLR}_{\mathrm{e}}^{2} \frac{\mathrm{N}\left(1+\mathrm{g}^{2}\right)}{\left(\beta^{2}-1\right)}
$$

Additionally, from fluid mechanics we know that:

$$
\tau=\eta(\dot{\gamma}) \dot{\gamma}
$$

where $\eta$ is the (instantaneous) shear viscosity.

Finally, combining (A.13) with (A.5), and (A.7) and (A.11), we obtain:

$$
\eta=\frac{\Gamma}{\mathrm{N}} \frac{\left(\beta^{2}-1\right)}{8 \pi^{2} \mathrm{LR}_{\mathrm{e}}^{2}\left(\mathrm{~g}^{2}+1\right)}
$$

Equations (A.11) and (A.14) are used for the modeling of the instantaneous values of the rheological properties of the polymer melt, during its mixing in the Haake mixer. They require the knowledge of:
a. The geometry of the mixing chamber $\left(L\right.$ and $\left.R_{e}\right)$
b. The rotation speed of the rotors $(\mathrm{N})$
c. The ratio of the rotation (g) (see equation (A.7))
d. The ratio of the radius $(\beta)$ (see equation (A.4)), and 
e. The instantaneous torque of the device $(\Gamma)$

For the knowledge of the ratio of the radius, the determination of the effective internal radius $R_{i}$ is necessary. This is calculated from equation (A.9) and needs at least one experiment in the Haake mixer with a fluid that follows the power law and its power law parameters are known. This is the reason why in Chapter 3 the description of the capillary rheometer was given, despite the fact that the characterization of the CRPP didn't take place in the capillary rheometer at all. In other words, the capillary rheometer was used for the calculation of the power law parameters (consistency index and power law index) of one polymer melt. These parameters with the torque value of that polymer melt were used for the determination of the effective internal radius $R_{i}$ of the Haake Mixer.

Bousmina et al. (1999) support that this technique provides good results for the modeling of the rheological properties of the polymer melt inside the Haake mixer. They provide experimental results that confirm the analytical solutions. Necessary conditions for efficient modeling are:

Narrow internal gap: equation (A.10).

No mixing between the two rotor areas of the mixing chamber. Each area is considered to mix independently of the other.

- The effective internal radius $\mathrm{R}_{\mathrm{i}}$ is independent of the nature of the fluid under mixing and the processing conditions: rotation, speed and temperature. 


\section{Appendix III}

\section{Parallel Plate Rheometer Frequency Sweeps of CRPP}

This section presents the frequency sweeps from the parallel plate rheometer for the 20 CRPP resins that were produced in the Haake mixer. These charts show the storage modulus $\left(G^{\prime}\right)$ and loss modulus $\left(G^{\prime \prime}\right)$ of the viscoelastic material vs. the imposed angular frequency $\omega$. Both of the quantities are plotted in the same chart, so the critical frequency (or crossover) where $G^{\prime}=G^{\prime \prime}$ can be found easily. The frequency sweep graphs are given in three parts, each one representing the three temperatures that were used for the experiment in the parallel plate rheometer: $170{ }^{\circ} \mathrm{C}$ (Figures AIII.1 to AIII.20), $190{ }^{0} \mathrm{C}$ (Fig. AIII.21 to AIII.40), and $210{ }^{0} \mathrm{C}$ (Fig. AIII.41 to AIII.60). In each chart are mentioned the initial conditions under which the respective CRPP was produced in the Haake mixer. The charts are numbered from left to right.

Figures AIII.1 to AIII.20: G' and G" vs. angular frequency, measured at $170^{\circ} \mathrm{C}$
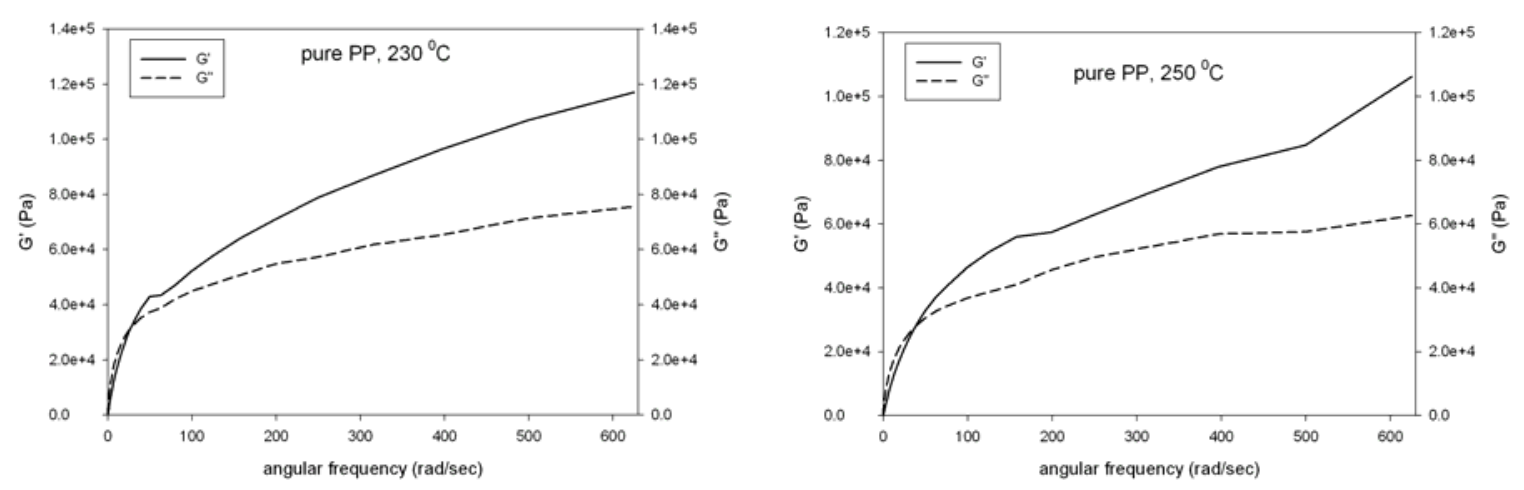
Appendix
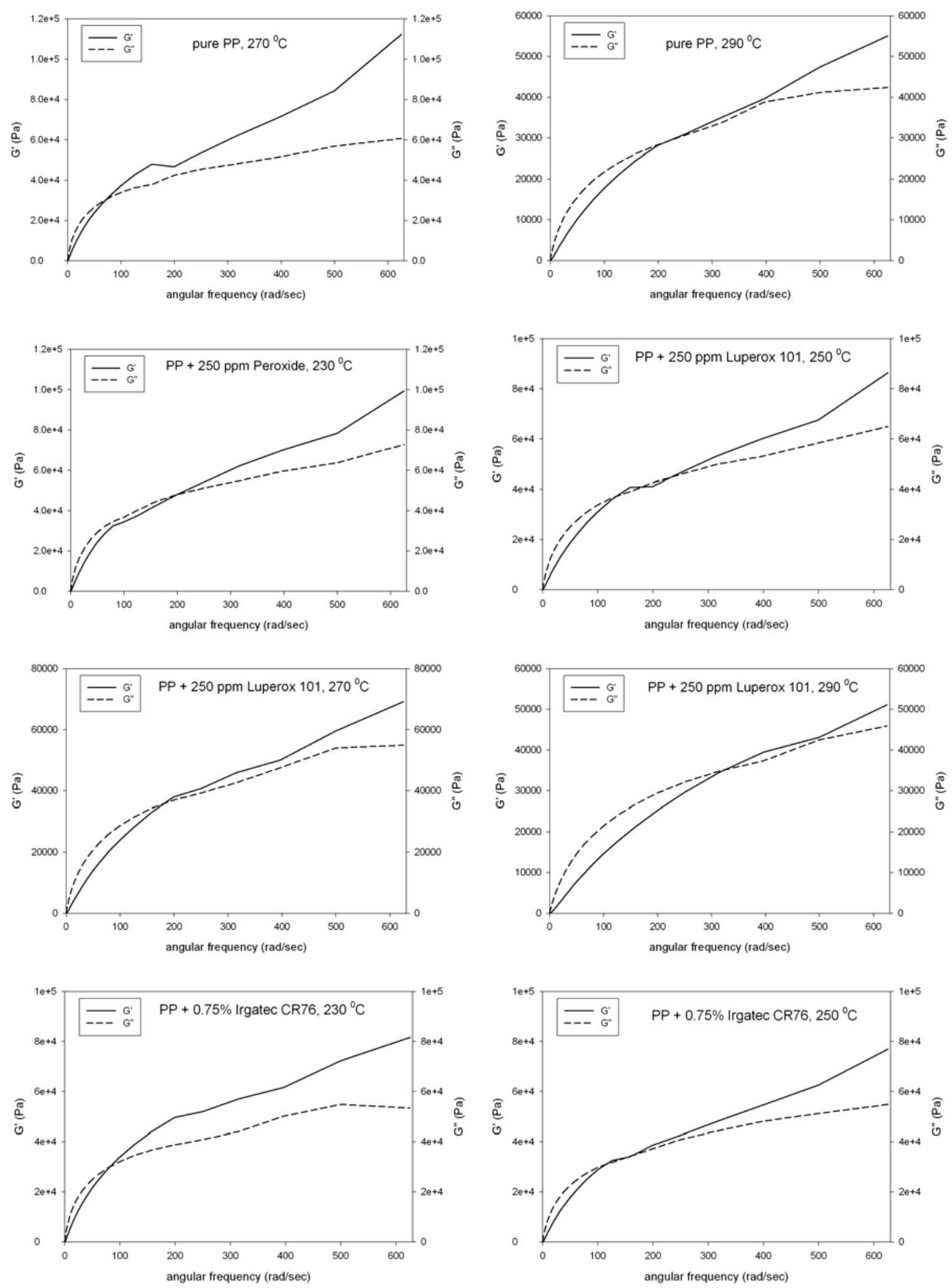

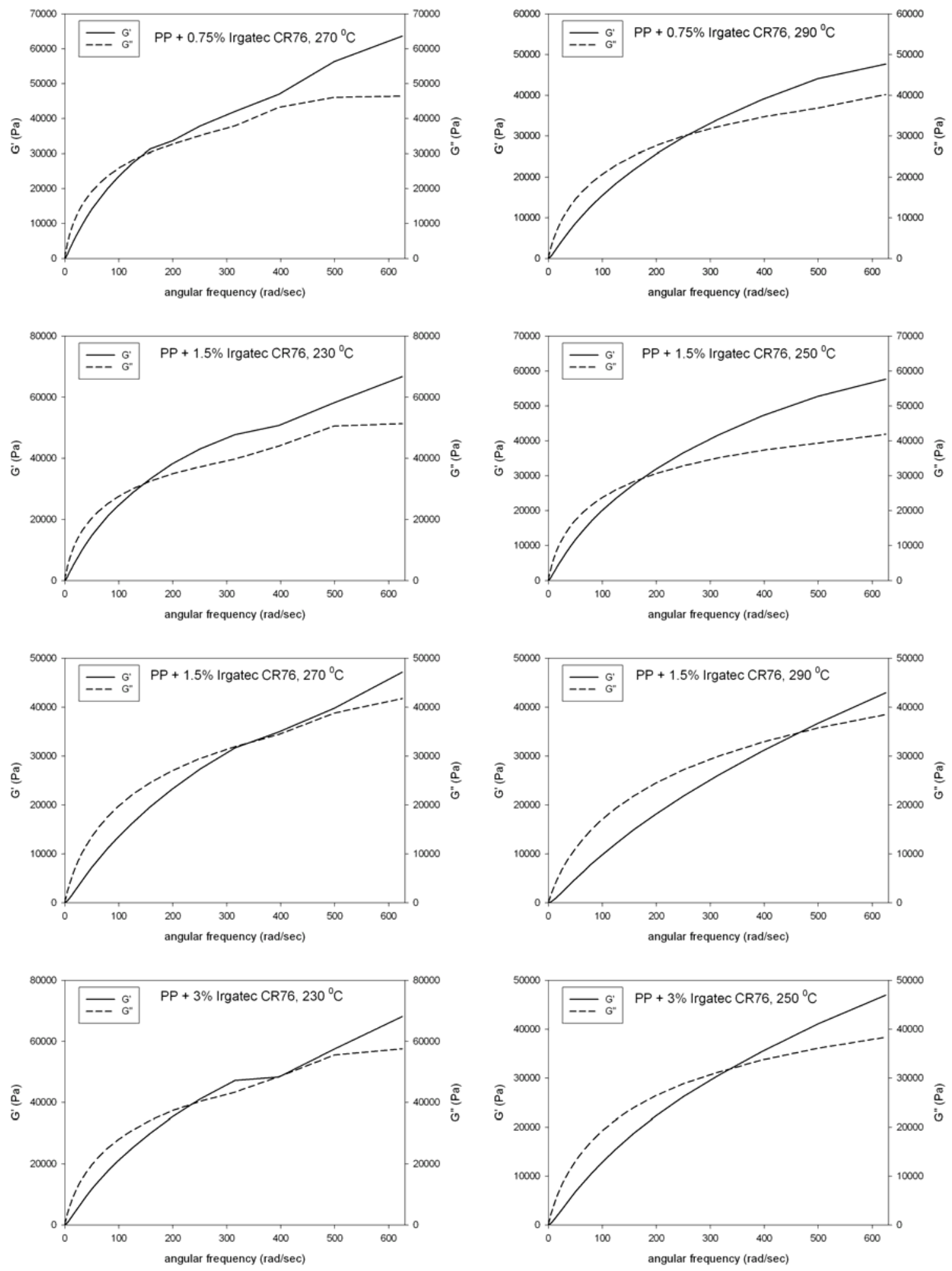

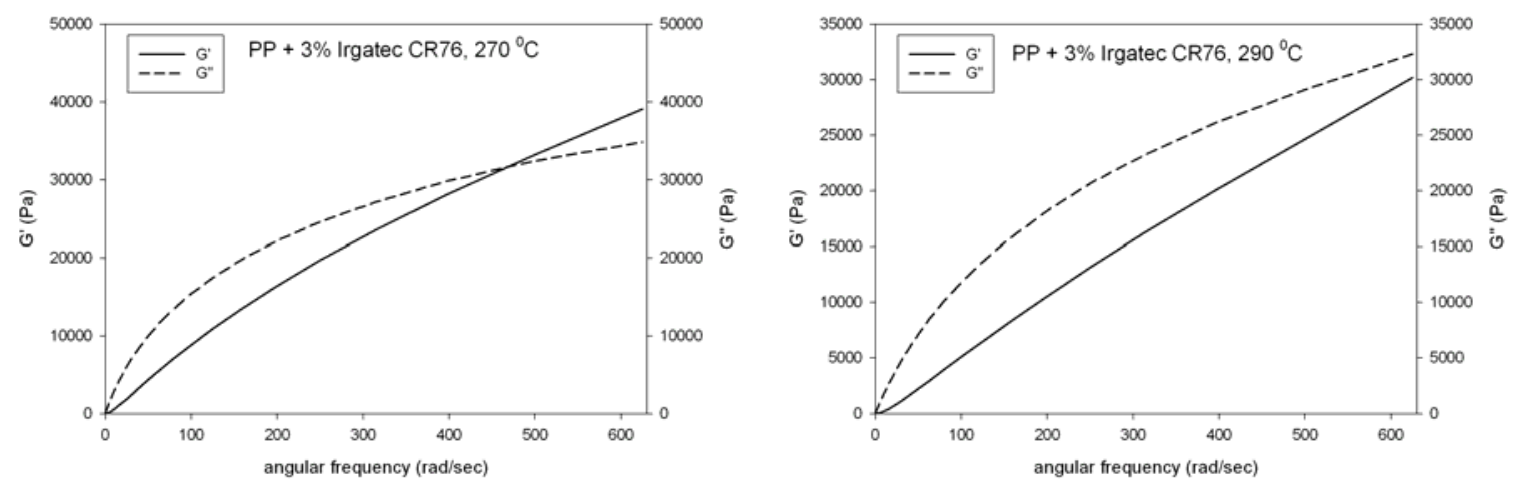

Figures AIII.21 to AIII.40: $\mathrm{G}^{\prime}$ and G" vs. angular frequency, measured at $190{ }^{\circ} \mathrm{C}$
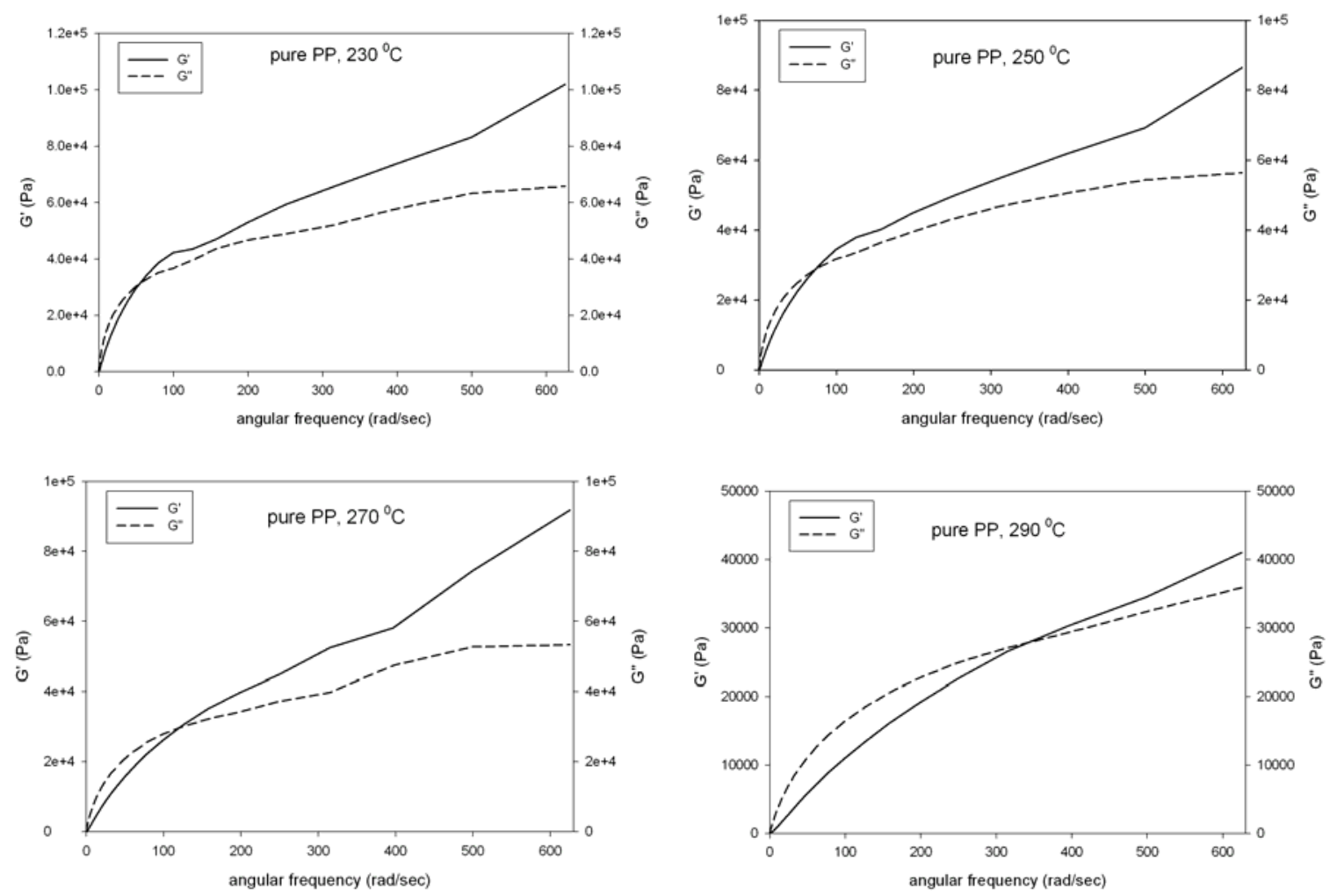

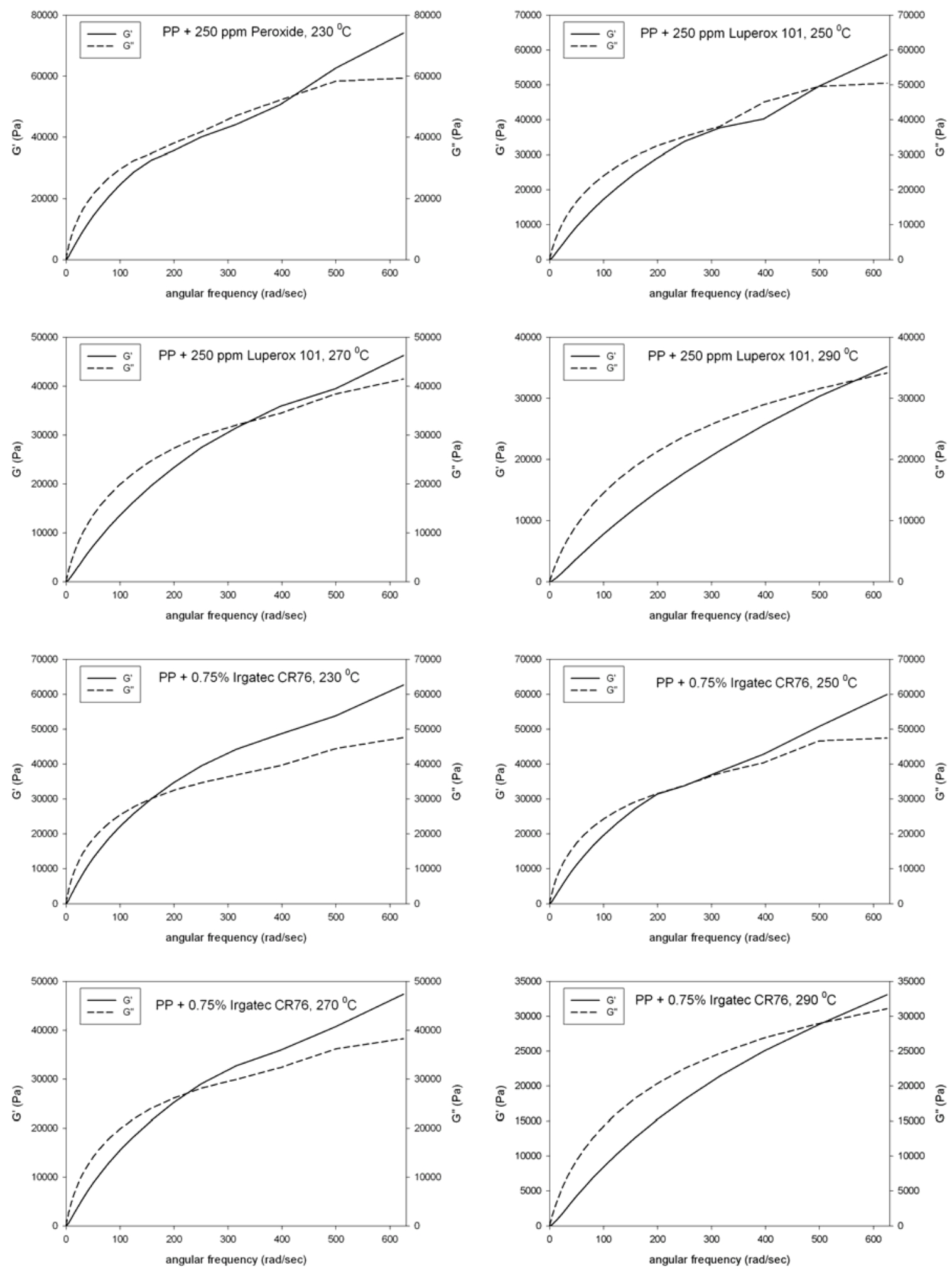

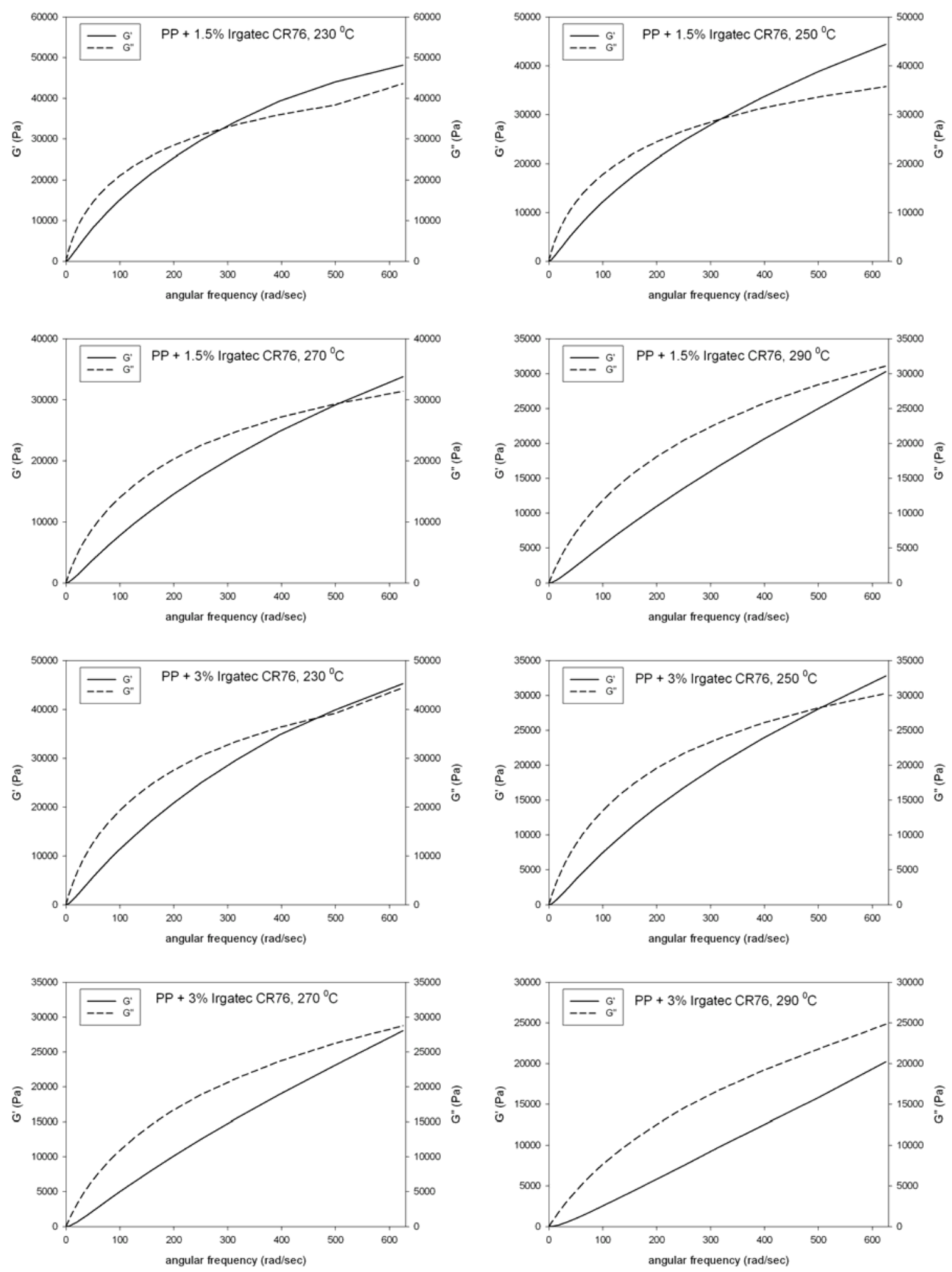


\section{Figures AIII.41 to AIII.60: G' and G" vs. angular frequency, measured at $210^{\circ} \mathrm{C}$}
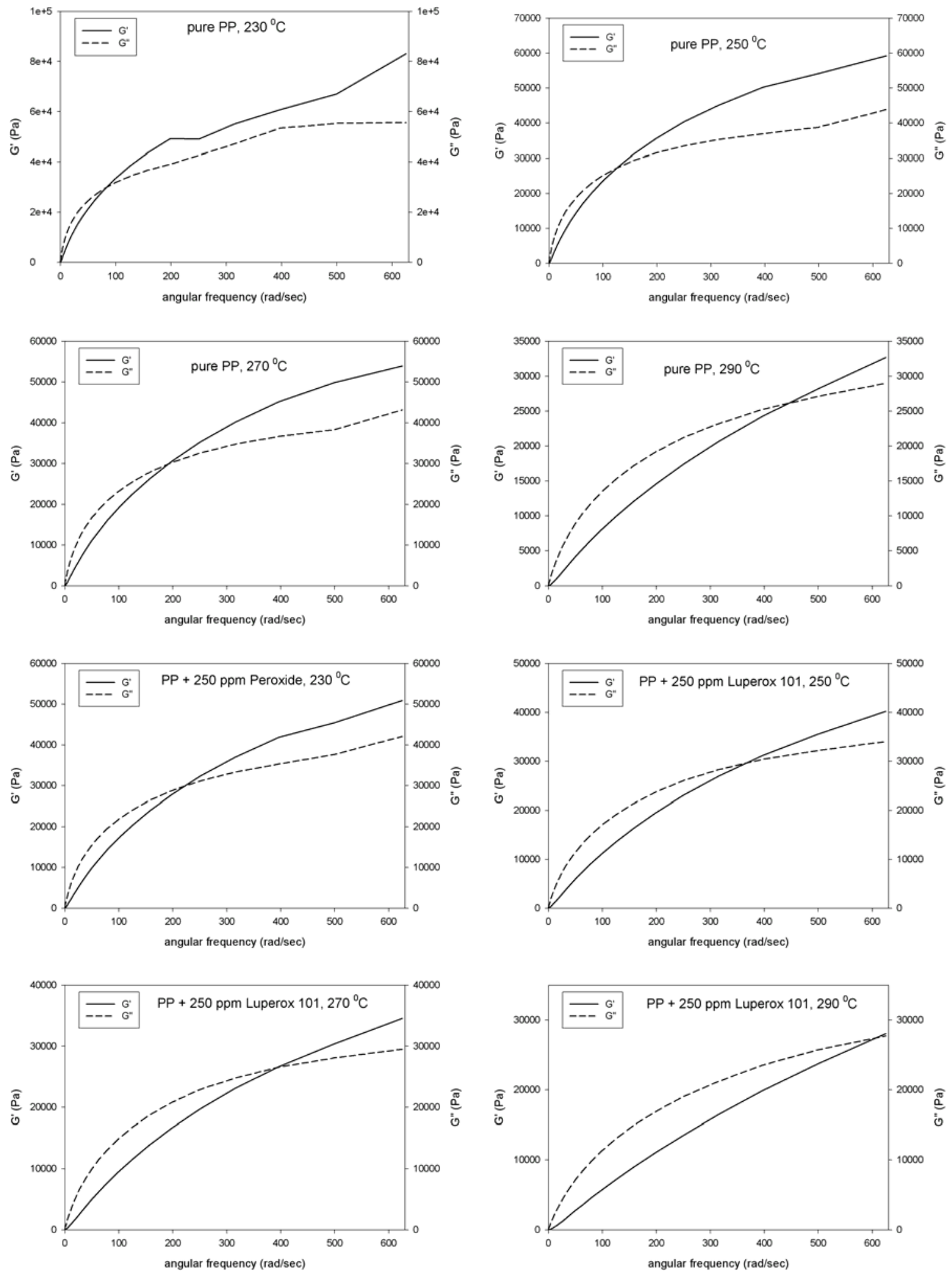

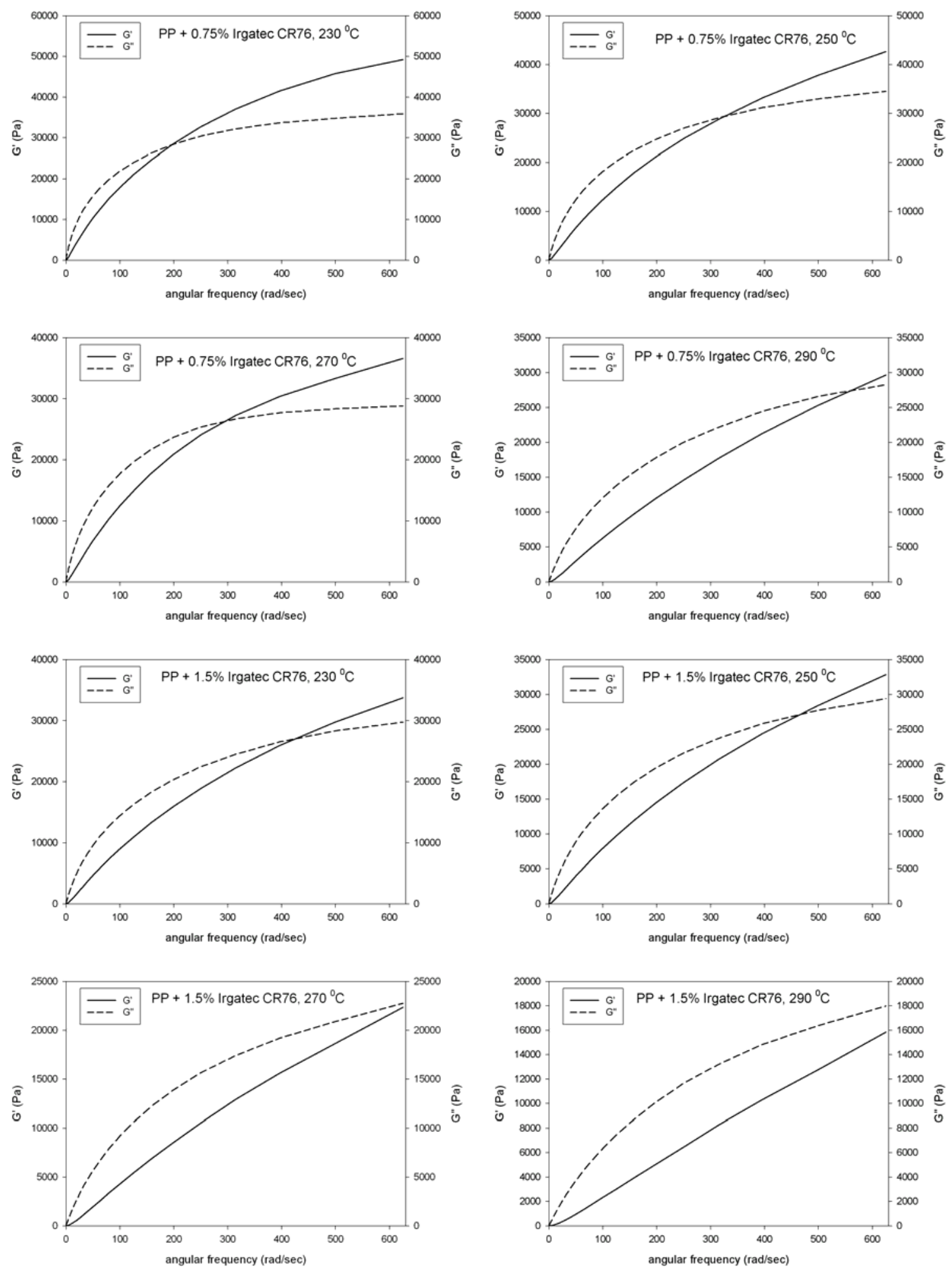
Appendix
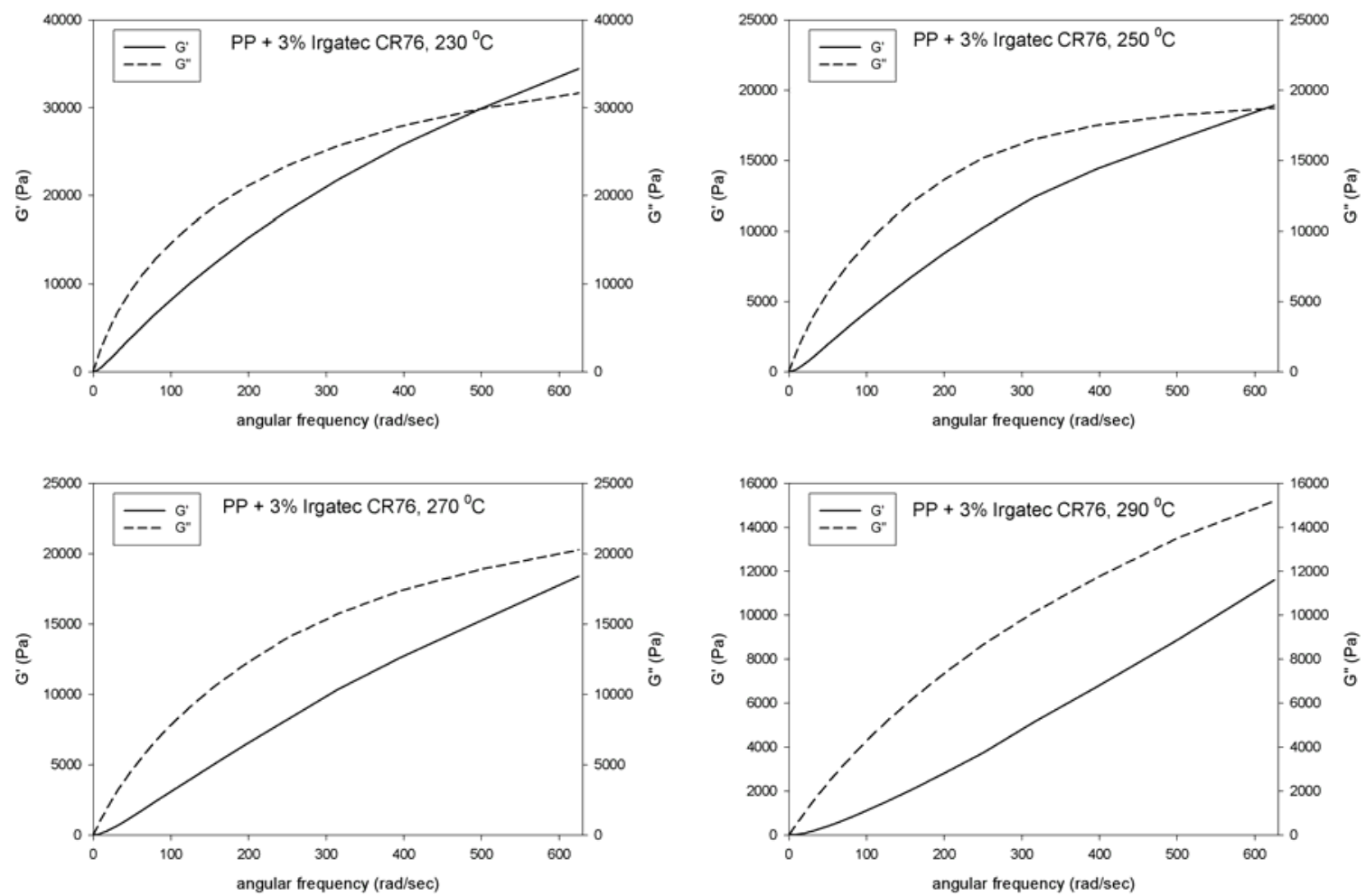


\section{Appendix IV}

\section{Fourier Transform Infrared (FT-IR) Spectra}

This section presents the spectra that were obtained from the FT-IR examination. As mentioned earlier, there are 80 charts for the 20 CRPP samples. That's because four plots are given for each sample. Every CRPP sample was examined twice in two independent experiments and in addition, two areas of the derived spectra are given. The first is the typical IR spectrum (wavenumber between 400 and $4,000 \mathrm{~cm}^{-1}$ ) and the second is an expansion for wavenumbers between 800 and $900 \mathrm{~cm}^{-1}$. Figures are again numbered from left to right.

Figures AIV.1 to AIV.80: FT-IR spectra for the CRPP resins
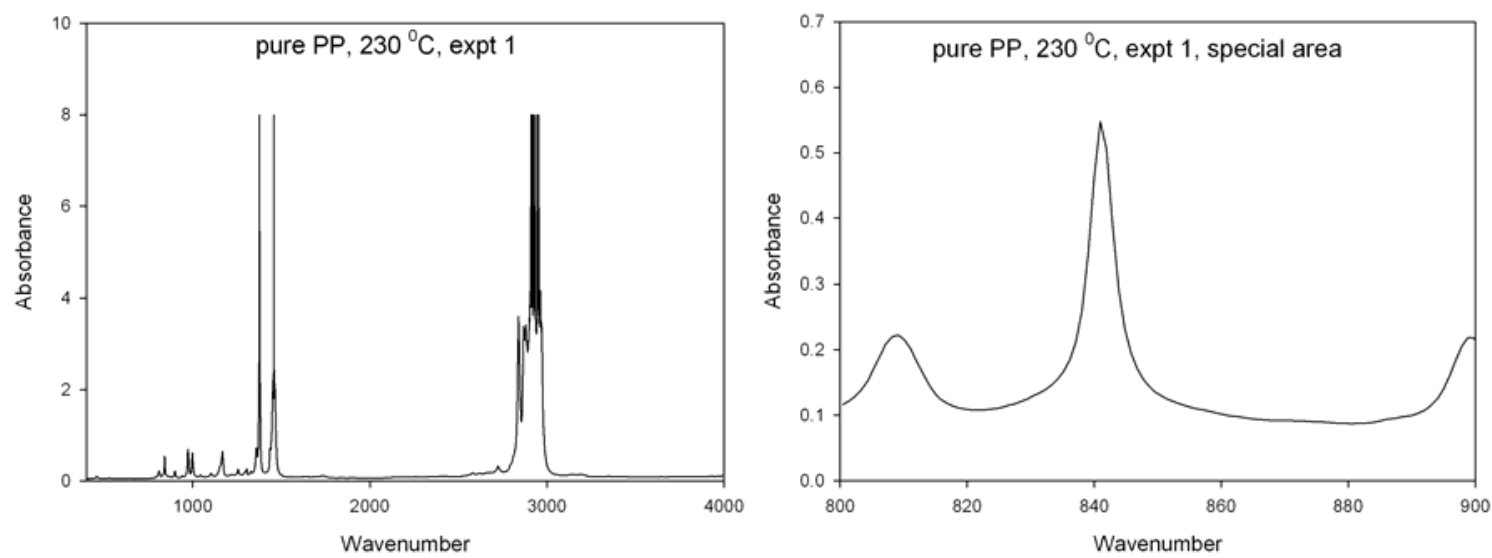

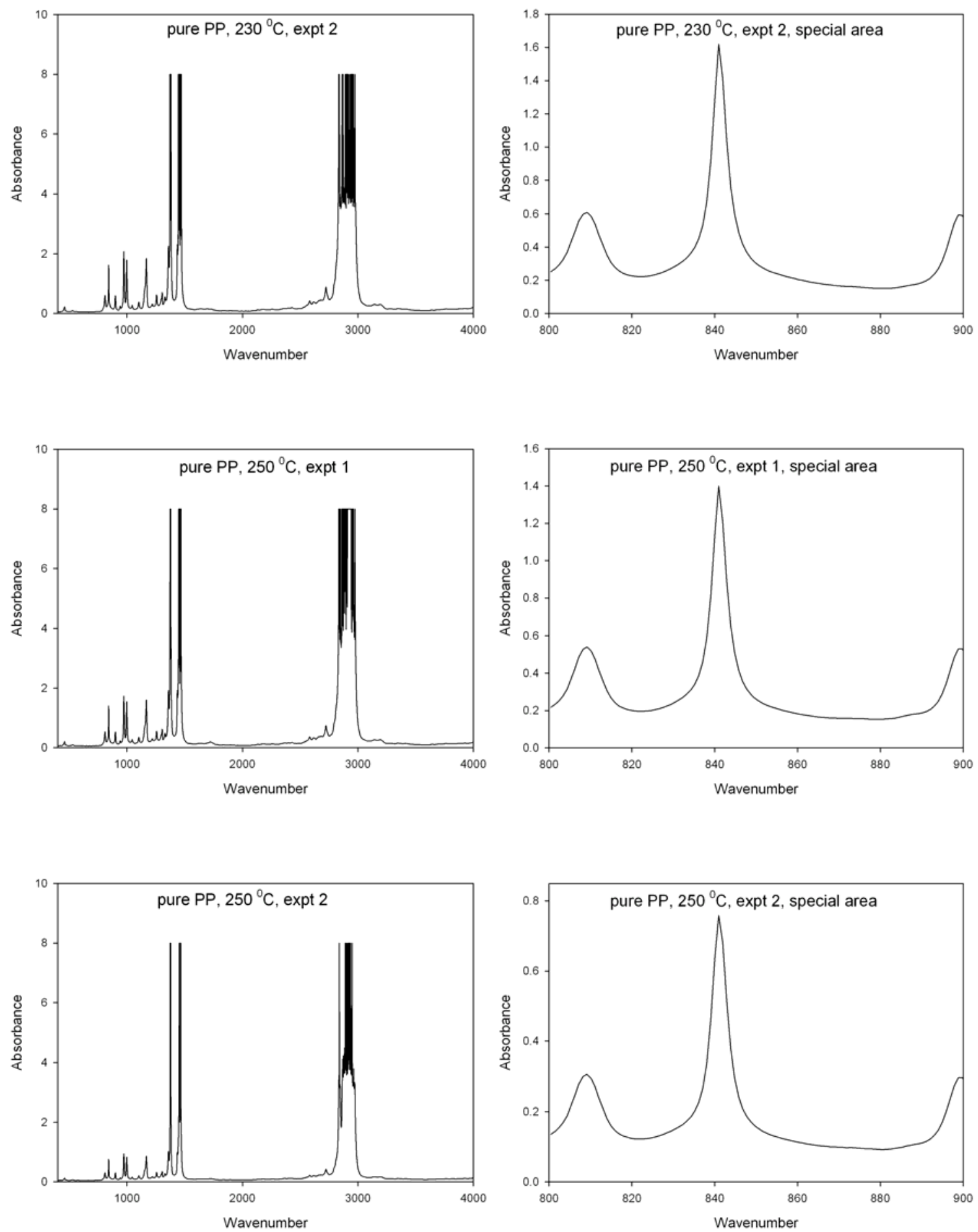

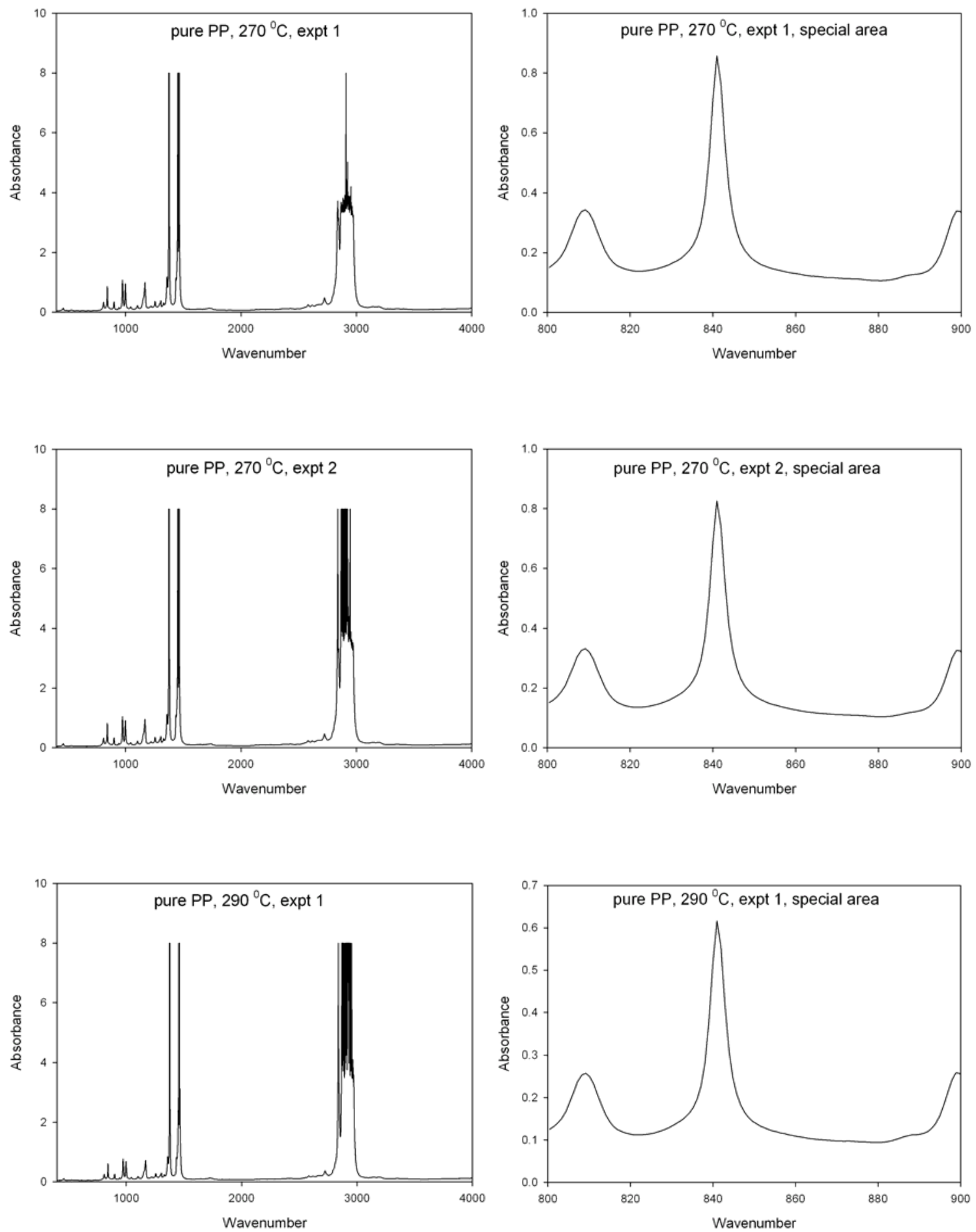

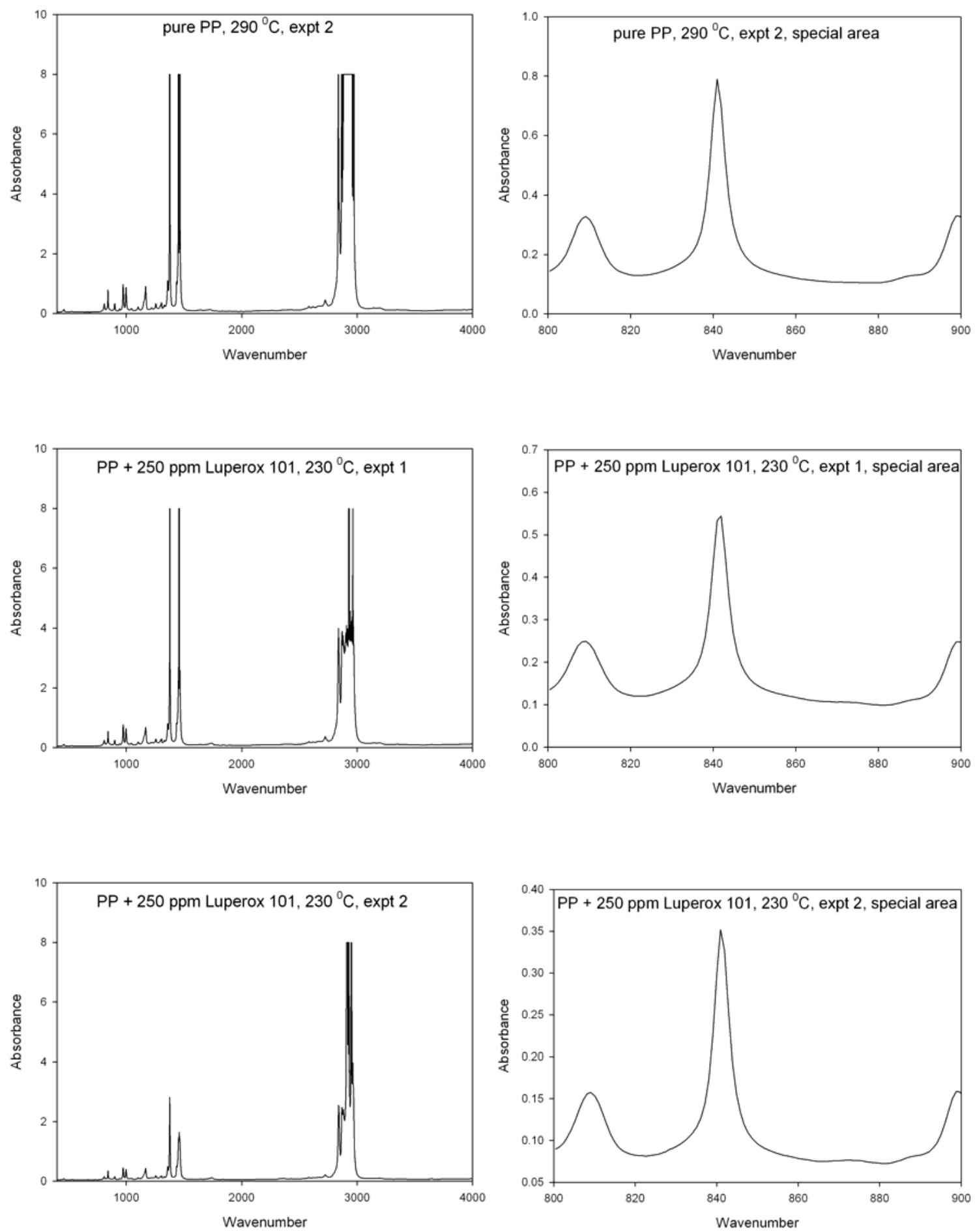

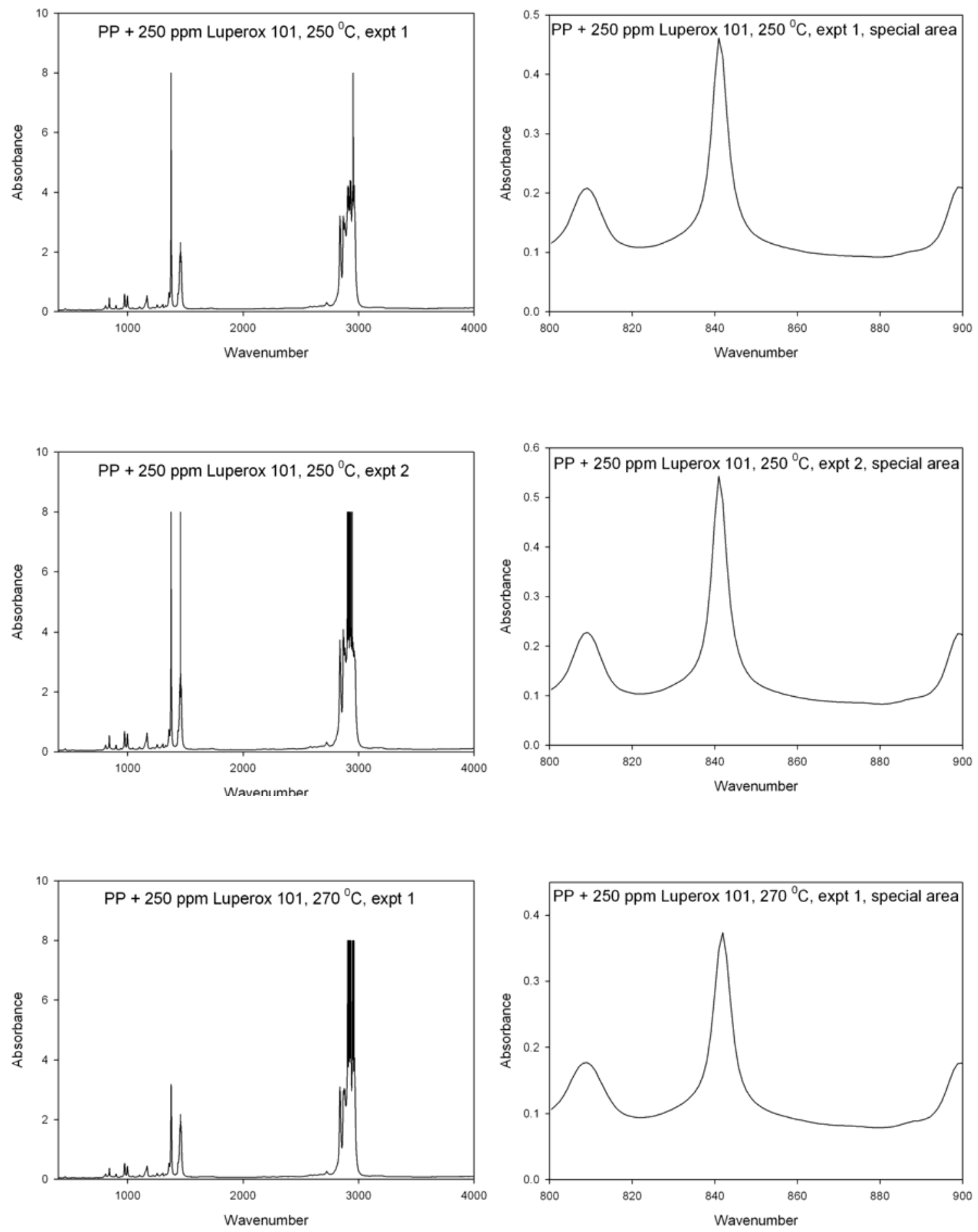

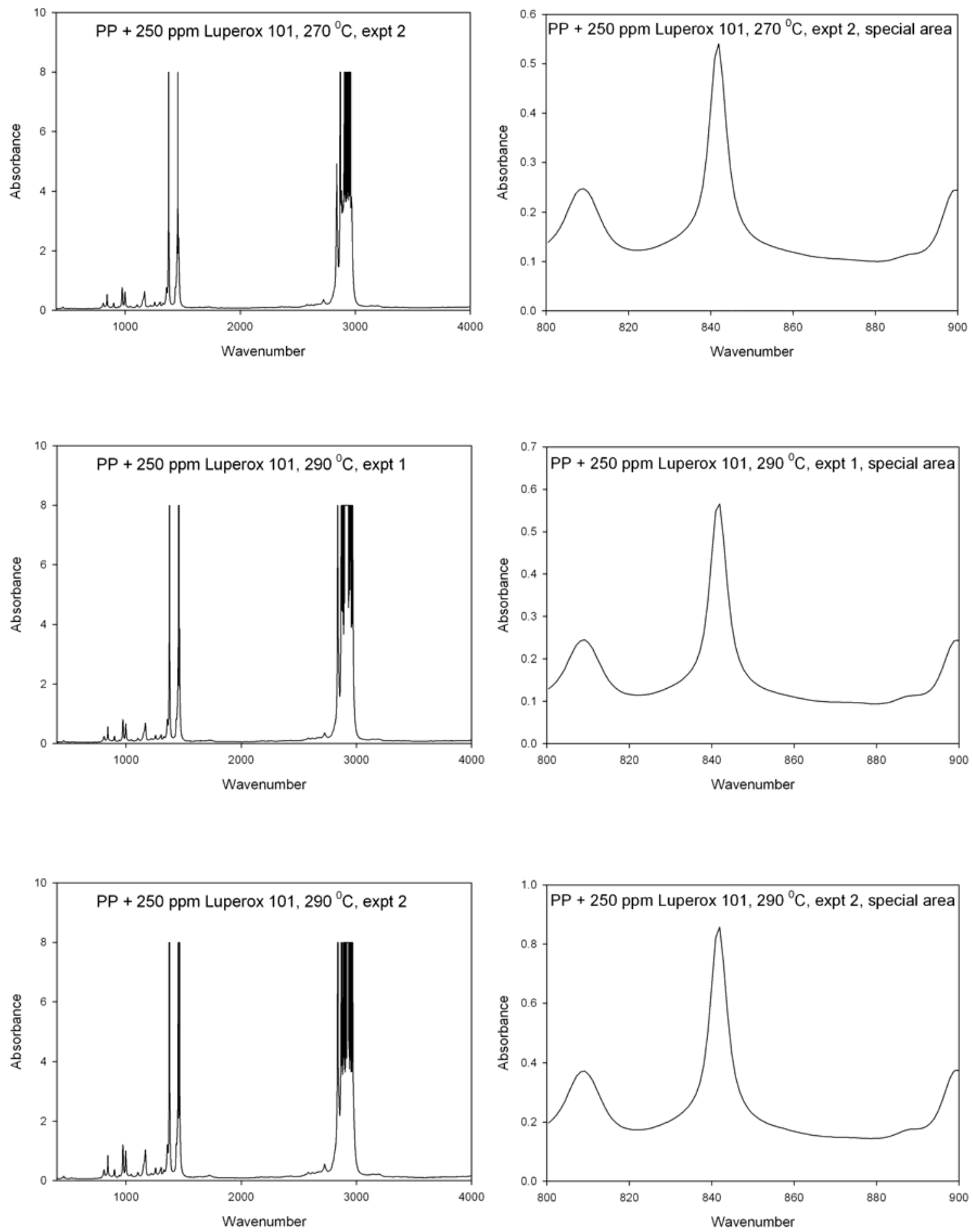

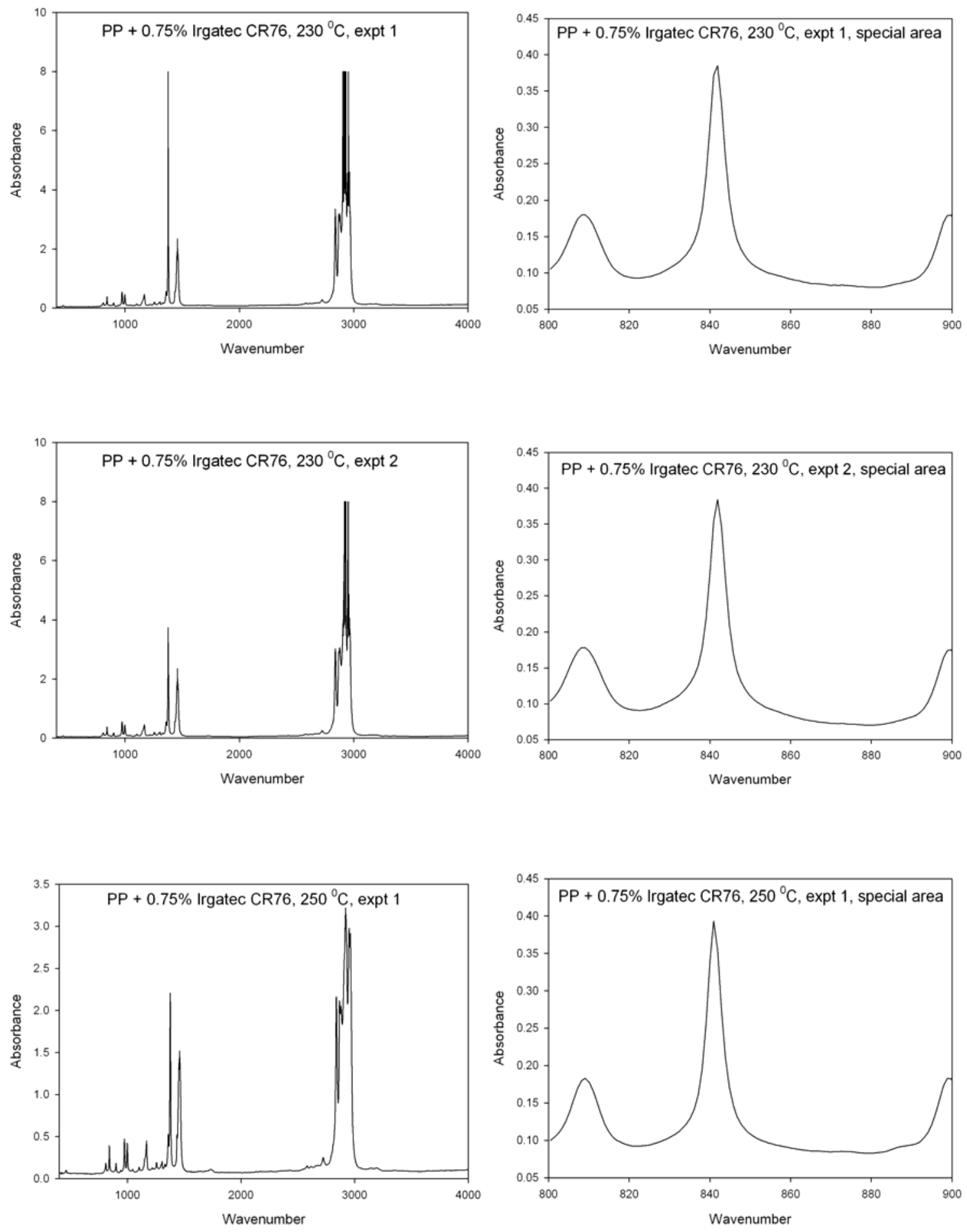

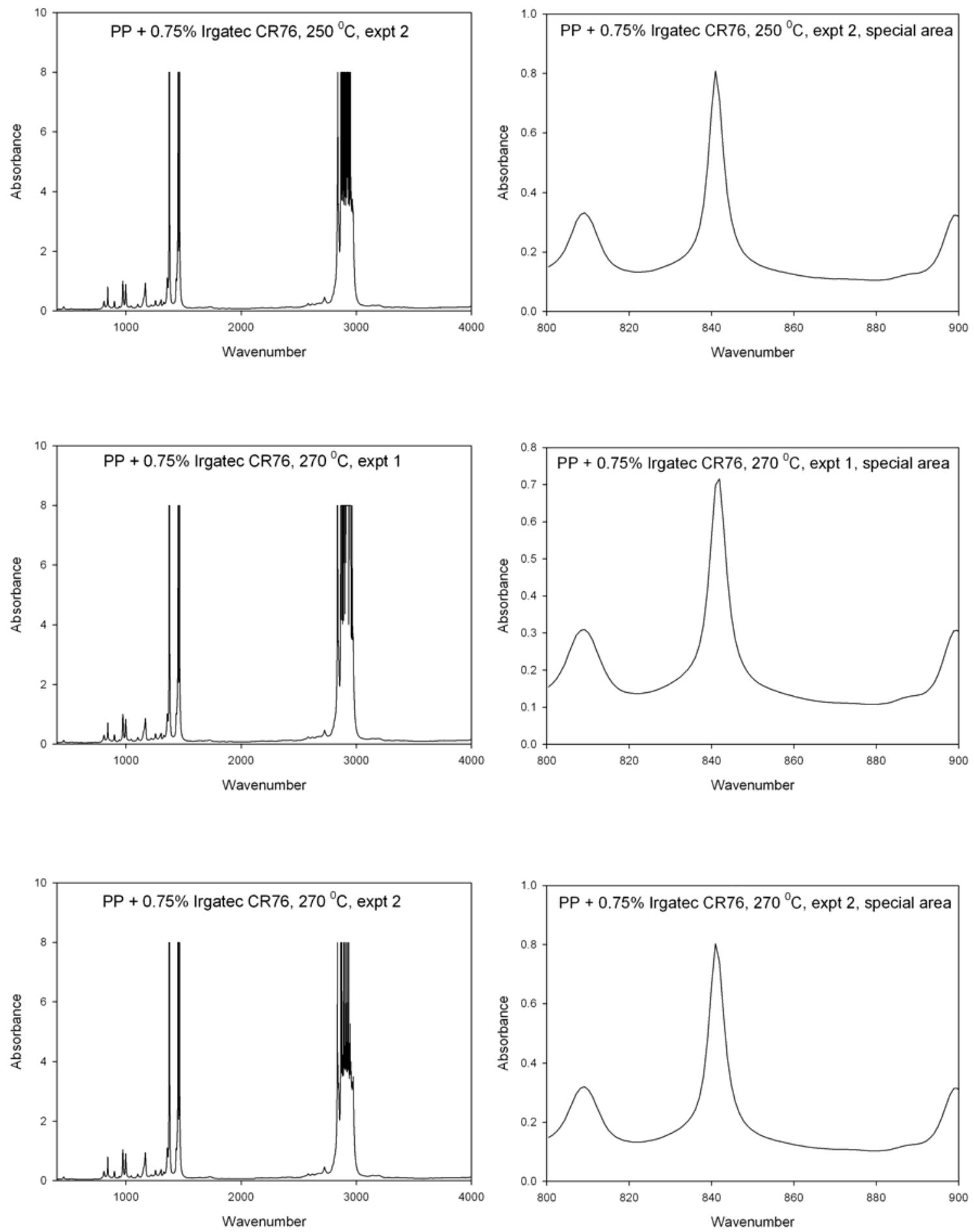

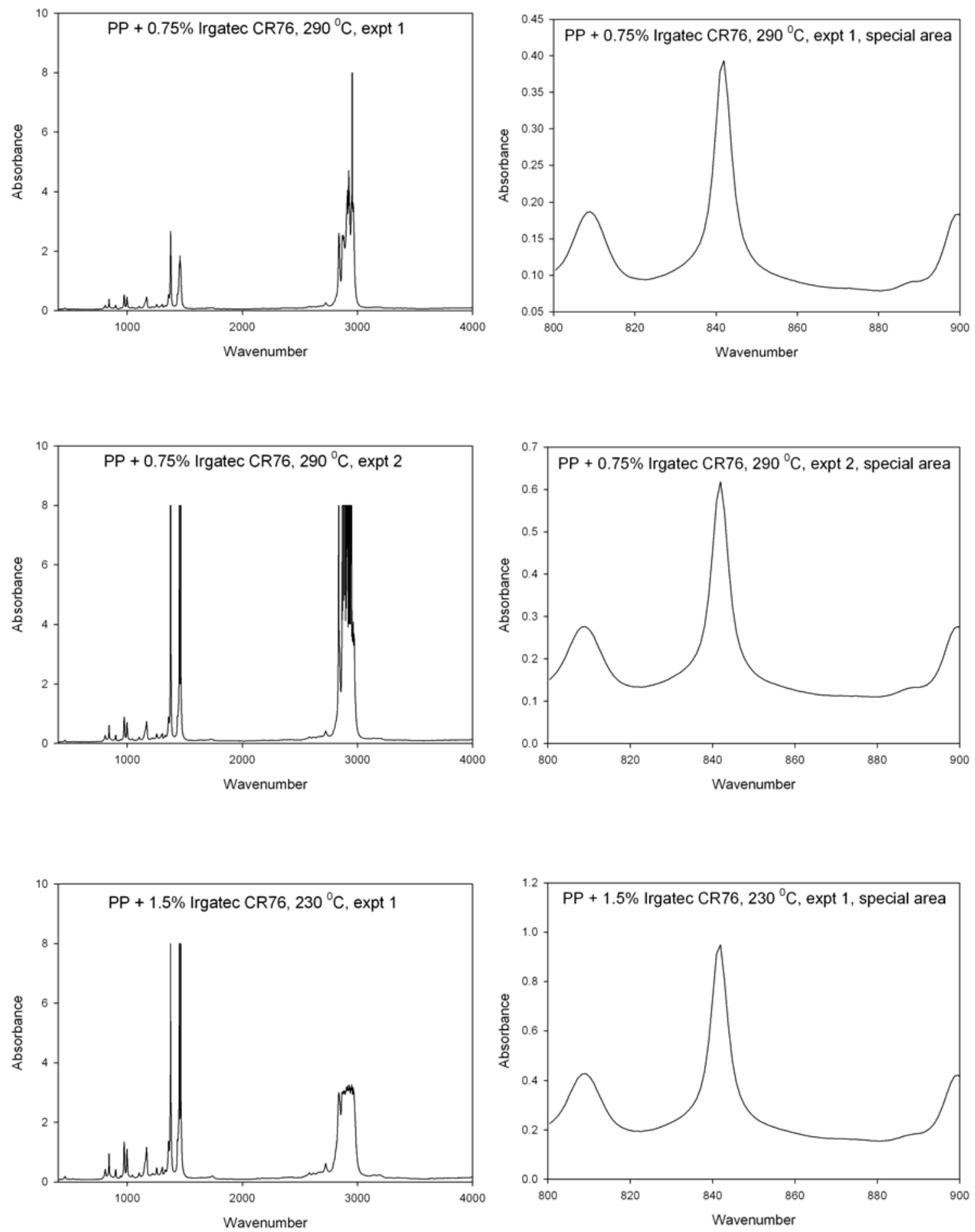

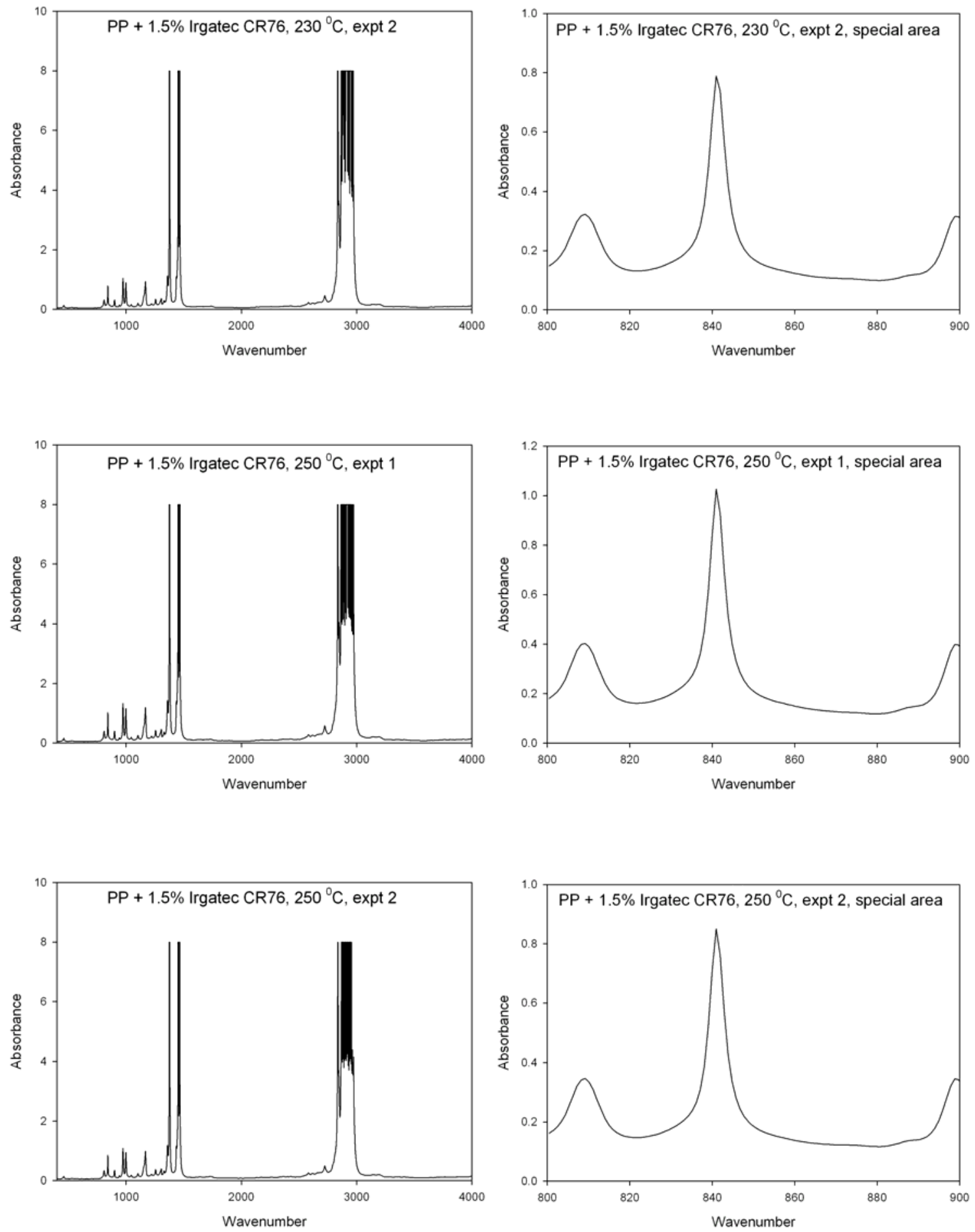

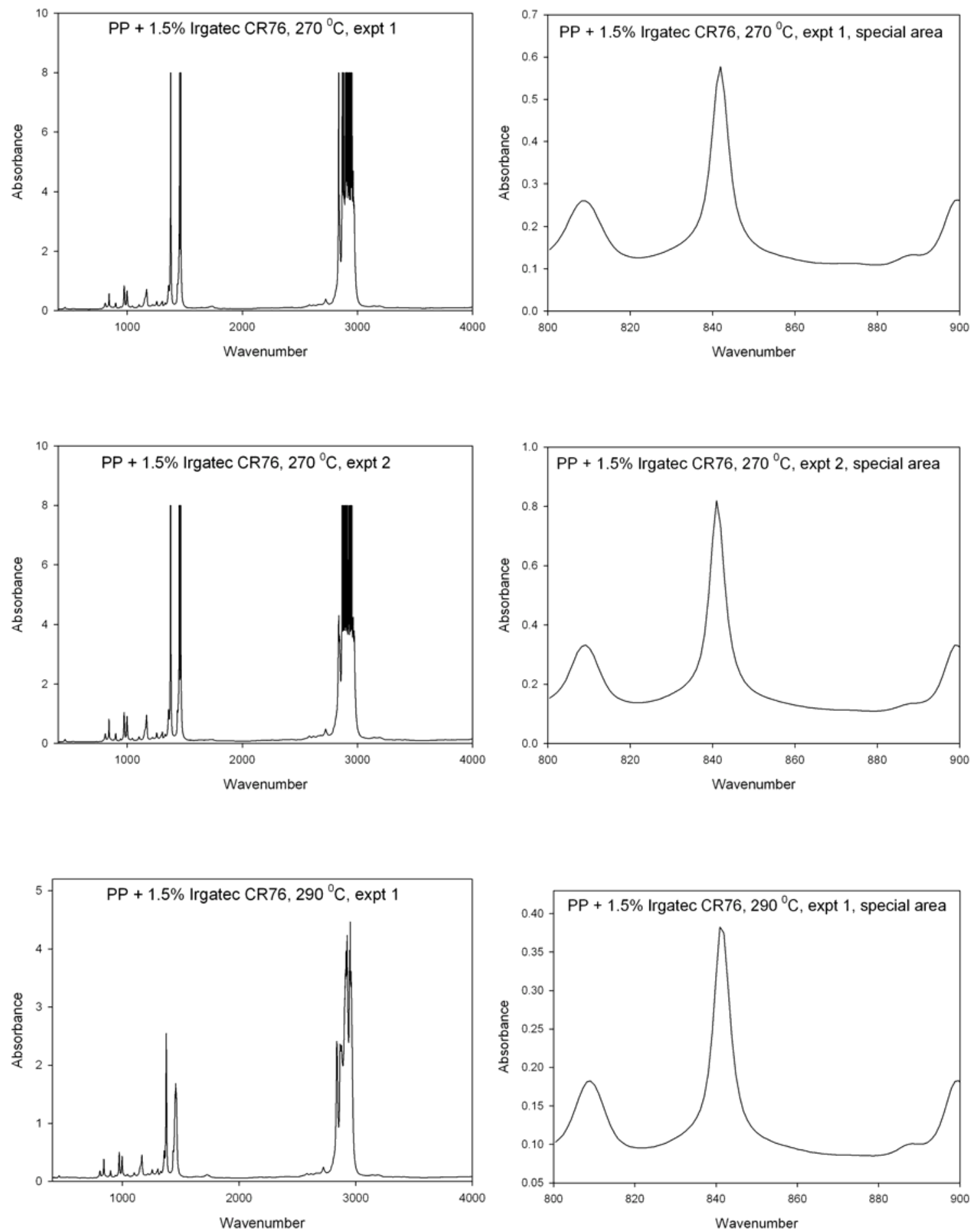

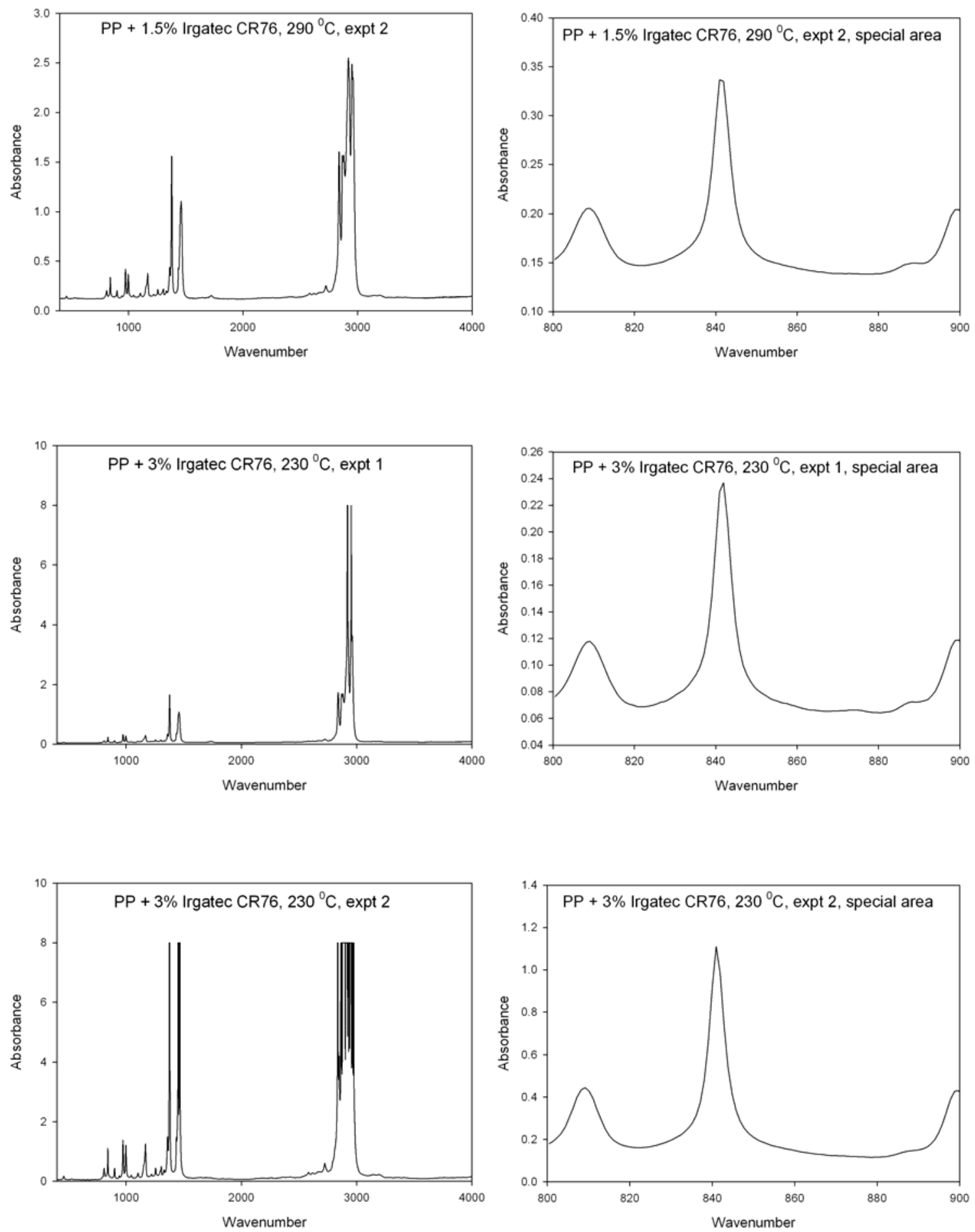

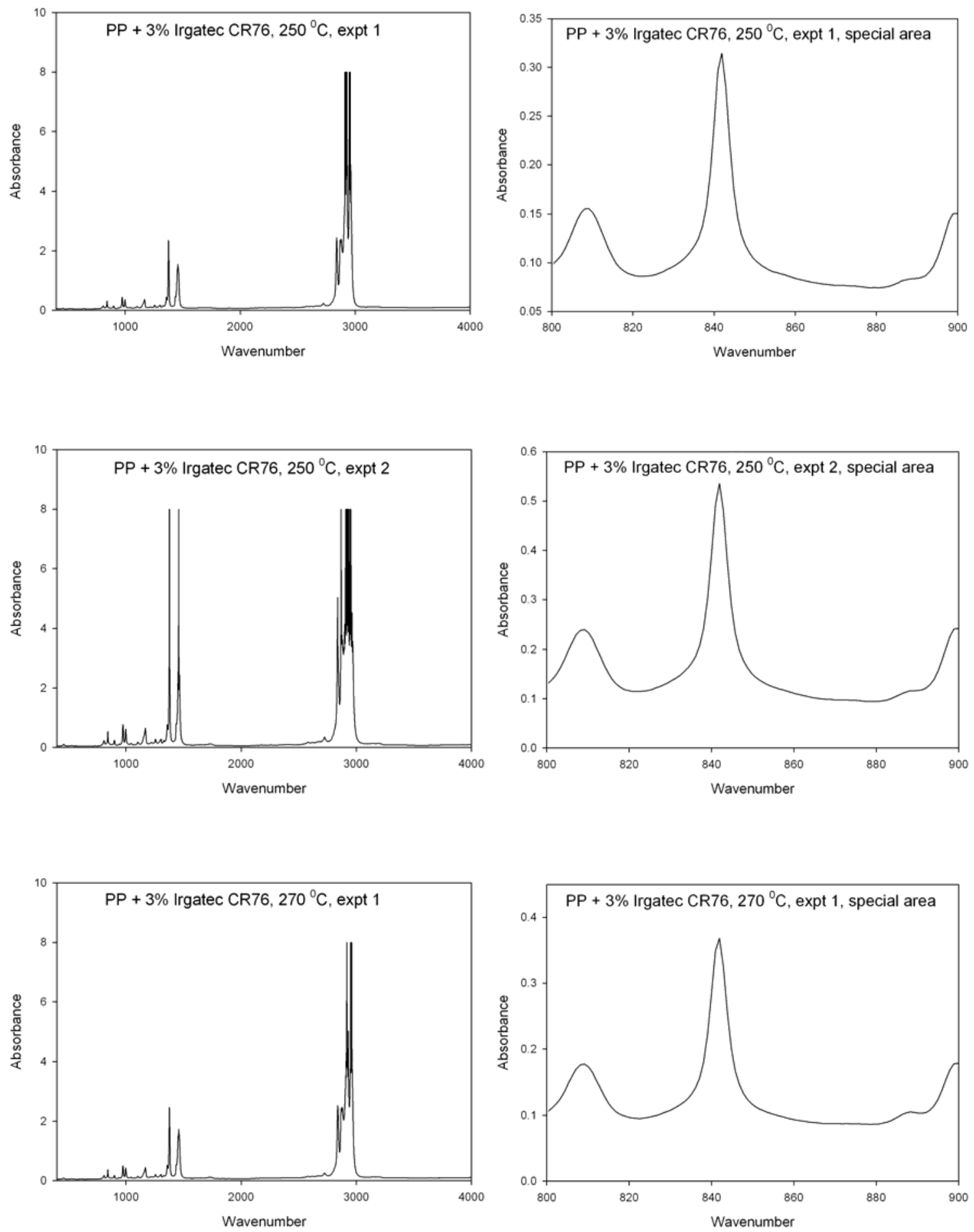

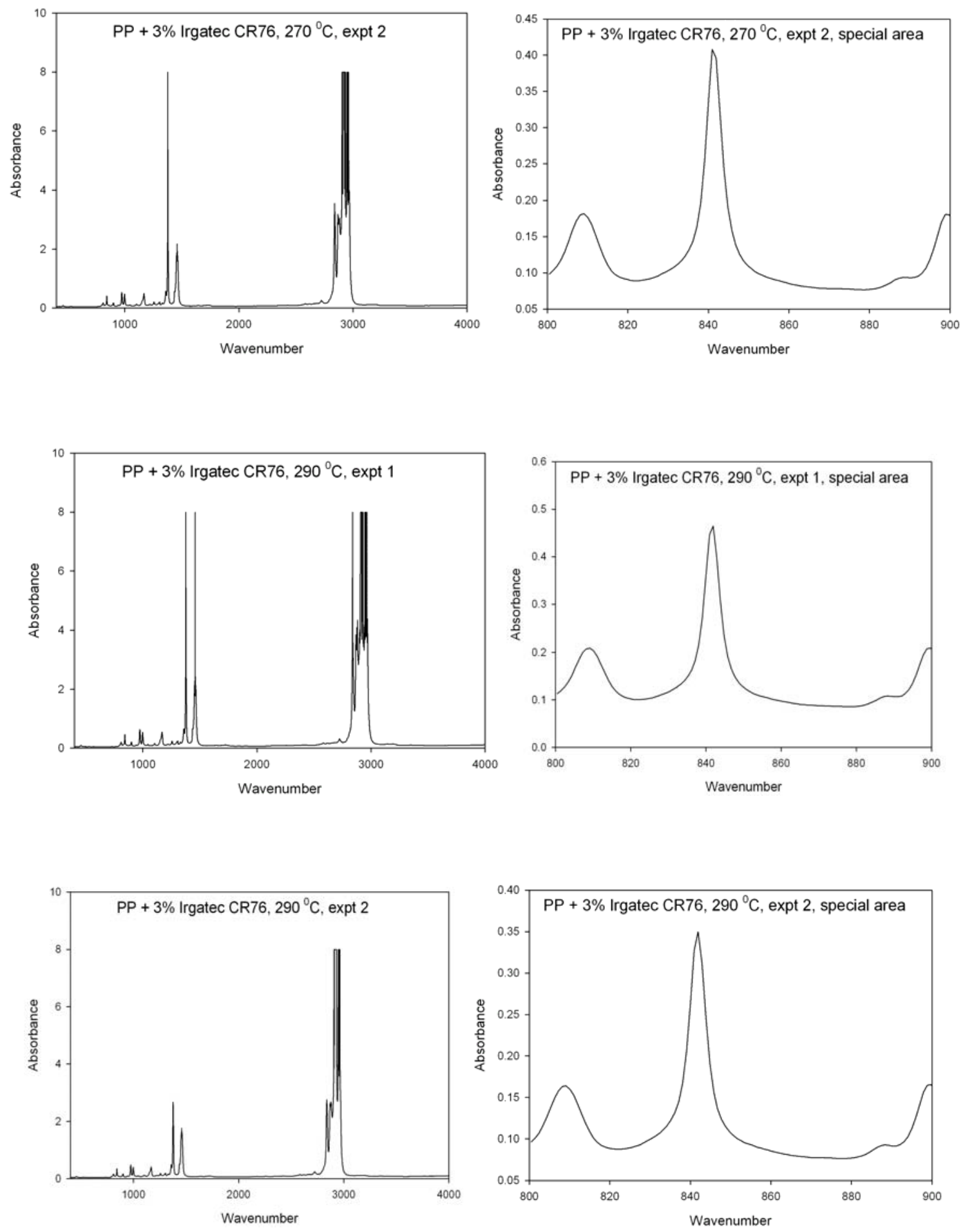